\title{
Opportunities in Otaki for improved energy efficiency in retail lighting and its offsetting through renewable resources
}

BY

\section{Quinten Heap}

\author{
A thesis \\ submitted to the Victoria University of Wellington \\ in fulfilment of the requirements for the degree of \\ Master of Building Science
}

Victoria University of Wellington 



\section{Author:}

Quinten Heap

School of Architecture

Victoria University of Wellington, New Zealand

heapquin@myvuw.ac.nz

\section{Research Supervisor:}

Nigel Isaacs

Senior Lecturer

School of Architecture

Victoria University of Wellington, New Zealand

nigel.isaacs@vuw.ac.nz 



\section{Acknowledgements:}

I wish to acknowledge the following people who without their help, this thesis could not have been completed.

I would like to thank Nigel Isaacs for his continued belief, guidance and support throughout the last four years, to bring me to this point.

The people of Otaki who allowed me access to their stores and town.

Steven Finlay and George Baird for introducing the Greater Otaki Project and the concepts of taking Otaki from the grid.

Shaan Cory for his continued role in supporting the audits in Otaki and for providing insights on a Net Zero New Zealand.

I would like to show my appreciation to the funders that made this year possible; The Dominion Post, the Building Energy End-use Study and the David Sievwright Memorial for their financial support and the Victoria University of Wellington.

Lastly I would like acknowledge my wife Liz, my family and fellow students for your listening, your suggestions and patience over the last year. Thank You. 



\begin{abstract}
:
In 2010 the town of Otaki decided to go 'Off the Grid', obtaining all its electricity supply from renewable resources. To support this goal, this thesis documents and quantifies the electricity demand for the Otaki retail stores along State Highway 1. It was found the majority of the load in these 33 stores was for lighting. To minimise the renewable electricity generation capital requirements, the load was optimised by exploring energy efficiency opportunities.

Energy audits to AS/NZS 3598:2000 Energy Audit Level 2 were undertaken in 23 of the stores. These created a consistent set of data on the lighting load and energy consumption. Potential energy savings opportunities were then identified to reduce the lighting load by $26 \%$ through lamp replacement and removal. When combined with improved lighting management, these could reduce annual electricity consumption by $34 \%$ to $248,321 \mathrm{kWh}$.

An investigation of available renewable resources (Photovoltaic (PV), wind and hydroelectric) found that PV generation was the most suitable for this urban setting. PV generation using 53 by $4 \mathrm{~kW}$ panels, at a capital cost of $\$ 1.3$ million, which would generate $250,425 \mathrm{kWh}$ per year. This would meet the annual electricity demand, but there would be a summer surplus and winter deficit. The absence of net metering provision makes this option uneconomic, although the creation of an Otaki mini-grid may be a viable alternative.
\end{abstract}





\section{TABLE OF CONTENTS}

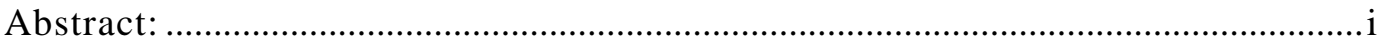

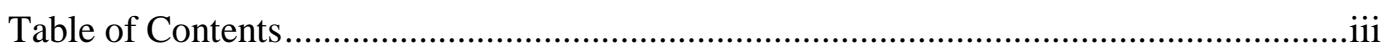

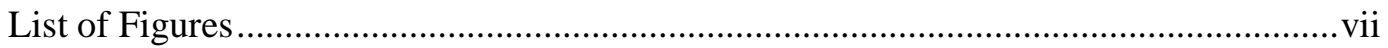

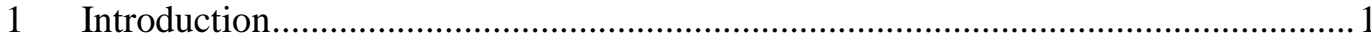

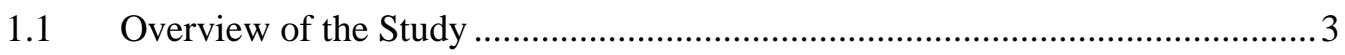

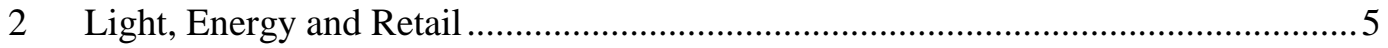

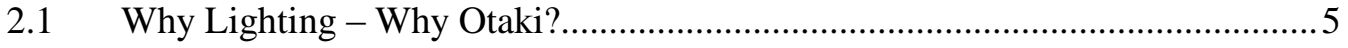

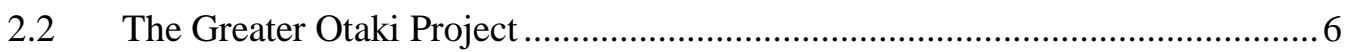

2.3 What is a Centre of Clean Technology? ......................................................... 7

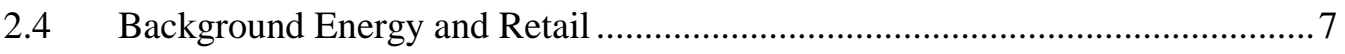

2.5 Lamp Types in New Zealand Retail .......................................................... 10

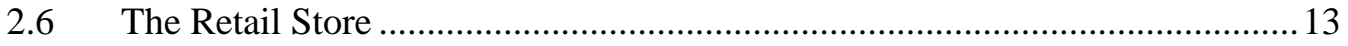

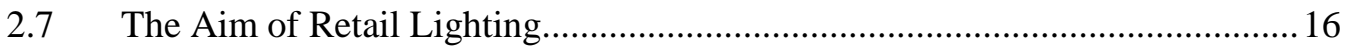

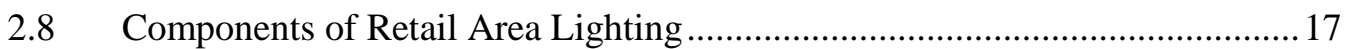

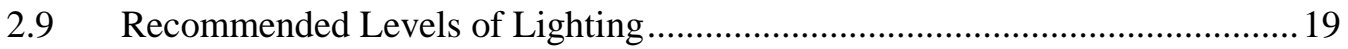

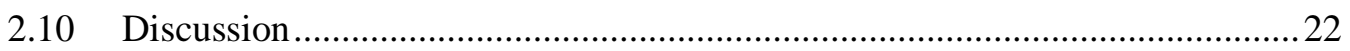

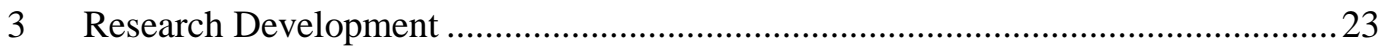

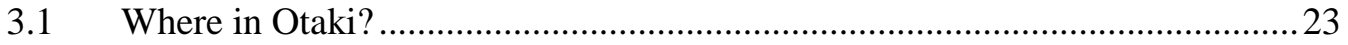

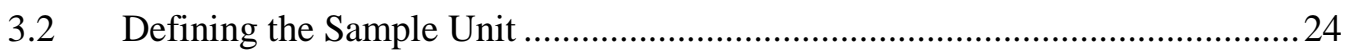

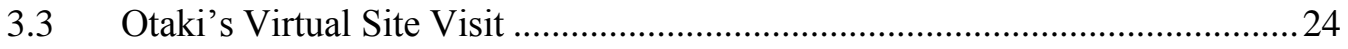

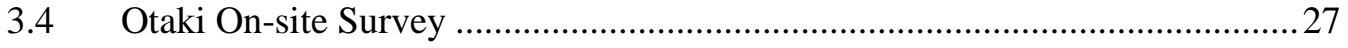

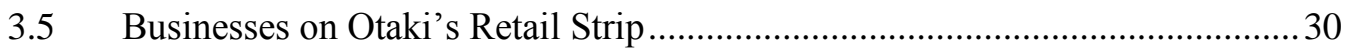

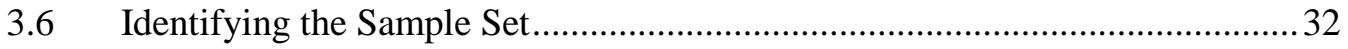

3.7 How to Recruit the Selected Buildings .............................................................. 33

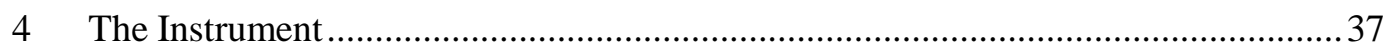

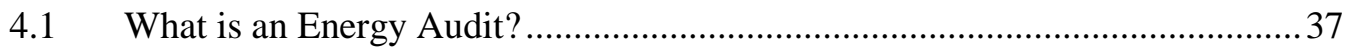

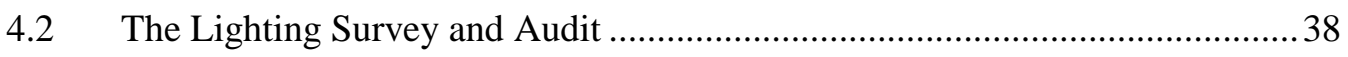




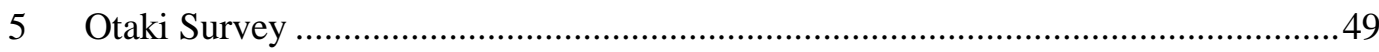

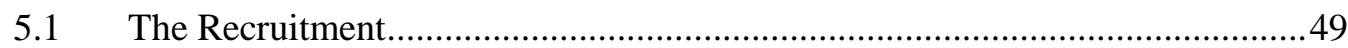

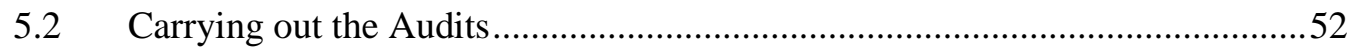

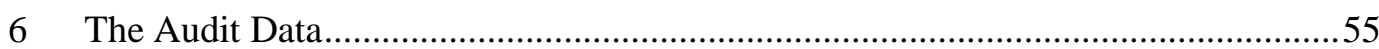

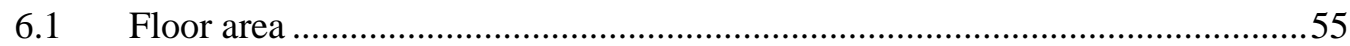

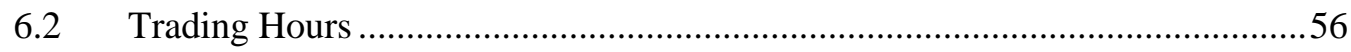

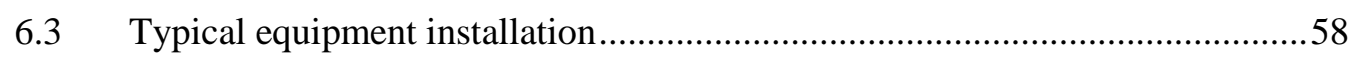

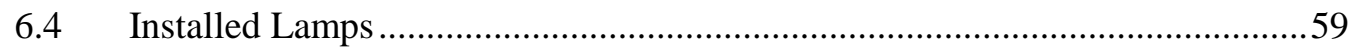

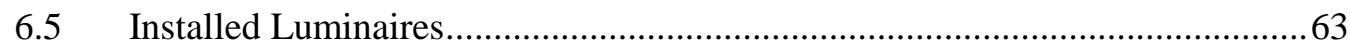

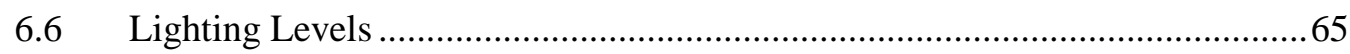

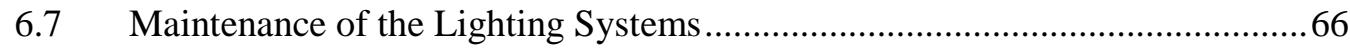

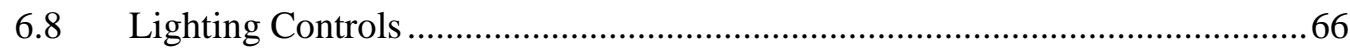

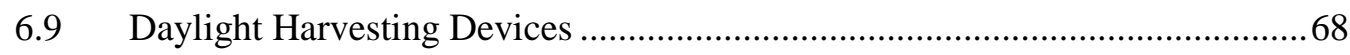

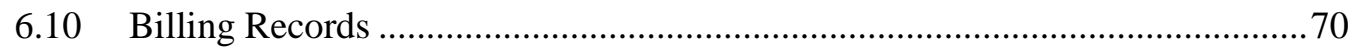

6.11 Electrical Energy, Lighting and Consumption............................................... 81

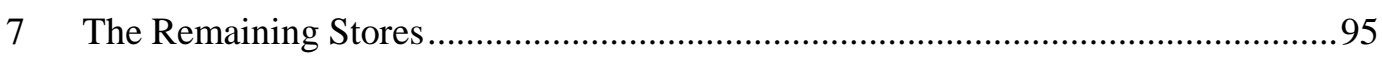

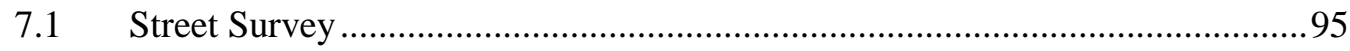

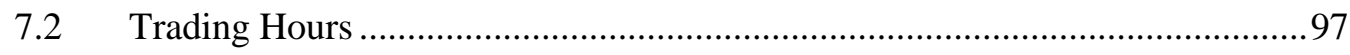

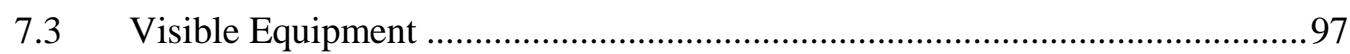

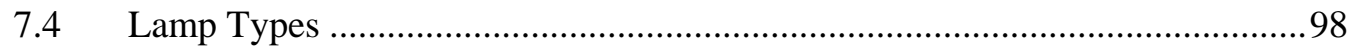

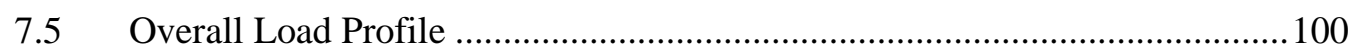

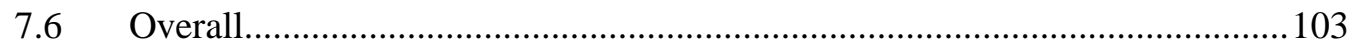

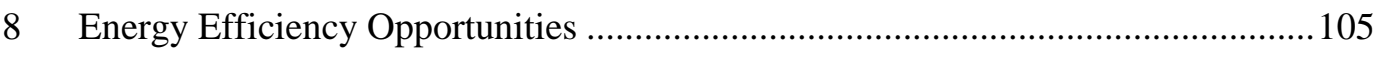

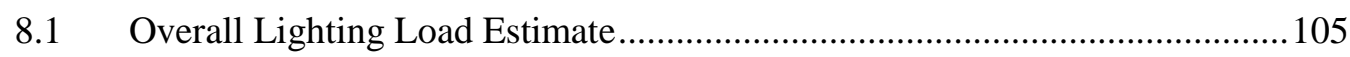

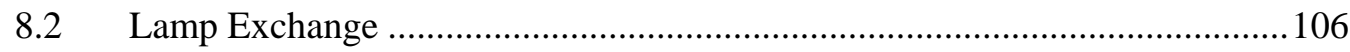

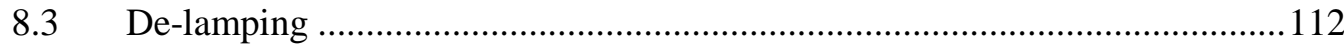

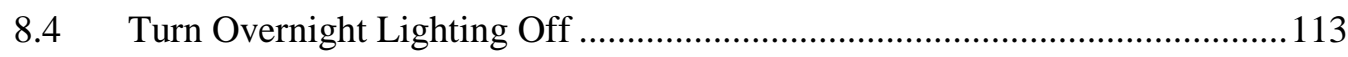

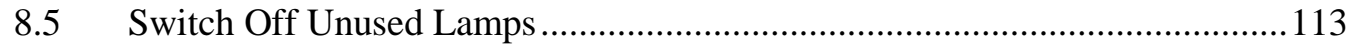


8.6 Daylight Harvesting ............................................................................... 114

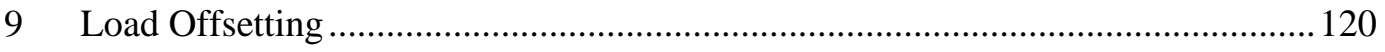

9.1 Solar Power - Photovoltaic's............................................................................. 120

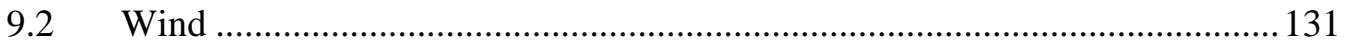

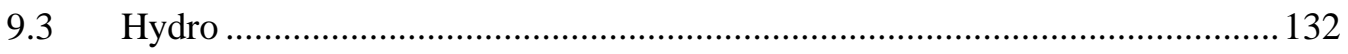

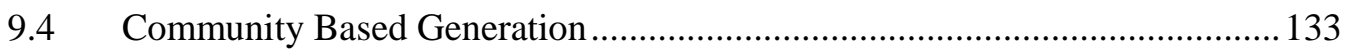

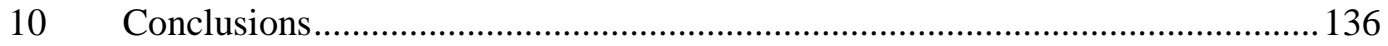

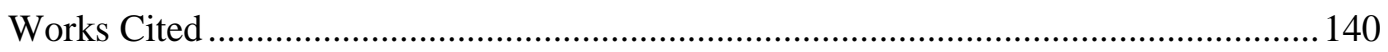

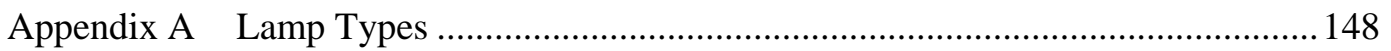

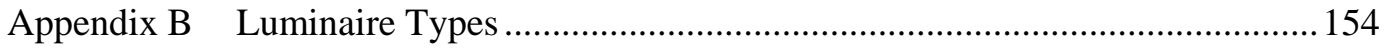

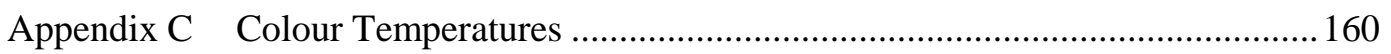

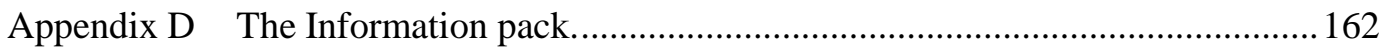

Appendix E The Boutique Fashion Store ................................................................. 170

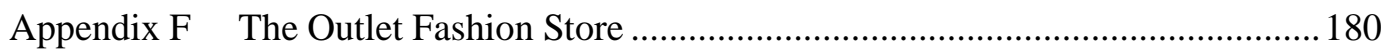

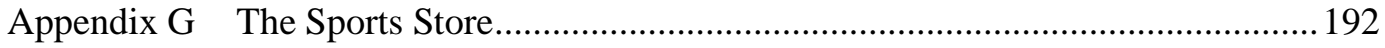

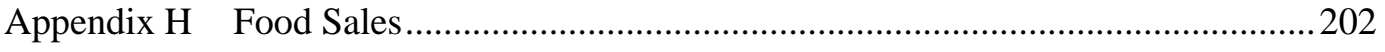

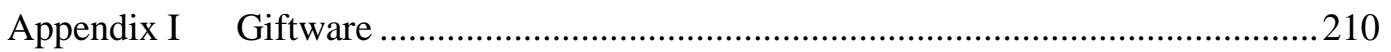

Appendix J Load Profile Assumptions...................................................................220 


\section{LIST OF FIGURES}

Figure 1: New Zealand Retail Lighting Technologies - from KEMA 2007 ...................... 11

Figure 2: Comparison of lighting Technologies (Source: OSRAM and Department of

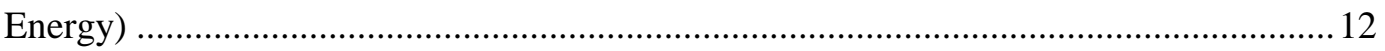

Figure 3: Image Showing Retail Area in an example store .......................................... 14

Figure 4: Image Showing Area of Display Window.................................................... 14

Figure 5: Image Showing an example of Sales Area ..................................................... 15

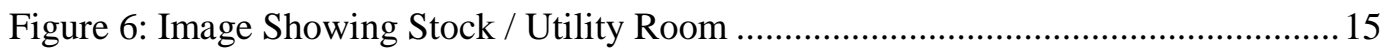

Figure 7: Image Showing Coverage of Ambient Lighting .............................................. 17

Figure 8: Image Showing Area of Spotlighting Use...................................................... 18

Figure 9: Image Showing Perimeter Lighting ............................................................. 18

Figure 10: Table showing Recommended Illuminance Levels (IESNA, 2000) ................20

Figure 11: Light Power Densities by Area and Product (ASHRAE, 2008)...................... 21

Figure 12: General area of Retail Strip (Source: Google Earth) .....................................2

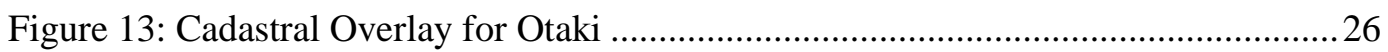

Figure 14: Google Street View Image (Source: Google Street View).............................26

Figure 15: Typology of the Otaki Retail Strip March, April \& November 2010 ............. 28

Figure 16: Businesses by Categories. .............................................................................. 30

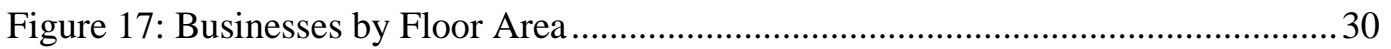

Figure 18: Retail Strip - Store Typology (Original Image: Google Earth) .........................31

Figure 19: Count of Included and Excluded Premises.......................................................... 32

Figure 20: Pilot Audit Premise Floor Plan.......................................................................... 41

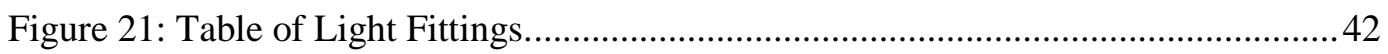

Figure 22: Wattage and Lamp Count for Each Half of the Store. …................................. 42

Figure 23: Lighting Load - Operational Watthour per Week ............................................4 43

Figure 24: Count of Equipment and Installed Wattage.................................................... 43

Figure 25: Wall Illuminance Values under a Metal Halide Wall Flood Light................... 44

Figure 26: Sketch of the Rear of the Store and Vertical Display Case ..............................45

Figure 27: Wall Illuminance Values under Fluorescent Lamp Array ..................................46

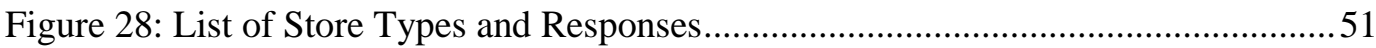

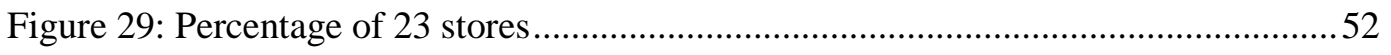

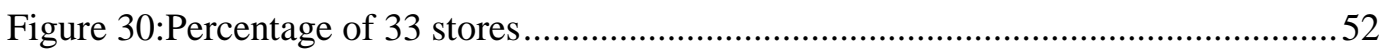

Figure 31: Store Category and Measured Floor Area .........................................................5

Figure 32: Example of the Daily trading Hours Per Store .................................................56

Figure 33: Weekdays, Weekends and Public Holidays .................................................57 
Figure 34: Monthly Calculated Hours .57

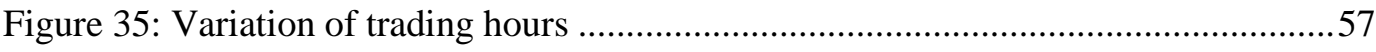

Figure 36: Cash Tills that are in use in Otaki. (Image: Positive Systems Solutions)........58

Figure 37: Type, Number and Total Wattage Installed per Lamp .....................................59

Figure 38: Lamp Styles by Store Type and Lighting Component ....................................60

Figure 39: Remaining Stores, Lamp Styles by Store Type and Lighting Components ....61

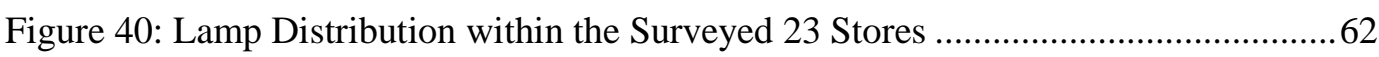

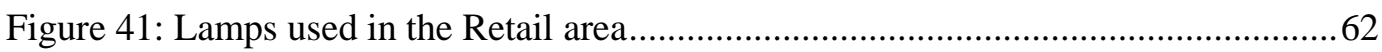

Figure 42: Fluorescent Lamp Count and the Calculated Installed Load...........................63

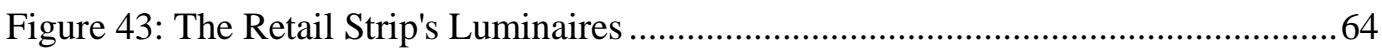

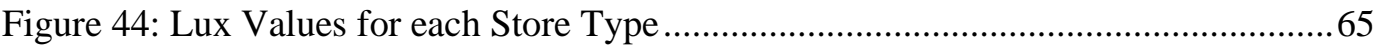

Figure 45: Light Switches Located near a Staff Exit (Authors Own Photos) ....................68

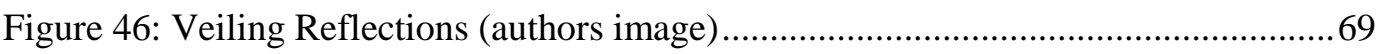

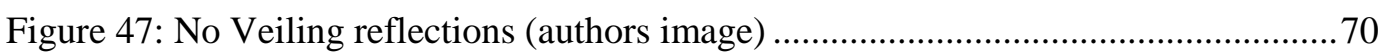

Figure 48: Percentage of Otaki Supply by Count of Energy Suppliers ............................71

Figure 49: Example of Billing Data from Contact Energy ............................................... 73

Figure 50: Example of Monthly Billing showing Estimate and Actual Reads ..................73

Figure 51: Example of Billing Data from Meridian Energy ..............................................74

Figure 52: Excerpt of Meridian Energy Invoice, defining the Billing Period.....................75

Figure 53 Meridian Monthly Billing showing Estimate and Actual Reads ......................75

Figure 54: Example of Billing Data from Genesis Energy ................................................76

Figure 55: energy Online Monthly Billing showing Estimate and Actual Reads ..............77

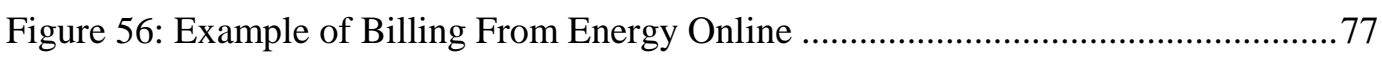

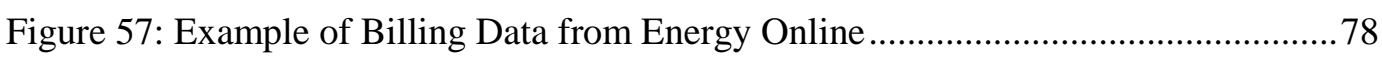

Figure 58: A Billing Record Demonstrating the Irregular Billing Periods.......................79

Figure 59: Example of how Billed Period Overlaps Calendar Months...............................8 80

Figure 60: Showing Billed Periods for October 2008 .................................................... 80

Figure 61: Calculating the Consumption for October 2008 ……......................................8 80

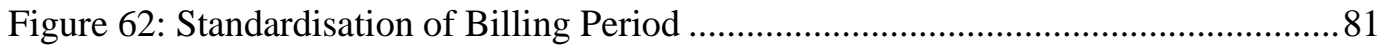

Figure 63: Annual Consumption for the Audited Stores ............................................... 81

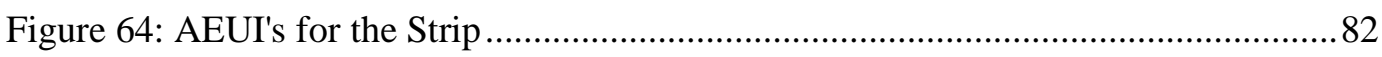

Figure 65: Bi-Monthly Energy Combined Electrical Consumption ................................83

Figure 66: Paraparaumu Airport Temperatures, High/Low Range and Average ..............8 84

Figure 67: Observed Lighting Levels against Installed Lighting Load ............................85

Figure 68: Lighting Electrical Consumption for Trading Hours and Non Trade...............86

Figure 69: Estimated Daily Lighting Load, Transition and Use (Friday) ..........................87

Figure 70: Estimated Combined Lighting Load and Operating Hours (Friday) ................88

viii 
Figure 71: Comparing the Calculated Lighting Load to Billed Consumption .89

Figure 72: Range of Lighting and Observed Levels ...................................................... 90

Figure 73: Comparison of the Lighting Load Range and Billed Amount..........................91

Figure 74: Proportions of Annual Lighting Load ............................................................ 91

Figure 75: AEUI Comparison for the Selected Stores ................................................... 92

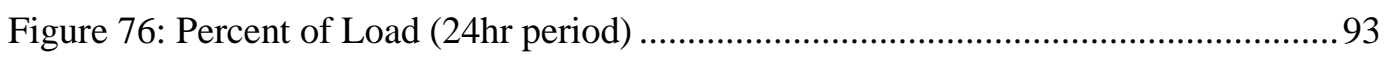

Figure 77: List of Remaining Premises with Light Count ................................................ 96

Figure 78: Advertised Store Trading Hours....................................................................97

Figure 79: Lamp Count of the Remaining 10 Stores ......................................................... 98

Figure 80: Lamp Share by Load along Remaining 10 Stores ............................................98

Figure 81: Installed Retail Area Lighting Load and Overnight Lighting load ................. 99

Figure 82: Retail Lighting Load Profiles for all 10 Stores ................................................ 99

Figure 83: Lighting Profile for the Remaining 10 Stores ............................................... 100

Figure 84: Calculated Fashion Store Lighting Proportions ........................................... 101

Figure 85: Calculated Lighting Proportions Fashion Accessories Store Lighting........... 102

Figure 86: kW Load for all Lighting in Non-Participating Stores ................................. 103

Figure 87: Combined Lighting Load for Retail Strip ................................................... 104

Figure 88: Combined Lighting Load Profile (Otaki Retail Strip)................................... 105

Figure 89: CFL and GLS wattages and potential savings............................................. 107

Figure 90: Possible Savings Due to CFL Installation ...................................................... 107

Figure 91: Payback for CFL Replacement...................................................................... 107

Figure 92: Possible Savings Due to Energy Efficient MR-16 Installation ...................... 109

Figure 93: Payback for OSRAM EE MR-16 Purchase (The Lightbulb Man, 2010)......109

Figure 94: Possible Savings Due to LED MR-16 Installation ..........................................110

Figure 95: Comparison of Energy Savings for Halogen Lamps. (OSRAM, 2010) ......... 111

Figure 96: Possible Savings Due to the Halogen Replacement Installation .....................111

Figure 97: Possible Savings Due to De-lamping ........................................................ 112

Figure 98: Possible Savings Due to Switching off the overnight lighting ......................113

Figure 99: Possible Savings Due to Switching Unused Lamps 'OFF'............................ 114

Figure 100: The Limiting Depth Rule (Otis \& Reinhart, 2009) ..................................... 115

Figure 101: The No-Skyline Limiting Depth Rule (Otis \& Reinhart, 2009) ................... 115

Figure 102: Visible Skyline in the Boutique Store and Outlet Store ..............................116

Figure 103: Spacing Criteria for the Solar Tube (Solatube, 2010) ................................. 117

Figure 104: Sunshine hours for Paraparaumu Airport (NIWA, 2011) ............................ 118

Figure 105: Load Offset due to Sunlight Hours............................................................ 118

Figure 106: Paraparaumu Solar Radiation by Month (NIWA, 2011) ..............................121

Figure 107: NREL Calculator Results for PV Generation (3 Main Centres) .................. 122 
Figure 108: Monthly Comparison of the Calculated PV Generation and Consumption 123

Figure 109: Wholesale Market Prices for 2010 (Electricity Authority, 2010).................124

Figure 110: Net Metering - Generated kWh Versus Consumed kWh ............................125

Figure 111: Buying and Selling Comparison on the Open Market.................................. 126

Figure 112: Calculated consumption and Generation - Purchasing/Selling as required.127

Figure 113: Cost of PV Arrays in New Zealand (Cell Power, 2010) ..............................129

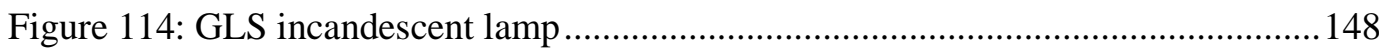

Figure 115: Example of a PAR Lamp (Source: OSRAM) ............................................. 149

Figure 116: Halogen lamp in classic configuration (Source: OSRAM) ………..............149

Figure 117: MR 16 Dichroic spot lamp (Source: OSRAM) ...........................................150

Figure 118: Halogen Lamp in Capsule Form (Source: OSRAM)..................................150

Figure 119: Linear halogen lamp (Source: Osram)...................................................... 151

Figure 120: Image of a Fluorescent lamp 1200 mm 36 W (Source: Osram) ....................151

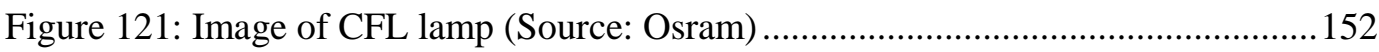

Figure 122: Colour Trends of the Metal Halide Lamp(Source: Authors Own) ...............153

Figure 123: Examples of Metal Halide Lamps (Source: OSRAM) .................................153

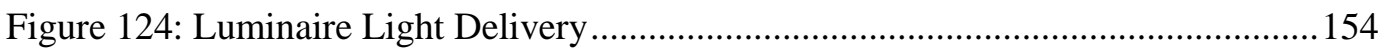

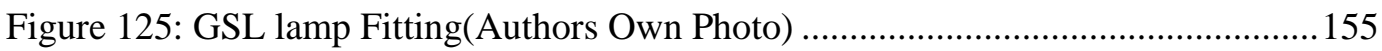

Figure 126: Examples of Down lighting Luminaires...................................................155

Figure 127: MR-16 Luminaire (Authors Own Photos)..................................................156

Figure 128: Flood light Luminaire (Authors Own Photos) ................................................. 157

Figure 129: Batten Style Fluorescent Luminaires (Authors Own Photos)....................... 157

Figure 130: Diffused Linear Fluorescent Lamp (Authors Own Photos)..........................158

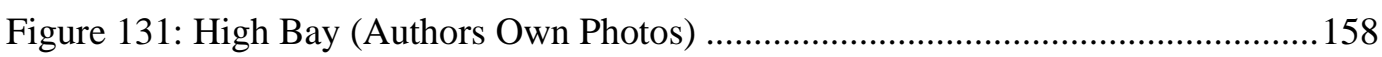

Figure 132: Colour temperature chart (LDS Group, 2010)..............................................160

Figure 133: Floor and Lighting Plan of the Boutique Store.............................................171

Figure 134: Total Lamp Count within the Stores........................................................... 171

Figure 135: Light Power Densities for Floor Area by Use ..............................................172

Figure 136: Lighting Load Consumption - Winter.......................................................... 173

Figure 137: Lighting Load Consumption - Summer..................................................... 173

Figure 138: Plug loads for Daily and Weekly Consumption .........................................174

Figure 139: Amount Consumed for Year (June 2009 - May 2010) ................................175

Figure 140: Billing Records for Store (Bi-monthly April 2008 - May 2010)...................176

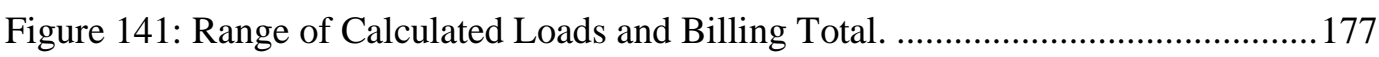

Figure 142: Simplified Load Profiles for Summer And Winter ..................................... 178

Figure 143: Floor Plan and Lighting Layout of Selected Outlet Store ...........................180

Figure 144: Total Lamp Count within the Store ............................................................ 181 
Figure 145: Light Power Densities for Floor Area by Use 181

Figure 146: Lighting Load Consumption - All Year..................................................... 182

Figure 147: Plug loads for Average Daily and Weekly Consumption............................ 183

Figure 148: Luminaire Position over Changing Rooms ................................................ 184

Figure 149: Electricity Consumption for Year (June 2009 - May 2010).......................... 185

Figure 150: Billed Energy Consumption (Jan 07 - Jun 10) .............................................. 185

Figure 151: Lighting Electrical Energy Consumption and Billed Amount ..................... 186

Figure 152: Simplified Load Profiles for Summer And Winter .................................... 187

Figure 153: Sport Store Floor Plan showing Lighting Layout........................................ 192

Figure 154: Total Lamp Count within the Store ………................................................ 193

Figure 155: Light Power Densities for Floor Area by Use ............................................ 194

Figure 156: Lighting Load Consumption .................................................................... 195

Figure 157: Plug loads for Average Daily and Weekly Consumption............................. 196

Figure 158: Amount Consumed for Year (June 2009 - May 2010) .................................. 197

Figure 159: Billing Data on Monthly Consumption (Feb 2008 - Jun 2010).................... 198

Figure 160: Lighting Electrical Energy Consumption and Billed Amount ...................... 198

Figure 161: Simplified Load Profiles for Summer And Winter ...................................... 199

Figure 162: Floor Plan and Lighting Layout of Food Store .........................................202

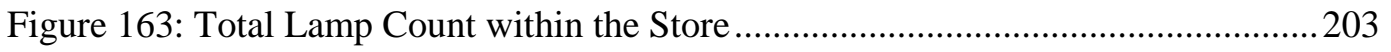

Figure 164: Light Power Densities for Floor Area by Use ...........................................2. 203

Figure 165: Lighting Load Consumption ......................................................................204

Figure 166: Plug loads for Average Daily and Weekly Consumption.............................204

Figure 167: Amount Consumed for Year (June 2009 - May 2010).................................205

Figure 168: Bi-Monthly Consumption for the Period June 08 - June 2010.....................206

Figure 169: Comparison of Billed Amount and Calculated Consumption......................207

Figure 170: Simple Load Profile showing an Average Winter and Summer Month......208

Figure 171: Floor Plan and Lighting Layout of the Giftware Store...............................210

Figure 172: Total Lamp Count within the Premises ......................................................211

Figure 173: Light Power Densities for Floor Area by Use ............................................211

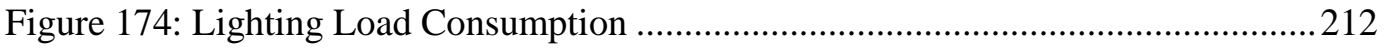

Figure 175: Plug loads for Average Daily and Weekly Consumption.............................212

Figure 176: Amount Consumed for Year (June 2009 - May 2010) ...............................2. 213

Figure 177: Billed Consumption Data (November 2008 - August 2010)........................214

Figure 178: Comparison of Billed Amount and Calculated Consumption......................214

Figure 179: Simplified Load Profiles for Summer And Winter .....................................2216

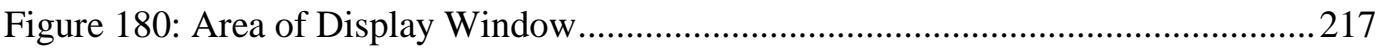




\section{INTRODUCTION}

Lighting is believed to consume up to $30 \%$ of all the energy used in commercial buildings (EECA, 2003). International and national studies have shown that a retail store's lighting, consumes as much as $60 \%$ of the electrical consumption (Itron, 2006), (KEMA, 2007).

The available studies, both international and New Zealand, focus on a wide selection of commercial buildings and thus do not provide sufficient details to explore the various end-uses in small retail stores. If a store is mostly comprised of retail space, then the existing studies only suggest the electricity network load from the store will largely be the lighting load.

In 2007 and 2009 two separate studies that focused on overnight lighting in commercial buildings, noted that the retail lighting on the ground floor was often left on overnight. Because of these observations it was decided that retail lighting in general may offer opportunities for energy savings if the illumination levels, loads and hours of operation could be identified.

Lighting in retail is used to highlight stock, entice customers and promote sales. How this is achieved has been the subject of many books and design courses, e.g. Lighting Design Basics - Karlen M, Benya J (2004), Design for Shopping: New Retail Interiors - Manuelli S (2006) and the DesignWorks program provided by the Lighting Research Centre at the Rensselaer Polytechnic Institute, Troy, New York.

The key message is that the effectiveness of a lighting design depends on how the designer, the client and the customer respond to current lighting fashions and trends. Each of the three groups will have their own opinions on lighting design, its intended effect and their response.

This thesis is firstly concerned with the electrical energy consumption of lighting installations in small retail stores. It will look at opportunities to improve the efficiency of the lighting energy use.

In 2008, a District Council on the Kapiti Coast developed an idea that they would become the nation's centre for sustainable energy (Kapiti District Council, 2009). The goals of this idea were to promote green energy technologies and community based electrical energy generation. The desired outcome is to become the first town in New Zealand to be classed as an 'Off the Grid' consumer. 
This idea has now become a part of the Greater Otaki Project. The project is based around a Centre of Clean Technology that promotes green energy and sustainable designs. It is hoped that products and ideas generated within the centre will allow Otaki to reach the goal of becoming energy self-sufficient. Before a town can be removed from the national supply grid, its load and the way in which it consumes electrical energy must be understood.

Otaki is known as a destination shopping centre. This activity is of significant economic importance to the town and district, and represented by a series of retail stores located along the main highway. Due to the number of stores and the associated retail space, it is expected that much of the load represented by this "Retail Strip" is due to merchandise lighting.

This thesis will secondly examine how this lighting energy use can be provided by renewable energy supplies.

\section{AIM}

The aim of this study is to explore how renewable energy can be used to supply the electricity used for retail lighting use in the Otaki retail strip.

\section{AIM STATEMENT}

To achieve this aim firstly requires a detailed understanding of the current electrical use along the retail strip in Otaki. This will allow the different retail lighting installations to be identified and then the optimising of energy use using models based on the most modern technologies.

In order to minimise the capital requirements for the future renewable energy installation, it will be necessary to minimise the retail lighting electrical energy use, without altering the design intentions.

This, in turn, requires the assessment of presently available, renewable electricity supply systems that are practical for installation in an urban or suburban setting.

It should be noted that the Otaki retail stores are all single level buildings, orientated along a straight road angled to the northeast. The results from this research, although specific to the Otaki retail strip in its location and climate, can be further explored for their applicability to other potential locations. 


\subsection{OVERVIEW OF THE STUDY}

Chapter 2 provides the background information on the reasons that Otaki was selected and why the research focus is on retail lighting. This chapter also provides the results from a literature review on retail store energy use. It examines various lamp types and compares them based on their output characteristics. Lastly it looks at the various areas within a retail store, detailing the associated lighting components, the recommended levels of illumination and the recommended lighting energy consumption for each of these areas based on New Zealand and international literature.

Chapter 3 defines the study geographical area and sample selection methodology. This chapter sets out the limitations for the study in terms of sample size and definitions. It provides details of the 'virtual site visit' method developed by the New Zealand Building Energy End-use Study (BEES) and how it is used to establish the building uses and occupants. This chapter also develops the methodology used to recruit the participants, including the development of a presentation pack and introduction letter.

Chapter 4 develops an instrument to quantify and measure the retail lighting use along the Otaki retail strip. The use of AS/NZS 3598:2000 Energy Audits is described. A pilot study was then used to trial the energy audit on a local Wellington retail store, to test the recruitment system and the carrying out of the audit in a real setting. The results from the pilot were used to generate the research data and to provide a suitable report to the participating building.

Chapters 5 and 6 examine the operational details and the results from the Otaki energy audits. Chapter 5 deals with the recruitment of the sample set, including the issues of dealing with various layers of retail store management. It describes the energy audit process used in the Otaki stores including the audit requirements. It sets out the process used to obtain up to two years of revenue data (billing records) from the energy suppliers and how this data supported the creation of an annual load profile for each store.

Chapter 6 describes the data that was gathered during the audits. The analysis examines both the behaviour of individual stores and the overall energy use for all the stores as a group, providing information on the times of peak load and the maximum total electrical consumption. Chapter 6 also examines the different lighting approaches and controls used in the different stores. It also explores the revenue energy data, documenting problems with the data and the development of appropriate solutions. The last part of Chapter 6 reports on the energy audits at store level, based on five example stores. It explores how electricity is used in the different stores, and then based on the revenue data calculates lighting electricity consumption. Using the different floor area uses, as 
described in Chapter 2, it examines the roles these play in determining lighting electricity use.

Chapter 7 uses the physical data in Chapter 6 to develop an estimated lighting electricity load for both time of day and annual consumption for all the Otaki retail stores.

Chapter 8 explores the opportunities to improve the efficiency of retail lighting energy use, based on the overall lighting load estimated in Chapter 7. These results are used to explore whether it is possible to alter the installed lighting load without altering the design intentions, and then it provides calculates of potential energy and peak power savings.

Chapter 9 then examines the opportunities and possibilities for the Otaki strip retail lighting energy use to be supplied from renewable sources. Chapter 9 evaluates the currently available technology and knowledge to explore the range of possible systems that would permit renewable electricity to supply the calculated lighting load.

Conclusions on current retail lighting energy use along the retail strip, the opportunities to improve the efficiency and the technology to provide alternative energy sources are made in Chapter 10. 


\section{LIGHT, ENERGY AND RETAIL}

This chapter sets out the process by which the town of Otaki was selected and why retail lighting energy use became the main focus of the research. A literature review of commercial building energy use research will be discussed in relation to retail store energy use. The different types of lamps found in the Otaki retail buildings and their output characteristics will be briefly discussed. The chapter concludes with a review of the various areas found in retail buildings and the recommended levels for both illumination and lighting energy use based on New Zealand and international literature.

\subsection{Why LighTING - WhY OTAKI?}

Lighting was the first service offered by electric utilities and continues to be one of the largest electrical end-uses. (IEA, 2006). Today lighting is considered to be one of the major electricity loads in commercial buildings.

A proportion of this load is due to lights being on when of no practical value, notably overnight. In 2007 a team of four students from the Worcester Polytechnic (Levin, Niemczycki, Walton, \& Woloschin, 2007, p. 45) reported in "A Study of Overnight Lighting in Non-Domestic Buildings" their development of a non-invasive, street observation method. This allowed them to estimate overnight lighting electric consumption for a selection of London low rise office blocks.

In 2009 the author of this study used these observation methods to test if the non-invasive methods were suitable for use in Wellington. This led to the 2009 Bachelor of Building Science Honours research report "Testing non-invasive auditing methods for overnight lighting in the Wellington Central Business District (CBD)" (Heap, 2009). That research showed that building height was a major issue in applying the non-invasive method in the Wellington CBD. The 2007 London study had been developed on 4-6 storey low rise offices, while the Wellington CBD typically had 14-18 storey buildings. It showed however that estimates of lighting installations and their electrical use could be developed at the lower levels where it was possible to see into the building from the street.

Neither the 2007 London nor the 2009 Wellington study considered retail lighting. The non-invasive observation method is based on the number of visible windows in the building and a set of common office lighting systems. Both studies considered that as most ground floor retail stores have just one display window combined with a variety of lights positioned close to that window, the retail sector would fall outside of the scope of the non-invasive observation overnight method. 
The 2009 Wellington study found that in many of the CBD buildings the ground floor is comprised of one or more retail shops. However, during these overnight surveys it was noticed that many of the ground floor retail stores remained illuminated overnight - well outside of the 'normal' trading hours - suggesting the energy consumption of retail lighting may be a larger issue than first thought.

These observations led to a research plan to investigate overnight lighting in retail areas and document the reasons why the lights may have been left on. During the planning period, it was learned through colleagues at Victoria University of Wellington that Otaki, a small town on the Kapiti coast, was interested in developing a project that would eventually take them off the national electricity supply grid - the "Greater Otaki Project". An important part of the Otaki economic base is retail, so there was a need to understand how the energy needs of the retail sector could be met.

\subsection{The GREATER OtAKI PRoject}

"The commercial/shopping centres are the most intensively used areas of the District. They also convey an "image" of each community to residents and visitors" (Kapiti Coast District Council, 2009).

In the 2009 Long Term Council Community Plan (LTCCP) for the Kapiti region it was identified that the retail sector has become one of the region's main employers. This growth meant that the district's centres are now reliant on retail, an activity with a narrow economic base that depends on consumer trends and spending (Kapiti District Council, 2009).

Acknowledgement of these changes and potential future trends led to the creation of the 2004/2005 Greater Otaki Project Vision. This vision placed an emphasis on the community to create skilled jobs and new employment opportunities. It called for the community and local businesses to develop an image and direction for the area that would be at the forefront of emerging technologies and not 'after the fact' or following behind these trends (Gael Ferguson, 2010).

The 2009 LTCCP sets out an undertaking to build a partnership with Grow Wellington (the regionally supported business development company) to establish a regional clean technology centre.

"The Kapiti Coast District Council believes that it is possible to promote and develop the Kapiti Coast as a Centre of Excellence for innovative sustainable domestic technologies, 
such as small scale energy systems and water conservation systems" (Kapiti District Council, 2009).

This concept was adopted by the Otaki Community Board and in February 2010 they approached the Kapiti Coast District Council with the following goal for the Greater Otaki Project:

"That the Otaki Community aspires to be the first New Zealand 'Off-Grid' town by becoming a net supplier to the national energy grid as part of the Greater Otaki Vision economic development strategy" (Gael Ferguson, 2010)

In February 2010, the Greater Otaki Project secured premises in an industrial development on Riverbank Road, Otaki. With the building secured the community now had the opportunity to base the Centre of Clean Technology in their region.

\subsection{What is a CENTRE of Clean TeChNOLOGY?}

Steven Finlay, Centres of Excellence Manager, Grow Wellington describes the Centre of Clean Technology as an incubator for business ideas. It is a space that will allow new businesses to be developed and commercialised. The idea is to place these new businesses in an area that already has experienced sustainable businesses that have already established green technologies in New Zealand.

It was intended that by locating the centre in Otaki, the results from the participating businesses would eventually permeate through to the community, allowing the town to eventually go 'off grid'. This goal was based on community level electricity generation, without the need for costly infrastructure. The work being undertaken by the community and the centre should enable the town to generate enough electricity to be energy selfsufficient and to be able to sell any surplus to the national grid.

\subsection{BACKGROUND ENERGY AND RETAIL}

There are no, currently available, completed New Zealand studies of energy use in the retail sector. An international literature review was undertaken to understand retail store energy use, but surprisingly no research specific to the retail sector was found. The following studies of commercial building energy use each include some component of retail energy use.

The four studies include two American studies - one at a State level in California and the other on commercial energy use throughout the United States. There are two New Zealand studies - a 2007 energy potentials study based on phone surveys and an ongoing study collecting data on non-residential building energy use. 


\subsubsection{AMERICAN STUDIES}

\section{Californian End Use Study (CEUS) (Itron, 2006)}

Completed in 2006, the four year CEUS was a comprehensive survey and analysis of the Californian commercial sector and its energy use. The aim of CEUS was to create energy models to show the energy consumption patterns and load profiles for the various building types within the commercial sector. The models were designed to permit state level forecasts of energy use so that the hourly impacts of energy efficiency measures, load management strategies, building standards and policies could be tested (Itron, 2006, p. 2).

The CEUS data covered all types of commercial activities, but of the 2,790 premises surveyed $461(17 \%)$ were described as retail. These retail stores represent $14.2 \%$ of the total floor area and $14.7 \%$ of all the electricity consumed. The internal lighting consumption was identified as being $43 \%$ of all electrical use in the retail stores.

Because the survey was concerned with state wide issues, retail premises of all sizes were studied. The CEUS data used the annual electrical energy (kWh) consumption of the site to define the size of the user. The survey considered retail premises to be 'small' when the annual consumption was less than $80,000 \mathrm{kWh}$; 'medium' if annually their consumption was between $80,000 \mathrm{kWh}$ and $900,00 \mathrm{kWh}$ ' and 'large' if greater than $900,000 \mathrm{kWh}$.

The CEUS reported lighting types (end-uses) were limited to 'retail lighting interior' and 'retail lighting exterior'. This provides no detail on the variety of different lighting uses or lighting types within the retail area. The overall figures for retail premises include malls, supermarkets, and all sizes of retail stores (Itron, 2006).

\section{The Commercial Buildings Energy Consumption Survey (CBECS)}

CBECS has been run eight times since 1979, with the 2003 survey being the most recent. CBECS obtains data on the energy use of a wide range of commercial buildings from throughout the United States. The 2003 CBECS included 5,215 individual buildings to develop a sample that is representative of the commercial building stock in America.

The buildings were classified based on the principal activity occupying the greatest area of floor space at the time of the survey - thus for example a building with $90 \%$ retail and $10 \%$ office areas would be classified as 'retail'. CBECS differentiates between standalone retail (individual stores used for merchandising) and malls (multiple connected establishments) (EIA, No Date). 
CBECS found that lighting consumed approximately 50\% of all the electrical energy consumed by retail buildings. Again this study was developed to be representative over a larger sample; so the breakdown for different sizes of retail buildings was not provided (US. EIA, 2010).

\subsubsection{NEW ZEALAND}

\section{KEMA - New Zealand Electric Energy-Efficiency Potential Study}

Carried out in 2006, this study was commissioned by the Electricity Commission and carried out by the American consultancy KEMA. This study aimed to identify electricity energy-efficiency potential in New Zealand, examining three sectors (Residential, Commercial and Industrial). It is the survey and results for the commercial sector that are of interest here.

The report identified a lack of available data on New Zealand commercial buildings and energy use, which meant instead of carrying out physical on-site surveys they had to use phone surveys and interviews. It was from these interviews that the energy use and potential loads were developed.

The KEMA study asked the phone survey respondents for information on the different lighting technologies that were used in their building(s). The study used telephone based interviews with energy end-users between September 2006 and January 2007. During this period 621 commercial end-users were contacted and asked to self-report on their energy consumption.

The analysis found that lighting accounts for approximately $60 \%$ of all retail electrical energy consumption, but no breakdown analysis of building size or type was provided. The report showed that the retail building type uses $11 \%$ of the total commercial energy consumption in New Zealand (KEMA, 2007).

\section{Building Energy End-use Study (BEES) (Isaacs, et al., 2010)}

Begun in 2008, the BEES project is New Zealand's first comprehensive study into the energy end-uses of non-residential buildings. The data gathered by the BEES project will allow a more efficient use of resources in the commercial buildings stock of New Zealand.

At the time of writing, the first of the BEES monitored energy use data was only just being analysed. The BEES Year 3 Study report notes that during the 2009/10 period, 34 buildings containing 42 premises were monitored. They found consumption ranging from a small retail store consuming $7.1 \mathrm{kWh} /$ day through to around $1,500 \mathrm{kWh} /$ day for a large 
office building. The smaller stores monitored by BEES were from smaller towns or suburbs, with daily electricity consumption between 10 and $30 \mathrm{kWh} /$ day.

BEES identified that lighting is the significant load in retail buildings, with one small store having $97 \%$ of their electrical consumption due to the lighting - this store had no space heating, no hot water and limited appliances (Isaacs, et al., p. ii).

\section{Summary}

These reports provide information on energy use in the retail sector, but only as part of the wider commercial building sector. Because their results are intended to be used at a state and national level, the sample sets were designed to allow the results to be representative of the commercial sector within that state or country. They provide limited exploration of the different energy end-uses, and in particular do not explore for the retail areas the types of lamps or the hours of use.

Although these studies are all much larger in scale than would be required to understand retail energy use in Otaki, they suggest that a small retail store may be expected to use between $50 \%$ and $97 \%$ of its electrical energy in lighting.

\subsection{LAMP TyPES IN NEW ZEALAND RETAIL}

To define every type and use of all lamps in the New Zealand retail sector is beyond the scope of this paper. For illustrations and descriptions of each type discussed in this section, see Appendix A.

The 2007 KEMA report to the Electricity Commission (KEMA, 2007) identified a basic list of lamp types that were installed in retail stores and quantified the use, based on floor area, of the different lighting technologies. Figure 1 shows the KEMA reported percentage of lighting technologies by floor area used in retail premises. 


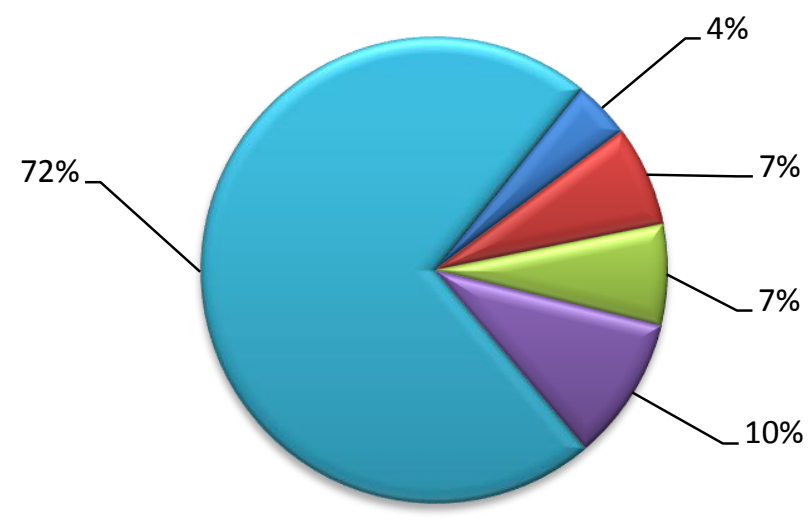

$\square$ Highbay Metal Halide $\square$ Halogen $\square$ CFL $\square$ Incandescent $\square$ Linear Fluorescent Lamps

Figure 1: New Zealand Retail Lighting Technologies - from KEMA 2007

\subsubsection{THE LAMPS}

Figure 1 above suggests that the largest share (nearly three quarters) of the surveyed floor area is lit by Linear Fluorescent Lamps (LFL) (72\%), with the remaining $28 \%$ lit by incandescent lamps (10\%). Almost equal floor areas are lit by Compact Fluorescent Lamps (CFL) (7\%) and halogens (7\%), with metal halide only accounting for around (4\%). But how do these lamps compare and why has one type been used over another?

\section{Comparison of Lamp Types}

Figure 2 below is based on "Typical Efficacies and Lifetimes of Lamps" in the United States Department of Energy, Buildings Energy Data Book (Department of Energy, 2009). The figure includes the typical wattages and average colour temperatures for each lamp type. These wattages and colour temperatures are representative only and have been taken from the OSRAM product catalogue (OSRAM, 2010). 


\begin{tabular}{|lrrrrrr|}
\hline Current Technology & $\begin{array}{l}\text { Typical } \\
\text { Wattage }^{1}\end{array}$ & $\begin{array}{l}\text { Efficacy } \\
\text { lm/W } \\
(1)^{2}\end{array}$ & $\begin{array}{l}\text { Typical } \\
\text { Hours2 }\end{array}$ & Rated & \multicolumn{2}{l|}{$\begin{array}{l}\text { Colour } \\
\text { CRI (2)2 } \\
\text { Temperature } \\
\text { K) } 1\end{array}$} \\
\hline Incandescent & $25-200$ & $10-19$ & $750-2,500$ & 97 & 2700 \\
\hline Halogen & $18-500$ & $14-20$ & $2,000-3,500$ & 99 & 3000 \\
\hline Fluorescent - T5(3) & $14-80$ & $25-55$ & $6,000-7,500$ & $52-75$ & $2500-8000$ \\
\hline Fluorescent - T8 & $10-58$ & $35-87$ & $7,500-20,000$ & $52-90$ & $2500-8000$ \\
\hline Fluorescent - T12 & $14-65$ & $35-92$ & $7,500-20,000$ & $50-92$ & $2500-8000$ \\
\hline Compact Fluorescent & $8-23$ & $40-70$ & $2000-10,000$ & 82 & $2700-4000$ \\
\hline Mercury Vapour(4) & $50-400$ & $25-50$ & 29,000 & $15-50$ & $3000+$ \\
\hline Metal Halide(5) & $20-400$ & $50-115$ & $3,000-20,000$ & $65-70$ & $3000+$ \\
\hline $\begin{array}{l}\text { High-Pressure } \\
\text { Sodium }\end{array}$ & $50-400$ & $50-124$ & 29,000 & 22 & 2000 \\
\hline $\begin{array}{l}\text { Low-Pressure } \\
\text { Sodium }\end{array}$ & $18-180$ & $18-180$ & 18,000 & 0 & - \\
\hline Solid State Lighting & $0.8-72$ & $(6)$ & $(7)$ & $70-80$ & $2540-10,000^{3}$ \\
\hline
\end{tabular}

Figure 2: Comparison of lighting Technologies (Source: OSRAM and Department of Energy)

1) Theoretical maximum luminous efficacy of white light is 220 lumens/Watt, (Department of Energy, 2009)

2) $\mathrm{CRI}=$ Colour Rendition Index, which indicates a lamp's ability to show natural colours (Department of Energy, 2009).

3) Many manufacturers are now specifying that their lamps are capable of 15000 hours of life. (OSRAM, 2010), (Philips, 2010).

4) Wattages can reach 1000Watts (OSRAM, 2010), this has been limited in this table to allow comparison within acceptable indoor levels

5) Wattages can reach 2150Watts (OSRAM, 2010), but the range has been limited to allow comparison within acceptable indoor levels

6) The DOE Solid State Lighting program has set an efficacy goal twice that of fluorescent lights (160 lumen per Watt) (Department of Energy, 2009)

7) Has not been determined (Department of Energy, 2009)

Typical Wattage: the rated energy consumption of the lamp. This is the lamp wattage only and does not include any ballast or extra control gear required to operate the light source.

Efficacy ( $(\mathbf{m} / \mathbf{W})$ : the total amount of light emitted from a source (Lumen, (lm)) divided by the input energy in Watts.

\footnotetext{
1 (OSRAM, 2010)

2 (Department of Energy, 2009)

3 (Philips, 2010)
} 
Typical Rated Hours: the expected lamp life span. The lamps that have low rated lives will also accrue higher maintenance costs as they are replaced at a greater frequency than the lamps with longer life spans.

CRI - Colour Rendering Index: an indication of a lamp's ability to show natural colours. The index is based on a figure between 0 and 100. The closer that a lamp's CRI is to 100 then the better that the light source can display natural colour.

Colour Temperature: the absolute temperature (Kelvin) of a blackbody radiator having a chromaticity equal to that of the light source (IESNA, 2000). Colours around 2700K can be considered as warm with a yellow tone, while those above $6000 \mathrm{~K}$ are known as cooler light sources due to the blue component in the light. Refer to Appendix C for a comparison of the scale.

\subsection{The RetaIl StORE}

This Section of the report provides a standard terminology for the various areas found within a retail store, detailing lamps that may be best suited to each area based on the lamp types and characteristics given in Figure 2.

The areas of the store listed here may be present in any small retail store, however not all stores necessarily have all areas.

\subsubsection{THE RETAIL AREA}

The retail area is part of the store in which the merchandise is displayed and where the customer can interact with the merchandise, as shown Figure 3. In a small store this area can be expected to command most of the total floor area within the store, as this is the area that generates the income for the store.

"Stock on the floor is Stock for sale" (Fitch \& Knobel, 1990)

The Illuminating Engineering Society of North America (IESNA) states that retail spaces 'should be conducive to initiating and completing sales transactions' (IESNA, 2000). This statement encompasses all of the actions and characteristics of the space. The area needs to be designed for the purpose, from the type of merchandise display through to the general layout. All aspects of the space need to convey to the customer that this is a product they need (Wills, No Date). Figure 4 shows in blue an example of the retail area 


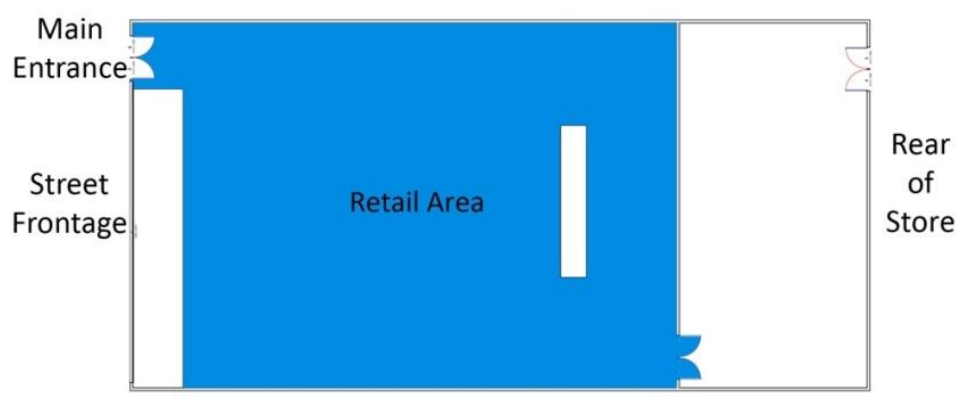

Figure 3: Image Showing Retail Area in an example store

The retail area is expected to contain the largest concentration of lighting as this is where the merchandise is displayed.

\subsubsection{THE DISPLAY WINDOW}

The display window often represents the first chance that a retailer has to attract and entice a passing customer into their store. The style of the display window varies greatly with some retailers preferring an open window display so that the store can be viewed through the window, while others prefer to close off the window display so that it becomes a small stage in which the merchandise can be arranged and highlighted. Figure 5 shows in green an example of the display window

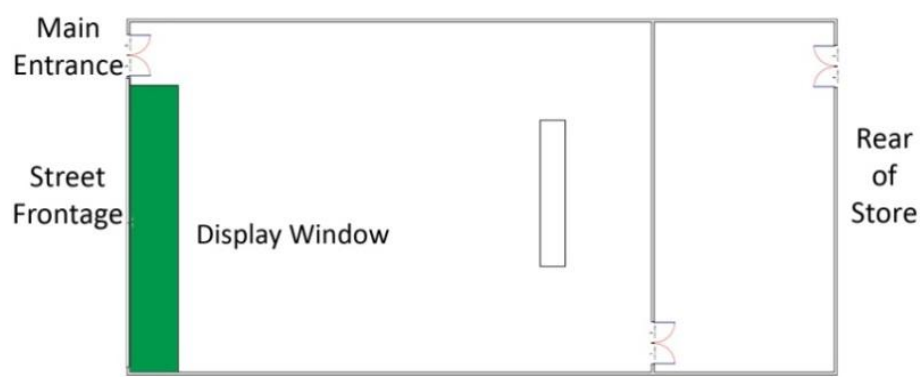

Figure 4: Image Showing Area of Display Window

Lighting in the display window can be expected to be maintained at a high level, as this space competes with natural daylight on the outside as well as with neighbouring stores that may be selling similar merchandise. 


\subsubsection{THE SALES AREA}

This part of the store needs to be well defined, with a clear navigation path so that it can be easily found by the customer. Once at the sales desk the customer needs good lighting to complete the transaction in a manner that is befitting the apparent cost of the item for sale. Figure 5 shows in orange an example of the sales area.

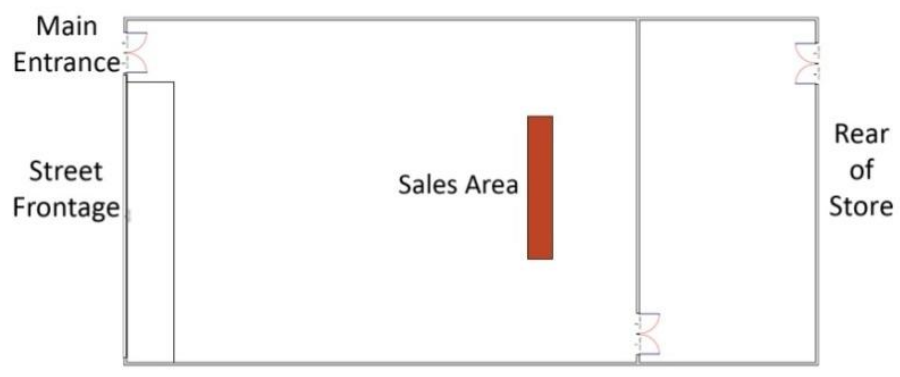

Figure 5: Image Showing an example of Sales Area

Lighting in the sales area is also expected to be higher than the surroundings, as the bright light may be used to guide the customer to this point.

\subsubsection{THE STOCK/UTILITY ROOM}

This space is used to store out of season stock and/or extra levels of merchandise for sale. This space is not expected to command much floor area based on the retail definitions above. This space may also double as the staff area and be fitted with kitchenette for staff breaks. Figure 6 shows in turquoise an example of a combined stock and utility room.

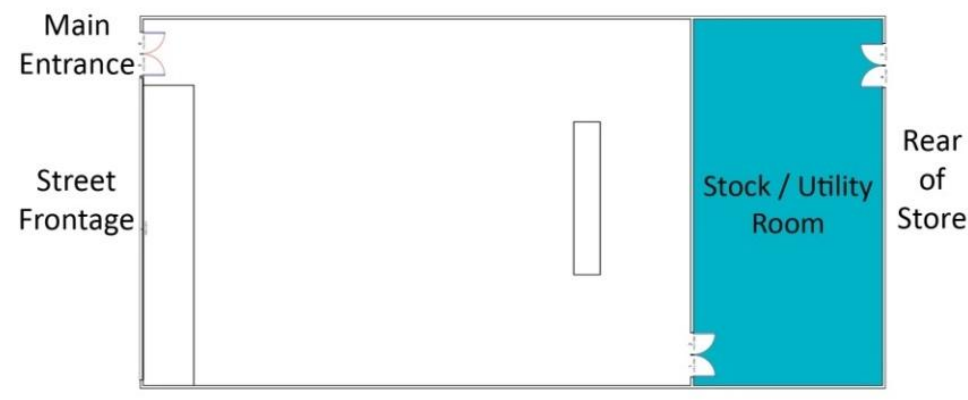

Figure 6: Image Showing Stock / Utility Room

Light levels may be held lower in this space as it is unlikely to be continually occupied on an average work day. 


\subsection{ThE AIM OF RETAIL Lighting}

"Merchandise apart, good store lighting rates above all else as an essential ingredient in retail design"

(Fitch \& Knobel, 1990)

The aim of a retail space must be to sell merchandise. "This is the place where customers make their purchasing decision - this is the place that must trigger this decision" (Otto Riewoldt, 2002).

But how a lighting installation actually achieves this desired goal, is as varied and subjective as there are stores to light. While the interaction of retail lighting and the consumer is a complex issue and can in some situations be described as art, the general aim of retail lighting can be defined as three basic goals (IESNA, 2000):

- To attract the customer

- To allow the customer to evaluate the product

- To enable the purchase

These three goals are the reoccurring themes throughout the guidance and publications provided by various lighting manufacturers such as ERCO (Ganslandt \& Hofman, 1992), Phillips (Philips, 2010) and OSRAM (OSRAM, 2010). 


\subsubsection{CORPORATE STRATEGY}

Stores that are part of a larger chain will often maintain a specific branding that is evident through its store design and merchandising strategy. This design and strategy remains the primary instrument of the store to communicate its identity to the customer (Otto Riewoldt, 2002).

Larger national chains may specify lamps and luminaires to create an atmosphere for all of their stores nationwide, rather than meeting any specific local goals.

\subsection{COMPONENTS OF Retail AREA Lighting}

Retail lighting can be divided into basic components that allow any aspect of the lighting design to be categorised. The retail designer Rodney Fitch (Fitch \& Knobel, 1990) described that retail lighting as providing either an ambient setting lit evenly over the entire space or lit theatrically using spot lights. IESNA have added a further category to these two, 'perimeter lighting', as perimeter lighting can create the illusion of space and increase the visual impact of merchandise on the stores walls.

\subsubsection{AMBIENT}

Ambient lighting is the term given to the general, background lighting. The light levels should remain constant over the entire sales area. Any type of lamp may be used to create this effect, but linear fluorescents are commonly used due to their even output along the length of the tube. Alternatively a tight grid pattern of down lights (incandescent, CFL, halogen or metal halide) can also be grouped to produce even levels of background lighting. Figure 7 provides an example of a lighting grid (luminaires shown in white) providing even ambient lighting (shown in yellow) across the retail area.

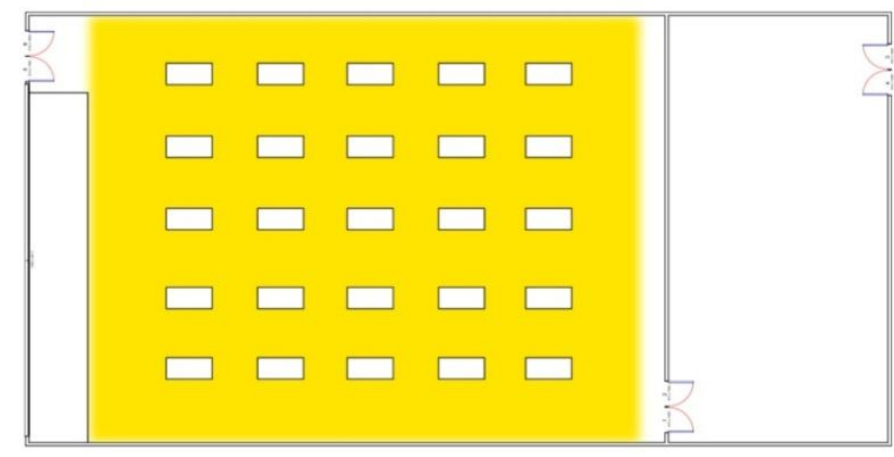

Figure 7: Image Showing Coverage of Ambient Lighting

\subsubsection{SPOT}

Spot lighting, sometimes called accent lighting, is used in stores to create the highlighting of specific items. This kind of lighting serves to attract the customer to certain displays or 
product (IESNA, 2000). The spot light helps focus the customer on both the merchandise for sale and the point of sale when they are ready to purchase. The types of lamps used for spot lighting are metal halides, halogens and PAR incandescent lamps. Figure 8 illustrates the use of spot lights to highlight the display window, sales area and the rear wall.

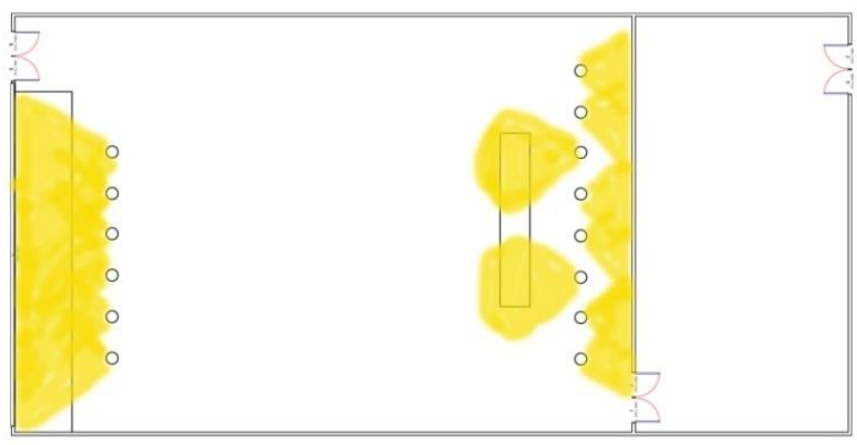

Figure 8: Image Showing Area of Spotlighting Use

\subsubsection{PERIMETER}

Perimeter lighting lights the interior walls to increase the general light levels and to give the customer a perceived sense of wellbeing and space (IESNA, 2000). Perimeter lighting is especially important if the merchandise has been displayed on the walls, or if walls are being used for some form of in store advertising. The lamps suited to perimeter lighting component are metal halide and halogen flood lights. Figure 9 illustrates the use of perimeter lamps to highlight the side walls of the retail area.

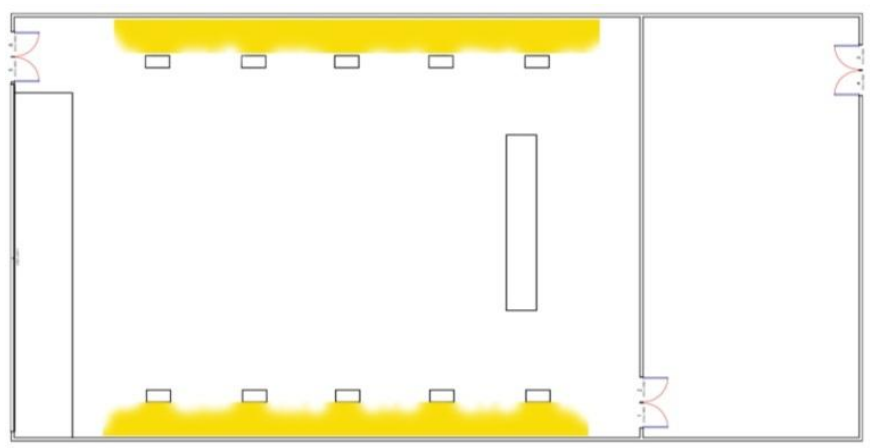

Figure 9: Image Showing Perimeter Lighting

Perimeter lighting may also be used at the rear of the store to illuminate it to a higher level than the surrounding walls in order to give an appearance of depth and brightness. This has the effect of drawing the customer into the store and into the merchandising area (IESNA, 2000). 


\subsection{RECOMMENDED LEVELS OF LIGHTING}

This Section documents the recommended lighting levels from published national and international literature.

\subsubsection{IESNA}

The IESNA has categorised stores into three categories (IESNA, 2000):

1. A low end or outlet store that specialises in mass marketing. The lighting is intended to match the simple style of mass marketing and is usually a single lighting system providing a general illuminance level between 750 and 1500 lux.

2. High end or boutique retail store. This type of store will use various levels of lighting to create contrast and intrigue within the store. The store can employ complex lighting systems that include a general level of lighting between 30 and 240 lux as well as spot lights and colour systems to highlight certain areas or merchandise.

3. In between the above two categories is a middle class of store. This type of store uses an ambient lighting system to illuminate the area to between 300 and 600 lux. As well as the ambient lighting system, spot lights or perimeter lights to highlight certain merchandise are also used, although not to the same level of contrast as the high end styled store.

The light levels that allow the completion of visual tasks are well documented such as those listed in Figure 10. This means that rather than suggest light levels for the store as a whole, the individual tasks within the store may be identified and have illuminance levels recommended based on the type of visual task ${ }^{4}$, its difficulty ${ }^{5}$ and the situation.

IESNA has developed recommendations shown in Figure 10 for the illuminance levels required in the different parts of a retail store. The levels are based on the type of task, the size of the task or object being considered and the area in which the task is being carried out.

\footnotetext{
${ }^{4}$ Visual task: The whole object (large or small) which is being examined e.g. Part of a car body under assembly, document or drawing being read, watch being repaired. (Standards New Zealand, 2006)

${ }^{5}$ Difficulty: Generally determined by the visibility of the most difficult element that must be detected or recognised in order to perform the task. (Standards New Zealand, 2006)
} 


\begin{tabular}{|c|c|c|}
\hline Space & Activity & Lux \\
\hline Alteration Room & $\begin{array}{l}\text { Performance of visual tasks of low contrast } \\
\text { or small size }\end{array}$ & $1000-2000$ \\
\hline $\begin{array}{l}\text { Fitting Room - Dressing } \\
\text { Area }\end{array}$ & $\begin{array}{l}\text { Performance of visual tasks of high contrast } \\
\text { or large size }\end{array}$ & $200-500$ \\
\hline $\begin{array}{l}\text { Fitting Room - Fitting } \\
\text { Area }\end{array}$ & $\begin{array}{l}\text { Performance of visual tasks of low contrast } \\
\text { or small size }\end{array}$ & $1000-2000$ \\
\hline Locker Room & $\begin{array}{l}\text { Working space where visual tasks are } \\
\text { sometimes undertaken }\end{array}$ & $100-200$ \\
\hline Stock Room & $\begin{array}{l}\text { Performance of visual tasks of high contrast } \\
\text { or large size }\end{array}$ & $200-500$ \\
\hline $\begin{array}{ll}\text { Wrapping } & \text { and } \\
\text { Packaging } & \\
\end{array}$ & $\begin{array}{l}\text { Performance of visual tasks of high contrast } \\
\text { or large size }\end{array}$ & $200-500$ \\
\hline Sales Transaction Area & $\begin{array}{l}\text { Performance of visual tasks of medium } \\
\text { contrast or small size }\end{array}$ & $500-1000$ \\
\hline \multicolumn{3}{|c|}{$\begin{array}{l}\text { The range of Lux levels given in the next section are based on activity levels in that space, the } \\
\text { largest being areas of high activity, the smaller being areas of low activity. }\end{array}$} \\
\hline Circulation (Ambient) & $\begin{array}{l}\text { Area not used for display, appraisal or sales } \\
\text { transactions }\end{array}$ & $100-300$ \\
\hline $\begin{array}{l}\text { Merchandising Areas } \\
\text { (all components) }\end{array}$ & $\begin{array}{l}\text { Where merchandise is displayed and } \\
\text { available for customer examination }\end{array}$ & $300-1000$ \\
\hline Feature Displays(Spot) & $\begin{array}{l}\text { Single item or items that require special } \\
\text { highlighting to visually attract. }\end{array}$ & $1000-5000$ \\
\hline Display Windows & Day Time & Night Time \\
\hline General & 2000 & 1000 \\
\hline Feature & $10000^{*}$ & $5000 *$ \\
\hline$*$ Night ti & level given for small town. & \\
\hline
\end{tabular}

The levels in Figure 10 are recommendations only and if a set task can be completed safely and adequately at lower light levels, then those levels can be considered adequate.

The other consideration when selecting light levels is the electrical energy used to enable the lighting systems to achieve the desired illuminance level(s). Energy efficiency codes and standards provide energy limits for different situations -the Lighting Power Density Limit (LPDL) which is normally given in Watts per square metre $\left(\mathrm{W} / \mathrm{m}^{2}\right)$.

\subsubsection{ASHRAE}

The American Society of Heating, Refrigerating and Air-Conditioning Engineers' (ASHRAE) Advanced Energy Design for Small Retail Buildings (ASHRAE, 2008), details recommended lighting levels both as LPDL and illuminance levels. This states the illuminance level for ambient lighting in a small retail site should be from 161 to 807 lux (15 to 75 foot-candles) (10.7 lux $=1$ foot-candle) depending on store type and retail strategy (ASHRAE 2006). The ASHRAE recommended LPDL for a range of retail stores is given in Figure 11. As the LPDL are originally given in $\mathrm{W} / \mathrm{ft}^{2}$, the converted $\mathrm{W} / \mathrm{m}^{2}$ are rounded to nearest whole number. 


\begin{tabular}{|lc|}
\hline Area & Lighting Power Density Limit \\
\hline Base Ambient level & $14 \mathrm{~W} / \mathrm{m}^{2}\left(1.3 \mathrm{~W} / \mathrm{ft}^{2}\right)$ \\
\hline $\begin{array}{l}\text { Additional Levels for adjustable lighting equipment used to highlight merchandise and controlled } \\
\text { separately from the general lighting. To be added to the base level. }\end{array}$ \\
\hline Sporting Goods/Electronics & $4 \mathrm{~W} / \mathrm{m}^{2}\left(0.4 \mathrm{~W} / \mathrm{ft}^{2}\right)$ \\
\hline Furniture, Clothing, Cosmetics and Art & $6 \mathrm{~W} / \mathrm{m}^{2}\left(0.6 \mathrm{~W} / \mathrm{ft}^{2}\right)^{*}$ \\
\hline Jewellery, Crystal and China & $10 \mathrm{~W} / \mathrm{m}^{2}\left(0.9 \mathrm{~W} / \mathrm{ft}^{2}\right)^{*}$ \\
\hline Spaces not listed above & $16 \mathrm{~W} / \mathrm{m}^{2}\left(1.5 \mathrm{~W} / \mathrm{ft}^{2}\right)^{2}$ \\
\hline \multicolumn{2}{|c|}{ Figure 11: Light Power Densities by Area and Product $($ ASHRAE, 2008) } \\
\hline
\end{tabular}

\subsubsection{NEW ZEALAND STANDARDS}

The two New Zealand standards that specify light levels used in this study are NZS4243:Part2:2007 Energy Efficiency - Large buildings, Part 2, Lighting and AS/NZS 1680.1:2006 Interior and Workplace Lighting - General.

AS/NZS 1680.1:2006 Interior and Workplace Lighting - General contains illuminance recommendations based on a given task. It uses general principles and recommendations to produce a visual environment in which a given task can be effectively carried out (Standards New Zealand, 2006). The standard does not identify retail lighting; rather it specifies some of tasks found in the retail situation which include the checking of stock, colour matching, and the inspection of work. AS/NZS 1680.1 does not cover lighting used for decoration, display, entertainment or sport.

This standard will be used as a way to identify acceptable illuminance levels that certain areas within the retail space may be illuminated to.

NZS4243:Part2:2007 Energy Efficiency - Large buildings, Part 2, Lighting specifies energy performance levels for buildings over $300 \mathrm{~m}^{2}$. This standard uses two methods to set the LPDL's for given space. These levels only apply to the general and ambient lighting systems within a space and are not intended to apply to display lighting, special purpose lighting, exterior lighting or lighting used in service areas. (Standards New Zealand, 2007). New Zealand Building Code (NZBC) H1/AS 1 Clause 6.1.1 (Department of Building and Housing, 2008) references the use of NZS 4243.2 section 3.3 or section 3.4 to demonstrate compliance with NZBC requirements.

The first method uses the schedule method, which uses a predetermined LPDL schedule when at least $80 \%$ of the floor area is used for one of the named purposes.

NZS4243:Part2:2007, Section 3.3 specifies the LPDL for ambient lighting in a supermarket or shopping context at $16 \mathrm{~W} / \mathrm{m}^{2}$ (Standards New Zealand, 2007). This will be used as a point of reference for the LPD levels found in the audited stores. 
The second is the calculation method (NZS4243:Part2:2007, Section 3.4) which determines the LPDL for the whole building, dependent on the maintained illuminance level from the AS/NZS 1680 series, the appropriate circuit efficacy, visual comfort, maintenance factor and room geometry (Standards New Zealand, 2007).

\subsection{DISCUSSION}

The creation of the community supported Kapiti Coast Centre of Clean Technology suggested that Otaki would be a good location to carry out a study into lighting, energy efficiency and the use of renewable energy sources.

The American studies, CBECS and CEUS, found that retail stores consume approximately $50 \%$ of all their electrical consumption as lighting. The New Zealand studies, KEMA and the limited data currently available from BEES, suggest retail store lighting consumption may be as high as $60 \%$ of electricity use. However, as these studies cover a wide range of different types of non-residential buildings, they generalise their results to cover all retail store sizes and uses.

This chapter also provided background to the different lamp types, the lighting styles used in the various areas of retail stores and current New Zealand and international lighting standards. 


\section{RESEARCH DEVELOPMENT}

This chapter sets out the study limits in terms of sample size and definitions. It defines the geographical area and sample selection methodology.

To identify the typology and end-uses of the buildings in Otaki, this chapter uses a method developed by the BEES based on an initial site visit carried out 'virtually' on a computer. This allows the survey site to be assessed for suitability before committing to the travel and expense of visiting the site itself. The virtual tour allows the types and numbers of businesses to be identified and the contact details to be obtained.

This chapter also develops the methodology used to recruit the participants, including the development of a presentation pack and introduction letter.

\subsection{WHERE IN OTAKI?}

To survey all the retail stores in the town of Otaki, then analyse where and how energy was used would require more than the timeframe given for a Masters project (12 months). It was decided to limit the study to the retail strip along the main highway, based on the discussions held with Grow Wellington and its economic importance to the town (Kapiti District Council, 2009).

\subsubsection{IDENTIFYING THE RETAIL STRIP}

The first step was to document the store types, sizes and energy uses. It was originally planned to travel to Otaki to assess the likelihood of carrying out the survey but during the 2008/2009 summer BEES developed a method that allowed them to assess sites using web based data, before making an actual site visit.

\section{BEES Virtual Site Visit}

In late 2008 BEES developed a method to 'virtually' visit a building before a physical visit was required. The virtual site visit took place in front of a computer, using applications such as Google Maps, Google Earth, and local council GIS systems could be used to explore the 'virtual site'. The virtual site visit provided information on the names of occupier(s), building construction types and appearance, as well as estimates of the building's height and floor area which was used to "document" the buildings.

This method allowed the BEES project to check almost any building, on any street, anywhere in New Zealand, which was perceived to be more economic than visiting each site, as well as making the final sample selection an informed process. 
There were issues in the process, as not all of the buildings could be found or identified. The reasons were as varied as "no such addresses from the web search through to cloud cover and image focus issues in Google Earth. Google Street View at the time was blanking any signs or wording in their images. This meant the names of the occupiers and streets in some situations could not be obtained. Nevertheless this approach permitted the Otaki sample design to be initially carried out before the need for a physical site visit.

\subsection{DEFINING THE SAMPLE UNIT}

It was decided that the base sample unit in Otaki was the 'premise', based on the CEUS definition that a "premise was a single commercial enterprise operating at a contiguous location" (Itron, 2006).

This base sample unit differs from the other major studies. BEES and CBECS both use the building as the base sample unit, but these studies are investigating building energy use and not just the individual tenant's energy use. These studies also developed their sampling using random selection based on floor area and typical end-use.

This study is concerned with lighting in the individual shops, not buildings, on the Otaki retail strip and this selection is not random.

\subsection{OTAKI's VIRTUAL SITE VISIT}

The first task, using the virtual site visit, was to identify the location in Otaki of the survey area and consider what constraints could be applied to limit the scope to what could be achieved within the available timeframe. Google Maps was used to provide aerial images and street maps, while Google Street View provided street level images.

In March of 2010, Google Maps was used to identify the general area of the retail strip along the State Highway One. This is shown below in Figure 12. 


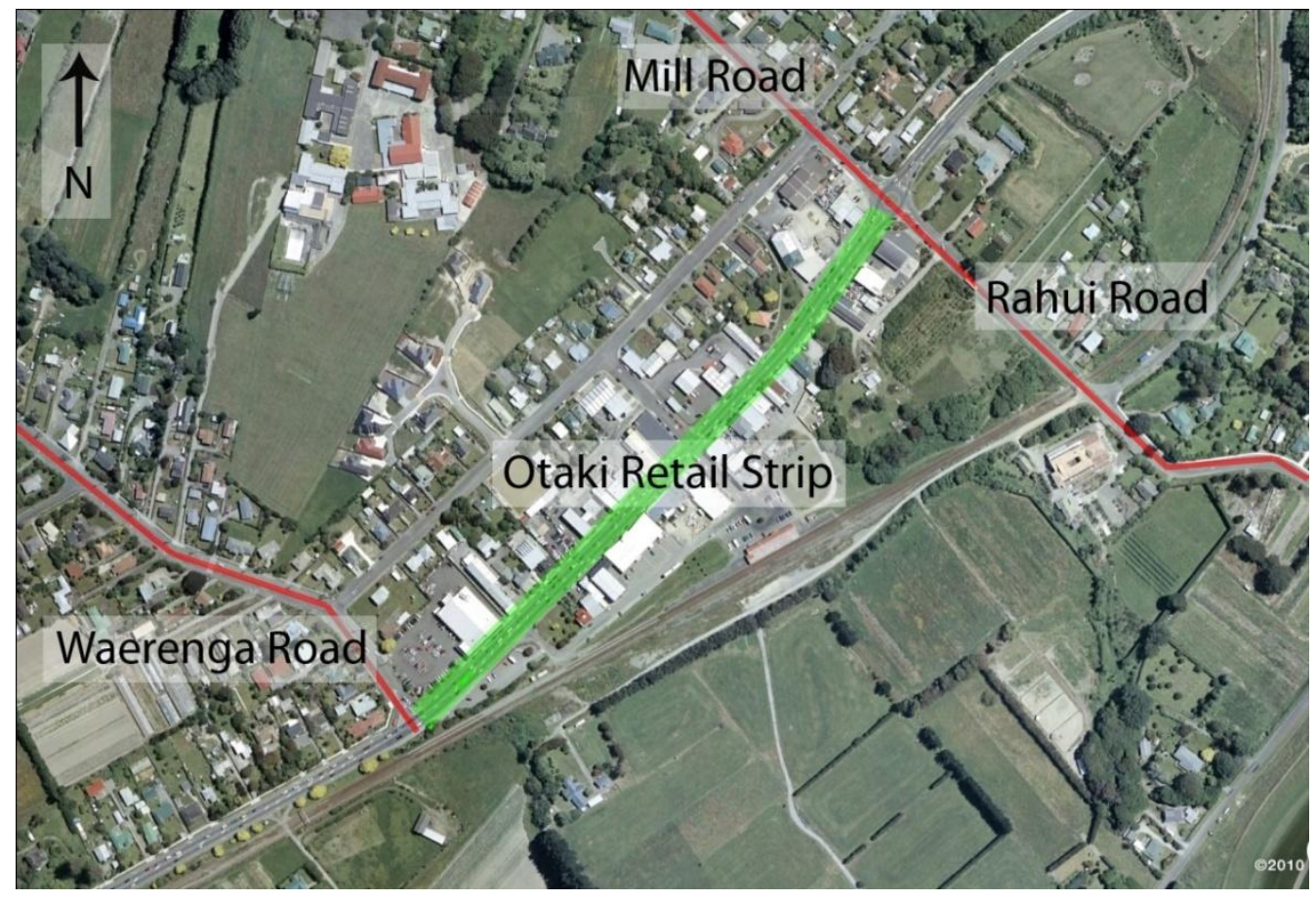

Figure 12: General area of Retail Strip (Source: Google Earth)

Figure 12 identifies the general area facing State Highway One, between Waerenga Road to the south and the intersection at Mill Road and Rahui Road to the north, as the survey area, which in this study has been named as the 'Retail Strip'. Newer shopping centres are now being developed to the west behind State Highway One, but these were not going to be completed within the research timeframe.

\subsubsection{OTAKI 'VIRTUAL' SURVEY}

The valuation data identified 40 legal titles along State Highway One in the retail strip, which are shown in Figure 13 as a Cadastral ${ }^{6}$ overlay. This provided an indication of the potential number of building owners, but not the type of buildings or the tenants.

\footnotetext{
${ }^{6}$ Cadastral Map: Kapiti District Council District Plan - Maps, (Kapiti Coast District Council, 1999)
} 


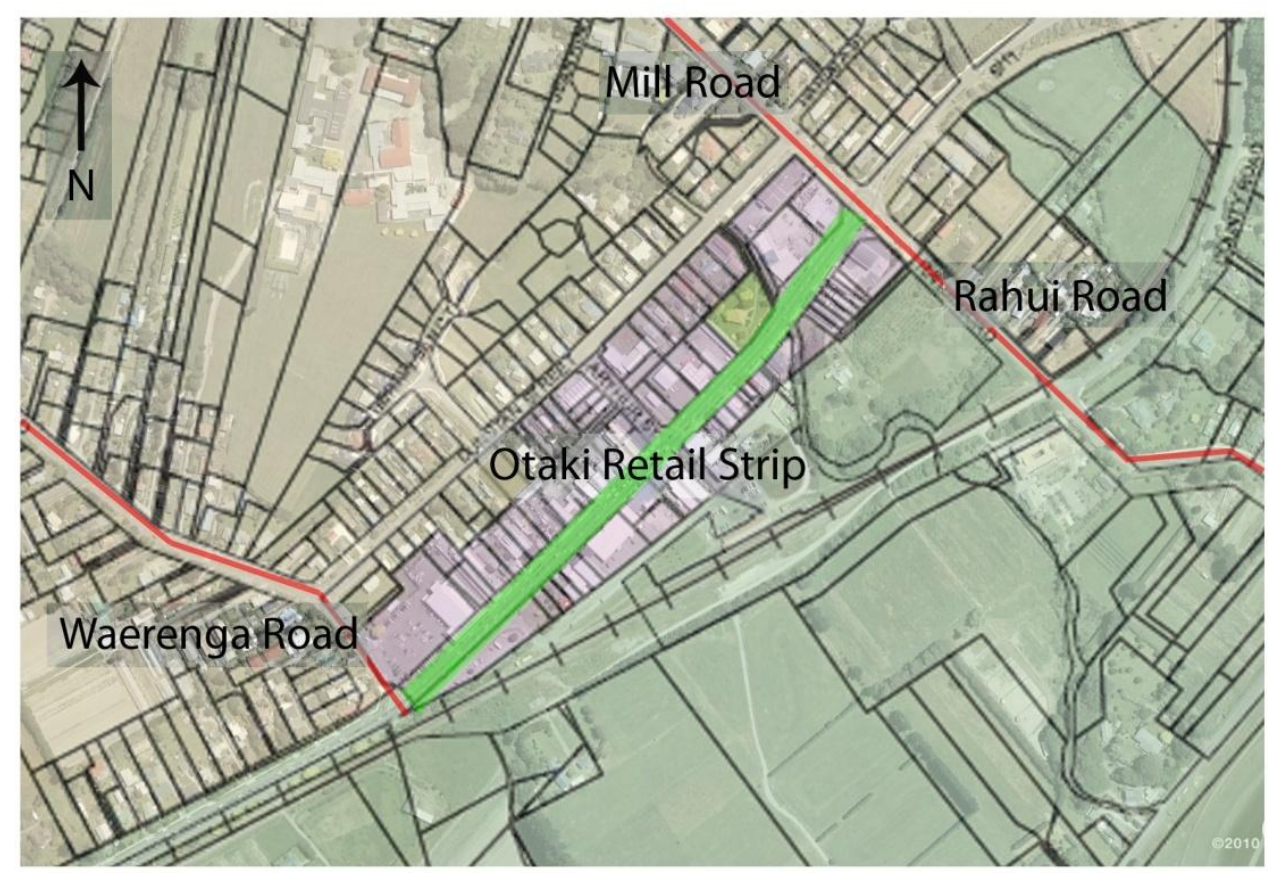

Zoned Residential

Zoned Rural

Zoned Commercial / Retail

Figure 13: Cadastral Overlay for Otaki

In late March 2010 a virtual site visit using the BEES methodology was carried out. It evaluated the size of the retail strip and the types of stores that populated it.

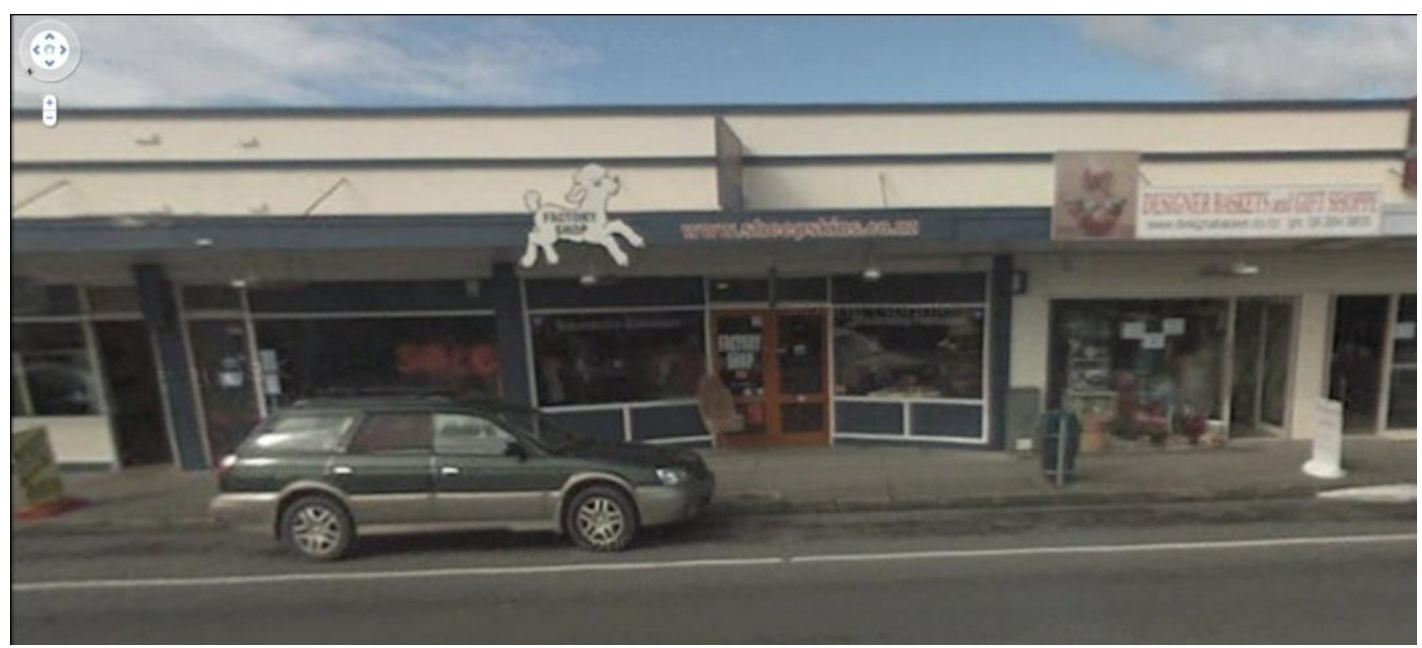

Figure 14: Google Street View Image (Source: Google Street View)

By 'viewing' the street using Google Street View (an example is shown in Figure 14) the names and type of each of the businesses could be recorded. From this database of business names the phone numbers, web addresses, and other contact details were obtained from the internet using websites such as the Yellow pages, individual retailer's 
web sites and business locating sites such as 'Zenbu' (www.zenbu.co.nz) and 'Finda' (www.finda.co.nz).

The business types were divided into five categories:

Fashion: Any store perceived to be selling clothing or any form of accessories. It also includes related trades such as an alterations service.

Vehicle: Any service or building that is related to a vehicle, including service station and tyre merchandiser.

Food: $\quad$ All food sales. It includes mass retail such as the supermarket through to the smaller cafes, bakeries and fast food outlets. Not included are the coffee carts that appear to be 'parasitic' in nature, in that they don't have their own electricity meter, as they are powered from existing sites.

Service: Any service related store. This includes realtors, engineering and lawyers.

Other: $\quad$ This is the miscellaneous section that includes the stores that only had one or two types identified such as sports and health stores. Also included in this section are the empty premises.

From the virtual site visit, there were 55 individual premises identified along the retail strip. The composition that was observed at the time (March 2010) is shown below in Figure 15. The most populous store type within the Otaki retail strip is in the fashion category (20 of 55) - perhaps the reason that Otaki is a destination town for outlet clothing shopping.

\subsection{OTAKI ON-SITE SURVEY}

The first on-site visit to Otaki was carried out in April 2010. This visit was planned to verify the list of stores developed through the virtual visits. By actually travelling up to Otaki and viewing the physical buildings, they could be assessed and compared to the list generated through the virtual study. Once in Otaki, the survey was completed on foot and did not involve any contact with the individual retail businesses.

The list that been developed by the virtual visit was checked against the businesses that occupied the building. Where a discrepancy was noted, the correction was marked the 'virtual list'. The on-site visit identified 54 individual premises, as documented in Figure 15: 


\begin{tabular}{|c|c|c|c|c|c|c|c|}
\hline \multirow[b]{2}{*}{ Categories } & \multirow[b]{2}{*}{ Description } & \multicolumn{2}{|c|}{ March 2010 } & \multicolumn{2}{|c|}{ April 2010} & \multicolumn{2}{|c|}{ November 2010} \\
\hline & & $\begin{array}{l}\text { Virtual } \\
\text { Count }\end{array}$ & $\begin{array}{l}\text { Virtual } \\
\text { Total }\end{array}$ & $\begin{array}{l}\text { Actual } \\
\text { Count }\end{array}$ & $\begin{array}{l}\text { Actual } \\
\text { Total }\end{array}$ & $\begin{array}{l}\text { November } \\
\text { Count }\end{array}$ & $\begin{array}{l}\text { November } \\
\text { Total }\end{array}$ \\
\hline \multirow[t]{7}{*}{ Fashion } & Fashion & 15 & & 18 & & 2 & \\
\hline & Fashion & & & & & & \\
\hline & Accessories & 4 & & 6 & & ( & \\
\hline & Fashion & & & & & & \\
\hline & Service & 0 & & 1 & & ( & \\
\hline & Hair Dresser & 1 & & 0 & & & \\
\hline & Total & & 20 & & 25 & & 26 \\
\hline \multirow[t]{6}{*}{ Vehicle } & Car Sales & 1 & & 1 & & 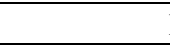 & \\
\hline & Car & & & & & & \\
\hline & Maintenance & 2 & & 2 & & 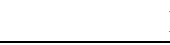 & \\
\hline & Service & & & & & & \\
\hline & Station & 3 & & 3 & & & \\
\hline & Total & & 6 & & 6 & & 5 \\
\hline \multirow[t]{6}{*}{ Food } & Supermarket & 1 & & 1 & & 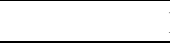 & \\
\hline & Food Sales & 2 & & 2 & & 2 & \\
\hline & Bakery & 1 & & 1 & & 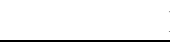 & \\
\hline & Cafe & 3 & & 2 & & 2 & \\
\hline & Fast-food & 2 & & 4 & & 5 & \\
\hline & Total & & 9 & & 10 & & 10 \\
\hline \multirow{9}{*}{ Service } & Service & & & & & & \\
\hline & Supplies & 1 & & 0 & & ( & \\
\hline & Engineering & & & & & & \\
\hline & Services & 1 & & 0 & & ( & \\
\hline & Lawyer & 1 & & 1 & & ( & \\
\hline & Real Estate & 6 & & 3 & & . & \\
\hline & Information & & & & & & \\
\hline & Centre & 1 & & 1 & & _t & \\
\hline & Total & & 10 & & 5 & & 4 \\
\hline \multirow{9}{*}{ Other } & Sporting & & & & & & \\
\hline & Goods & 1 & & 1 & & & \\
\hline & Giftware & 2 & & 2 & & 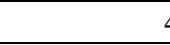 & \\
\hline & Health & & & & & & \\
\hline & Products & 2 & & 0 & & ( & \\
\hline & Stamp & & & & & & \\
\hline & Evaluator & 1 & & 1 & & & \\
\hline & Empty & 4 & & 4 & & i & \\
\hline & Total & & 10 & & 8 & & 8 \\
\hline Total** & & & 55 & & 54 & & 54 \\
\hline
\end{tabular}

\subsubsection{CHANGES OVER TIME}

It was noticed between the first virtual (March 2010) and second physical (April 2010) visits that some of the retail stores had changed. It was decided to monitor these changes, which are briefly analysed in the following notes.

\section{March - April 2010}

The largest increase in store numbers between the virtual visit and the actual visit occurred in the Fashion Stores. The fashion retailers and accessories retailers increased 
from 20 to 25 stores (36\% to $46 \%$ respectively of all premises). The casualty in this sector was the hairdresser, whose store premises were taken over by the expansion of a neighbouring fashion retailer. This expansion also accounts for the decrease from 55 to 54 individual stores.

In the Vehicle sector the numbers did not alter between the visits, however the businesses themselves changed owners and therefore brands.

In the Food section the cafes have decreased from three down to two. The total however has increased from nine up to ten, due to the number of fast food outlets increasing.

The decrease in the Service category occurred with the number of real estate offices halving to the present level of three. There was also a loss of the engineering and service supplies, which were replaced with additional outlet fashion stores.

In the Other category there was a decrease in numbers due to the two health stores closing and the premises changing in use to a fast food store and cafe. It should be noted that the identified empty stores in the 'Virtual Visit' are not the same stores that were identified as empty in the actual visit.

\section{April 2010 - November 2010}

On the last visit to the town in November 2010, the number of stores remained the same, although again the composition had altered. One of the 'fashion accessories' stores had merged into its 'fashion' neighbour, while another fashion store split into two separate fashion stores.

Between the initial virtual site visits in March to the actual visit in November, the number of fashion stores increased from $26 \%$ to $37 \%$ of all premises. Including the fashion accessories shops, the fashion category increased from 36\% in March to $48 \%$ of all premises in November.

Only two premises remained empty in November, with one of the fast food outlets closing but advertised to be shortly reopening as an outdoor/golf store. The other empty premise was previously a lawyer's office, but its future use was unclear. 


\subsection{BUSINESSES ON OTAKI's RETAIL STRIP}

This section looks at the store types and their location on the strip, exploring the data collected during visits in April and November 2010.

Figure 16 shows the percentages of each different category of retail stores for April by both count and floor area.

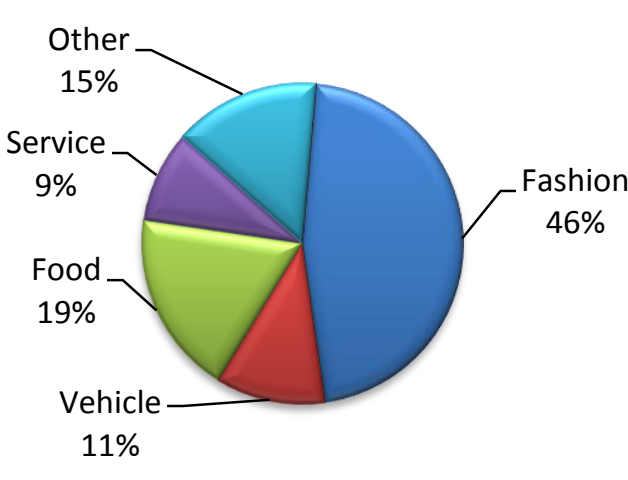

Figure 16: Businesses by Categories.

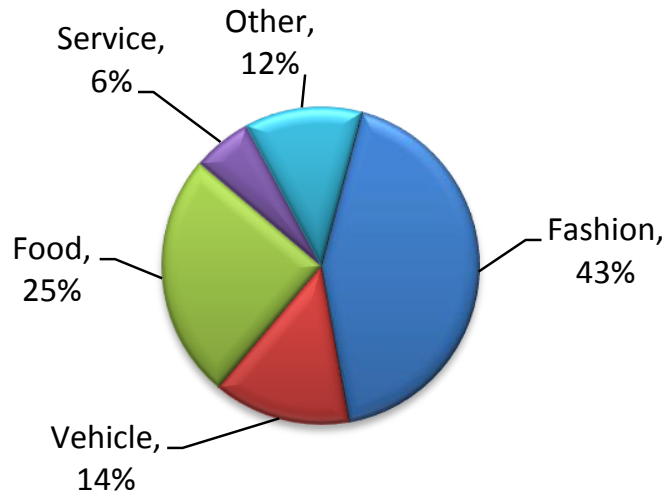

Figure 17: Businesses by Floor Area

During the April on-site survey 54 stores were operating on the retail strip. Figure 16 shows that $46 \%$ of the stores are 'fashion', which Figure 17 shows occupy $43 \%$ of the floor area.

Floor area estimates generated using Google Earth, based on stores' footprints, show $10,100 \mathrm{~m}^{2}$ are available. The estimates are based on the building roof layout, which include any overhangs or eaves but exclude footpath canopies. In the vehicle category, any forecourt was also excluded.

Figure 17 plots the floor area for each category. The food category shows an increase of $6 \%$ over the store count (19\% vs. $25 \%$ ). This is because of the 10 stores in the food category, the $1,400 \mathrm{~m}^{2}$ supermarket accounts for over half of the floor area $(55 \%)$.

Figure 18 shows the distribution of the different store categories along the retail strip. The eastern side of the strip has $54 \%$ of the available floor area but only $38 \%$ of the store count. However, the supermarket (shown in green, lower left Figure 18) accounts for $30 \%$ of the floor area on that side of the strip. 


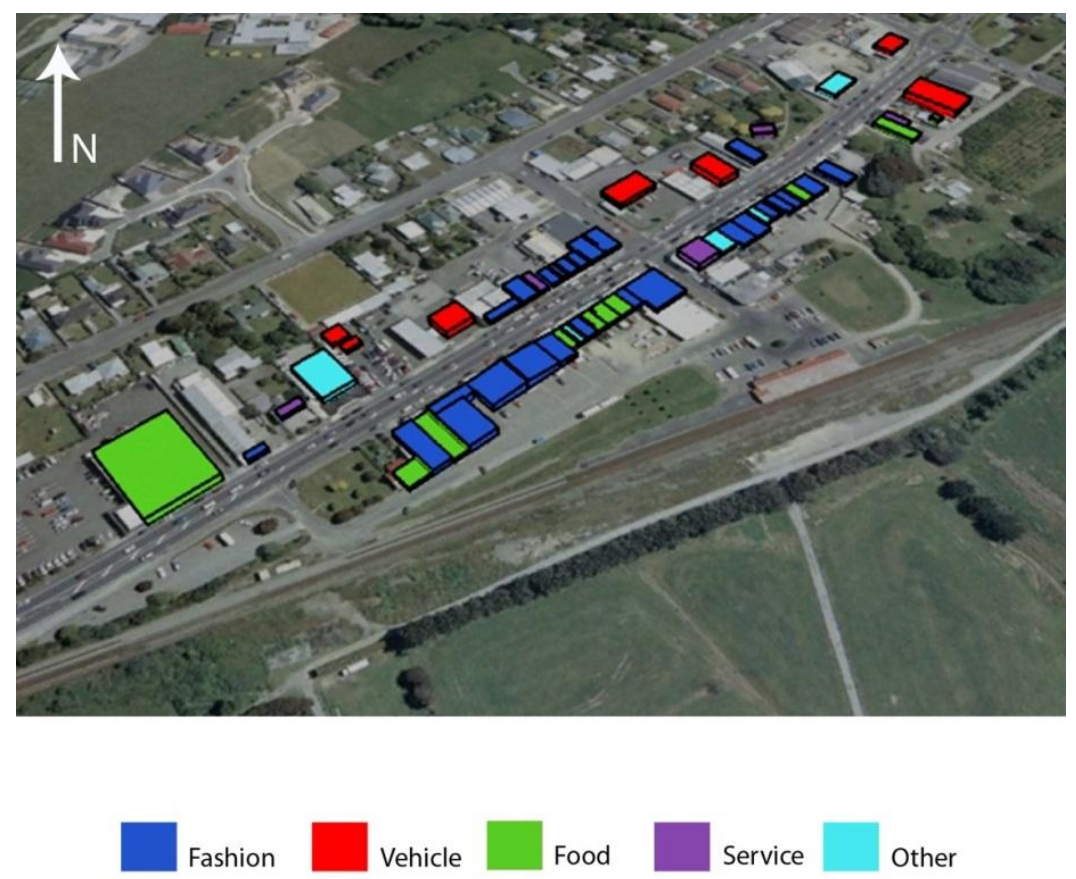

Figure 18: Retail Strip - Store Typology (Original Image: Google Earth)

Figure 18 shows that while retail shops are well represented on both sides of the road, the food and vehicle categories are almost exclusively each on one side. All of the stores are rectangular in shape, usually with the shortest wall facing State Highway One. This wall is usually glazed with a display window, with the store stretching away from it giving the 'depth'. The only store not having 'depth' is one of the fashion stores on the western side (top side in Figure 18) which has its display window along the long wall facing the road.

Around $50 \%$ of all stores use some form of solar management window treatment. That varies from a reflective film through to moveable blinds that can be drawn during the afternoon. The blinds are exclusively found in stores that face west in order to control the low angle, late afternoon sunlight.

Of the 27 stores using some form of window treatment, $16(60 \%)$ of them use window advertising to reduce the visible glazing. 12 of these are located on the eastern side of the road. None of the east facing stores used either blinds or full window advertising. Only the sports store on the western side of the road had no display windows, but this was related to security.

The stores that used display windows often used the open back configuration to allow the customer to see right into the store. Most had some form of display but only three stores created a dedicated space for window displays - two boutique fashion stores and one outlet store. 
As discussed in Section 3.2, the research focus is on the individual stores to fully document the lighting. Analysis of the April site visit revealed that 18 stores (33\%), such as fast food outlets, cafes and car maintenance garages, contained energy using process equipment. As these stores primarily use ambient lighting systems with limited display lighting and hence differ significantly from the specialty merchandising stores, it was decided to further limit the project.

The Australian and New Zealand Standard Industrial Classification (ANZSIC) Division $G$ - The Retail Trade defines the 'retail trade division' as "units that are mainly engaged in the purchase and on selling of goods without significant change to the general public" (ANZSIC, 2006). This definition was then used to select the shops for investigation.

\subsubsection{EXCLUDED}

Of the 55 premises observed, 13 were excluded based on the 'retail trade division' definition - clothing alteration; fast food outlets; cafes; information services; all car maintenance; real estate brokers and the lawyers.

The service stations were excluded due to their retail diversity. Although all of the service stations sold petrol and had a grocery section, they also had a cafe - a type of business excluded based on the above definition.

Initially the supermarket was considered for inclusion in the study. However, as with the service stations, the supermarket provides a wide range of services, including a bakery and cafe, so was also excluded.

Figure 19 gives the count of included and excluded premises along the Otaki retail strip.

\begin{tabular}{|c|c|c|c|}
\hline Included & Count & Excluded & Count \\
\hline Fashion Stores & 18 & Supermarket & 1 \\
\hline Fashion Accessories & 6 & Service Station & 3 \\
\hline Car Sales & 1 & Car Maintenance & 2 \\
\hline Food Sales & 2 & Fashion Service & 1 \\
\hline Sporting & 1 & Fast Food Outlet & 4 \\
\hline \multirow[t]{7}{*}{ Giftware } & 2 & Bakery & 1 \\
\hline & & Cafe & 2 \\
\hline & & Lawyer & 1 \\
\hline & & Information & 1 \\
\hline & & Stamp Evaluator & 1 \\
\hline & & Empty & 4 \\
\hline & & Real Estate & 3 \\
\hline Totals & 30 & & 24 \\
\hline
\end{tabular}




\subsection{How To ReCRUIT THE SELECTED BUILDINGS}

The first meeting with Grow Wellington's Centres of Excellence Manager, Steven Finlay was held in March 2010 at Grow Wellington's CBD office. The aims and overall goals of the Greater Otaki Project were discussed.

At the time, the building for the Centre of Excellence had just been completed by a property developer, the owner of the industrial sub-division in which the building was placed. The following week after this meeting, the author and a class from VUW Building Science programme (BILD 321 - Sustainable and Regenerative Design) made a site visit to look at the building and attend a Centre of Clean Technology presentation. This presentation provided information on several 'green' recycling businesses and two power generation companies, one of which had just completed their business program in conjunction with the Centre of Excellence. Some of the local Otaki retail strip property owners were also in attendance, and contact details were provided for other owners.

The building owners expressed an interest in the research, but they all stated that the final decision to participate in the study had to be with the tenant. They advised that the tenants should be directly approached and if there were access issues then the building owner would be available for assistance.

The start of the research in February 2010 coincided with the first public advertising of the Greater Otaki Project and the development of the Centre of Excellence for Clean Energy. On the 25 February 2010 the Otaki Mail ran a four page article on the Greater Otaki Project (reproduced in Appendix D). This article detailed the ongoing Kapiti District Council commitment and the opportunities that the Centre could offer.

Following the site visit in March, a meeting was held in Otaki on the $23^{\text {rd }}$ of April 2010 with Steven Finlay. He offered to assist this study as part of his planned promotion for the Greater Otaki Project. He was already planning to visit all the retail strip businesses talking about the Greater Otaki Project, and during this he would also introduce this research study. His visits were to be completed the following week (26 - 30 April), so the study recruitment could commence the week after.

As a result of this offer of assistance, it was decided to develop an information pack that could be hand delivered during the first recruitment call. As Otaki is a small town, it was felt a direct approach to each store manager would allow personal engagement and increase the chances of that business agreeing to participate in the study. 
One of the local building owners, as well as operating one of the fashion stores also operated one of the real estate offices. In discussions, he expressed interest in having his real estate business included into the study. In order to increase the likelihood of participation in the study of some of the fashion stores along the retail strip, this (and the other two) real estate offices were included, even though this business type does not strictly fit with the ANZSIC 2006 retail trade definition.

The real estate offices form part of the ANZSIC Division L - Rental, Hiring and Real Estate Services and this class is defined as consisting "of units mainly engaged in valuing, purchasing, selling (by auction or private treaty), managing or renting real estate for others." (ANZSIC, 2006) 


\subsubsection{DEVELOPING AN INFORMATION PACK}

The information pack needed to combine the background information on the research study in a coherent, visual-based package. It was comprised of the following:

\section{Letter of introduction}

The letter of introduction in Appendix D was created to introduce the research and researcher. It detailed the aims of the research and how it integrated with the Greater Otaki Project. As an offer of goodwill, the stores were offered the opportunity to receive their results in the form of a short report detailing their energy use.

\section{Consent Forms}

Two consent forms were required - one that allowed access to the store and the other to the electrical billing records. The access consent set out the activities planned to be undertaken in the store (measurements, data collection) and recorded the formal agreement of the store manager/owner to these. The second consent form, once completed, was sent to the billing supplier to access the last two years of billing data.

\section{The Greater Otaki Project Cover Letter and Information}

Steven Finlay, manager of Grow Wellington's Centres of Excellence produced a cover letter on behalf of the Clean Energy Centre and the Greater Otaki Project. This letter introduced the study as the first part of community research to enable Otaki to go 'off the grid'. It was attached to a copy of the four page article that had run in the Otaki mail. This is reproduced in Appendix D. 


\section{THE INSTRUMENT}

This chapter describes the development of the instrument used to quantify and measure the retail lighting use along the retail strip. How a building uses its energy is dependent on any number of variables. They include the type of business, where it is located, occupancy and the actions of that occupant.

To quantify the installed load, an energy audit was carried out using the methodology of AS/NZS 3598:2000 Energy Audits. The use of this Standard allows a consistent set of data to be developed for each of the surveyed stores. A pilot study was undertaken on a local Wellington retail store to trial the recruitment presentation and energy audit in a real setting. The pilot also gave the opportunity to evaluate the type of results that could be produced for the Otaki shops.

\subsection{WHAT IS AN ENERGY AUDIT?}

The Oxford Dictionary defines an audit as;

“A systematic review or assessment of something” (Oxford University Press, 2010)

An energy audit is best described as a systematic review of energy consumption in a specific location, building or space. An energy audit provides essential information to allow a business to formulate an effective energy management program.

\subsubsection{THE NEW ZEALAND ENERGY AUDIT}

The Australian and New Zealand Energy Audit Standard, AS/NZS 3598:2000, Energy Audits was produced as a guide to create a uniform method of commissioning and carrying out an energy audit (Standards New Zealand, 2000). The energy audit provides the opportunity for businesses to identify and monitor their energy use. By carrying out an energy audit the business has the opportunity to establish possible cost and energy savings that would be the result of more efficient energy use.

Because each energy user is different, the standard defines three levels of energy audit that can be applied to any size and type of energy user.

1) The Level One or 'overview' audit is carried out at a basic level and has no requirement for an auditor to visit the site. Of the three levels the level one audit is easily the most simple. The auditor looks at the overall energy use (either through billing records or the energy supplier data) and compares this to a benchmark of energy use in that sector. This level of audit is used to determine whether or not a 
site's energy use is reasonable or excessive. It is expected to have an accuracy of \pm 40\% (EECA, 2007).

2) The Level Two audit includes all of the gathered data in a Level One audit, but must also include a site visit to quantify the energy end-uses. This level of audit provides moderate detail on the energy uses, as well as including an energy balance.

An energy balance compares energy purchases from billing records to the energy end-uses within the building, taking into account the operating hours and load variations. This level of audit is used to identify recommendations in the general areas in which savings could be made. It is expected to have an accuracy of $\pm 20 \%$ (EECA, 2007).

3) The Level Three audit is the most comprehensive audit, with an expected accuracy of $\pm 10 \%$ (EECA, 2007). It encompasses the detail in both the Level One and Level Two audits, but also includes specific energy measurement in a particular area or end-use. This means that not only are the site or area end-uses accounted for, but specific end-uses or areas may be monitored to develop usage profiles for that item or area.

The recommendations made from a Level Three energy audit are the most accurate, and thus a Level Three audit is recommended before the owner or energy user invests in substantial upgrades.

\subsection{The Lighting SurVeY AND Audit}

To ensure that a suitable level of understanding of Otaki retail store electrical energy use, it was decided to use a Level Two energy audit. This would provide good data on the main energy uses and their relative importance.

The process of the energy audit was to firstly enter the space and record dimensional details, such as size and layout, on a sketched plan. The distances were measured using a laser 'tape' measure (Leica Disto A3) with a claimed accuracy of $\pm 1.5 \mathrm{~mm}$ at 100 metres.

A copy was then made of the initial sketch plan and details noted on the lighting layout, window positions, the Sales Area and approximate locations of the store's merchandise.

Light level (lux) readings were taken using a digital illuminance meter (Lutron LX-102) and recorded in the appropriate position on the plan. The light temperature in Kelvin $\left({ }^{\circ} \mathrm{K}\right)$ was also measured using a chroma meter (Minolta xy-DC). 
It was originally thought that the recorded light levels could be entered directly into a spreadsheet but this method would have required two surveyors - one to operate the computer while the other carried out the measurements. While involving two people in the measurement was not a problem, the measurements would need to be called across the store. This would have interfered unnecessarily in the normal store operations of serving customers or trying to complete a sale, so the measurements were recorded by the person operating the meter.

With all of the light related measurements completed, the lamp types and count of the number of lamps per fixture were recorded, along with the type of control and the number of lighting circuits.

The final step in the audit was to undertake an equipment count of the various appliances and record basic information on the heating and/or cooling methods (if present).

On completion of the data gathering activities, generic power values were applied to each item to generate a 'maximum' power load $(\mathrm{kW})$. This maximum load is then combined with the trading hours, to develop a basic estimate of consumption for the day/week ( $\mathrm{kWh} /$ day or $\mathrm{kWh} /$ week).

The lighting electric loads in some cases need to be adjusted above the lamp wattage. This was because some lamp types, such as metal halides, linear fluorescents and low voltage halogens, use control gear with its own electric load that needs to be included in the total load calculation.

The loads can also be used to calculate the energy balance for the shop. The energy balance compares the billed energy data from the previous two years to the audit calculated energy use. Any differences between the calculated and the billed energy use may indicate problems with the audit or areas where potential energy savings could be identified.

\subsection{PILOT Audit}

A Wellington city store, close to the School of Architecture, was used to test the proposed audit procedures. The trial of the methodology started with an approach to the store manager in a local fashion store, asking if they would consent to a trial audit and survey. The manager consented to having the store audited, but noted that as the store was a part of a national chain he did not control the energy bills or payments. In the end the store manager was not able to acquire the billing records from head office within the available time. The lack of head office involvement also meant that it was not possible to 
take photographs of the store, nor identify the store's or manager's name. The following provides a brief diary for the pilot audit.

\subsubsection{THE APPROACH}

On Thursday the $15^{\text {th }}$ of April, 2010 the store manager was approached to explain the study and to obtain access to the site for the purposes of testing the audit structure.

As the manager was known, he was approached directly and presented with the information pack. As this was not Otaki, the Greater Otaki Project was explained in some detail, along with the general aim of going 'Off the Grid'. The discussion and presentation pack helped create a relationship within which the study could be discussed.

The information pack also provided the backup details should he have any additional questions or any aspect had not been covered during the discussion. This method also set up an informal feel to the survey by engaging the store manager in the use of the measuring equipment and readings within the space.

Once consent to run the survey had been given, a suitable time for the audit process to be carried out was agreed. It was decided that the following Monday morning would be the best, as this was often the quietest time after the busier weekend.

\subsubsection{THE VISITS}

On Monday $19^{\text {th }}$ of April, the first audit visit took place. This was followed up by two further visits, once in the afternoon on the same day, and again on Wednesday the $21^{\text {st }}$ April

The first, and main, visit took around 90 minutes to complete the initial audit. During this visit various recording measures were tested. These included blank paper, audit forms developed from the EECA - Energy Audit Manual 2007 (EECA, 2007) and notebooks that contained a list of the required data.

When the lux measurements were started, it was discovered that the meter batteries were flat, so another visit was rescheduled to carry out the light level readings.

On the second visit of the day the lux measurements were taken on the horizontal plane, as much of the merchandise was displayed horizontally on tables, rather than vertically on the walls or display stands. During the afternoon visit the manager also identified the stock room that had not been included in the morning's audit. The stock room was included so that all lighting could be taken into account. 
It was necessary to return for a third time on Wednesday to carry out further lux readings and to ask questions on lamp use and occupancy. The extra lux readings were taken on the walls under the various lamps to see how the light was distributed on the merchandise. The findings from all three visits are discussed below.

\subsubsection{THE AUDIT}

The local store used in the pilot was of a similar size and layout to the Otaki fashion stores - rectangular in shape the longer length stretches back away from a large, street facing, display window. Internally the store used central display tables and wall mounted merchandise. The store had undergone refurbishment in the last 36 months, as well as an expansion into some floor space that existed behind the store. This mixture of old and new provided useful opportunities for the pilot study.

The front half of the store was refurbished based on a head office design. This included dark colours, carpeted floors and specific lighting details such as wall floods and spot lighting to highlight certain areas such as the Sales Area and small item racks.

The rear half of the store expanded in a new space developed from former office space. It still retained the standard office lighting. The fluorescent tubes were all located in recessed luminaires, with three tubes per fixture. This style of lighting gives the rear half of the store an even white light, not appearing to highlight anything in particular.

Figure 20 shows the Wellington store floor plan. Totalling $155 \mathrm{~m}^{2}$, the internal dimensions of the rectangular store are just over 6 metres wide by 25.5 metres deep. The storage room and 'office' space is $25 \mathrm{~m}^{2}$ leaving $130 \mathrm{~m}^{2}$, or $84 \%$, for retail use.

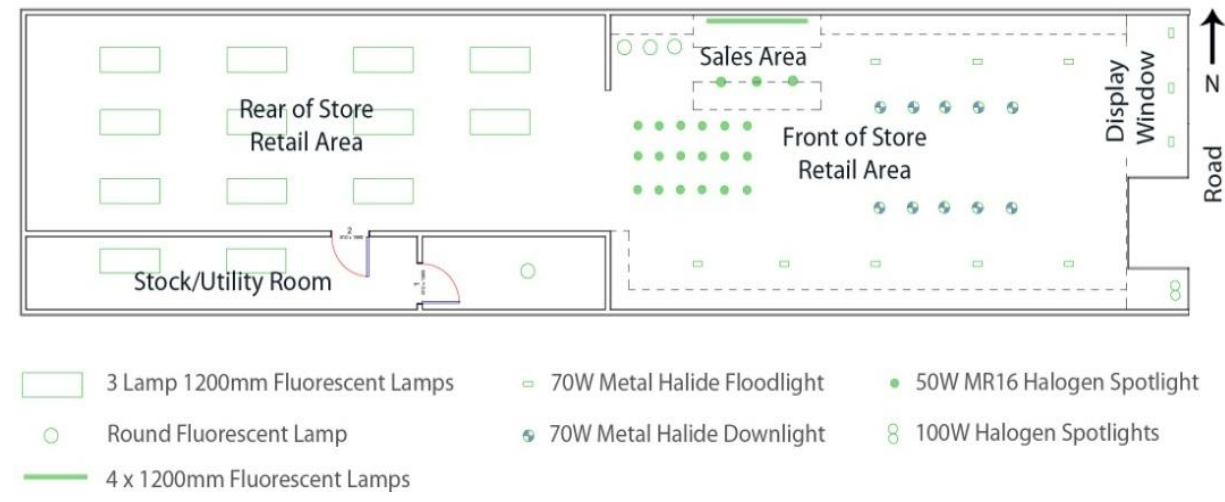

Figure 20: Pilot Audit Premise Floor Plan

For the audit, the store was systematically approached starting from the front entrance and moving to the rear, listing on a pad all of the lighting and installed equipment. 
The first task was to count the lighting fixtures and lamps. The results of this are summarised in Figure 21.

\begin{tabular}{|c|c|c|c|c|c|c|}
\hline Lamp type & $\begin{array}{l}\text { Lamp } \\
\text { Count } \\
\text { (A) }\end{array}$ & Fitting & $\begin{array}{l}\text { Lamp } \\
\text { Wattage } \\
\text { (B) }\end{array}$ & $\begin{array}{l}\text { Ballast } \\
\text { (C) }\end{array}$ & $\begin{array}{l}\text { Total } \\
=(A) *(B+C)\end{array}$ & Wattage \\
\hline $\begin{array}{l}\text { Metal Halide } \\
\text { Flood }\end{array}$ & 11 & Semi-flush & 70 & 14 & & 924W \\
\hline $\begin{array}{l}\text { Metal Halide } \\
\text { Spot }\end{array}$ & 10 & Recessed -Flush & 70 & 14 & & $840 \mathrm{~W}$ \\
\hline MR16-50W & 21 & Flush & 50 & 5 & & $1,155 \mathrm{~W}$ \\
\hline $\begin{array}{l}\text { Round } \\
\text { Fluorescent }\end{array}$ & 4 & $\begin{array}{l}\text { Exposed } \\
\text { Luminaire }\end{array}$ & 22 & 9 & & $124 \mathrm{~W}$ \\
\hline 1200mm LFL & 39 & Recessed -Flush & 36 & 9 & & $1,755 \mathrm{~W}$ \\
\hline $\begin{array}{l}\text { Vertical } \\
1200 \mathrm{~mm} \text { LFL }\end{array}$ & 4 & Advertising & 36 & 9 & & $180 \mathrm{~W}$ \\
\hline $\begin{array}{l}\text { Halogen } \\
\text { Spots }\end{array}$ & 2 & Exposed & 100 & - & & 200 \\
\hline Totals & 89 & - & - & - & & $5,178 \mathrm{~W}$ \\
\hline
\end{tabular}

Figure 21 shows the store has just under $5.2 \mathrm{~kW}$ of lighting installed across both parts of the store. There are six separate circuits in the store and these are controlled manually from the 'office'/store area. Both halves of the store contain completely different styles of lighting, each with their own load, as summarised in Figure 22.

\begin{tabular}{|lcc|}
\hline & Front of Store & Rear of Store \\
\hline Installed Watts & $3,392 \mathrm{~W}$ & $1,786 \mathrm{~W}$ \\
\hline Lamp Count & 51 & 40 \\
\hline LPD & $44 \mathrm{~W} / \mathrm{m}^{2}$ & $23 \mathrm{~W} / \mathrm{m}^{2}$ \\
\hline \multicolumn{3}{|c|}{ Figure 22: Wattage and Lamp Count for Each Half of the Store. } \\
\hline
\end{tabular}

The store opening hours were also recorded, as were the staff schedules. The manager reported that on average staff arrived 30 minutes before opening and turned the lights off 15 - 30 minutes after closing time, using the non-customer time to carry out store cleaning or re-stocking. He also reported that the lights were either all on or all off, with the exception of the display window lighting. The manager believed that the display window represented a perfect opportunity for advertising. Therefore it remains on at all times.

The store opening hours vary across the week. Between Monday and Thursday the store is open from 9:00am and closes at 6:00pm (9 hours) while the lights remain on for 10 hours. On a Friday night the store opens at the same time but closes an hour later, so the lights are on for 11 hours. During Saturdays the lights are on 8 hours and Sundays they are on for 4 hours. Over seven days, the lights are 'on' for approximately 63 hours. 
Figure 23 looks at the lighting load for based on the average opening hours.

\begin{tabular}{|c|c|c|c|c|c|}
\hline Lamp Type & Total Watts & $\begin{array}{c}\text { Average } \\
\text { Daily Hours } \\
\text { 'on' }\end{array}$ & $\begin{array}{l}\text { Watt } \\
\text { Hours } \\
\text { /day }\end{array}$ & $\begin{array}{c}\text { Hours } \\
\text { 'On'/week }\end{array}$ & $\begin{array}{l}\text { Watt Hours } \\
\text { /Week }\end{array}$ \\
\hline $\begin{array}{l}\text { Metal Halide } \\
\text { Flood }\end{array}$ & 672 & 9 & 6,048 & 63 & 42,336 \\
\hline $\begin{array}{l}\text { Metal Halide } \\
\text { Flood (Display } \\
\text { Window) }\end{array}$ & 252 & 24 & 6,048 & 168 & 42,336 \\
\hline $\begin{array}{l}\text { Metal Halide } \\
\text { Spot }\end{array}$ & 840 & 9 & 7,560 & 63 & 52,920 \\
\hline MR16-50W & 1,155 & 9 & 10,395 & 63 & 72,765 \\
\hline $\begin{array}{l}\text { Round } \\
\text { Fluorescent }\end{array}$ & 124 & 9 & 1,116 & 63 & 7,812 \\
\hline 1200mm LFL & 1,755 & 9 & 15,795 & 63 & 110,565 \\
\hline $\begin{array}{l}\text { 1200mm LFL } \\
\text { (Advertising) }\end{array}$ & 180 & 9 & 1,620 & 63 & 11,340 \\
\hline Halogen Spots & 200 & 24 & 4,800 & 168 & 33,600 \\
\hline Total & & & & & 373,674 \\
\hline
\end{tabular}

Along with the lighting load, Figure 24 shows the count of the installed equipment or plug loads. In Figure 24 the equipment hourly loads are from the Energy Audit Manual, (EECA, 2007), unless otherwise specified.

\begin{tabular}{|c|c|c|c|c|c|c|c|}
\hline $\begin{array}{r}\text { Equipment } \\
\text { type }\end{array}$ & Count & $\begin{array}{r}\text { Average } \\
\text { Daily } \\
\text { Watts } \\
\text { Hourly } \\
\text { Load } \\
\end{array}$ & $\begin{array}{r}\text { Average } \\
\text { Night } \\
\text { Time }\end{array}$ & $\begin{array}{l}\text { Daily } \\
\text { Load }\end{array}$ & $\begin{array}{l}\text { Night } \\
\text { Load }\end{array}$ & $\begin{array}{r}\text { Load in } \\
24 \mathrm{hr} \\
\text { Period }\end{array}$ & $\begin{array}{r}\text { Average } \\
\text { Watts } \\
\text { hours } \\
\text { per } \\
\text { Week } \\
\end{array}$ \\
\hline EPoS Till $^{7}$ & 1 & 65 & 5 & 585 & 75 & 660 & 4,620 \\
\hline EFtPoS $^{8}$ & 1 & 7 & 7 & 63 & 105 & 168 & 1,176 \\
\hline Printer $(\mathrm{sm})$ & 1 & 5 & 5 & 45 & 75 & 120 & 840 \\
\hline Phone & 1 & 0.3 & 0.3 & 2.7 & 4.5 & 7.2 & 50.4 \\
\hline Stereo & 1 & 5 & 0 & 45 & 0 & 45 & 315 \\
\hline Fax & 1 & 5 & 5 & 45 & 75 & 120 & 840 \\
\hline Fridge $(\mathrm{sm})$ & 1 & 20 & 20 & 180 & 300 & 480 & 3,360 \\
\hline Totals & & 107 & 42 & 965 & 634 & 1,600 & 11,201 \\
\hline
\end{tabular}

The store has been calculated to use approximately $385 \mathrm{kWh}$ on a weekly basis, with most of the consumption for lighting (97\%).

${ }^{7}$ EPoS till energy use is based on the computer values developed in the energy audit manual for a computer plus LCD screen (65 Watts)

${ }^{8}$ EFT-PoS - energy uses based on personal measurements of three units. 
Lighting energy is just one of the factors that can be considered when looking at lighting effectiveness. How much light is being received to illuminate the task is also important if excessive light is provided, this can also be considered as an inefficient use of energy.

\section{Lux}

Light levels (lux) were taken throughout the store and around merchandise. Visually the front of the store offered more contrast with shadows and brightly lit merchandise. The rear of the store appeared evenly lit and in general to be lit to a higher level.

Using the Lutron LX-102 illuminance meter, the working plane illuminance was checked. The working plane in the store was defined as the horizontal display tables in the centre of the store, and the vertical displays along the walls. Readings taken at the front of the store on the horizontal plane varied between 640 lux in a 'dead' space between two light sources up to 2400 lux directly under one of the metal halide spots.

Because there are vertical displays, readings were taken under the metal halide wall floods that illuminate the wall-mounted merchandise, as shown in Figure 25.

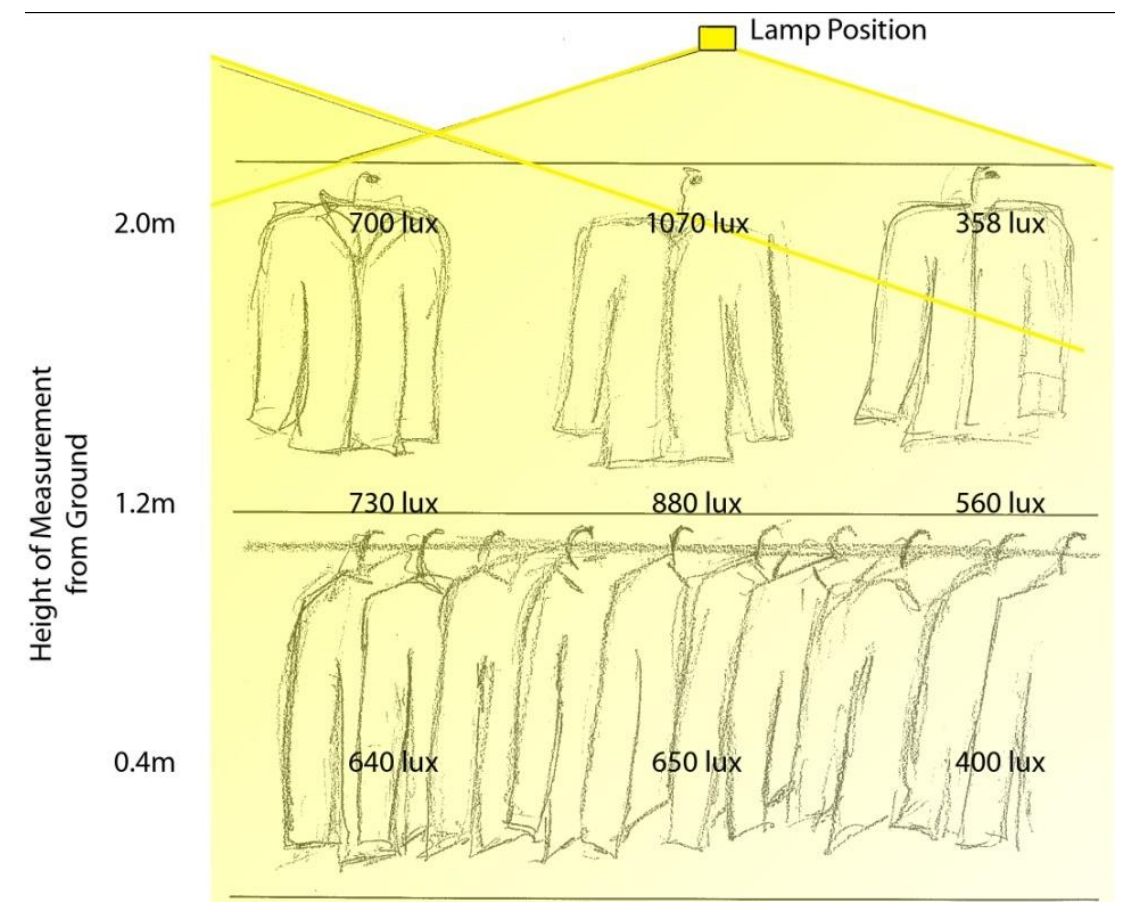

Figure 25: Wall Illuminance Values under a Metal Halide Wall Flood Light

Even though the flood light is designed to produce a consistent illuminance, Figure 25 shows the centre of the lamp has the highest levels. The lower light levels on the right side are a result of the surrounding surface treatments. These measurements were made at a corner location where both walls are covered with dark coloured cloth merchandise. 
The rear of the store is illuminated by an ambient lighting system that has no individual spotlights or contrast lights. The illuminance readings varied from 570 lux to 690 lux dependant on the position of the lights above. The dominant display feature in the rear of the store is a large vertical display rack, which displays clothing on each side in a vertical fashion. Figure 26 illustrates the layout of the rear of the store and the position of the vertical display case.
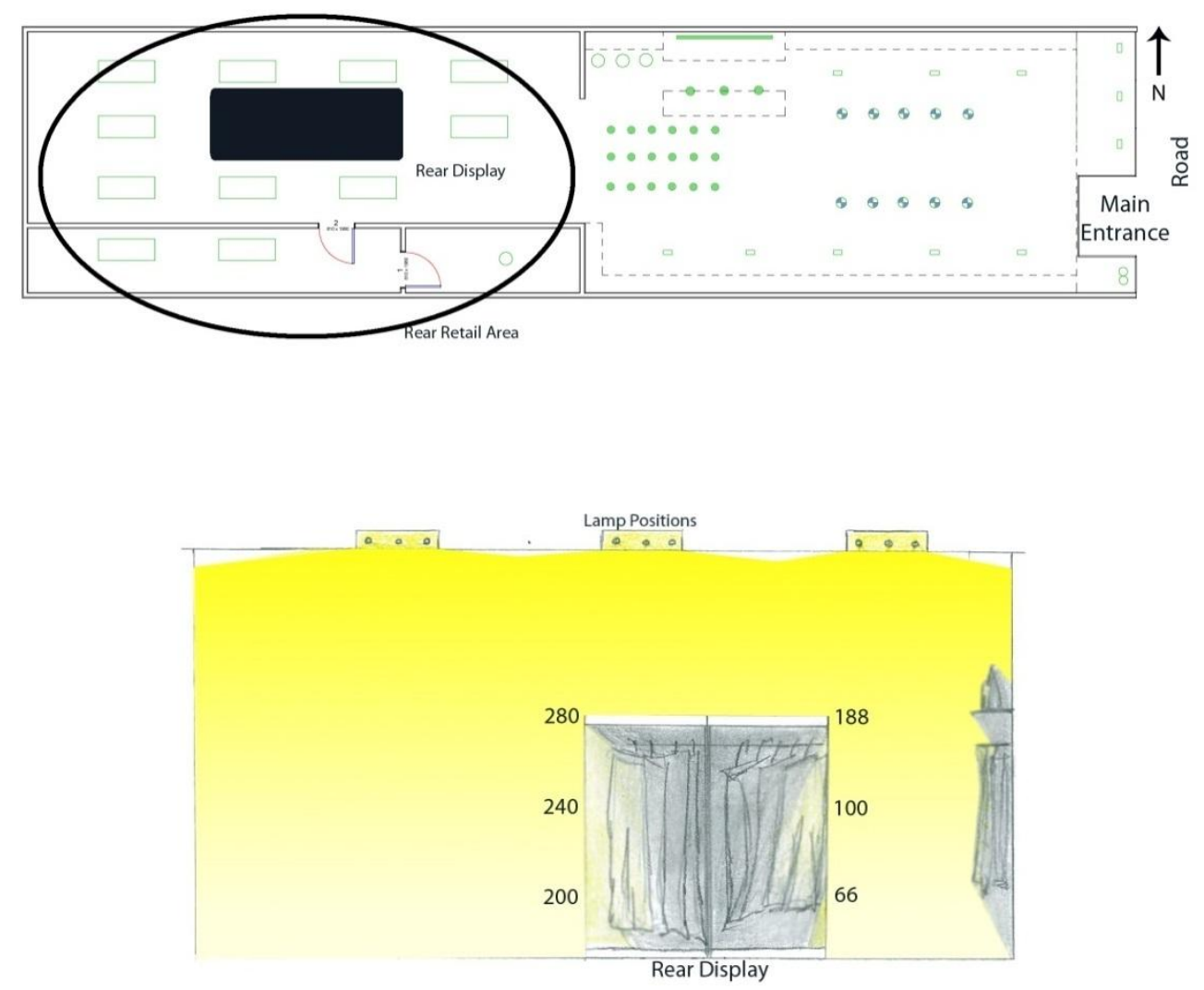

Figure 26: Sketch of the Rear of the Store and Vertical Display Case

Because of the luminaire locations, the position of the display can block out the light as illustrated in Figure 26 even though the luminaires are positioned so that the long dimension is parallel to the display case length. The lux levels around the display case varied from 66 to 188 lux on one side and 200 to 280 lux on the other.

Measurements were also taken on the rear wall under the fluorescent lamp array, and the results are shown below in Figure 27. 


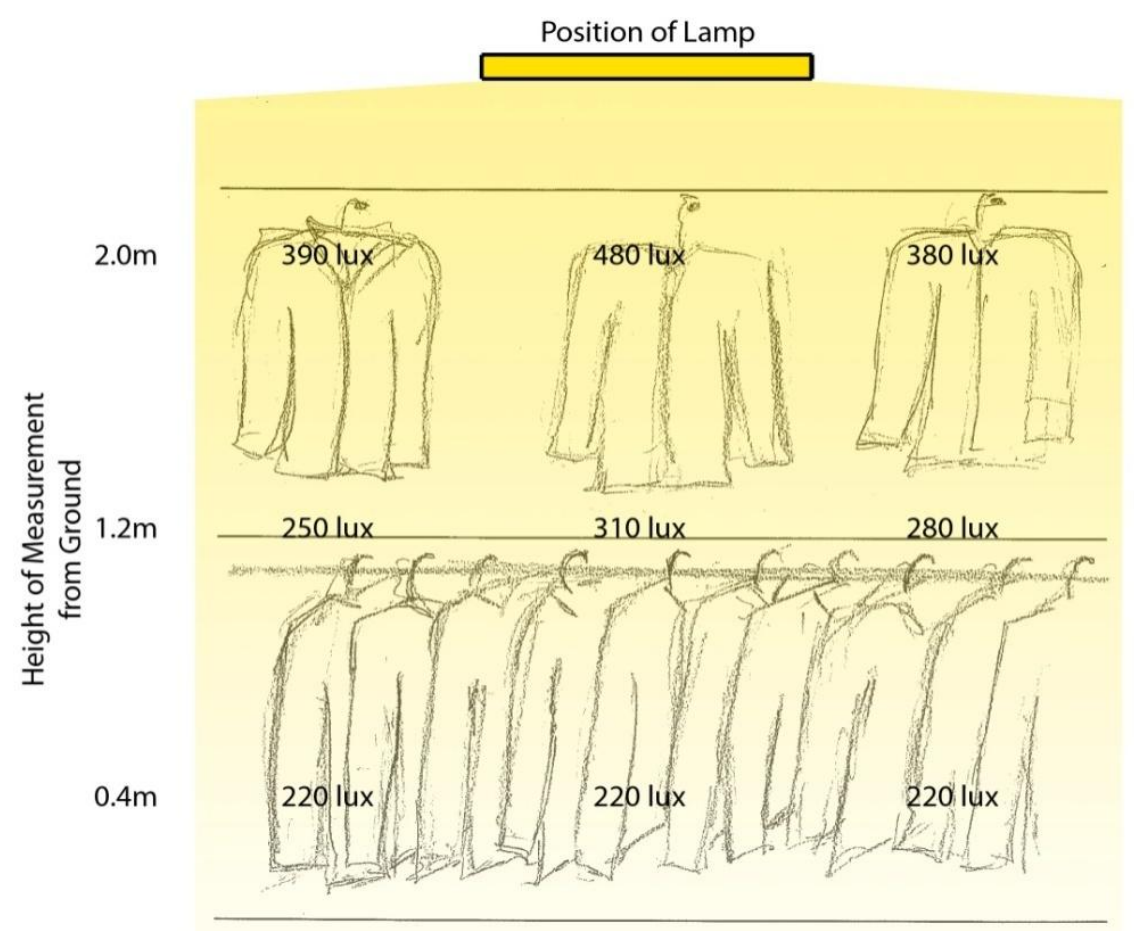

Figure 27: Wall Illuminance Values under Fluorescent Lamp Array

Although the rear of the store appears to be the brighter lit of the two regions, the front area with its contrast and specific lighting delivers more than twice the illuminance to the vertical plane, so the merchandise is fully illuminated.

Illuminance on the horizontal plane in the rear of the store averages around 570 to 690 lux. As the space is been lit by three lamp luminaires, energy savings could be achieved by de-lamping by one tube reducing energy use by a third although this would also reduce the available light by a third to around 350 to 460 lux. These are within the 300 to 1000 lux band identified by the IESNA as being suitable for retail areas (see Figure 10). However, even with all of the lamps in place, as discussed above, the centre display is not well lit so de-lamping would need to be accompanied by reconsideration of the lighting layout. 


\subsubsection{FINDINGS OF THE PILOT}

Based on the experiences of the pilot store, changes were made to the original audit plans.

Because a store is a business, meaning the full attention of the manager can't be guaranteed, two people should be used to audit each store. Two people speed up the audit enabling it to be completed earlier and with greater accuracy than was achieved by only one person. Two people allow one to engage the manager to obtain an understanding of the store operation and history, while the second person records the dimensions and measures light levels, etc.

In the pilot study three approaches were trialled for the recording of the results - blank paper; pre-printed audit forms; and prepared notebooks. It was found managing the blank pages was confusing and that items were being missed. The pre-printed forms worked well, but under the time pressures it was easy to fill in the wrong line and confuse the data. The best solution was the A-5 notebooks with the lists already entered. The use of notebooks also allowed the floor plan to be sketched and the data overlaid.

It was found that in the process of recording the data, it helps to record two floor plans the first notes the dimensions, layouts and construction, while the second records the lighting layout and lux levels.

As well as the lists for equipment and lamp types, the notebooks have to include questions on occupancy and lighting controls which for consistency need to be written.

An important lesson from the pilot study was to check the operation of the equipment before the audit, especially if a specialist battery could not be obtained in the field or easily changed on site.

It was also important to ensure that it would be possible to make a second visit if required. This would be needed if incorrect or missing data was found when the records are processed or if discrepancies are identified. 


\section{OTAKI SURVEY}

This chapter deals with the recruitment of the Otaki sample and details some of the issues identified when dealing with the various layers of retail store management. It provides summary information on the survey respondents and their responses. The last part deals with the Level Two energy audit requirements.

\subsection{THE RECRUITMENT}

Based on the interviews with some of the building owners in Otaki (Section 3.7), it was decided to directly contact the store managers. This was further developed during the meetings with the Centres of Excellence Manager of Grow Wellington (Section 3.7), whose advice was to present the information pack in person and create a personal relationship with each store manager.

The Greater Otaki Project representatives were to have visited the town on Friday $30^{\text {th }}$ April 2010 introducing the Centre of Clean Technology and the retail lighting study. This would allow the community to engage with both the Great Otaki Project and this study, have their questions answered, and encourage support with the research to ensure its success.

As mentioned in Section 3.7 on How to Recruit the Selected Buildings that during the week of the $26^{\text {th }}-30^{\text {th }}$ of April the opportunity was taken to meet with several of the building owners. It was suggested that I directly contact the store owners, but that a Monday was unlikely to be the best day, as many managers took that day off after the weekend sales effort.

\subsubsection{FIRST APPROACH}

On the morning of Tuesday the $4^{\text {th }}$ of May, the store managers in the first 20 (of 33) buildings were approached with the presentation pack. It was decided that the first approach would be limited to just the morning, as it was observed during the external site-visits and during the pilot study that customer numbers increased over the day.

It was found that due to illness the visit by the Greater Otaki Project representatives had not occurred on the $30^{\text {th }}$ of April. This meant that the store managers had to be introduced to both the Greater Otaki Project and the retail lighting study and that they had questions on both.

In retrospect, it would have been better to post the letter of introduction out to all of the stores first, detailing the research and when a visit was planned. This would have 
increased the amount of information available to the managers and may have improved the success rate with the larger chain stores.

In all cases the first contact was with a sales person, who then either directed the survey to the store manager if they were on-site or a meeting time could be arranged. By the end of the first day, 13 stores (out of the 20 stores) had been recruited for the study. These had on-site managers who had the rights to access the energy accounts.

Seven of the stores either did not have a manager present or the manager did not have the authority to sign the consent form to access the energy accounts. In the first case a meeting time was scheduled to meet the manager. In the second case, the manager was requested to contact the correct head office people to obtain approval and then a further meeting could be scheduled.

\subsubsection{SECOND APPROACH}

The final 13 stores (out of 33) and the remaining seven stores from the first visit were approached on the following Friday, $7^{\text {th }}$ May. On this day a further five stores consented to take part, with the others not having a manager present.

On each occasion a time to meet with mangers was arranged, although some of the appointments were guesswork on behalf of the sales person as some managers only intermittently visited the stores.

Over the course of the two weeks between the $4^{\text {th }}$ and the $17^{\text {th }}$ of May, all of the selected stores were visited and presentations were made to the store manager. Not all of the stores were able to provide the consent to access their energy bills as they needed head office authority. These stores required further recruitment visits. There were still approval discussions with some of the managers underway even as the first audits commenced.

\subsubsection{COMPLEXITIES OF MANAGEMENT}

It was during the first visit on May the $4^{\text {th }}$ that some of the complexities of retail and chain stores became apparent. The 13 recruited stores on that visit were all either owner operated, or the managers had full authority for their store.

In other cases the managers felt they had the authority to consent to the store being used for the study, but did not have access to the energy accounts. In those cases, contact with the head office for chain stores or with the owner for locally owned stores was required.

When it was necessary for the owner of the business to be contacted separately from the manager, the project had to be re-introduced and then full consent (store and billing) had to be obtained from the owner. This was not found to be a problem if the on-site store 
manager had consented to use the store as the owner then felt it appropriate to consent to the study.

In some situations the manager might have had control of the accounts, but still needed to gain head office approval before providing consent. In stores which were part of a national fashion chain, the managers were not responsible for the accounts. In three cases, the head office needed to be contacted in order to obtain consent to both use the store and to access the billing data before the store management would even consider participation in the research. This required contact with the head office, a further presentation of the information pack and then consent to be arranged, before it was possible to re-contact the store to finally organise the audit.

The longest time frame for the consent process occurred when the store managers took the information back to head office themselves. While this approval process proceeded, as it was not possible to contact head office, the progression of the approval process was often unknown until the store manager returned with an answer. This created the opportunity for confusion, with one store declining participation as they considered that as their head office had not replied then they were not interested in the research.

\subsubsection{RESPONDENTS}

Of the 53 premises on the strip, the selection process in Section 3.6 on Identifying the Sample Set, identified that there were 33 retail stores suitable for the study. By the end of August 2010, 23 stores had consented fully to participate.

\begin{tabular}{|rrrrrr|}
\hline Category & Store type & Recruited & No Response & Declined & Total Type \\
\hline Fashion & Fashion & 11 & $3^{*}$ & 4 & 18 \\
\hline & Fashion Accessories & 4 & $2 * *$ & - & 6 \\
\hline Vehicle & Car Sales & 1 & - & - & 1 \\
\hline Food & Food sales & 1 & 1 & - & 2 \\
\hline Service & Real Estate & 3 & - & - & 3 \\
\hline Other & Sporting Goods & 1 & - & - & 1 \\
\hline \multicolumn{7}{r}{ Total } & Giftware & 2 & - & 4 \\
\hline
\end{tabular}

Figure 28 above summarises the study respondents. In the no response column under the Fashion category one store consented to the study (*), but could not secure the head office consent to access the account information. In this case the store was audited, although this data was not able to be compared to the billing data. One of the stores under the no response in the Fashion Accessories category (**), verbally agreed to participate on several occasions, but never signed the consent forms. 
The store in the Vehicle category is wholly owned and operated in Otaki, as are the giftware stores that are in the Other category.

The Food and Sporting Goods stores are both locally owned franchises that report back to a central located head office. The real estate stores in the Service category are all owned and operated locally, but they all belong to larger national brands.

Six stores in the fashion category are part of larger national chains. These stores have lighting systems and displays that are similar to other stores within the chain.

Figure 29 shows the perception of Otaki as a clothing outlet town is reinforced by the percentage of retail stores that are in the Fashion Category (in Blue). This category includes both fashion stores and fashion accessories stores.

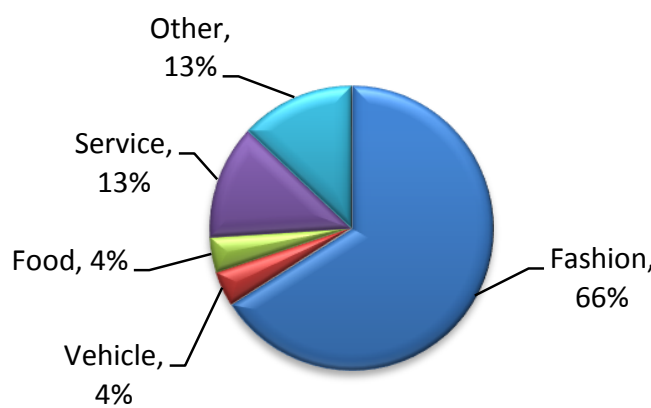

Figure 29: Percentage of 23 stores

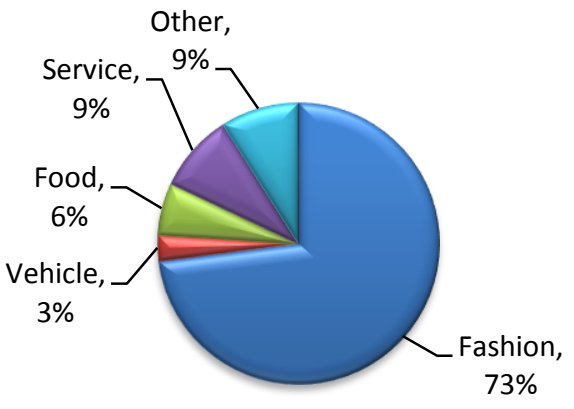

Figure 30:Percentage of 33 stores

Figure 29 shows the proportions of each category in the consenting 23 stores, and compares this to Figure 30 showing the 33 stores in the Otaki retail strip. In both charts, the fashion category remains the most significant on the strip.

\subsection{CARRYING OUT THE AUdiTS}

The first 13 buildings to consent to the study were audited by the author with support from Shaan Cory, a fellow student, on the $21^{\text {st }}$ May 2010. The audits were carried out at times that suited the respondent, generally during the quieter periods in terms of customer numbers The audits were completed by $2: 00 \mathrm{pm}$, at which time the customers along the strip appeared to increase.

The number of audits scheduled for the day was based on the time taken to complete the audit in the pilot study, although using a two man team halved the time on site.

On average the audits themselves took about 20 minutes per store, although the exact time was dependent on the floor area and store type. Open plan stores with stock laid out 
on tables and hanging along the perimeter were easier to audit than some of the smaller stores that were full of numerous products e.g. giftware.

As the audit visit was scheduled, the store managers were ready and had set time aside to help in the audit. The only limitation on the research was in one of the fashion stores that did not allow any photos to be taken within the store.

It took three further visits to complete the audits in Otaki. These visits took place on the $25^{\text {th }}$ of May, the $9^{\text {th }}$ and the $25^{\text {th }}$ of June. The reason for the long gaps between the visits was the time it took some respondents to provide consent. Time was also spent waiting on the store that had sent the consent forms to head office and not heard back.

The last audit was carried out on the $25^{\text {th }}$ of June, when the stores that were still waiting for head office consent were notified that this phase of the study was now closing. In case this consent was obtained, then an appointment would be made for an audit. At the time of writing there had been no further consents to participate in the study.

\subsubsection{NIGHT OBSERVATIONS}

The sites were also visited at night and in the early morning to observe any lights left on outside of the normal trading hours. Two visits were made to see if any stores changed the number of lights on outside normal trading hours. These visits took place in the morning of Sunday the $18^{\text {th }}$ July and at night on Wednesday the $25^{\text {th }}$ July 2010. In November the site was visited during the weekday morning of Tuesday the $16^{\text {th }}$.

During these visits the number of the lamps used directly by the store, both within and outside, were recorded. The operation of the lamps under the verandas was recorded, but these were not considered as part of the retail store load. This was because several of the store managers reported that the veranda lighting was controlled by the council and that they paid for that lighting as part of their rates. Observations made during the visits found all of these lights switched simultaneously 'on' at night and 'off' in the morning, suggesting a common control.

\subsubsection{BILLING RECORDS AND ENERGY SUPPLIERS}

A separate consent form was used to obtain permission to access to energy consumption records from energy suppliers. As part of the BEES support for this research, their systems and processes for accessing suppliers and handling the energy data were used.

The consent form requested that the respondent provide all of their suppliers' details for electricity, gas, or other fuels. This included the ICP (Installation Control Point) number from the electricity account, the account number as well as the account holders name and 
finally their signature granting the research access to their account information. The ICP number identifies the meter installation as an individual connection to the energy supplier. The account number and name allowed the supplier to accurately identify the required meter and billing data.

These consents were signed at the same time as the consent to carry out the audit. The signed originals were then taken to the BEES research team, who batched the consents in order of the date the consent was signed and the energy supplier. The first batch was sent to the energy suppliers on the $2^{\text {nd }}$ of June 2010 , the last batch was received back on the $7^{\text {th }}$ of October 2010.

The consent form for the data access is provided in Appendix D. 


\section{The Audit DATA}

This chapter describes and analyses the data gathered during energy audits. The analysis examines both the behaviour of individual stores and the overall energy use for all stores, providing information on the times of peak load and total electrical consumption. This chapter also examines the different lighting approaches and controls used in the different stores. The last part explores the revenue energy data.

The results of this chapter and the next will be used to create a series of load profiles that will be used to identify where possible savings and energy efficient opportunities may exist.

\subsection{FLOOR AREA}

Section 3.5 identified some $10,100 \mathrm{~m}^{2}$ of floor area along the retail strip. The 33 retail stores account for approximately $55 \%\left(5,600 \mathrm{~m}^{2}\right)$ while the 23 participant stores total 4,100 square meters or $40 \%$ of the overall area.

The end-uses of the 23 stores have been classified into the five categories defined in Section 3.4. Figure 31 gives a count of the consenting stores by category and the range of floor areas. The floor areas in Figure 31 have been developed from the measurements of the inside dimensions of each store, excluding any interior walls or permanent displays within a space.

\begin{tabular}{|crc|}
\hline Store Category & Store Count & Total Floor Area $\left(\right.$ Range) $\left.\mathbf{( m}^{\mathbf{2}}\right)$ \\
\hline Fashion & 15 & $3,297(35-740)$ \\
\hline Vehicle & 1 & $150(-)$ \\
\hline Food & 1 & $50(-)$ \\
\hline Service & 3 & $422(87-225)$ \\
\hline Other & 3 & $487(47-340)$ \\
\hline Figure 31: Store Category and Measured Floor Area \\
\hline
\end{tabular}

The estimated floor areas based on Google Earth (discussed in Section 3.5) are often within 5 to $10 \%$ of the measured floor area. The measured floor area in different stores was found to both above or below the estimate, as some stores shared a common roof making estimation difficult. All of the buildings along the retail strip used internal gutters with no overhangs past these external walls, the only overhangs were the verandas over the footpaths. Overall, the estimated floor area was found to be within $5 \%$ of the measured floor area that accounted for the variance due to wall thickness. 
The store trading hours vary between 38.5 hours and 56 hours per week, based on the advertised trading hours. The advertised hours have been used as the individual stores can alter the time that they remain open based on any number of external influences.

In discussions with the store managers, they identified that over the calendar year the store may alter its operating hours based on the season, customer numbers and weather conditions. There were no set patterns in the cause or reasons for these variations. Store managers are reluctant to shut the store right on closing time, if a customer was still present, so if the store was still full at closing it would remain open another 10-15 minutes. In winter, some stores may close early $(30 \mathrm{~min})$ if the day was particularly cold and there were no customers.

In discussions about the opening times, all of the store managers commented that the advertised hours were a fair representation of a standard trading week. The only store type not follow this was the real estate offices. This is because these offices contain multiple agents who operate on a commission basis. Their hours are based on the office opening times; however the actual operation of the premises may be longer due to the irregular hours of the agents.

Therefore, using the advertised trading hours applied the same conditions to each store, excluding occupant behaviour.

Figure 32 provides examples of the advertised trading hours for four stores. Public holiday hours have been recorded if they were advertised, or alternatively the common practice using Sunday trading hours are recorded if no reference was made to the store opening on a Public holiday (indicated by *).

\begin{tabular}{|lcccc|}
\hline & $\begin{array}{c}\text { Weekday } \\
\text { opening }\end{array}$ & $\begin{array}{c}\text { Saturday } \\
\text { Opening }\end{array}$ & $\begin{array}{c}\text { Sunday } \\
\text { Opening }\end{array}$ & $\begin{array}{c}\text { Public } \\
\text { Holidays }\end{array}$ \\
\hline Store 1 & 9 & 7 & 0 & 0 \\
\hline Store 2 & 8.5 & 8.5 & 6.5 & $6.5^{*}$ \\
\hline Store 3 & 8.5 & 8.5 & 7.5 & 7.5 \\
\hline Store 4 & 8.5 & 8.5 & 6.5 & 6.5 \\
\hline Store 5 & 8 & 8 & 8 & 8 \\
\hline \multicolumn{5}{|c}{ Figure 32: Example of the Daily trading Hours Per Store } \\
\hline
\end{tabular}

Based on the daily trading hours given in Figure 32, the opening hours each month could be calculated based on the number and type of days in a month. Figure 33 below documents the number of each type of day each month from September 2009 to May 2010, inclusive. 


\begin{tabular}{|lccccccccc|}
\hline & $\begin{array}{c}\text { Sep- } \\
\mathbf{0 9}\end{array}$ & $\begin{array}{c}\text { Oct- } \\
\mathbf{0 9}\end{array}$ & $\begin{array}{c}\text { Nov- } \\
\mathbf{0 9}\end{array}$ & $\begin{array}{c}\text { Dec- } \\
\mathbf{0 9}\end{array}$ & $\begin{array}{c}\text { Jan- } \\
\mathbf{1 0}\end{array}$ & $\begin{array}{c}\text { Feb- } \\
\mathbf{1 0}\end{array}$ & $\begin{array}{c}\text { Mar- } \\
\mathbf{1 0}\end{array}$ & $\begin{array}{c}\text { Apr- } \\
\mathbf{1 0}\end{array}$ & $\begin{array}{c}\text { May- } \\
\mathbf{1 0}\end{array}$ \\
\hline Weekday & 22 & 21 & 21 & 21 & 20 & 19 & 23 & 20 & 21 \\
\hline Saturday & 4 & 5 & 4 & 3 & 4 & 4 & 4 & 4 & 5 \\
\hline Sunday & 4 & 4 & 5 & 4 & 5 & 4 & 4 & 2.5 & 5 \\
\hline $\begin{array}{l}\text { Public } \\
\text { Holiday }\end{array}$ & 1 & & 2 & 2 & 1 & & 1 & \\
\hline No Trade & & & & 1 & & & & 2.5 & \\
\hline Total & 30 & 31 & 30 & 31 & 31 & 28 & 31 & 30 & 31 \\
\hline \multicolumn{7}{|c|}{ Figure 33: Weekdays, Weekends and Public Holidays } \\
\hline
\end{tabular}

Shops are not permitted to open on the no trade days, such as Christmas Day, Easter Friday, Easter Sunday and ANZAC day morning (Department of Labour, 2011). Figure 34 provides examples for four stores of the monthly open hours, based on the number and type of days in each month multiplied by the advertised trading hours for that type of day.

\begin{tabular}{|cccccccccc|}
\hline $\begin{array}{c}\text { Store/ } \\
\text { Month }\end{array}$ & $\begin{array}{c}\text { Sep- } \\
\mathbf{0 9}\end{array}$ & $\begin{array}{c}\text { Oct- } \\
\mathbf{0 9}\end{array}$ & $\begin{array}{c}\text { Nov- } \\
\mathbf{0 9}\end{array}$ & $\begin{array}{c}\text { Dec- } \\
\mathbf{0 9}\end{array}$ & $\begin{array}{c}\text { Jan- } \\
\mathbf{1 0}\end{array}$ & $\begin{array}{c}\text { Feb- } \\
\mathbf{1 0}\end{array}$ & $\begin{array}{c}\text { Mar- } \\
\mathbf{1 0}\end{array}$ & $\begin{array}{c}\text { Apr- } \\
\mathbf{1 0}\end{array}$ & $\begin{array}{c}\text { May- } \\
\mathbf{1 0}\end{array}$ \\
\hline Ot-1 & 226 & 224 & 217 & 210 & 208 & 199 & 235 & 208 & 224 \\
\hline Ot-3 & 247 & 253.5 & 245 & 243 & 249.5 & 228 & 255.5 & 226.7 & 253.5 \\
\hline Ot-5 & 251 & 258.5 & 250 & 249 & 256.5 & 233 & 259.5 & 230.2 & 258.5 \\
\hline Ot-6 & 247 & 253.5 & 245 & 243 & 249.5 & 228 & 255.5 & 226.7 & 253.5 \\
\hline Ot-7 & 240 & 248 & 240 & 240 & 248 & 224 & 248 & 220 & 248 \\
\hline \multicolumn{1}{c|}{ Figure 34: Monthly Calculated Hours } \\
\hline
\end{tabular}

Figure 35 shows variation due to the number and type of days as a percentage of the trading hours across all 23 of the audited stores.

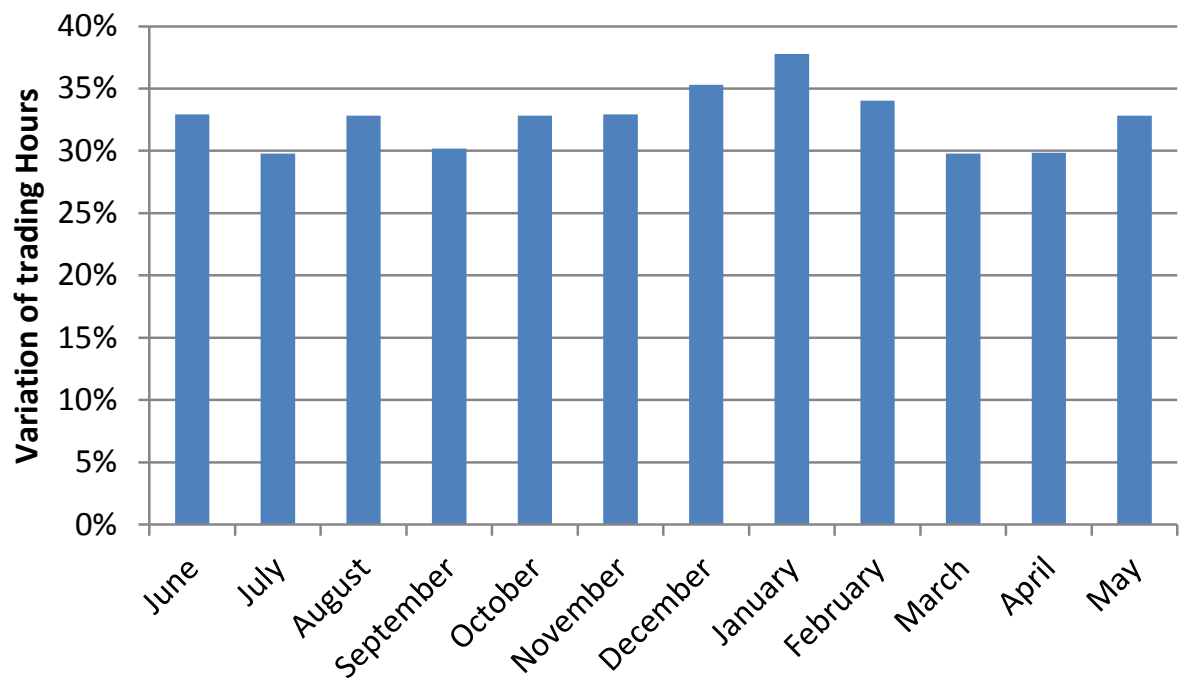

Figure 35: Variation of trading hours 
While the opening hours remain fairly constant on a month to month basis, the largest variation (38\%) occurs in January 2010 when there were five Sundays and two public holidays. Six stores did not trade on Sundays.

\subsection{TYPICAL EQUIPMENT INSTALLATION}

During the audits, all of the installed energy using equipment was recorded. The only common electrical equipment types found in all stores were phones and burglar alarms.

As most of the stores surveyed involved the direct on-selling of products to customers, Electronic Fund Transfer - Point of Sale (EFT-PoS) terminals were used in all but the Service category. This category is made up of the real estate sales offices which deal only in large-ticket items, and use payments through banks or by cheque.

Figure 36 shows examples of the two types of till used in the stores to deal receipt cash and other payments. The first is the Electronic Point of Sale (EPoS) till, typically a small computer with LCD screen, which is also able to monitor transactions and stock levels. The other style is the electronic cash register that only calculates the total sale amount and the amount of change required. Both have change drawers to hold coins, notes and other sales documentation.

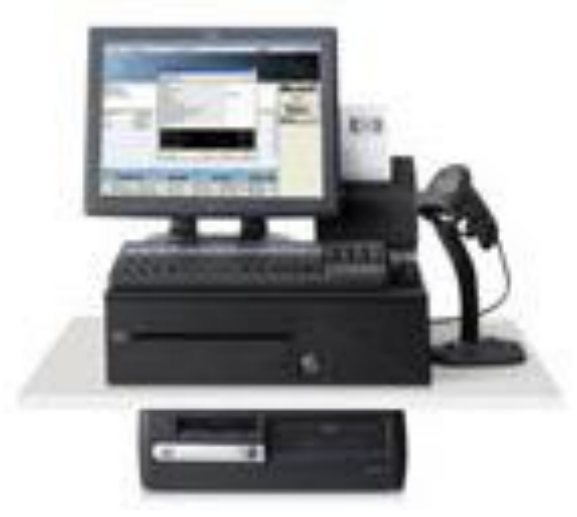

EPoS Till

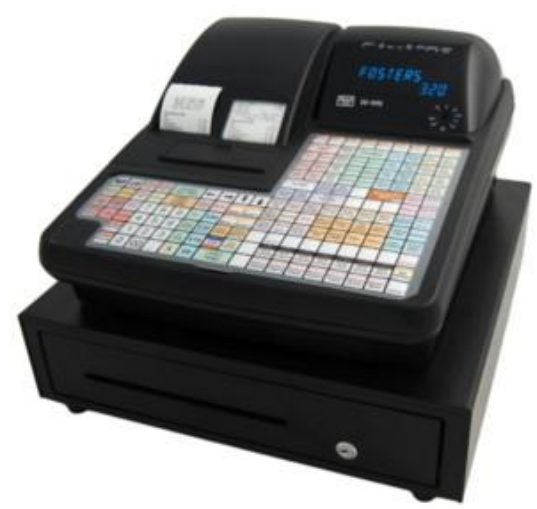

Cash Register

Figure 36: Cash Tills that are in use in Otaki. (Image: Positive Systems Solutions ${ }^{9}$ )

Other miscellaneous items that are widely used include kitchenette items such as electric jugs (90\% of stores), microwaves (70\%) and small fridges (57\%).

\footnotetext{
${ }^{9}$ http://www.pss.ie/cashregister/erc1-2/
} 
Two of the fashion accessory stores included a manufacturing area on-site with equipment such as clothes presses and sewing equipment. These items are used only as required so are considered as process equipment and are thus outside the scope of this study. They are noted here to record their limited impact on the overall electric load.

\section{$6.4 \quad$ INSTALLED LAMPS}

This section examines the various lamp types that are in use in the Otaki shops. Some of the lamps were not observed to be turned 'on' during the audit but have been included in the overall total as a part of the 'potential' or installed load.

\begin{tabular}{|lccr|}
\hline Lamp Type & $\begin{array}{l}\text { Total } \\
\text { of Lamps }\end{array}$ & $\begin{array}{l}\text { Typical Wattage } \\
\text { (Lamp + Ballast) }\end{array}$ & $\begin{array}{l}\text { Total } \\
\text { Watts/Lamp } \\
\text { Type }\end{array}$ \\
\hline CFL - 20W & 55 & $24(20+4)$ & 1,320 \\
\hline Fluorescent - 1200mm & 622 & $45(36+9)$ & 27,990 \\
\hline Fluorescent - 1500mm & 295 & $72(58+14)$ & 21,240 \\
\hline Fluorescent - 1500mm T-12 & 1 & $100(80+20)$ & 100 \\
\hline Fluorescent - 600mm & 44 & $27(18+9)$ & 1,188 \\
\hline Fluorescent - 900mm & 5 & $39(30+9)$ & 195 \\
\hline Fluorescent - Round & 15 & $31(22+9)$ & 465 \\
\hline Halogen Downlights & 6 & 100 & 600 \\
\hline Halogen Flood & 4 & 500 & 2,000 \\
\hline Halogen Lamp & 1 & 20 & 20 \\
\hline Incandescent - 100W & 69 & 100 & 6,900 \\
\hline Incandescent - 150W & 2 & 150 & 300 \\
\hline Incandescent - 40W & 15 & 40 & 600 \\
\hline Incandescent - 75W & 10 & 75 & 750 \\
\hline Incandescent - 80W & 1 & 80 & 80 \\
\hline Metal Halide - Flood & 1 & $480(400+80)$ & 480 \\
\hline Metal Halide - High Bay & 12 & $480(400+80)$ & 5,760 \\
\hline Metal Halide - Wall Wash & 43 & $84(70+14)$ & 3,612 \\
\hline MR11 - 20W & 8 & $22(20+2)$ & 200 \\
\hline MR16 - 50W & 143 & $55(50+5)$ & 7,865 \\
\hline PAR - 120W & 2 & 120 & 240 \\
\hline PAR - 80W & 29 & 80 & 2,320 \\
\hline Sodium & 6 & $240(200+40)$ & 1,320 \\
\hline Total & $\mathbf{1 , 3 8 9}$ & & $\mathbf{8 5 , 5 4 5}$ \\
\hline & & & \\
\hline & Figure 37: Type, Number and Total Wattage Installed per Lamp & \\
\hline
\end{tabular}

The lamp types and total count of the lamps found in the 23 stores are shown in the first two columns of Figure 37. Appendix A provides images and brief descriptions of each lamp type and for the luminaires.

The typical wattage calculated for each is given in the third column. This includes not only the nominal lamp wattage but also the wattage for any control gear or ballast that is required to operate the lamp. These values were developed from manufacturers catalogues such as OSRAM (OSRAM, 2010) and Philips (Philips, 2010), and from markings on the lamps themselves 
The last column in Figure 37 is the calculated load for each lamp type over all 23 stores. In total the 23 stores have 1,389 lamps, with a calculated total installed electrical load of $85.5 \mathrm{~kW}$. The most significant lamp type is the linear fluorescent lamp which accounts for $57.5 \%$ of the calculated load and is installed in $22(96 \%)$ of the surveyed stores. The next style of lamp that is used extensively on the strip is the MR-16 Halogen Dichroic which differs in style to the fluorescent lamps as it supplies light as a concentrated spot and not as a diffuse pattern.

There are two types of technology that permit the MR-16 halogen dichroic lamp to be exchanged for a more energy efficient lamp. Because of this, for the reminder of the study the 'standard' MR-16 halogen dichroic will be termed as the MR-16 lamp.

As discussed in Section 2.9 the store categories can be further subdivided into the style of store, whether they are a boutique, an outlet or a middle store. Figure 38 lists these subcategories for the different Fashion stores showing the various lamp types and the lighting component for which they have been used are discussed in Section 2.8.

Where there are no lamps used for the listed purpose, a '-" is shown.

\begin{tabular}{|c|c|c|c|}
\hline Outlet Stores & Ambient & Perimeter & Spot \\
\hline 1 & Fluorescent & PAR & PAR \\
\hline 2 & Fluorescent & Metal halide & Metal halide \\
\hline 3 & Fluorescent & - & - \\
\hline 4 & Fluorescent & Downlights & - \\
\hline 5 & Fluorescent & - & - \\
\hline 6 & Fluorescent & Metal halide & - \\
\hline 7 & Fluorescent & - & MR-11 \\
\hline 8 & Fluorescent & - & PAR \\
\hline \multicolumn{4}{|l|}{ Boutique Stores } \\
\hline 1 & Fluorescent & CFL & - \\
\hline 2 & MR-16 & CFL & - \\
\hline 3 & MR-16 & - & MR-16 \\
\hline \multicolumn{4}{|l|}{ Middle Stores } \\
\hline 1 & Fluorescent & - & - \\
\hline 2 & Fluorescent & - & - \\
\hline 3 & Fluorescent & - & Halogen \\
\hline 4 & Fluorescent & - & - \\
\hline Figure 38: Lai & yles by Store & d Lighting Co & \\
\hline
\end{tabular}

Figure 38 above shows that the fluorescent lamp is preferred for ambient lighting.

As discussed in Section 2.9, the boutique store would be expected to use a variety of light sources to create contrast and intrigue. In two examples in Figure 38, the stores have chosen the MR-16 lamps to provide ambient light. The MR-16 is more suited to 
spotlighting as it supplies a narrow beam of light 10 to 50 degrees wide, so to achieve an acceptable ambient level, there must be a significant level of overlap of the lamp beams which increases the installed load and energy use.

The lamp and purposes for the remaining (non-fashion) stores are given in Figure 39.

\begin{tabular}{|llll|}
\hline Store Category & Ambient & Perimeter & Spot \\
\hline Car Sales - & PAR & & PAR \\
\hline Food - Boutique & MR-16 & - & - \\
\hline Other - Boutique & Fluorescent & Metal halide & MR-16 \\
\hline Other - Boutique & Fluorescent & MR-16 & MR-16 \\
\hline Other - Boutique & Fluorescent & MR-16 & - \\
\hline Service - Real Estate- & Fluorescent & - & - \\
\hline Service - Real Estate- & Fluorescent & - & - \\
\hline Service - Real Estate- & Fluorescent & - & \multirow{2}{*}{ Figure 39: Remaining Stores, Lamp Styles by Store Type and Lighting Components } \\
\hline \multicolumn{2}{|}{} \\
\hline
\end{tabular}

In the Other- boutique category, LFL's have been used as the general ambient light source with either metal halide or MR-16s providing both the perimeter lighting and spotlighting.

Not all of the lamps are used specifically for the display of retail stock to be sold. Lamps are also used to illuminate offices, stock/utility rooms and any staff areas. Figure 40 shows the distribution of the lighting load for the surveyed stores, based on the percentage of load for each type from the overall installed lighting load.

The term 'Retail' in Figure 40 applies to any lamps that illuminate stock for retail sale. Although many of the stores surveyed used the utility room as their office space, some stores had specific areas set aside for use as an Office. The Utility area covers the part of the store that may contain the kitchen, storage, staff areas and amenities. The 'Other' category covers the exterior lighting, signage, workshop areas and warehousing.

Figure 40 shows that in these retail stores, most of the installed lighting load is located in the retail area for the purpose of lighting the stock. 


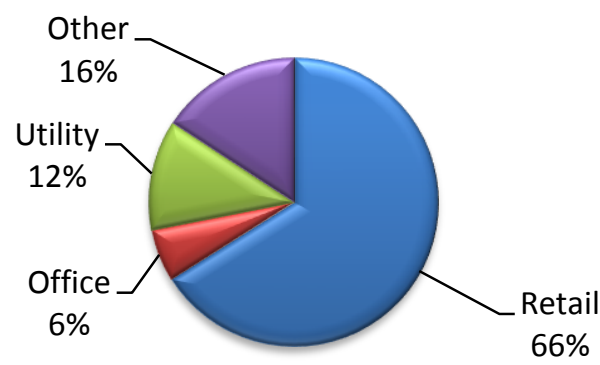

Figure 40: Lamp Distribution within the Surveyed 23 Stores

Figure 41 is the lamp count and installed load in Watts for the areas designated for the purposes of selling stock ('retail areas'). It should be noted that some lamp types are not preferred for retail lighting, including incandescent lamps and lamps such as the sodium (due to poor colour rendition) and 400 Watt metal halide flood lamps that are used almost exclusively in exterior settings.

\begin{tabular}{|c|c|c|c|c|}
\hline Lamp & Type & $\begin{array}{r}\text { Store } \\
\text { Count }\end{array}$ & $\begin{array}{r}\text { Lamp } \\
\text { Number }\end{array}$ & Watts \\
\hline CFL - 20W & Fashion & 3 & 10 & 240 \\
\hline \multirow[t]{2}{*}{ Fluorescent - 1200mm } & Fashion & 7 & 538 & 24210 \\
\hline & Fashion Accessories & 2 & 32 & 1440 \\
\hline \multirow[t]{4}{*}{ Fluorescent - 1500mm } & Fashion & 5 & 72 & 5184 \\
\hline & Fashion Accessories & 2 & 18 & 1296 \\
\hline & Giftware & 2 & 20 & 1440 \\
\hline & Sporting Goods & 1 & 26 & 1872 \\
\hline \multirow[t]{2}{*}{ Fluorescent - 600mm } & Fashion & 4 & 42 & 1134 \\
\hline & Fashion Accessories & 1 & 2 & 54 \\
\hline Fluorescent - 900mm & Fashion & 1 & 1 & 39 \\
\hline Fluorescent Round & Fashion & 1 & 6 & 186 \\
\hline Halogen Downlights & Fashion & 1 & 6 & 600 \\
\hline Incandescent - 100W & Fashion & 1 & 1 & 100 \\
\hline Incandescent - 40W & Fashion Accessories & 1 & 14 & 560 \\
\hline Metal Halide - Highbay & Fashion & 1 & 12 & 5760 \\
\hline \multirow{2}{*}{ Metal Halide - Wall Wash } & Fashion & 3 & 42 & 3528 \\
\hline & Giftware & 1 & 1 & 84 \\
\hline MR11 - 20W & Fashion Accessories & 1 & 8 & 200 \\
\hline \multirow[t]{4}{*}{ MR16-50W } & Fashion & 3 & 45 & 2475 \\
\hline & Food & 1 & 30 & 1650 \\
\hline & Giftware & 2 & 24 & 1320 \\
\hline & Sporting Goods & 1 & 44 & 2420 \\
\hline \multirow[t]{2}{*}{ PAR - 80W } & Fashion & 2 & 8 & 640 \\
\hline & Giftware & 1 & 1 & 80 \\
\hline Retail Area Totals & & & 1,003 & 56,512 \\
\hline Overall Total All Areas & & & 1,389 & 85,545 \\
\hline & gure 41: Lamps usec & e Retail & & \\
\hline
\end{tabular}


Figure 41 shows that the installed lighting load for only the retail areas is $56 \mathrm{~kW}$ or $66 \%$ of the overall total calculated load, while $72 \%$ of the installed lamps are in retail areas.

While the $1200 \mathrm{~mm}$ Linear Fluorescent Lamp (LFL) is the most common by count, this type of lamp is only installed in nine (out of the 23) shops for the purposes of lighting the retail area. Other lamps used in several store types include the longer LFL at $1500 \mathrm{~mm}$ and the MR-16.

The LFL is the significant lamp in terms of load, representing $57 \%$ of the total calculated load. The count and installed wattage of all of the $1200 \mathrm{~mm}$ and $1500 \mathrm{~mm}$ fluorescent lamps given in Figure 37 is shown below in Figure 42.

\begin{tabular}{|lccc|}
\hline LFL type & Lamp Count & Watts (Lamp + Ballast) & Installed Watts \\
\hline Fluorescent - 1200mm & 622 & $45(36+9)$ & 27,990 \\
\hline Fluorescent - 1500mm & 295 & $72(58+14)$ & 21,240 \\
\hline \multicolumn{2}{|c|}{ Figure 42: Fluorescent Lamp Count and the Calculated Installed Load } \\
\hline
\end{tabular}

Although the $1200 \mathrm{~mm}$ fluorescent luminaire is only $63 \%$ of the electric load of a 1500 mm luminaire, the shorter tube is used more than twice as often as the longer tube. As a result, $1200 \mathrm{~mm}$ luminaires represent $28 \mathrm{~kW}$ of installed load compared to $21 \mathrm{~kW}$ of 1500 mm fittings.

Figure 41 shows that the use of $1500 \mathrm{~mm}$ LFL is spread across all store types, while the $1200 \mathrm{~mm}$ LFL is almost entirely used by the fashion category.

\subsection{INSTALLED LUMINAIRES}

The types of luminaires were also counted to assess whether any particular type was preferred or if the selection was simply based on the lamp type and cost.

It is expected that an outlet store would choose to use fittings that have relatively low initial purchase cost and running costs, such as exposed fluorescent luminaires. Alternatively, an image conscious boutique store may choose fashionable luminaires and lamps that suit the style of the store but end up costing more to purchase and/or to run.

\subsubsection{THE LUMINAIRES}

Even with the wide variety of luminaires found in these stores, they can be classified into simple families based on whether the lamp is the main component, if it is recessed or exposed and if the light is provided in a spotlight form or a wash. Appendix B provides illustrations of the different types of luminaires. 


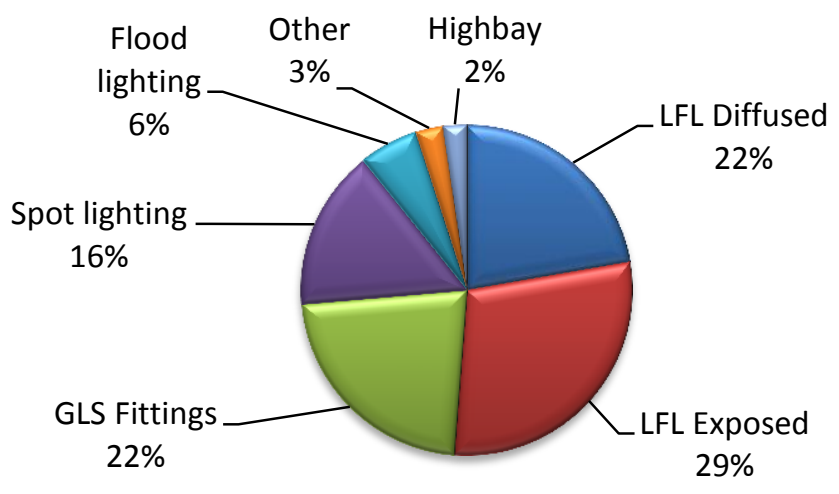

Figure 43: The Retail Strip's Luminaires

The most significant families of luminaires are those that suit the linear fluorescent lamps with $51 \%$ of the observed luminaires fitting into one of the two categories.

The Diffused LFL luminaire accounts for $22 \%$ of the luminaires. This style uses either an opaque covering or prismatic array as the diffuser. These coverings are subject to soiling that would reduce the amount of light that is able to be transmitted. The New Zealand Audit manual (EECA, 2007) notes that these need to be regularly cleaned, or the degradation will affect the available light output.

The Exposed LFL accounts for $29 \%$ of the installed luminaires. Not subject to the same degradation of light as the diffused lamps, these lamps have a basic appearance and may be sources of glare within the store.

In order of significance, the next luminaire style is the General Lighting Service (GLS) Fittings. This is the most basic of all the luminaires and can contain either the Bayonet or Edison screw lamp holders. These GLS lamp holders are capable, with some minor exceptions, of mounting PAR, incandescent or CFL lamps. This type is commonly found in the wash rooms.

The luminaires typically used for spotlighting contain either the MR-16 halogen or PAR 38 lamps. These luminaires are specifically designed for the lamps, as it is the lamp itself creating the spot and not the luminaire.

Luminaires that have been used for flood lighting account for $6 \%$ of all luminaires. These can contain either a metal halide wall wash lamp or a halogen strip lamp. The luminaire for the metal halide lamps will contain control gear but the strip halogen does not require any control gear. See Appendix A for illustration and description. 
The last two categories are the other category and the high bay luminaires. The other category contains luminaires that mount speciality lamps such as the round fluorescent lamps and halogen or CFL down lamps. The last category contains the luminaires for the HID lamps that are typically high bay due to the light output.

The metal halide high bay luminaire accounts for just $2 \%$ of the installed luminaires. These lamps provide large pools of light so when they hung high enough, will provide an even ambient light at the work plane

In most of the 23 audited stores the luminaire type appears to be a simple design containing an exposed lamp. Only two stores in the study use tracked luminaires that in theory allow an infinite number of mounting positions.

\subsection{LIGHTING LEVELS}

Evaluating lighting through its energy consumption does not consider the service it provides - the amount of light that is provided to illuminate the space.

Figure 44 below provides the range and average ambient lux levels measured in the surveyed stores, and the recommended levels discussed in Section 2.9. The Fashion category has been separated into the two sub categories, Outlet and Boutique, as the two have different approaches and aims in respect to their lighting systems. The Other and Service categories have also been split.

\begin{tabular}{|c|c|c|c|}
\hline Categories & Sub-categories & $\begin{array}{l}\text { Measured lux Average } \\
\text { (Range Measured) }\end{array}$ & $\begin{array}{c}\text { Range of } \\
\text { Recommended } \\
\text { Levels }\end{array}$ \\
\hline Fashion & Outlet Fashion & $1,120 \quad(270-3,090)$ & $750-1500 \operatorname{lux}(\mathbf{1})$ \\
\hline Fashion & Boutique Fashion & $(210-2,270)$ & $40-240 \operatorname{lux}(\mathbf{1})$ \\
\hline Fashion & Fashion Accessories & $(330-1,500)$ & $40(\mathbf{2})-1500 \operatorname{lux}(\mathbf{1})$ \\
\hline Service & Real Estate & $(100-1,760)$ & $240-400 \operatorname{lux}(2)$ \\
\hline Other & Giftware & $575 \quad(300-1,300)$ & $40-240 \operatorname{lux}(\mathbf{1})$ \\
\hline Vehicle & Vehicle & $(50-1,250)$ & $240-400 \operatorname{lux}(2)$ \\
\hline Food & Food & $500 \quad(370-2,330)$ & $240-400 \operatorname{lux}(2)$ \\
\hline Other & Sports & $160 \quad(80-300)$ & $40(\mathbf{2})-1500 \operatorname{lux}(\mathbf{1})$ \\
\hline \multicolumn{4}{|c|}{$\begin{array}{l}\text { (1) IESNA, Boutique, Middle and Outlet Fashion }-2.9 \\
\text { (2) AS/NZS 1680.1:2006 Interior and Workplace Lighting Part 1-Section } 2.9\end{array}$} \\
\hline
\end{tabular}

Figure 44 shows that the lighting levels in some stores are in excess of the suggested levels under the IESNA recommendations (Section 2.9) and AS/NZS 1680.1:2006 Interior and Workplace Lighting Part 1, suggesting there may be potential for energy savings. 


\subsection{MAINTENANCE OF THE Lighting Systems}

The maintenance practices were discussed as part of the audit with the store managers. It was general practice in half of the stores that a staff member would only change a light bulb in the retail area if that light was easily reachable and a standard fitting. The preference is to wait until two or three lamps have failed and then bring in an electrical contractor. This lowers the overall cost per lamp for the change.

Metal halides change in colour over time so that if only the failed lamp is replaced the replacement may look brighter and 'whiter' than its counterparts (see Figure 122, Appendix A). Even with this knowledge, these lamps are likely to only be replaced as they fail due to the high cost of the lamp itself. Most of the managers with metal halides installed in their store said that they understood that re-lamping of all the lamps at the same time would result in all the lamps maintaining the same colour.

The lamp replacements were handled by local electrical contractors who in some cases had advised on the design itself. Six of the audited fashion stores maintained at least one replacement bulb on site, but in four of the cases the staff member responsible said that they would not change the lamp and instead would contact the local electrician.

\subsection{Lighting CONTROLS}

In New Zealand the standard manual lighting control is a $10 \mathrm{Amp}$, single pole, double throw switch, that when operated connects the electrical power to the lighting circuit. The same style light switch is used both in residential and commercial buildings.

The number of switches installed in any situation is dependent on several factors, including:

- The calculated lighting power load that the switch may operate. The $10 \mathrm{Amp}$ switch can control a maximum load of 2,400 Watts (240 Volts at 10 Amps). Although this is a maximum, not all switches are loaded to this level.

- The type of lamp can determine the circuit design. For example, metal halide and sodium lamps have requirements that limit their operation. Both of these lamp types have a standard time before they can be re-lit if they are switched off and because of this, it is usual to have such lamps on their own circuit.

- The lighting circuit location and activity. For example, window display lights may operate for longer periods than the lights in the retail space, requiring each have their own circuit. Similarly there are likely to be different use requirements for toilets, storage spaces and staff areas. 
- The occupant needs. For example, there may be specific requirements concerning the number of switches controlling the circuit e.g. switches at different locations to control the lighting circuit.

The actual situations in which a designer, or often the electrician, determines the number and location of the light switches are varied and expansive. While the load is the limiting upper factor, there are many other factors that will determine the actual switch load or coverage.

\subsubsection{SWITCH LOCATION}

Switch locations are referred to in NZS4243:Part2:2007 Energy Efficiency - Large buildings, Part 2, Lighting Section 3.2 as;

"Lighting shall be provided with controls to enable operation when and where required" (Standards New Zealand, 2007)

"Manual switches should be located in the proximity of the controlled area". (Standards New Zealand, 2007)

Although NZS4243:Part 2:2007 only applies to buildings larger than $300 \mathrm{~m}^{2}$, it has been observed in small premises that the light switches are often located near entry and exit points to allow the occupants to operate the lights without having to cross a dark space.

It can be argued that the location of the switches can impact on the potential energy savings opportunities. If the occupants are unable to easily access the switches, lighting levels may not be reduced in appropriate circumstances e.g. high levels of daylight. These issues were not considered in this study, although they may offer additional energy efficiency opportunities.

\subsubsection{WHAT WAS OBSERVED IN OTAKI?}

In the audited 23 stores, all the light switches were observed to be manual and located near an entry or exit point for staff. Only two of the stores had the switches in the retail area, as this was the main entry/exit for staff as well as customers. 


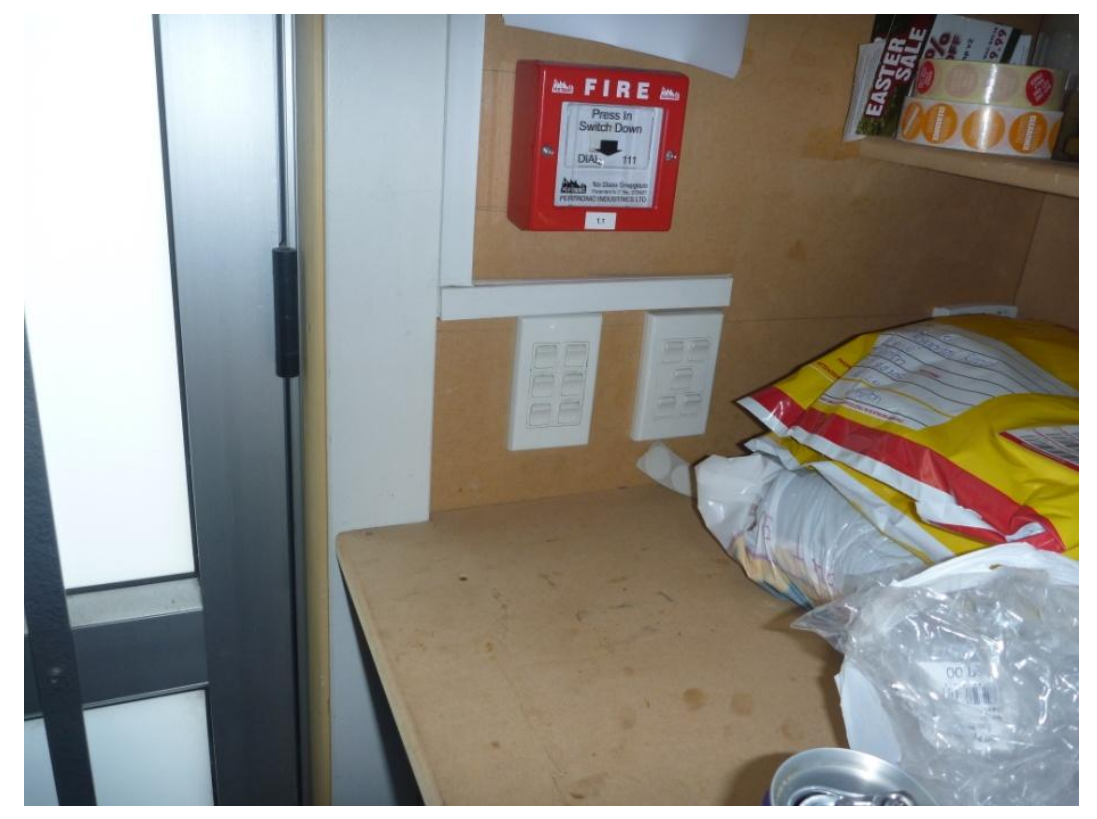

Figure 45: Light Switches Located near a Staff Exit (Authors Own Photos)

The actual number of switches also varied between each store, although the numbers were apparently not related to the number of lights in each store. The store with the greatest lighting load used three switches for the main retail area and a further five in the stock / utility rooms to control five different circuits. The store that contained the greatest number of light switches contained 21 different circuits.

In the stores that used some form of speciality lamp e.g. Metal halides, halogen down lights and MR-16 spotlights, were all switched independently of the ambient lighting systems. This included symmetrical switching, where lamps of the same type located on either side of the retail space are independently controlled.

In discussion with the retailers, three store managers commented that they were able to use the lighting systems as a method of controlling customers. At the end of the day if there were customers left in the store at closing time, the staff would shut down the front retail area or display window lighting. This had the effect of indicating to the remaining customers that closing time was approaching, as well as preventing anybody else from trying to enter the store as it looked closed.

\subsection{Daylight HaRvesting DeVICES}

Two of the boutique fashion stores on the strip had lighting energy saving devices installed in the store. In both of these cases, the devices were installed in the large display windows in an effort to harvest the available daylight. 
The stores used fluorescent lamps for ambient lighting, with metal halide flood lights for the window display and perimeter lighting. The design was specified by the local electrical contractor, who also suggested that daylight harvesting might be an option to lower electrical costs.

The stores are lit with high levels of ambient lighting. The first is lit to an average of 1100 lux and the second to around 700 lux.

The first store has a dedicated window display, which can be considered as a three quarter enclosed display. This allows some transparency into the store, but most of the display window is backed by a solid wall. The display windows are lit with five metal halide flood lights operated separately to the rest of the store's lighting. As these metal halide lamps are unable to be dimmed, they have been fitted with automatic daylight sensors that switch the lamps off when the outside light levels rise.

The second store uses sensors that control only the front two flood lights operating near to the display window. The sensors have to switch these lamps completely off, as they do not have the control gear that allows them to dim. The sensors in this store are controlled on a separate circuit which allows the staff to select whether the lamps remain on or switch with the daylight levels. When asked about the switching, the staff members did not know how the system operated and always selected the lamps to 'on' - so in practice in this store the sensors are never used, even though they are available.

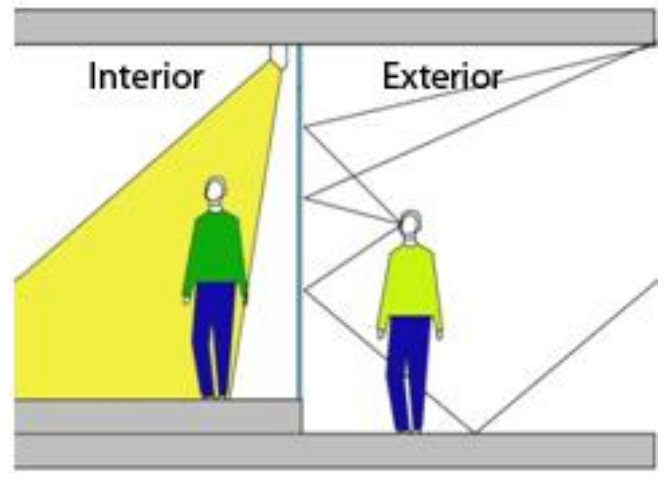

Figure 46: Veiling Reflections (authors image)

If the display window lights are dimmed, or lowered by switching, below the exterior light levels then 'veiling reflections' may result. These are where the display window reflects the scene around it, preventing the passerby from 'seeing' into the window 
display. Figure 46 illustrates how the veiling reflections may result due to interior lighting choices. When viewed from the outside, if the display windows are dimmed the store may appear to be closed.

Veiling reflections can be prevented by ensuring the light levels inside the display window always remain higher than the ambient levels outside the window. This is shown in Figure 47, where a passerby is able to view into the store as the light levels internally are higher than the external levels

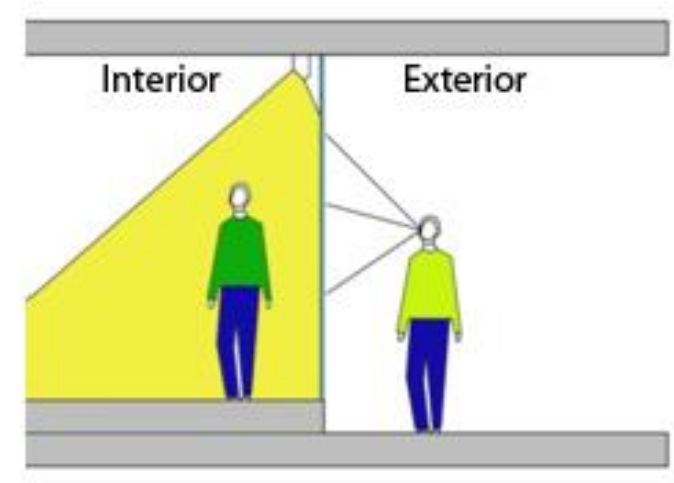

Figure 47: No Veiling reflections (authors image)

\subsection{BILLING RECORDS}

This section looks at the billing data provided by the various energy suppliers. Some of the inconsistencies that exist in the billed data will also be documented, so that the consumption levels of each store may be compared through the creation of an annual load profile.

\subsubsection{MAINTAINING ANONYMITY}

The consent given by the store owner or manager was on the understanding that the data for the store would be kept confidential, and no identifying references would be used in the published results (the form is given in Appendix D).

Each of the 53 original premises along the retail strip was given the identification code 'Ot' plus a number between 1 and 53 e.g. OT-01. This number was randomly assigned through Microsoft Excel and is in no way related to the store location or business type. The identification codes were given to all of the original 53 premises, so the audited 23 stores were not renumbered.

\subsubsection{ENERGY SUPPLIERS}

The 2010 Energy Data File identifies that $97 \%$ of the total electrical supply is provided either directly from one of the main five generators or one of their subsidiaries (Ministry 
of Economic Development, 2010). The five main generating companies are Contact Energy, Genesis Energy, Meridian Energy, Trustpower and Mercury Energy.

The Energy Data File also identifies that Genesis Energy and its subsidiary Energy Online combine to hold the largest market share at 27\% (Ministry of Economic Development, 2010)

The breakdown of suppliers for the 23 surveyed stores is shown in Figure 48, showing four of the main players in the electricity market are represented in Otaki. Figure 48 is based on the number of customers and not the $\mathrm{kWh}$ consumption. Genesis and Energy Online supply $57 \%$ of the surveyed stores.

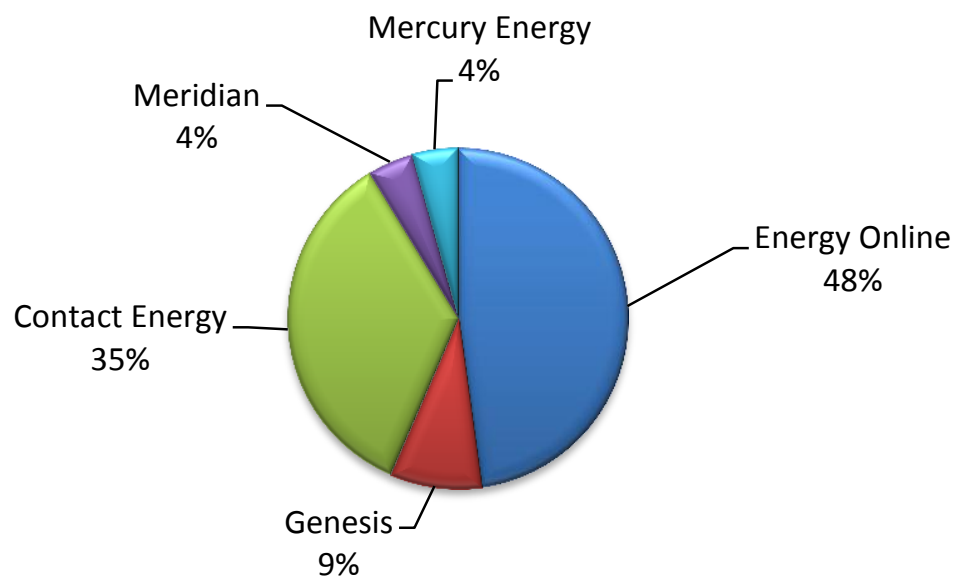

Figure 48: Percentage of Otaki Supply by Count of Energy Suppliers

\subsubsection{TYPES OF METERING}

As part of the audit process, consent was obtained to request the previous two years of billing data. At the time the study was being developed, it was expected that some of the stores would contain 'Time of Use' metering. This type of metering usually involves half hourly readings that allow the businesses to adjust their electrical use to suit specific times or tariffs. The data from these meters also allows the auditor to develop an in-depth hourly/half hourly profile of energy use that may help identify potential energy savings.

The 'Time of Use' metering is usually for larger businesses that are supplied on a contract basis. This metering uses multiple tariffs that allow the business to alter its electrical use to suit specific loads or times. The supply industry specifies that any site consuming 345 kVA (500 Amps) or greater is required to have 'Time of Use' metering (Contact, 2010). 
Contact Energy was one of the first suppliers approached for access to the energy data. They identified that because of the general size of the business activity along the Otaki retail strip, that most of the sites would be considered 'Profile Meter' customers, which meant their meter would not provide half hourly data. Contact Energy also identified that because the electricity use was considered to be low, all of the other electrical suppliers would also use the same style of metering.

A profile meter is the type of meter that is installed on small to medium businesses that is read on a monthly to bi-monthly cycle much the same as the typical residential meter. To calculate the usage from this metering type, the previous reading is subtracted from the current reading to determine the consumption for a set period (Contact, 2010).

\subsubsection{ENERGY REVENUE RECORDS}

Although the previous two years of electrical energy consumption data was requested for each site, not all of the suppliers were able to provide data for that period of time. Some of the issues that prevented the supply of two years' worth of data were:

- That the business had not occupied the site that long, therefore only the occupied period could be supplied

- That the suppliers upgraded some of the accounts which meant that the older data was archived and not available under the consent that was signed.

Of the 23 stores audited, 15 of them had two years of data or more, however two stores were only able to provide 14 months based on their occupancy of the premise.

Each supplier used their own billing system when invoicing the customer. Although the overall goal of invoicing the customer was the same between the suppliers, each had differences in the way the bill was calculated and displayed, meaning that the data was not in a consistent format. The basic formats and data that was provided by each of the suppliers is described below.

Contact Energy supplied the meter reading data in Microsoft Excel, including the invoice date, read dates, reading types (estimate or actual) and the quantities. The read dates usually occurred within 3-5 days following the end of a calendar month with the bill being invoiced to the customer 3-5 days after the last read, as shown in Figure 49. 


\begin{tabular}{|l|c|l|l|c|c|c|}
\hline Bill Date & $\begin{array}{l}\text { Read } \\
\text { Type }\end{array}$ & $\begin{array}{l}\text { Read } \\
\text { From }\end{array}$ & Read To & $\begin{array}{l}\text { Period } \\
\text { (Days) }\end{array}$ & Amount kWh & $\begin{array}{l}\text { Average } \\
\text { kWh/period }\end{array}$ \\
\hline 04-Aug-08 & I & 03-Jul-08 & 01-Aug-08 & 30 & 697 & 23.23 \\
\hline 04-Sep-08 & R & 02-Aug-08 & 02-Sep-08 & 32 & 710 & 22.19 \\
\hline 03-Oct-08 & I & 03-Sep-08 & 03-Oct-08 & 31 & 704 & 22.71 \\
\hline 05-Nov-08 & R & 04-Oct-08 & 04-Nov-08 & 32 & 678 & 21.19 \\
\hline 04-Dec-08 & I & 05-Nov-08 & 04-Dec-08 & 30 & 658 & 21.93 \\
\hline 07-Jan-09 & R & 05-Dec-08 & 06-Jan-09 & 33 & 599 & 18.15 \\
\hline 04-Feb-09 & I & 07-Jan-09 & 04-Feb-09 & 29 & 579 & 19.97 \\
\hline \multicolumn{7}{|c|}{ Figure 49: Example of Billing Data from Contact Energy } \\
\hline
\end{tabular}

Contact Energy describes its readings as an interim read (I) or as an actual read (R). Their goal is to provide monthly readings to all of their customers, however due to the location actual readings may be made bi-monthly using an interim reading in between. Their customer service centre ${ }^{10}$ stated that an interim read is an estimate that is an average of the previous actual read and the previous interim read. Figure 50 is an example of the monthly billing provided by Contact Energy for one of the sites on the retail strip. The period covers the months from May 2008 through to May 2010.

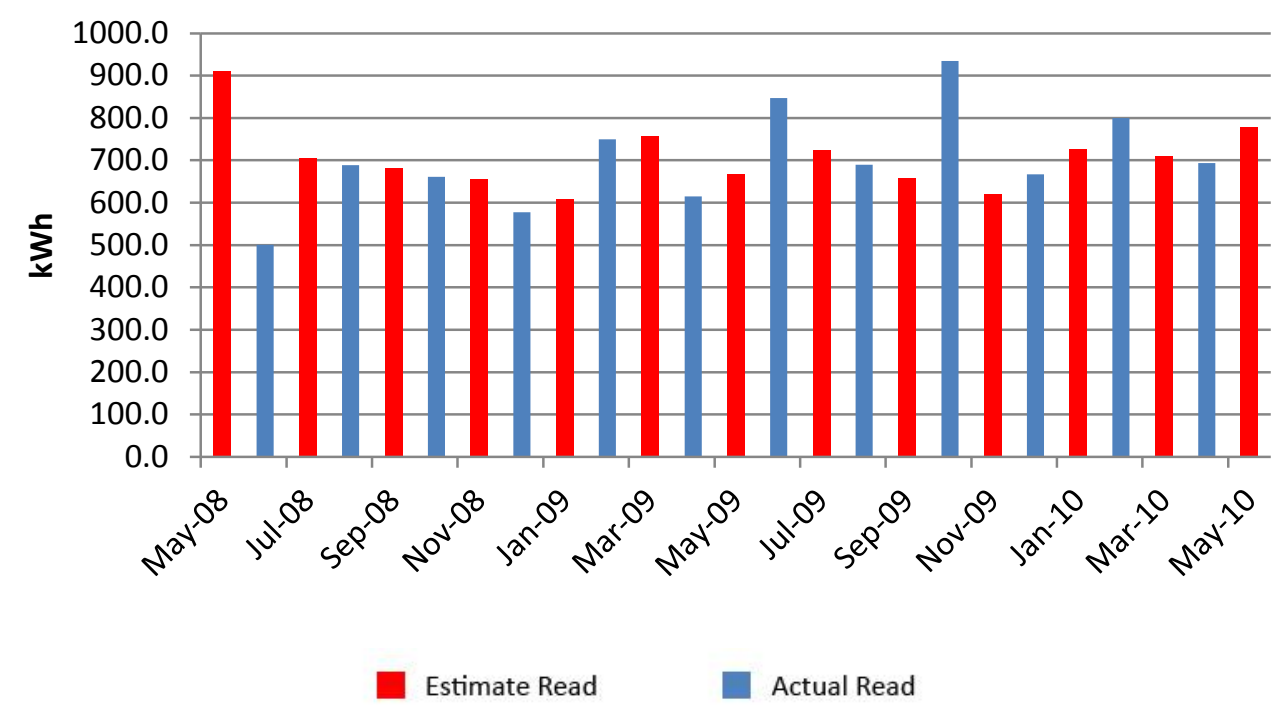

Figure 50: Example of Monthly Billing showing Estimate and Actual Reads

Figure 50 shows that the estimating system must also use some method of moderation based on previous readings. The $935 \mathrm{kWh}$ spike in October 2009 should produce an average estimate the following month of around $800 \mathrm{kWh}$, but the system has created an estimate $180 \mathrm{kWh}$ lower at $620 \mathrm{kWh}$.

\footnotetext{
${ }^{10}$ Contact Customer Service, 080080 9000, (18 November 2010).
} 
The Contact Energy data does not provide a cumulative total that represents the actual meter read. Instead each month has a level of consumption that represents the units used. Using the above figure as an example, if a month is under estimated then the next read will be read higher as it will appear that more units have been consumed, likewise if an estimate is over read then the following read will calculate that less units were consumed.

Under this system it is not possible to calculate the actual monthly usage, as the amounts vary based on the accuracy of the estimate. However the bi-monthly total will represent the consumption for both months as the actual read will 'correct' the estimation for the previous month. Because of this 'correction' the annual consumption total can also be assumed to represent the actual consumption by the site.

Meridian Energy also supplied the data in the Excel format; however the data was only supplied for the billed date and the number of days that related to that bill. The notes provided with the data indicated that the date of the bill was usually within two days of the end of the period that the bill relates to. They also provided the read type, whether it was an estimate (I), or an actual read (R). They did not provide any details concerning customer reads.

\begin{tabular}{|l|c|c|c|}
\hline BILL_DATE & $\begin{array}{c}\text { NUMBER OF } \\
\text { DAYS }\end{array}$ & $\begin{array}{c}\text { CONSUMPTION } \\
\text { QTY }\end{array}$ & $\begin{array}{c}\text { READ TYPE } \\
\text { CODE }\end{array}$ \\
\hline 27JUN2006:00:00:00 & 29 & 1540 & $\mathrm{I}$ \\
\hline 31JUL2006:00:00:00 & 31 & 1483 & $\mathrm{R}$ \\
\hline 28AUG2006:00:00:00 & 31 & 1590 & $\mathrm{I}$ \\
\hline 29SEP2006:00:00:00 & 31 & 3700 & $\mathrm{R}$ \\
\hline 01FEB2007:00:00:00 & 31 & 1633 & $\mathrm{R}$ \\
\hline 29MAR2007:00:00:00 & 28 & 923 & $\mathrm{R}$ \\
\hline \multicolumn{3}{|c|}{ Figure 51: Example of Billing Data from Meridian Energy } \\
\hline
\end{tabular}

The calendar days that a billing period encompassed are not immediately evident in Figure 51. The other issue with the data in this format was that the bill date does not follow a sequential progression. For example, a number of months can be seen to be 'missing' between 29 September 2006 and 01 February 2007. This occurs because the bill was not initially sorted based on these dates and the 'missing' dates are located further down in the billed records.

The notes supplied with the data stated that the billed period preceded the invoice date by two days. To calculate the actual calendar days of the period, the number of days in a period was back dated from the billed date less two days to generate a start point. When this was calculated for a year, some of the periods overlapped. This meant that the bill date did not exactly follow the two day delay. 
Meridian Energy also provides its reads as an Interim (I) and Actual (R). Their system uses a database of previous electrical use on the site and provides estimates based on previous month's usage that is moderated by the previous year's data if it is available. Meridian Energy's customer service centre ${ }^{11}$ was able to advise that they use two methods of generating an estimate. The first was the automated method, developed by the database. The second was a manual method that enabled them to manually enter the consumption value. They were unclear at the time as to when and why this function would be used.

Since the interim estimate is computer generated it was expected that the estimate would have been generated on the day of the invoice date. By using the interim date as the last day of the billing period, all of the invoice consumption periods could be aligned across the year (Figure 52).

\begin{tabular}{|l|c|c|c|c|}
\hline Billed from & Billed to & Bill Issue date & Difference & Read/Interim \\
\hline $28 / 02 / 2009$ & $27 / 03 / 2009$ & $30 / 03 / 2009$ & 3 & $\mathrm{R}$ \\
\hline $28 / 03 / 2009$ & $27 / 04 / 2009$ & $27 / 04 / 2009$ & 0 & $\mathrm{I}$ \\
\hline $28 / 04 / 2009$ & $28 / 05 / 2009$ & $29 / 05 / 2009$ & 1 & $\mathrm{R}$ \\
\hline $29 / 05 / 2009$ & $29 / 06 / 2009$ & $29 / 06 / 2009$ & 0 & $\mathrm{I}$ \\
\hline $30 / 06 / 2009$ & $28 / 07 / 2009$ & $29 / 07 / 2009$ & 1 & $\mathrm{R}$ \\
\hline $29 / 07 / 2009$ & $28 / 08 / 2009$ & $28 / 08 / 2009$ & 0 & $\mathrm{I}$ \\
\hline $29 / 08 / 2009$ & $28 / 09 / 2009$ & $30 / 09 / 2009$ & 2 & $\mathrm{R}$ \\
\hline $29 / 09 / 2009$ & $28 / 10 / 2009$ & $28 / 10 / 2009$ & 0 & $\mathrm{I}$ \\
\hline \multicolumn{6}{|l|}{ Figure 52: Excerpt of Meridian Energy Invoice, defining the Billing Period } \\
\hline
\end{tabular}

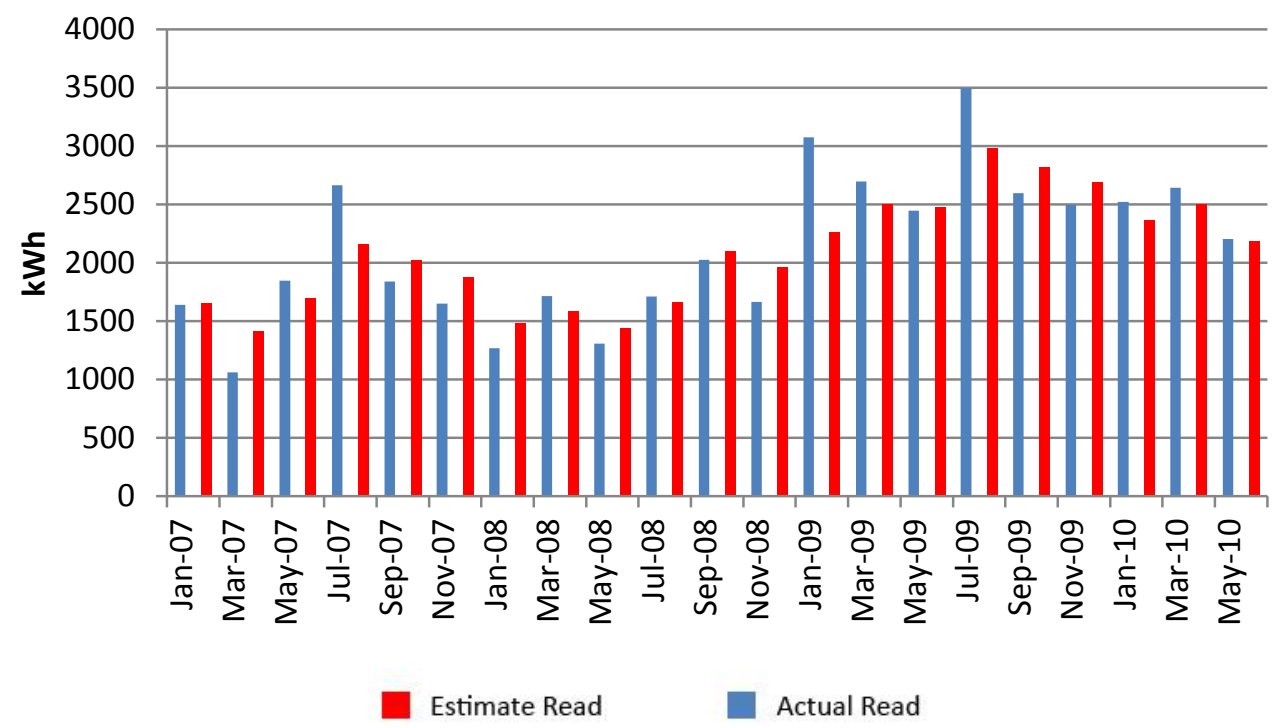

Figure 53 Meridian Monthly Billing showing Estimate and Actual Reads

\footnotetext{
${ }^{11}$ Meridian Energy, 0800496 496, (18 November 2010)
} 
Because every second month is an estimated read, the same corrections occur here as they did for Contact Energy. If the site is under or overestimated in one month, the following actual read will correct the overall consumption for both months.

Again under this system it is not possible to calculate accurate monthly usage, although the bi-monthly reading can be considered as correct. The same applies for the annual total as each actual read will correct the overall consumption value.

Genesis Energy was also represented, even though its subsidiary Energy Online also operated along the strip. Genesis Energy provided Microsoft Excel data sheets which included read dates, read, type identification data, consumption rates and current accumulated read totals. There was only the one site that Genesis Energy supplied and it had three energy rates supplied through three meters. This meant that for the one ICP number there were essentially three readings that needed to be combined to generate the overall consumption for any month. These readings were normally entered into the system on the $16^{\text {th }}$ of that month.

\begin{tabular}{|c|c|c|c|c|c|c|}
\hline Entry Date & $\begin{array}{c}\text { Read to } \\
\text { Date }\end{array}$ & $\begin{array}{c}\text { Period } \\
\text { (days) }\end{array}$ & $\begin{array}{c}\text { Read } \\
\text { Type }\end{array}$ & $\begin{array}{c}\text { Current } \\
\text { Read }\end{array}$ & $\begin{array}{c}\text { Meter } \\
\text { Type }\end{array}$ & $\begin{array}{c}\text { Consumption } \\
\text { Amount }\end{array}$ \\
\hline $16 / 11 / 2006$ & $7 / 07 / 2009$ & 32 & IR & 16022 & DP8 & 502 \\
\hline $16 / 11 / 2006$ & $7 / 07 / 2009$ & 32 & IR & 27686 & DOP8 & 1037 \\
\hline $16 / 11 / 2006$ & $7 / 07 / 2009$ & 32 & IR & 5601 & NCN8 & 216 \\
\hline $16 / 11 / 2006$ & $7 / 08 / 2009$ & 31 & OR & 5717 & NCN8 & 116 \\
\hline $16 / 11 / 2006$ & $7 / 08 / 2009$ & 31 & OR & 28972 & DOP8 & 1286 \\
\hline \multicolumn{7}{|c|}{ Figure 54: Example of Billing Data from Genesis Energy } \\
\hline
\end{tabular}

The read types used by Genesis Energy are an estimated read (IR) and an actual read (OR). Similar to Meridian Energy, Genesis Energy use previous readings and annual data on the electrical consumption on site to generate the estimates. The goal is to provide bimonthly readings that 'correct' the estimates made the month before. Figure 55 is an example of the monthly records provided for a site in Otaki by Genesis Energy. 


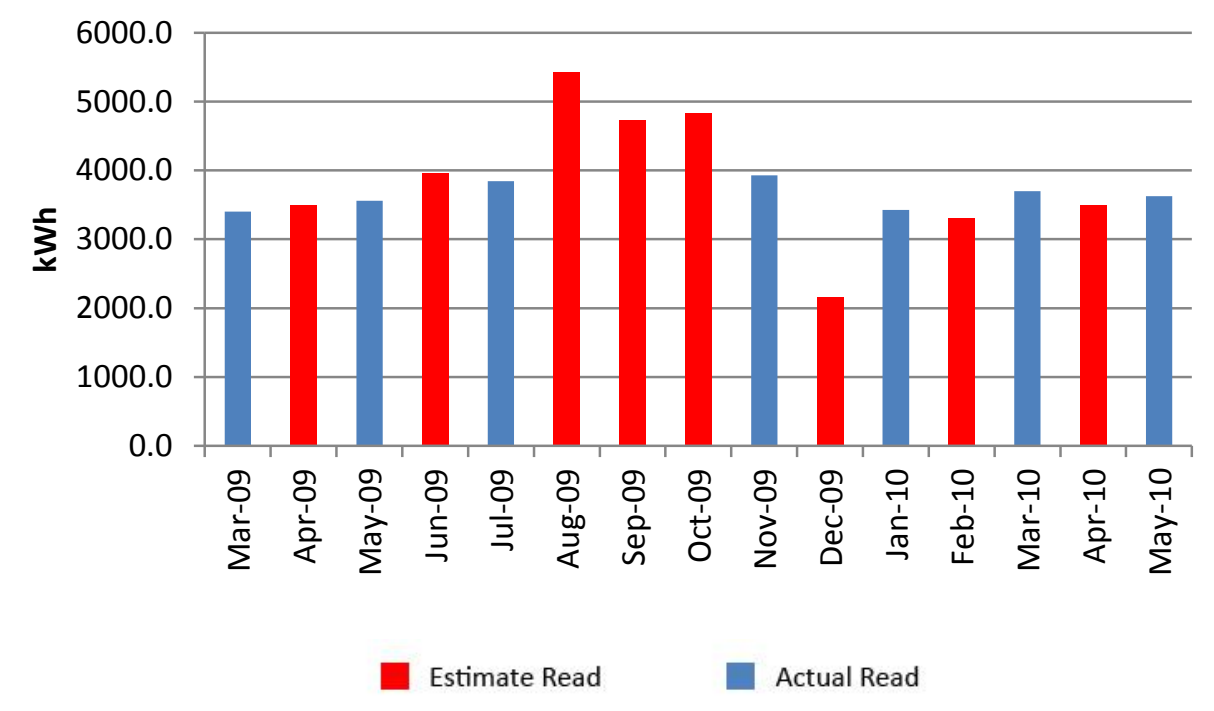

Figure 55: energy Online Monthly Billing showing Estimate and Actual Reads

This particular bill shows that the meter reads were carried out bi-monthly, with the estimates being used every other month. The exception to this is in September 2009, when an estimate was provided due to access issues for the meter reader.

As the readings correct each estimate, the bi-monthly readings can be considered as the consumption values for the site. Annually the consumption data can be considered as accurate as the corrections will not alter the final overall total.

Although Energy Online is a part of Genesis Energy, it uses a separate style of billing. Energy Online provided the data in a Microsoft Excel worksheet; but it was in the form of screen dumps from their billing system. This meant that the data had to be transferred into an operating spreadsheet before it was usable. The data given included billing period, read dates, the accumulated consumption total and the calculated monthly usage

\begin{tabular}{|c|c|c|c|c|c|c|c|c|c|}
\hline \multicolumn{4}{|c|}{ Meter: Lighting/1 } & \multirow[b]{2}{*}{ Read } & Retrieve & \multicolumn{2}{|c|}{ Regenerate_usage } & \multicolumn{2}{|l|}{ Show: } \\
\hline Period Id & & Period Type & Start Date & & End Date & Read & Actual Us & Profiled & sage \\
\hline $15 / 10 / 2008$ & $\nabla$ & BILLING & 01-11-08 & 0.00 & 14/11/2008 & 10.00 & & & \\
\hline $15 / 11 / 2008$ & $\nabla$ & BILLING & $14-11-08$ & 10.00 & $14-12-08$ & 33.00 & & & \\
\hline $15 / 12 / 2008$ & $\nabla$ & BILLING & $14-12-08$ & 33.00 & $14-01-09$ & 56.00 & & & \\
\hline $15 / 01 / 2009$ & $\nabla$ & BILLING & $14-01-09$ & 56.00 & $14-02-09$ & 80.00 & & & \\
\hline $15 / 02 / 2009$ & $\nabla$ & BILLING & $14-02-09$ & 80.00 & $14-03-09$ & 103.00 & & & \\
\hline $15 / 03 / 2009$ & $\nabla$ & BILLING & 14-03-09 & 103.00 & $14-04-09$ & 129.00 & & & \\
\hline $14 / 04 / 2009$ & $\nabla$ & BILLING & $14-04-09$ & 129.00 & $14-05-09$ & 156.00 & & & \\
\hline $1 / 05 / 2009$ & $\nabla$ & BILLING & $14-05-09$ & 156.00 & $10-06-09$ & 181.00 & & & \\
\hline $1 / 05 / 2009$ & $\nabla$ & BILLING & $10-06-09$ & 181.00 & $31-07-09$ & 231.00 & & & \\
\hline $1 / 05 / 2009$ & $\nabla$ & BILLING & $31-07-09$ & 231.00 & $31-08-09$ & 259.00 & & & \\
\hline $1 / 05 / 2009$ & $\nabla$ & BILLING & 31-08-09 & 259.00 & 30-09-09 & 285.00 & & & \\
\hline
\end{tabular}

Figure 56: Example of Billing From Energy Online 
During the audit, copies of actual bills were obtained where possible. Comparing the reported monthly consumption data with the actual bills provided by three of the stores, it was found that two of the stores had appeared to have lower invoiced energy use than recorded in supplier provided data. After some investigation, and discussions with the supplier, it was found that this had occurred because the supplier had searched their system using the premise address and not the account or ICP number. This only identified one meter for these stores and not the two that were actually installed. This resulted in a recheck of all accounts and correct consumption data was then provided.

Energy Online seek to provide actual reads on the $14^{\text {th }}$ of every month (Figure 56). The Energy Online call centre ${ }^{12}$ advised that although the meter reads are every month, their customers requested that the invoices were representative of the calendar month. To achieve this they use a customer package called "End of Month Billing". This system takes the read on the $14^{\text {th }}$ of every month and then estimates the last part of the month from the $15^{\text {th }}$ onward. This estimate is then corrected the following read on the $14^{\text {th }}$. By carrying the reads out this way the estimates are continually being corrected, but never truly identify the consumption amount.

Personal correspondence with Energy Online ${ }^{13}$ identified that they treat each bill as being an actual read and therefore correct. As the energy supplier accepts that the billing is valid, this study will consider the monthly bill as a fair representation of the load consumption. For analysis, the monthly data will be combined to create bi-monthly readings so that energy consumption between stores can be compared.

Mercury Energy also supplied the data in Microsoft Excel, consisting of the billing date, total accumulated read and the monthly usage. There were no identifying accounts or ICP related numbers accompanying the data, so it had to be accepted on face value. The billing date was usually made between two and nine days following the end of a calendar month.

\begin{tabular}{|ccc|}
\hline Bill Date & Cumulative & Consumption Amount \\
\hline 06.09 .2010 & 192981 & 2898 \\
\hline 06.08 .2010 & 190083 & 2900 \\
\hline 08.07 .2010 & 187183 & 3012 \\
\hline 09.06 .2010 & 184171 & 2872 \\
\hline 10.05 .2010 & 181299 & 2411 \\
\hline \multicolumn{2}{|r}{ Figure 57: Example of Billing Data from Energy Online } \\
\hline
\end{tabular}

${ }^{12}$ Energy Online, 0800086400 (18 November 2010)

${ }^{13}$ Energy Online, 0800086400 (18 November 2010) 


\subsubsection{STANDARDISATION OF THE SUPPLIED RECORDS}

As profile meter customers, the stores along the retail strip are billed on their consumption for a given period. Because of all of the different systems and billing dates, to be able to compare consumption between users, the period of consumption had to be standardised to the month.

The Californian Commercial End-Use Survey (CEUS) (Section 2.4.1) also found inconsistencies with the billing records involving irregular billing periods that required standardisation into the respective calendar months. In the CEUS study it was called 'calendarisation' and took the average daily energy use for a period and applied it to the days of the month that the period overlapped (Itron, 2006). It was this method that was used to standardise the energy supplier's data in this study.

Figure 58 is an example of a billing record provided by one of the suppliers. Across the page the columns are; the invoice date, whether the number is a read or an estimate, the billed period (read from / read to) based on calendar days, the billed period in days, the consumption amount and the average calculated daily consumption.

\begin{tabular}{|lcccccc|}
\hline Bill Date & $\begin{array}{c}\text { Read } \\
\text { Type }\end{array}$ & $\begin{array}{c}\text { Read } \\
\text { From }\end{array}$ & $\begin{array}{c}\text { Read To } \\
\text { Period } \\
\text { (Days) }\end{array}$ & Amount kWh & $\begin{array}{c}\text { Average } \\
\text { kWh/period }\end{array}$ \\
\hline 04-Aug-08 & I & 03-Jul-08 & 01-Aug-08 & 30 & 697 & 23.23 \\
\hline 04-Sep-08 & R & 02-Aug-08 & 02-Sep-08 & 32 & 710 & 22.19 \\
\hline 03-Oct-08 & I & 03-Sep-08 & 03-Oct-08 & 31 & 704 & 22.71 \\
\hline 05-Nov-08 & R & 04-Oct-08 & 04-Nov-08 & 32 & 678 & 21.19 \\
\hline 04-Dec-08 & I & 05-Nov-08 & 04-Dec-08 & 30 & 658 & 21.93 \\
\hline 07-Jan-09 & R & 05-Dec-08 & 06-Jan-09 & 33 & 599 & 18.15 \\
\hline 04-Feb-09 & I & 07-Jan-09 & 04-Feb-09 & 29 & 579 & 19.97 \\
\hline \multicolumn{7}{|c|}{ Figure 58: A Billing Record Demonstrating the Irregular Billing Periods. } \\
\hline
\end{tabular}

As the consumption is for a given period, the total consumption for that period can be divided equally across all the days. The above example of the billing record shows that for the billed month ending 4 November 2008, the daily average of the period was 21 $\mathrm{kWh} /$ day. 
This daily average can then be applied to the calendar days of the month that occur during the identified billed period. A graphical example of how the billing period overlaps the calendar month is shown in Figure 59.

\begin{tabular}{|c|c|c|l|l|l|}
\hline & Billed Period (32 Days) & & \\
\hline First month (October) & \multicolumn{3}{|c|}{ Second month (November) } \\
\hline
\end{tabular}

Using Figure 58 and the example above for the billed period ending on the $4^{\text {th }}$ November 2008 , it can be seen that the billed period is 32 days in length. This period commenced on the $4^{\text {th }}$ October 2008 and finished on the $4^{\text {th }}$ November 2008.

To standardise the period consumption to a calendar month, the average daily consumption is applied to the days of the calendar month that period overlaps. In the above example, 28 days of the billed period are October and the remaining 4 days are from November.

To calculate the calendar month of October the remaining three days outside of the billed period needs to be added and using Figure 58, the previous three days in October consume on average $23 \mathrm{kWh} /$ day, as shown in Figure 60.

\begin{tabular}{|lcccccc|}
\hline Bill Date & $\begin{array}{c}\text { Read } \\
\text { Type }\end{array}$ & $\begin{array}{c}\text { Read } \\
\text { From }\end{array}$ & Read To & $\begin{array}{c}\text { Period } \\
\text { (Days) }\end{array}$ & Amount kWh & $\begin{array}{c}\text { Average } \\
\text { kWh/period }\end{array}$ \\
\hline 03-Oct-08 & I & 03-Sep-08 & $03-$ Oct-08 & 31 & 704 & 23 \\
\hline 05-Nov-08 & R & 04-Oct-08 & 04-Nov-08 & 32 & 678 & 21 \\
\hline \multicolumn{7}{|c|}{ Figure 60: Showing Billed Periods for October 2008. } \\
\hline
\end{tabular}

Figure 61 shows the calculation for the monthly consumption in October based on the above example.

\begin{tabular}{|ccccc|}
\hline Billed Period & $\begin{array}{c}\text { Days from } \\
\text { October }\end{array}$ & Average kWh/day & $\begin{array}{c}\text { October } \\
\text { Consumption }\end{array}$ \\
\hline 03-Sep-08 & 03-Oct-08 & 3 & 23 & 68 \\
\hline 04-Oct-08 & 04-Nov-08 & 28 & 21 & 593 \\
\hline \multicolumn{5}{|c}{ Figure 61: Calculating the Consumption for October 2008 } \\
\hline
\end{tabular}


Figure 62 shows the calculated monthly and daily consumption for October 2008.

\begin{tabular}{|lccc|}
\hline Month & Days & Monthly Consumption & Average daily Consumption \\
\hline October & 31 & $661 \mathrm{kWh}$ & $21 \mathrm{kWh} / \mathrm{day}$ \\
\hline \multicolumn{4}{c}{ Figure 62: Standardisation of Billing Period } \\
\hline
\end{tabular}

The above method standardised all of the billed periods to the equivalent calendar months consumption. It should be noted however that as the standardised rate applies the same consumption amount to each day in that month, it does not account for any public holidays, weekends or any no-trade days. This was the simplest method that allowed comparisons between the stores for average daily and monthly

\subsection{ELECTRICAL ENERGY, LIGHTING AND CONSUMPTION}

This section compares the billed records to the installed loads. The goal is to create load profiles that will provide information on the times of peak load and the total electrical consumption.

Small retail stores in Otaki consume most of their energy through the lighting of stock during normal trading hours therefore the calculated lighting totals will be developed based on the advertised trading hours.

As it has been shown that some energy suppliers can alter the billing records to correct estimations, the comparisons and average figures will all be developed from the bi-monthly records. These comparisons will be for the year 1 June 09 to 31 May 10 (inclusive) as all stores have data available for this period.

\subsubsection{ANNUAL CONSUMPTION}

Combining the billed records for all 23 stores identified a combined electrical consumption of $368,165 \mathrm{kWh}$. Figure 63 shows the estimated trading hours and range of individual consumption levels that were used to create the annual figures.

\begin{tabular}{|lll|}
\hline & Average (Range) & Total \\
\hline Open Hours & $2,812(2,071-3,030)$ & 62,722 \\
\hline Total $\mathrm{kWh}$ & $16,007(3,546-46,420)$ & 368,165 \\
\hline & \multicolumn{2}{|c|}{ Figure 63: Annual Consumption for the Audited Stores } \\
\hline
\end{tabular}

For the year June 2009 - May 2010, the audited stores consumed on average 1,000 kWh per day. 


\subsubsection{AREA ENERGY USE INDEX (AEUI)}

The AEUI allows a comparison between individual stores and developed benchmarks. The AEUI is calculated by dividing the store's annual energy consumption by its floor area. Figure 64 shows the calculated range of AEUIs for each category, the comparison targets and comparison type.

\begin{tabular}{|c|c|c|c|}
\hline $\begin{array}{l}\text { Store } \\
\text { Category }\end{array}$ & Average AEUI (range) & $\begin{array}{c}\text { AEUI } \\
\text { Comparison }\end{array}$ & Comparison Type \\
\hline Fashion & $94(23-176)$ & $60-200$ & Retail (Small(1) - Large(2)) \\
\hline Vehicle & 63 & $87-98$ & Office (Small(1)) \\
\hline Food & 509 & $360-410$ & Small Food (General(3)) \\
\hline Service & $93(84-101)$ & $87-200$ & Office (Small(3) - Medium(2)) \\
\hline Other & $92(60-150)$ & $60-200$ & Retail (Small(1) - Large(2)) \\
\hline \multicolumn{4}{|c|}{$\begin{array}{l}\text { (1) BetarG } \\
\text { (2) NZS } 4220: 1982 \text { Code of practice for energy conservation in non-residential buildings } \\
\text { (3) CIBSE }\end{array}$} \\
\hline \multicolumn{4}{|c|}{ Figure 64: AEUIs for the Strip } \\
\hline
\end{tabular}

AEUI comparisons are developed from NZS 4220:1982 Code of practice for energy conservation in non-residential buildings (Standards New Zealand, 1982), BETARG (Isaacs, Baird, Sterios, \& Rollo, 1993) and overseas targets from the Chartered Institution of Building Services Engineers (CIBSE) (CIBSE, 1982). As all these benchmarks are based on data from the early 1980s the validity of comparison with the current consumption is not known. NZS 4220:1982 Code of practice for energy conservation in non-residential buildings is still listed as current ${ }^{14}$ by Standards New Zealand and is therefore assumed to remain an acceptable benchmarking tool.

Figure 64 provides comparisons against benchmarks with similar activities to the studied stores. In the case of the service and vehicle categories, the main spaces are best described as small open plan offices rather than general retail space, so comparing to a small - medium office was a more appropriate comparison.

14 Queried on the Standards New Zealand Website at 'http://www.standards.co.nz/webshop/?action=basicShopSearch\&mod=search \&SearchBox 1 txtShopName $=4220 \&$ selStatus=CUR RENTANDDRAFT\&catalog=NZ' on January $14^{\text {th }} 2011$. 
Based on the AEUI data, the stores can be categorised based on their level of performance. The categories have been adapted from the CIBSE Technical Manual TM22 (CIBSE, 1999).

Good - when the stores calculated AEUI is below the EUI Comparison range identified in Figure 64.

Fair - When the AEUI is calculated to be within the range in Figure 64.

Poor - When the calculated AEUI exceeds the range in Figure 64.

Figure 64 suggests the Otaki surveyed shops AEUI levels are good to fair users of energy.

\section{Bi-Monthly Consumption}

Figure 65 provides a comparison of the bi-monthly consumption over a year for all participants. It clearly shows that energy use is higher in winter (June - July) than in the summer (December - January) months.

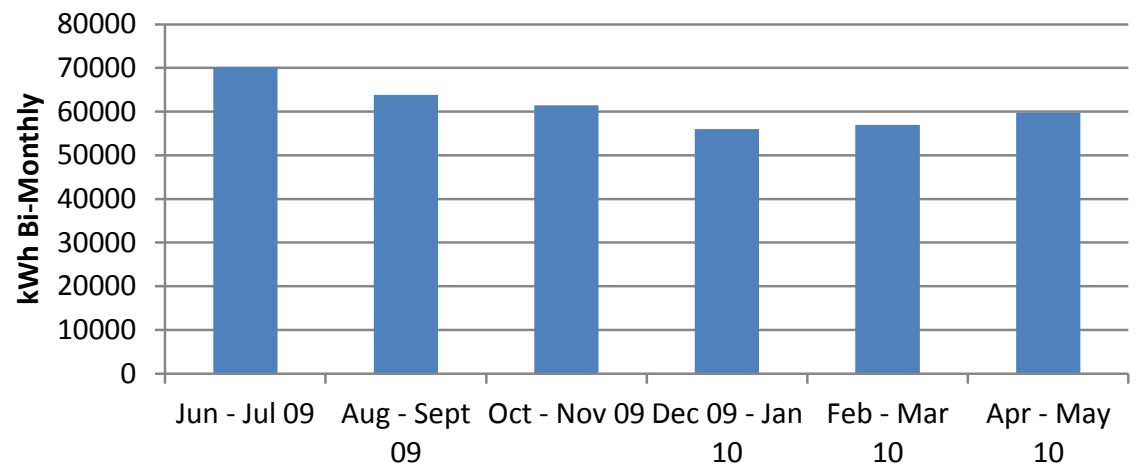

Figure 65: Bi-Monthly Energy Combined Electrical Consumption

When comparing the variation in Figure 65 with the annual temperatures from Paraparaumu airport in Figure 66, the $\mathrm{kWh}$ variation can be seen to follow the temperatures. Figure 66 is an annual temperature graph that contains the minimum (bottom of the month bar) and maximum (top of month bar) for each month, as well as the mean average temperature (marker on each month bar) (NIWA, 2011). 


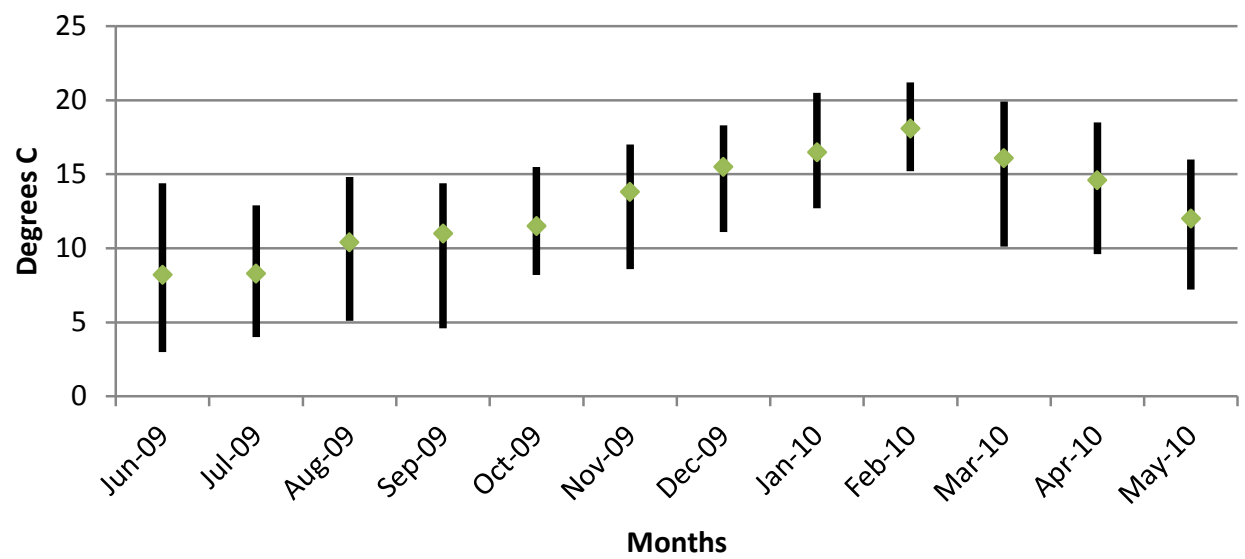

Max - Min Temperatures

$\checkmark$ Average Mean Temperature

Figure 66: Paraparaumu Airport Temperatures, High/Low Range and Average

The high energy use in winter may indicate that electrical heating is used in some stores, but it is also possible that shorter winter days with less daylight may also lead to longer lighting use. The implication is that any combination of extended lighting and/or space heating has the possibility to alter the monthly and annual energy use.

\subsubsection{LIGHTING LOADS}

Knowing the magnitude of the lighting load does not explain how the retail strip uses its lighting energy. The audit recorded which lamps were in use and for what purpose. This identified lamps being used continually and those only being used in a transient manner to illuminate a short task or item.

As discussed in the Section 5.2, the sites were visited at night on three occasions. The lighting that was left 'on' within the stores was assessed from the street. Combined with the knowledge of the lamp types and electricity load from the audit, an overnight load profile could be developed.

It was decided that the lamps observed as 'on' during the day would be considered as the 'standard' lighting. Standard overnight lighting was identified as lamps that were seen to remain 'on' over two of the three visits.

A lamp was not recorded as being 'on' if it was in use temporarily or if it was 'off' when it was observed. 


\begin{tabular}{|lccccc|}
\hline $\begin{array}{l}\text { Premise } \\
\text { Identifier }\end{array}$ & $\begin{array}{c}\text { Installed } \\
\text { Lighting Load } \\
(\mathbf{W})\end{array}$ & $\begin{array}{c}\text { Day Light Load Observed } \\
(\mathbf{W}) \text { and Percent of } \\
\text { Installed }\end{array}$ & $\begin{array}{c}\text { Night Light Load } \\
\text { Observed (W) and } \\
\text { Percent of Installed }\end{array}$ \\
\hline Ot-1 & 3,935 & 872 & $22 \%$ & 0 & $0 \%$ \\
\hline Ot-3 & 8,498 & 6,038 & $71 \%$ & 80 & $1 \%$ \\
\hline Ot-5 & 10,033 & 9,648 & $96 \%$ & 1,440 & $14 \%$ \\
\hline Ot-6 & 4,510 & 4,286 & $95 \%$ & 216 & $5 \%$ \\
\hline Ot-7 & 1,865 & 1,785 & $96 \%$ & 0 & $0 \%$ \\
\hline Ot-8 & 5,082 & 4,506 & $89 \%$ & 0 & $0 \%$ \\
\hline Ot-9 & 8,505 & 8,412 & $99 \%$ & 0 & $0 \%$ \\
\hline Ot-11 & 1,659 & 1,576 & $95 \%$ & 72 & $4 \%$ \\
\hline Ot-12 & 6,592 & 4,580 & $70 \%$ & 1,312 & $20 \%$ \\
\hline Ot-14 & 1,104 & 929 & $84 \%$ & 0 & $0 \%$ \\
\hline Ot-15 & 1,804 & 1,504 & $83 \%$ & 45 & $2 \%$ \\
\hline Ot-16 & 2,926 & 2,206 & $75 \%$ & 48 & $2 \%$ \\
\hline Ot-17 & 5,898 & 5,212 & $88 \%$ & 396 & $7 \%$ \\
\hline Ot-21 & 2,425 & 2,425 & $100 \%$ & 0 & $0 \%$ \\
\hline Ot-22 & 6,203 & 6,203 & $100 \%$ & 252 & $4 \%$ \\
\hline Ot-23 & 1,701 & 1,332 & $78 \%$ & 288 & $17 \%$ \\
\hline Ot-24 & 1,028 & 1,028 & $100 \%$ & 244 & $24 \%$ \\
\hline Ot-25 & 940 & 940 & $100 \%$ & 72 & $8 \%$ \\
\hline Ot-26 & 4,722 & 4,422 & $94 \%$ & 720 & $15 \%$ \\
\hline Ot-30 & 1,478 & 1,378 & $93 \%$ & 330 & $22 \%$ \\
\hline Ot-32 & 1,482 & 1,482 & $100 \%$ & 0 & $0 \%$ \\
\hline Ot-36 & 2,145 & 2,145 & $100 \%$ & 249 & $12 \%$ \\
\hline Ot-37 & 1,010 & 810 & $80 \%$ & 0 & $0 \%$ \\
\hline Average & 3,719 & 3,205 & $87 \%$ & 242 & $7 \%$ \\
\hline & Figure 67: Observed Lighting Levels against Installed Lighting Load \\
\hline
\end{tabular}

Figure 67 shows the participating stores and their installed lighting loads. The remaining columns show the observed lighting loads for both day and night, developed from the observations and interviews with staff. These have been compared to the installed lighting load for each store to show the percentage of lighting that operates during a normal trading day and at night.

Even though the lighting load during daylight hours was based on interviews and observations, for the purpose of this analysis the levels observed are assumed to apply to the entire year of trading. It should be noted that the above observations do not account for any extended trading hours or for any lights that are accidentally left on.

Figure 67 shows that, on average, the stores use $87 \%$ of their installed lighting during the day and just $7 \%$ at night.

The special case in Figure 67 is Ot-1. The occupants of this premise use daylight as the primary means of illuminating the working/retail space. The electric lighting is used infrequently and usually only to supplement the window day lighting. It should also be noted that of the merchandising stores, it is the only one to hold and display their stock outdoors. 
In Figure 68 the lighting loads identified above were applied to the advertised daily trading hours for each store to calculate daily lighting energy use divided into trading hours and outside trading hours.

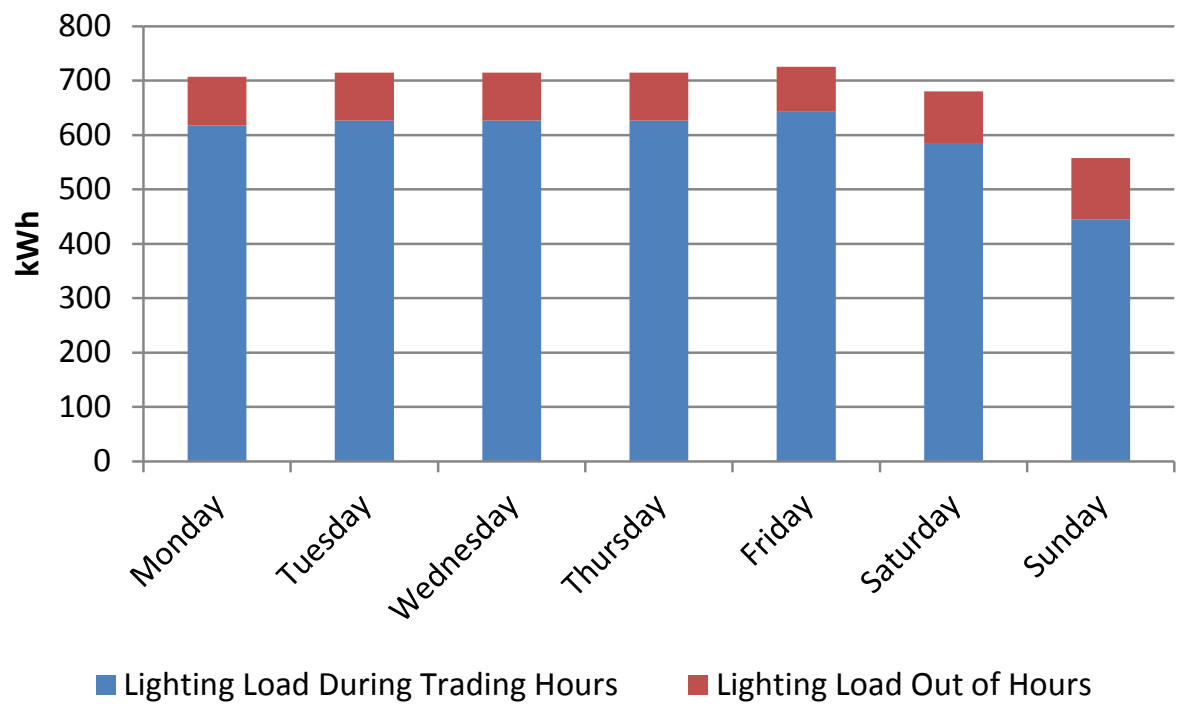

Figure 68: Lighting Electrical Consumption for Trading Hours and Non Trade

During the week there is less than $4 \%$ of variation between the days, with the weekend being lower in terms of energy use. Because of this small variation between the days, the trading hours for Friday were selected for exploration, as some stores use this night as 'late night shopping' night.

Applying the observed loads to Friday's advertised trading hours creates a simple load profile that indicates the $\mathrm{kW}$ required by the lighting and the period for which it is required for each shop (Figure 69). The 'step' occurs due to one store remaining open longer on this particular night (Friday). 


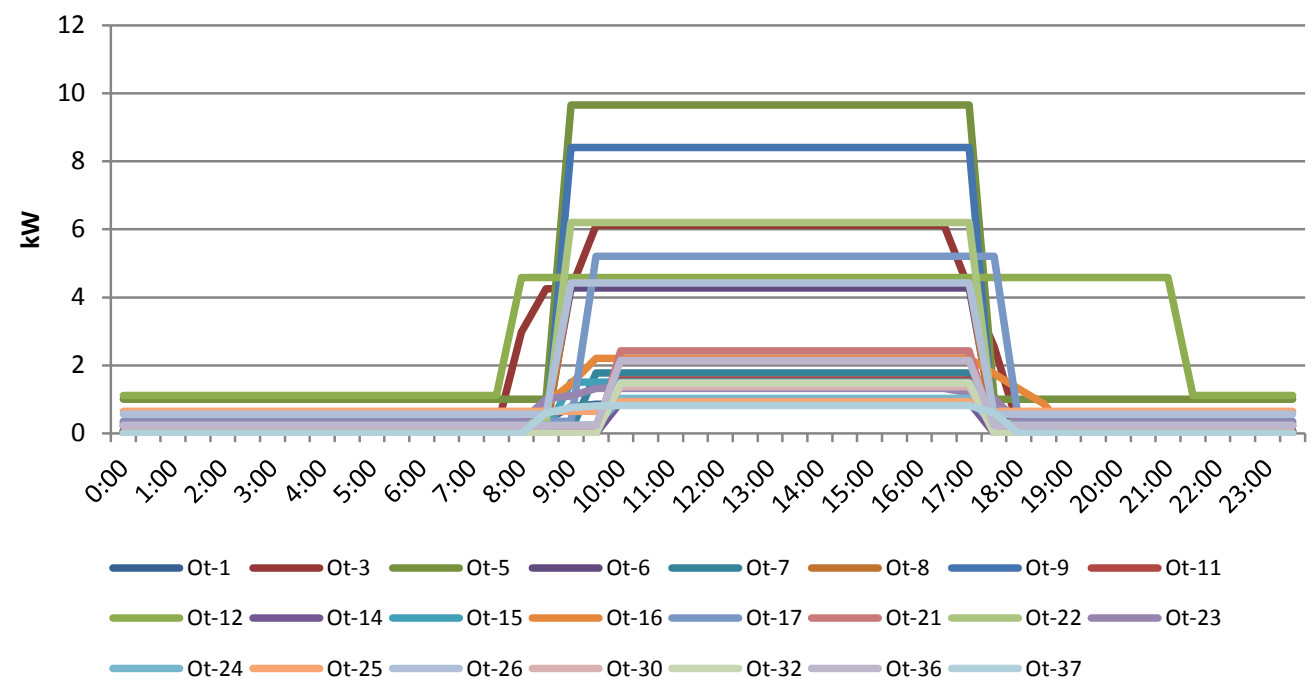

Figure 69: Estimated Daily Lighting Load, Transition and Use (Friday)

Figure 69 represents the individual store loads hour by hour over the day. Most of the stores have sharp transitions from the overnight lighting levels to the opening levels. This would most likely be a result of the first person entering the space switching on all of the lights. Due to switch placement, most stores have all of their lighting switched on at the same time. The load in some shops can be seen to 'step up' which is probably a result of the stores that contain separate office space, where lighting will be turned incrementally as the offices are occupied.

Figure 70 shows the combined loads for all the surveyed shops on a Friday, showing the approximate period in which the load can be expected to be used. It identifies that the load is likely to transition around 9:00 am when it switches from the low overnight levels of around $6 \mathrm{~kW}$ up to the operating load of approximately $75 \mathrm{~kW}$ per hour. This load is expected to be maintained until approximately 5:00 pm. 


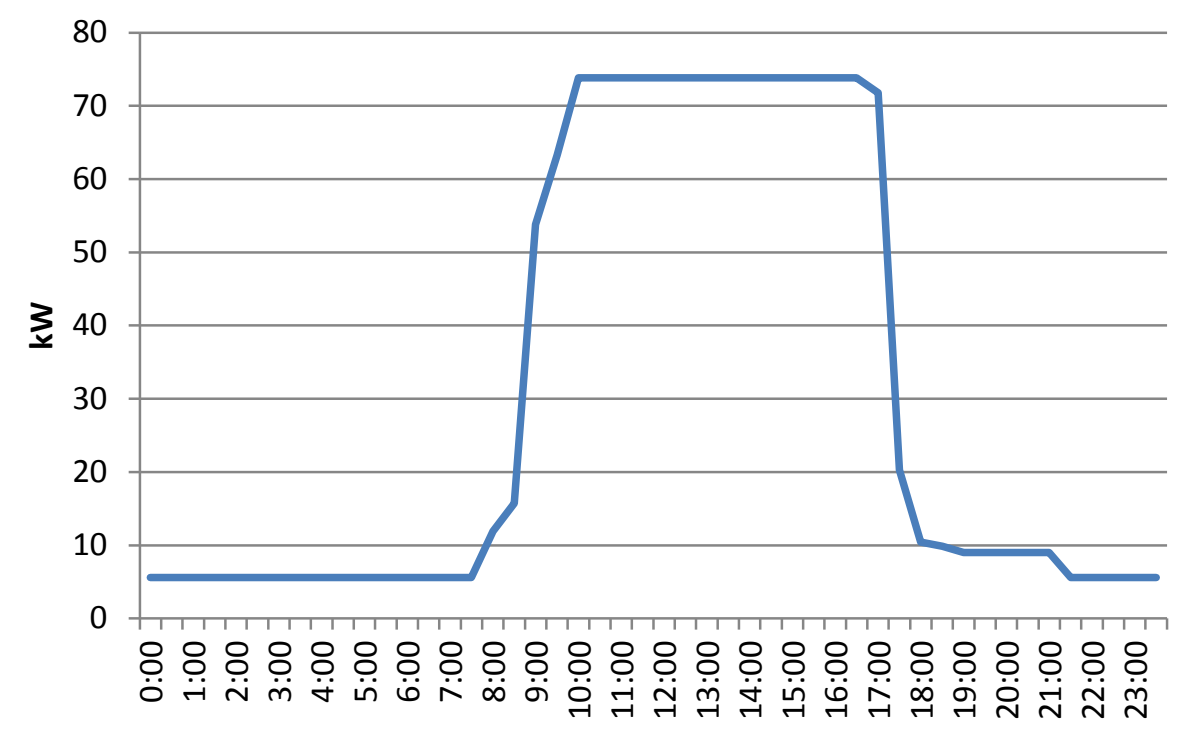

Figure 70: Estimated Combined Lighting Load and Operating Hours (Friday)

Figure 70 provides an overview of lighting power over a 24 hour period. The area underneath the line represents the required energy to maintain the installed lighting load for an average Friday. This consumption level has been calculated as being $696 \mathrm{kWh} / \mathrm{day}$.

Using the annual billed total of $368,165 \mathrm{kWh} / \mathrm{year}$, the average daily consumption is $1,008 \mathrm{kWh} /$ day. Based on this the lighting energy consumption is $66 \%$ of the annual electricity use. Figure 71 compares the observed lighting load and the range of lighting that can be selected in each store to the billed amount. 


\begin{tabular}{|c|c|c|c|c|}
\hline \multirow[b]{2}{*}{ Identifier } & \multicolumn{4}{|c|}{$\begin{array}{l}\text { Percentage of Lighting Load Versus Annual Billed Amount June 2009 - May } \\
\qquad 2010\end{array}$} \\
\hline & $\begin{array}{c}\text { Total lighting } \\
\text { All on (8760 } \\
\text { Hrs) }\end{array}$ & $\begin{array}{c}\text { Total Lighting } \\
\text { Trading Hours } \\
\text { Only }\end{array}$ & $\begin{array}{c}\text { All Areas } \\
\text { Observed 'on' } \\
\text { Lighting }\end{array}$ & $\begin{array}{l}\text { Retail Area Only } \\
\text { Observed 'on' } \\
\text { Lighting }\end{array}$ \\
\hline Ot-1 & $363 \%$ & $109 \%$ & $24 \%$ & $4 \%$ \\
\hline Ot-3 & $428 \%$ & $144 \%$ & $86 \%$ & $19 \%$ \\
\hline Ot-5 & $188 \%$ & $65 \%$ & $62 \%$ & $62 \%$ \\
\hline Ot-6 & $208 \%$ & $70 \%$ & $67 \%$ & $64 \%$ \\
\hline Ot-7 & $66 \%$ & $22 \%$ & $21 \%$ & $19 \%$ \\
\hline Ot-8 & $273 \%$ & $96 \%$ & $85 \%$ & $85 \%$ \\
\hline Ot-9 & $225 \%$ & $77 \%$ & $76 \%$ & $74 \%$ \\
\hline Ot-11 & $148 \%$ & $45 \%$ & $43 \%$ & $43 \%$ \\
\hline Ot-12 & $257 \%$ & $85 \%$ & $59 \%$ & $55 \%$ \\
\hline Ot-14 & $160 \%$ & $48 \%$ & $40 \%$ & $40 \%$ \\
\hline Ot-15 & $210 \%$ & $70 \%$ & $58 \%$ & $58 \%$ \\
\hline Ot-16 & $136 \%$ & $47 \%$ & $35 \%$ & $32 \%$ \\
\hline Ot-17 & $179 \%$ & $58 \%$ & $51 \%$ & $51 \%$ \\
\hline Ot-21 & $192 \%$ & $59 \%$ & $59 \%$ & $58 \%$ \\
\hline Ot-22 & $171 \%$ & $59 \%$ & $59 \%$ & $51 \%$ \\
\hline Ot-23 & $145 \%$ & $50 \%$ & $39 \%$ & $35 \%$ \\
\hline Ot-24 & $165 \%$ & $39 \%$ & $39 \%$ & $38 \%$ \\
\hline Ot-25 & $138 \%$ & $43 \%$ & $43 \%$ & $33 \%$ \\
\hline Ot-26 & $221 \%$ & $72 \%$ & $67 \%$ & $12 \%$ \\
\hline Ot-30 & $285 \%$ & $88 \%$ & $72 \%$ & $72 \%$ \\
\hline Ot-32 & $366 \%$ & $106 \%$ & $75 \%$ & $62 \%$ \\
\hline Ot-36 & $266 \%$ & $78 \%$ & $77 \%$ & $77 \%$ \\
\hline Ot-37 & $363 \%$ & $35 \%$ & $28 \%$ & $25 \%$ \\
\hline
\end{tabular}

The different calculations in Figure 71 demonstrate how the levels of installed and operated lighting relate to the billed amounts. For this study the maximum lighting load will be considered as $100 \%$ illumination during 'normal' trading hours combined with the observed overnight lighting.

The minimum load has been defined as the lighting used to illuminate the retail area (sales area and display window) or any lighting used to illuminate stock for sale.

For example, if store Ot-26 used its total lighting load for the maximum annual hours then the lighting load alone would represent approximately $221 \%$ of its current total billing. If the store uses all of its lighting for the identified trading hours only, then the lighting would account for $72 \%$ of the billed amount. While under observation the store was observed to be using a lighting load that equated to $67 \%$ of the annual billed amount.

Figure 72 displays the range of lighting for each store and the observed lamp load when they are compared as a percentage of the billed totals, using the values from Figure 71. 


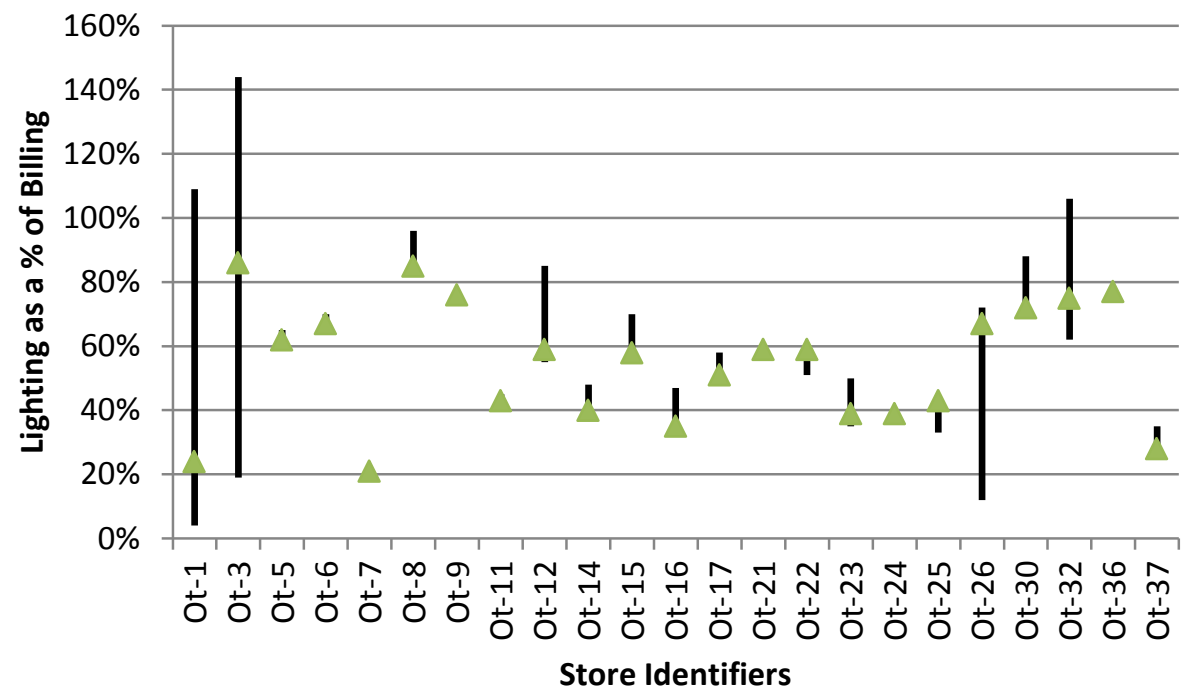

Figure 72: Range of Lighting and Observed Levels

The black vertical lines in Figure 72 represent the range of lighting that the occupant can control in relation to the billed amount for each store. For example, store Ot-3 has a lighting load that accounts for $86 \%$ of its billed amount, but if the store was to operate all of the lighting within the premise then the lighting load alone would represent $144 \%$ of the current billing amount. If only the lights in the retail area were used, then the lighting load would be $19 \%$ of the billing.

Although never observed in any shop on the retail strip, the maximum lighting load would occur if all of the lamps were left 'on' permanently. This would have the effect of doubling or even tripling the billed amount in an annual period, as shown in the left column of Figure 71. Based on the interviews and observations of store operation, it is believed that this event is unlikely to occur and therefore has not been used in the renewable energy investigation. 
The annual levels to which the occupant can alter the energy consumption through the lighting load are shown in Figure 73, with an energy comparison of the lighting estimates and billing records.

\begin{tabular}{|ll|l|l|}
\hline & kWh/yr & Billed June 09 - May 10 & Percentage of Billed \\
\hline Lighting all on (8760hrs) & 749,374 & & $204 \%$ \\
All Lighting Trading Hours & 281,798 & \multirow{3}{*}{$368,165 \mathrm{kWh} / \mathrm{yr}$} & $76 \%$ \\
Observed Lighting & 244,236 & $66 \%$ \\
\hline Retail Lighting Only & 178,327 & $48 \%$ \\
\hline
\end{tabular}

The observed lighting load accounts for $66 \%$ of the billed electricity indicating that plug loads, including heating, use about $34 \%$ of the retail strip's consumption.

The 'all lighting trading hours' number in Figure 73, 281,798 kWh/yr represents all of the lighting within the store operating at $100 \%$ for the trading hours combined with the observed overnight lighting. This is considered to be the maximum annual lighting load from these stores.

The observed lighting, 244,236 kWh/yr represents the levels observed during the audits and night time site-visits.

Retail lighting only, at $178,327 \mathrm{kWh} / \mathrm{yr}$ is the lighting used only in the retail area to illuminate stock.

Figure 74 shows these as a percentage of the maximum annual lighting load.

\begin{tabular}{|cccc|}
\hline $\begin{array}{l}\text { Maximum Annual } \\
\text { Lighting Load }\end{array}$ & Retail Lighting Only & Overnight Lighting & All Other Lighting \\
\hline $281,798 \mathrm{kWh} / \mathrm{yr}$ & $178,327 \mathrm{kWh} / \mathrm{yr}$ & $33,960 \mathrm{kWh} / \mathrm{yr}$ & $69,510 \mathrm{kWh} / \mathrm{yr}$ \\
\hline $100 \%$ & $63 \%$ & $12 \%$ & $25 \%$ \\
\hline \multicolumn{4}{c}{ Figure 74: Proportions of Annual Lighting Load } \\
\hline
\end{tabular}




\subsubsection{A SELECTION OF STORES}

To understand how some of the stores use their lighting, five stores were investigated in detail and are described in the appendices Appendix E through Appendix I.

The five store types used to explore the results from the energy audits are as follows:

- Boutique Fashion Store;

- Outlet Fashion Store;

- Sports Store;

- Food Sales; and

- Other Store types

To understand how well these stores use energy, the AEUI for each of the five stores will be compared to the 'good', 'fair' and 'poor' levels of performance. These are based on the AEUI ranges reported in Section 6.11.

The AEUI for each store will be identified as the bold text within the AEUI range in Figure 75. These have been generated from the results listed in the relevant stores Appendix. The assumptions for the energy balances for each of the five stores are given in Appendix J.

\begin{tabular}{|l|cccc|}
\hline Store Type & $\begin{array}{c}\text { Calculated } \\
\text { AEUI }\end{array}$ & $\begin{array}{c}\text { Good } \\
\left(\mathbf{k W h} / \mathbf{y r} . \mathbf{m}^{2}\right)\end{array}$ & $\begin{array}{c}\text { Fair } \\
\left(\mathbf{k W h} / \mathbf{y r} . \mathbf{m}^{\mathbf{2}}\right)\end{array}$ & $\begin{array}{c}\text { Poor } \\
\left(\mathbf{k W h} / \mathbf{y r} . \mathbf{m}^{2}\right)\end{array}$ \\
\hline Fashion - Boutique & $108 \mathrm{kWh} / \mathrm{yr} . \mathrm{m}^{2}$ & $<52-100$ & $\mathbf{1 0 0}-\mathbf{2 0 0}$ & $>200$ \\
\hline Fashion - Outlet & $176 \mathrm{kWh} / \mathrm{yr}^{2} \mathrm{~m}^{2}$ & $<52-100$ & $\mathbf{1 0 0}-\mathbf{2 0 0}$ & $>200$ \\
\hline Retail Other - Sports & $66 \mathrm{kWh} / \mathrm{yr} . \mathrm{m}^{2}$ & $<\mathbf{5 2}-\mathbf{1 0 0}$ & $100-200$ & $>200$ \\
\hline Food - Food & $509 \mathrm{kWh} / \mathrm{yr} \cdot \mathrm{m}^{2}$ & $<360$ & $360-410$ & $>\mathbf{4 1 0}$ \\
\hline Retail Other - Gift & $128 \mathrm{kWh} / \mathrm{yr}^{2} \mathrm{~m}^{2}$ & $<100$ & $\mathbf{1 0 0 - 2 0 0}$ & $>200$ \\
\hline \multicolumn{5}{r}{ Figure 75: AEUI Comparison for the Selected Stores } \\
\hline
\end{tabular}

In Figure 75, four of the five stores can be considered as good or fair users of energy, with just the food sales store being identified as a poor user. All of these stores have some potential for energy savings. See appendices Appendix E through Appendix I for further details on each store.

In Figure 72 above, the lighting consumption for all 23 stores is compared to the annual billed amount. In all of the stores the lighting represents between $20 \%$ and $85 \%$ of the billed amount for the year. The average of which is just 66\% as shown in Figure 73. These percentages have been developed from all lighting use within in the store including daytime, overnight and stock/utility lighting. To understand how the different stores use their lighting in the retail areas, five stores have been detailed in the appendices Appendix E through Appendix I. 
Figure 76 is based on the individual analysis and is representative of a single 24 hour period. The loads have been calculated based on the observed lighting, plug loads and the standard trading hours.

It was identified in the individual analysis that one of the stores used high levels of process energy, while another used occupant controlled heating. These have been identified below as $*$ and $* *$. The single $*$ relates to the store that uses high levels of process energy when compared to the lighting. The ** relates to the occupant controlled heating.

\begin{tabular}{|c|c|c|c|c|}
\hline Store Type & $\begin{array}{c}24 \text { hr Load } \\
\text { Consumption } \\
\text { Watthours } \\
\text { (\% of total) }\end{array}$ & $\begin{array}{c}\text { Day Lighting Load } \\
\text { Watthours } \\
\text { (\% of total) }\end{array}$ & $\begin{array}{c}\text { Night Lighting } \\
\text { Load } \\
\text { Watthours } \\
(\% \text { of total }) \\
\end{array}$ & $\begin{array}{l}\text { Plug Load } \\
\text { Watthours } \\
(\% \text { of total })\end{array}$ \\
\hline $\begin{array}{l}\text { Fashion } \\
\text { Boutique }\end{array}$ & $\begin{array}{l}17,338 \\
(100 \%)\end{array}$ & $\begin{array}{l}13,084 \\
(75 \%)\end{array}$ & $\begin{array}{l}2,640 \\
(15 \%) \\
\end{array}$ & $\begin{array}{l}1,614 \\
(10 \%)\end{array}$ \\
\hline $\begin{array}{l}\text { Fashion } \\
\text { Outlet }\end{array}$ & $\begin{array}{l}87,429 * \\
(100 \%)\end{array}$ & $\begin{array}{l}53,723 \\
(61 \%)\end{array}$ & $\begin{array}{l}2,016 \\
(2 \%)\end{array}$ & $\begin{array}{l}3,169 \\
(4 \%)\end{array}$ \\
\hline $\begin{array}{l}\text { Retail Other - } \\
\text { Sports }\end{array}$ & $\begin{array}{l}71,810 \\
(100 \%) \\
\end{array}$ & $\begin{array}{l}47,457 \\
(66 \%) \\
\end{array}$ & $\begin{array}{l}8,800 \\
(12 \%) \\
\end{array}$ & $\begin{array}{l}15,553 \\
(22 \%) \\
\end{array}$ \\
\hline $\begin{array}{l}\text { Retail Other - } \\
\text { Food }\end{array}$ & $\begin{array}{c}69,000 * * \\
(100 \%)\end{array}$ & $\begin{array}{l}14,280 \\
(20 \%)\end{array}$ & $\begin{array}{l}1,440 \\
(2 \%)\end{array}$ & $\begin{array}{l}53,280 \\
(78 \%) \\
\end{array}$ \\
\hline $\begin{array}{l}\text { Retail Other - } \\
\text { Giftware }\end{array}$ & $\begin{array}{l}20,669 \\
(100 \%) \\
\end{array}$ & $\begin{array}{l}17,160 \\
(83 \%) \\
\end{array}$ & $\begin{array}{l}2,640 \\
(13 \%) \\
\end{array}$ & $\begin{array}{c}869 \\
(4 \%) \\
\end{array}$ \\
\hline
\end{tabular}

Figure 76 shows the lighting range for day lighting load only, this range varies between $20 \%$ and $85 \%$ of the total daily consumption. The small selection of stores used shows that the lighting versus total load is not a simple relationship and is based on the type of equipment, plug loads and lighting selection by the occupant.

Figure 76 shows that the giftware store's day lighting load accounts for $83 \%$ of the stores installed load. While the food store because of its product requirements has higher plug loads that is shown above to be $78 \%$ of the total load, leaving the day lighting load to be just $20 \%$.

The fashion - boutique store is an example of how the occupant can alter the lighting levels within the store. This store alters its plug load and lighting use based on the season. Shown above is the winter calculation that includes kitchenette equipment and night lighting. In summer this store does not utilise the kitchenette nor does it use night lighting which increases the lighting as a percentage of the overall load to $92 \%$. 
The fashion - outlet store uses occupant controlled, electrical heating and cooling. In this store with the increased plug load the day lighting only represents $61 \%$ of total consumption.

The sports store also uses higher levels of plug loads due to the nature of its sporting products, this store uses two thirds (66\%) of the annual billed amount as daylighting only.

This shows that the plug loads and lighting selection within a store can alter the perceived lighting. 


\section{THE REMAINING STORES}

To estimate the electrical load lighting from all the shops on the Otaki retail strip, the electricity use for remaining ten stores which had not participated in the study needed to be quantified. The lighting load profile representing the retail strip requires an estimate based on the store types, normal trading hours, their lighting styles and lamp count.

The ten remaining store types are seven fashion stores, two fashion accessories and one food store. As the stores had not consented to the study and to remove any confusion with the existing study, these are given the identifier Otaki - (I-X) e.g Otaki - I.

\subsection{Street SURVEY}

The overnight lighting study discussed in Section 2.1 was used to estimate the day and night time light load for the remaining 10 stores. (Heap, 2009) noted that the methodology was most suited to single storey buildings. All of the Otaki retail stores are at ground level and the non-participating stores have large display windows with mostly open-backed displays. This combination of height and open displays meant that there were clear site lines through to the rear of eight out of ten stores.

The onsite count and survey of the non-participating premises took place on Wednesday the $25^{\text {th }}$ of August 2010. The survey involved a walking by each of the ten stores during normal trading hours so the 'normal' lighting use could be observed. The lights being used and the advertised trading hours of each store were then recorded.

In many of the stores, the lamps were laid out in symmetrical pattern, placing some of the lamps near to the front door or display window. Because of their proximity to the street, identification could be made.

However, in other stores the lamps were hidden by the luminaire, although this was mostly to the rear of the store near the changing rooms. Assumptions were made on these lamp types based on the lighting used in surveyed stores of a similar style.

In two of the stores that did not return the consent forms, the store managers allowed access to their store to carry out the audit while they waited on head office confirmation. However, as head office for these stores never consented, they have been included in the non-participating ten although the lamp counts are considered accurate.

Figure 77 is a summary of the quick facts on the remaining ten stores. 


\begin{tabular}{|c|c|c|c|c|c|c|}
\hline $\begin{array}{l}\text { Unique } \\
\text { Record ID }\end{array}$ & Store Type & $\begin{array}{l}\text { Area Of } \\
\text { Premises } \\
\left(\mathbf{m}^{2}\right)\end{array}$ & $\begin{array}{l}\text { Installed } \\
\text { Lighting } \\
\text { Load } \\
\text { (Watts) } \\
\end{array}$ & $\begin{array}{l}\text { Heating } \\
\text { Type }\end{array}$ & $\begin{array}{l}\text { Lighting } \\
\mathrm{W} / \mathrm{m}^{2}\end{array}$ & $\begin{array}{l}\text { Trading } \\
\text { Hours per } \\
\text { week }\end{array}$ \\
\hline Otaki - I & $\begin{array}{l}\text { Fashion } \\
\text { Accessories }\end{array}$ & 55 & 4228 & $\begin{array}{l}\text { Heat } \\
\text { Pump }\end{array}$ & 77 & 49 \\
\hline Otaki - II & Fashion & 180 & 2772 & $\begin{array}{l}\text { Heat } \\
\text { Pump }\end{array}$ & 15 & 54 \\
\hline Otaki - III & Fashion & 110 & 2403 & $\begin{array}{l}\text { Heat } \\
\text { Pump }\end{array}$ & 22 & 54 \\
\hline Otaki - IV & Fashion & 225 & 3745 & None & 17 & 54 \\
\hline Otaki - V & Fashion & 240 & 1980 & $\begin{array}{l}\text { Heat } \\
\text { Pump }\end{array}$ & 8 & 55 \\
\hline Otaki - VI & Food & 240 & 2592 & $\begin{array}{l}\text { Heat } \\
\text { Pump }\end{array}$ & 14 & 61 \\
\hline Otaki - VII & Fashion & 120 & 1944 & $\begin{array}{l}\text { Heat } \\
\text { Pump }\end{array}$ & 16 & 54 \\
\hline Otaki - VIII & $\begin{array}{l}\text { Fashion } \\
\text { Accessories }\end{array}$ & 120 & 1922 & $\begin{array}{l}\text { Heat } \\
\text { Pump }\end{array}$ & 16 & 55 \\
\hline Otaki - IX & Fashion & 230 & 2970 & $\begin{array}{l}\text { Heat } \\
\text { Pump }\end{array}$ & 13 & 55 \\
\hline Otaki - X & Fashion & 120 & 1745 & None & 15 & 51 \\
\hline
\end{tabular}

The calculated floor areas range from a small boutique at $55 \mathrm{~m}^{2}$ through to the larger outlet stores at $240 \mathrm{~m}^{2}$. The floor area estimate was created using the BEES virtual site visit method and does not account for any overhangs or loading bays.

There is a wide variety of LPD levels, the highest $\left(77 \mathrm{~W} / \mathrm{m}^{2}\right)$ is in the smallest 'fashion accessories' boutique store. The light power density levels identified in Figure 77 are lower than those identified in appendices Appendix E through Appendix I, as the lighting load reported here is only for the retail area, while the floor area encompasses the entire store. 


\subsection{TRADING HOURS}

The trading hours, given in Figure 78 have been developed from the advertised trading hours from either the store front door or the internet site for that particular store chain.

\begin{tabular}{|lcccc|}
\hline Store & $\begin{array}{c}\text { Trading } \\
\text { Hours per } \\
\text { week }\end{array}$ & $\begin{array}{c}\text { Monday - } \\
\text { Friday }\end{array}$ & Saturday & Sunday \\
\hline Otaki - I & 49 & $10-5$ & $10-5$ & $10-5$ \\
\hline Otaki - II & 54 & $9-5$ & $9-5$ & $10-4$ \\
\hline Otaki - III & 54 & $9-5$ & $9-5$ & $10-4$ \\
\hline Otaki - IV & 54 & $9-5$ & $9-5$ & $10-4$ \\
\hline Otaki - V & 55 & $9-5$ & $9-5$ & $10-5$ \\
\hline Otaki - VI & 54 & $9-5$ & $9-5$ & $10-4$ \\
\hline Otaki - VII & 54 & $9-5$ & $9-5$ & $10-4$ \\
\hline Otaki - VIII & 55 & $9-5$ & $9-5$ & $10-5$ \\
\hline Otaki - IX & 54 & $9-5$ & $9-5$ & $10-4$ \\
\hline Otaki - X & 51 & $9: 30-5$ & $9: 30-5$ & $10-4$ \\
\hline & Figure 78: Advertised Store Trading Hours & \\
\hline
\end{tabular}

The average trading week and day will be based on the above advertised hours for each store.

\subsection{VISIBLE EQUIPMENT}

Because the stores were surveyed from the street, not all of the installed equipment could be observed. In all of the stores the type of till, appliance identification was limited to whether EFT-PoS and/or phone were present. In two of the stores some equipment that was located in the backrooms could be identified, but no equipment count could be made. 


\subsection{LAMP TYPES}

Figure 79 lists the lamps identified in the remaining ten stores.

\begin{tabular}{|lccc|}
\hline Lamp Type & $\begin{array}{c}\text { Total Number } \\
\text { of Lamps }\end{array}$ & $\begin{array}{c}\text { Typical Wattage } \\
\text { (Lamp + Ballast) }\end{array}$ & $\begin{array}{c}\text { Total Watts/Lamp } \\
\text { Type }\end{array}$ \\
\hline 1200 mm Fluorescent Lamps & 115 & $45(36+9)$ & 5,175 \\
\hline 1500 mm Fluorescent Lamps & 70 & $72(58+14)$ & 5,040 \\
\hline 900 mm T5 Fluorescent lamp & 2 & $39(30+9)$ & 48 \\
\hline CFL & 17 & $24(20+4)$ & 408 \\
\hline CFL - PAR spot & 2 & $28(23+5)$ & 56 \\
\hline Halogen Downlights & 4 & 100 & 400 \\
\hline Halogen Flood Light & 7 & 500 & 3,500 \\
\hline Halogen Spotlight & 1 & 20 & 20 \\
\hline Incandescent - 100W & 2 & 100 & 200 \\
\hline Incandescent- 75W & 1 & 75 & 75 \\
\hline Metal Halide - High Bay & 10 & $480(440+40)$ & 2,800 \\
\hline Metal Halide Down Light & 25 & $84(70+14)$ & 1,344 \\
\hline Metal Halide Flood Light & 16 & $84(70+14)$ & 3,135 \\
\hline MR-16 & 57 & $55(50+5)$ & \\
\hline Store Total & $\mathbf{2 6 , 3 0 1}$ \\
\hline \multicolumn{5}{c}{ Figure 79: Lamp Count of the Remaining 10 Stores } \\
\hline
\end{tabular}

Figure 79 shows that there are 329 lamps used to light the retail areas of the remaining non-participants. The five main lamp types have been identified as the same as those identified in Section 6.4. The main difference is shown in Figure 80, with the distribution of the installed load. It shows that the LFL, the metal halide and the halogen lamp loads are more or less evenly distributed.

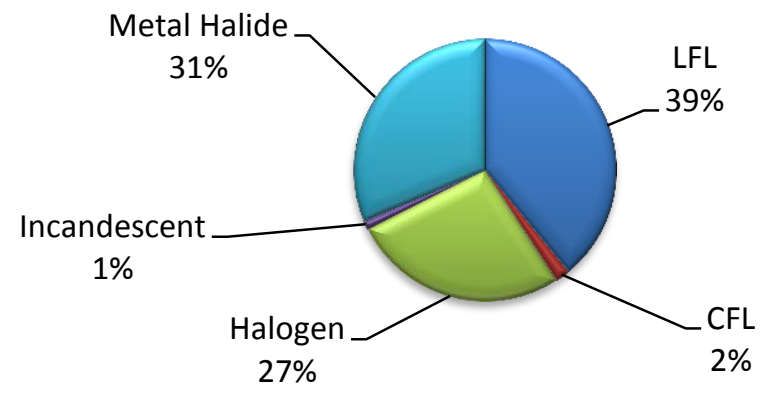

Figure 80: Lamp Share by Load along Remaining 10 Stores 
Based on these observations, Figure 81 gives the installed 'on' load for each store. The installed retail lighting load represents $100 \%$ of the lamps turned on, while the overnight levels are the observed levels after normal operating hours.

\begin{tabular}{|lcc|}
\hline Store & $\begin{array}{c}\text { Installed Retail Area Lighting Load } \\
\text { (Watts) }\end{array}$ & $\begin{array}{c}\text { Overnight Lighting Load } \\
\text { (Watts) }\end{array}$ \\
\hline Otaki - I & 4228 & 48 \\
\hline Otaki - II & 2772 & 252 \\
\hline Otaki - III & 2403 & 144 \\
\hline Otaki - IV & 3745 & 0 \\
\hline Otaki - V & 1980 & 192 \\
\hline Otaki - VI & 2592 & 0 \\
\hline Otaki - VII & 1944 & 24 \\
\hline Otaki - VIII & 1922 & 168 \\
\hline Otaki - IX & 2970 & 90 \\
\hline Otaki - X & 1745 & 288 \\
\hline \multicolumn{2}{|c|}{ Figure 81: Installed Retail Area Lighting Load and Overnight Lighting load } \\
\hline
\end{tabular}

With the trading hours and observed loads identified, a basic load profile (Figure 82) can be developed giving the maximum retail lighting load and its duration for these ten stores.

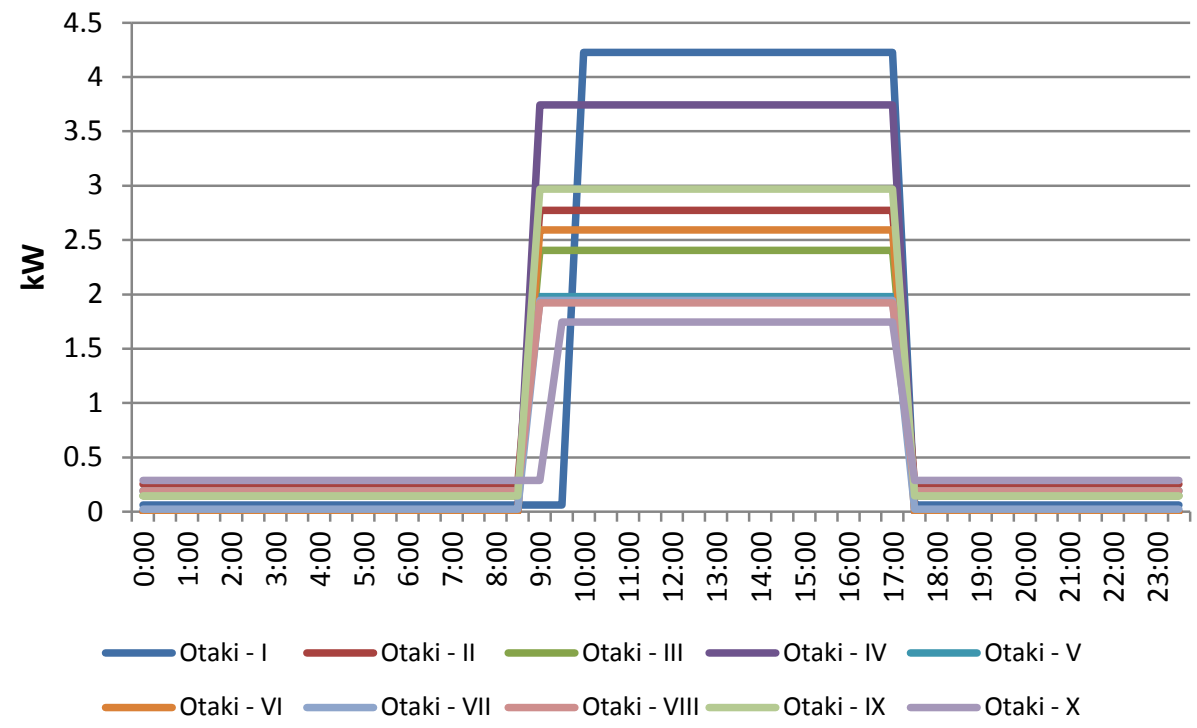

Figure 82: Retail Lighting Load Profiles for all 10 Stores

By combining the load profiles in Figure 83 provides the combined hourly load per average day for the remaining ten stores. It shows that these stores can be expected to operate in similar manner to the stores that underwent audits. 


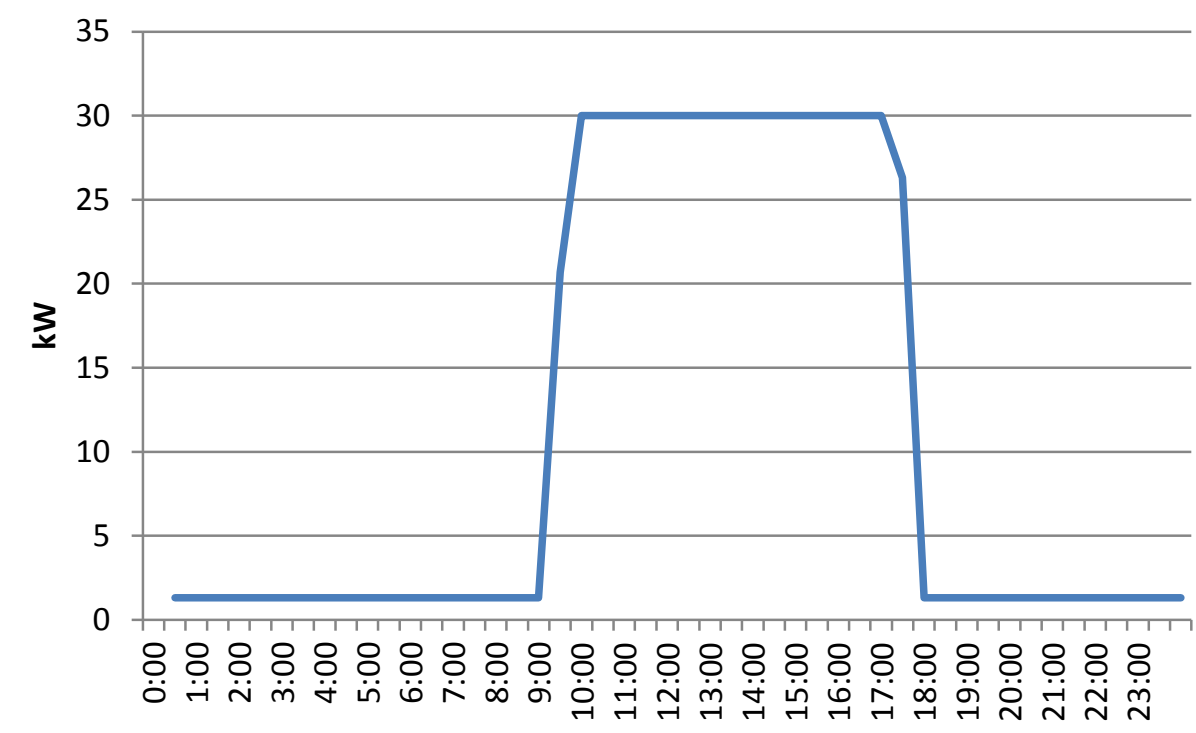

Figure 83: Lighting Profile for the Remaining 10 Stores

Figure 83 shows, as for the profile developed in Section 6.11, the maximum load is during the day, between 9:00am and 5:30pm. The area under the curve in Figure 83 gives the total energy load required by the lighting, which is calculated to be $239 \mathrm{kWh}$ per day.

Based on the trading hours developed in Section 6.2, the consumption due to the retail daytime lighting and the observed overnight lighting is calculated for the remaining 10 stores at $80,823 \mathrm{kWh}$ per year of which $73,026 \mathrm{kWh} / \mathrm{yr}$ (approximately $90 \%$ ) is the lighting used during the day in the retail area.

\subsection{OVERALl LoAd PROFILE}

The lighting load identified above, $80,823 \mathrm{kWh}$, does not include all the energy used for lighting within the store. Section 6.11 calculated that the lighting used in retail area during the day was $63 \%$ of the total annual energy use, with the overnight lighting representing $12 \%$ of the annual total energy use.

In order to calculate the overall lighting load and to quantify the portion that is retail lighting, the remaining stores will be firstly classified by store type and then the annual energy use calculated using the loads determined earlier in this chapter.

\subsubsection{OTHER FASHION STORES}

Seven of the 10 non-participants were identified as fashion stores. Based on the earlier analysis in Figure 79, these stores have $18 \mathrm{~kW}$ of installed lighting which is calculated to use $48,751 \mathrm{kWh} / \mathrm{yr}$ in the daytime lighting of the retail area and $6,262 \mathrm{kWh} / \mathrm{yr}$ in overnight lighting. What is not known is the 'Other' lighting load that may be used in the storage areas of these stores. 
To generate the 'other lighting load', data from ten of the eleven audited fashion stores can be used. These audited fashion stores have $45 \mathrm{~kW}$ of installed lighting, calculated to consume $154,812 \mathrm{kWh} / \mathrm{yr}$ of electrical energy of which approximately $126,915 \mathrm{kWh} / \mathrm{yr}$ $(82 \%)$ is attributed to retail lighting only, $17,385 \mathrm{kWh} / \mathrm{yr}(11 \%)$ being the overnight lighting consumption and the remainder (7\%) being the stock/utility area lighting.

\begin{tabular}{|cccc|}
\hline $\begin{array}{c}\text { Fashion Stores, All } \\
\text { Lighting }\end{array}$ & Retail Only & Overnight Lighting & Other Lighting \\
\hline $154,812 \mathrm{kWh} / \mathrm{yr}$ & $126,915 \mathrm{kWh} / \mathrm{yr}$ & $17,385 \mathrm{kWh} / \mathrm{yr}$ & $10,512 \mathrm{kWh} / \mathrm{yr}$ \\
\hline $100 \%$ & $82 \%$ & $11 \%$ & $7 \%$ \\
\hline Installed Lighting Load & & & $3 \mathrm{~kW}$ \\
\hline $45 \mathrm{~kW}$ & $41 \mathrm{~kW}$ & - & $7 \%$ \\
\hline $100 \%$ & $91 \%$ & - & \\
\hline \multicolumn{4}{|c|}{ Figure 84: Calculated Fashion Store Lighting Proportions } \\
\end{tabular}

The other lighting load $(10,512 \mathrm{kWh} / \mathrm{yr})$ of the ten audited stores represents $8 \%$ of the retail lighting load only in Figure 84 of 126,915 kWh/yr.

Applying the calculated 8\% to the non participating Fashion stores gives these stores an annual consumption of other lighting in the stock / utility areas of 3,400 kWh per year ( $8 \%$ of . $48,751 \mathrm{kWh} / \mathrm{yr}$ ).

Calculating the same for the installed load gives the stock / utility areas $1.4 \mathrm{~kW}$ (7\% of $18 \mathrm{~kW}$ ) of lighting installed in the seven non-participant stores.

The remaining $2 \%$ of the installed load not identified in Figure 84 is in unused exterior lighting and lit signage, neither of which was observed in any of the remaining 10 nonparticipating stores.

One of the audited stores was left out of the above comparison, as it is the only fashion store of its type on the strip. This store only uses $12 \%$ of its floor area and just $15 \%$ of the installed lighting load for retail. The store also contains offices, warehousing and manufacturing areas that no other fashion store was observed to contain, because of this it was omitted from the above comparison.

\subsubsection{OTHER FASHION ACCESSORIES STORES}

Two of the non-participating stores are fashion accessories stores. Together they account for 6,150 Watts of the installed lighting load and are calculated to consume 16,145 $\mathrm{kWh} / \mathrm{yr}$ during trading hours and 1,534 kWh/yr overnight.

Two of the four audited fashion accessories stores will be used for comparison, as the other two both include manufacturing areas that use process energy and lighting. The two 
comparison stores use $8,490 \mathrm{kWh} / \mathrm{yr}$ in lighting of which $6,323 \mathrm{kWh}$ can be considered as retail only.

\begin{tabular}{|cccc|}
\hline $\begin{array}{c}\text { Fashion Accessories } \\
\text { Stores, All Lighting }\end{array}$ & Retail Only & $\begin{array}{c}\text { Overnight } \\
\text { Lighting }\end{array}$ & Other Lighting \\
\hline $8,490 \mathrm{kWh} / \mathrm{yr}$ & $6,323 \mathrm{kWh} / \mathrm{yr}$ & $699 \mathrm{kWh} / \mathrm{yr}$ & $1,468 \mathrm{kWh} / \mathrm{yr}$ \\
\hline $100 \%$ & $75 \%$ & $8 \%$ & $17 \%$ \\
\hline Installed Lighting Load & & & \\
\hline $2.7 \mathrm{~kW}$ & $2.2 \mathrm{~kW}$ & - & $0.5 \mathrm{~kW}$ \\
\hline $100 \%$ & $81 \%$ & - & $19 \%$ \\
\hline \multicolumn{2}{r}{ Figure 85: Calculated Lighting Proportions Fashion Accessories Store Lighting } \\
\hline
\end{tabular}

Figure 85 above shows that the other lighting has been calculated to consume 1,468 kWh per year, or $17 \%$ of all lighting energy. The $1,468 \mathrm{kWh}$ represents $23 \%$ of the retail lighting only, from which the non-participating fashion accessories stores are calculated to have $1.4 \mathrm{~kW}(23 \%$ of $6,150 \mathrm{~kW})$ installed in the other lighting category, which has been estimated to consume $3,700 \mathrm{kWh} / \mathrm{yr}$.

\subsubsection{OTHER FOOD STORE}

The remaining store type is the food store. This store has been observed to contain 2,592 Watts of installed retail area lighting, which is expected to consume $8,130 \mathrm{kWh} / \mathrm{yr}$ in the daytime lighting of the retail area only.

A simple comparison is not possible between the audited store and the non-participant food stores due to the difference in floors areas and products being sold.

The rear storage space for the non-participant food store can be observed from the street, as the main wall contains a garage door that opens to the street and there are no internal walls or doors. The storage space in this store was observed to be using a fluorescent lamp for lighting in a similar manner to the rest of the shop. It would appear that the rear storage area is lit using a single $1500 \mathrm{~mm}$ LFL with an installed load of 72 Watts.

This would increase the installed lighting load to 2,664 Watts that is expected to increase the annual lighting energy use for the store to $8,336 \mathrm{kWh} / \mathrm{yr}$. 


\subsection{OVERALL}

Although the type of store varied, the lamp types remained similar, as shown in Fig Figure 79 and Figure 41. The analysis showed that most stores could alter their electrical consumption based on the selection of lights they used and their operating regime.

The chapter then looked at the ten remaining stores that had not participated in the study. Through observations from the street and analysis of the advertised trading hours, a basic weekly profile was developed that gave the hourly energy load. As the stock/utility areas could not observed from the street, these loads were estimated from the audited stores.

Figure 86 shows the estimated lighting load for the 10 stores including overnight lighting and the 'other lighting'. Overall, these stores consume approximately $87,000 \mathrm{kWh} / \mathrm{yr}$ in lighting alone, with an installed lighting load of $30 \mathrm{~kW}$.

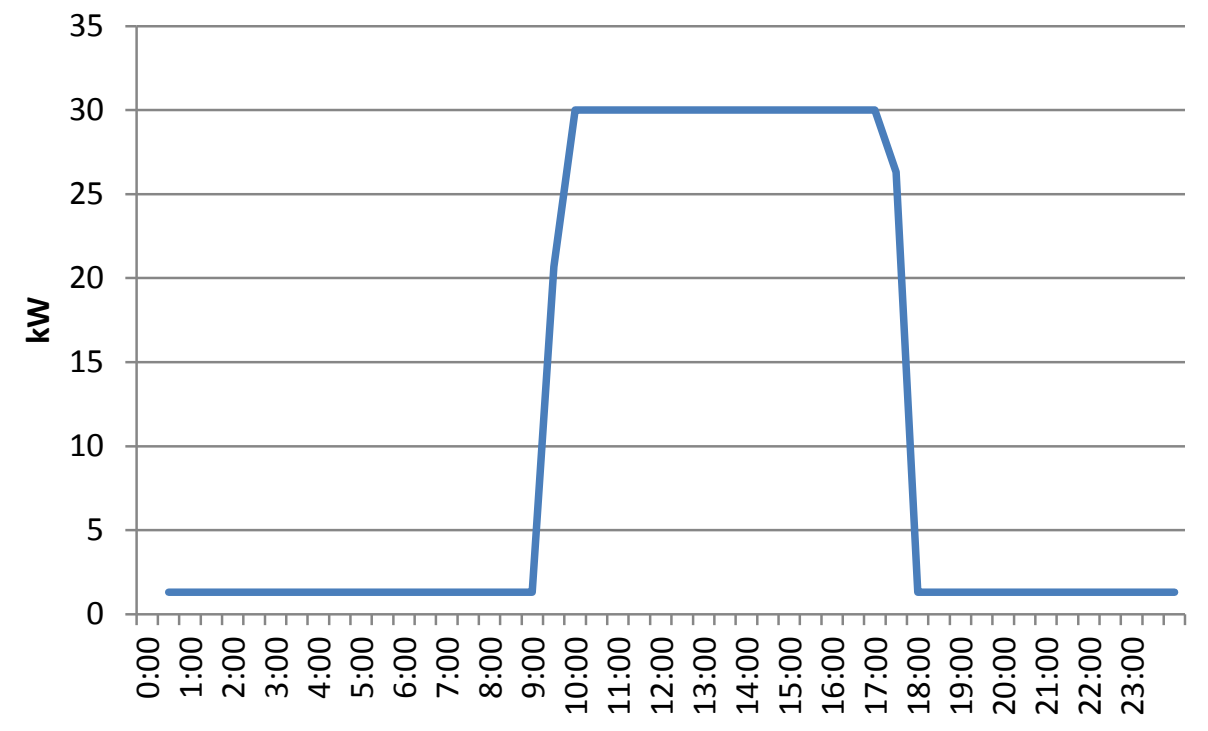

Figure 86: kW Load for all Lighting in Non-Participating Stores 
By adding the lighting profile for the ten observed stores to the lighting profile for the audited 23 stores (Section 6.11), the lighting profile for the entire Otaki retail strip can be calculated and is shown below in Figure 87.

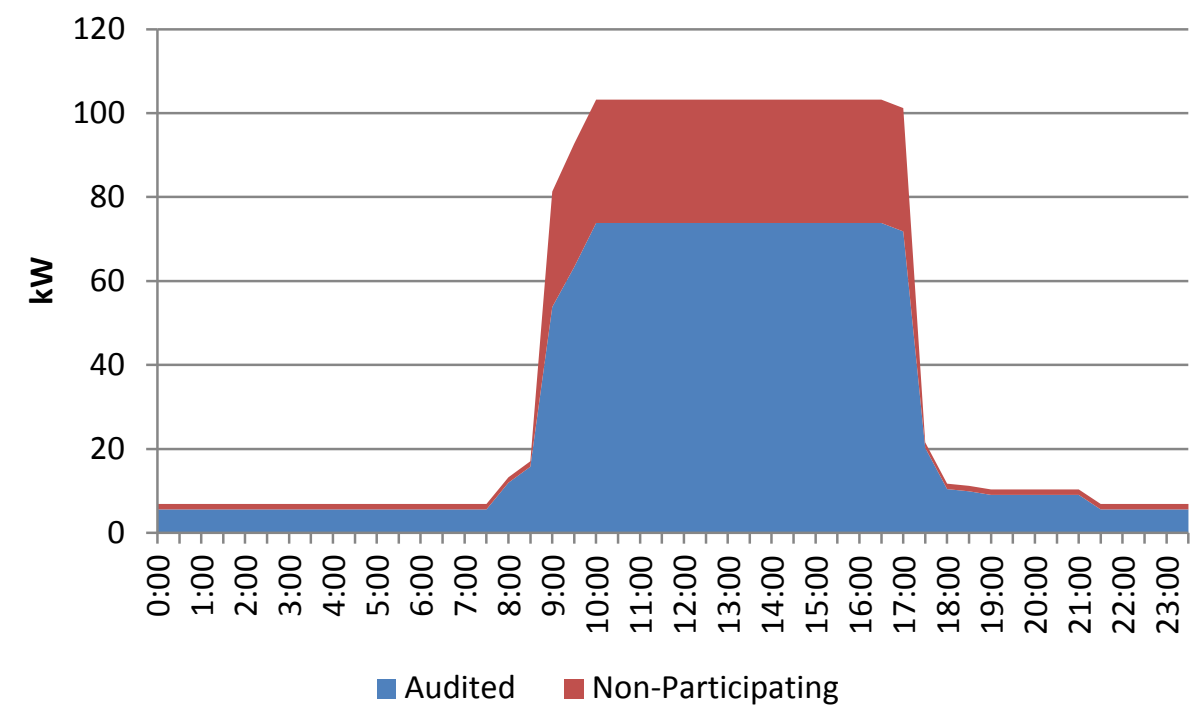

Figure 87: Combined Lighting Load for Retail Strip

The graph's magnitude in Figure 87 is the estimated daily lighting load, which has been estimated as being $105 \mathrm{~kW}$ per hour during trading hours and $7 \mathrm{~kW}$ outside the trading period. Extrapolating this out suggests the lighting in the 33 stores consumes approximately $370,000 \mathrm{kWh} / \mathrm{yr}$ at an average of $1,013 \mathrm{kWh} /$ day.

This was calculated from the 23 audited stores in Section 6.11 and the loads calculated for the 10 non-participates in this Chapter.

While the utmost care was taken in the creation of the annual estimate, the variation in store uses and the seasonal pattern of energy use, errors are expected to be within 20\%, as in AS/NZS 3598:2000, Energy Audits. This percentage was identified, as this is the target error used in all of the energy audits as defined by The Australian and New Zealand Energy Audit Standard, AS/NZS 3598:2000, Energy Audits. 


\section{ENERGY EFFICIENCY OPPORTUNITIES}

This chapter explores the opportunities to improve the efficiency of retail lighting energy use, and whether it is possible to reduce the installed lighting load without altering the design intentions. The focus will be optimising lighting equipment and lighting use where potential savings can be achieved without large capital expenditure - picking the 'low hanging fruit'.

The savings will be calculated in terms of power $(\mathrm{kW})$, energy $(\mathrm{kWh})$ and money to quantify the likely payback.

\subsection{OVERALL Lighting LOAD ESTIMATE}

Lighting in the 33 retail stores on the Otaki shopping strip consumes approximately $370,000 \mathrm{kWh} / \mathrm{yr}$ of electrical energy, averaging 1,013 kWh/day.

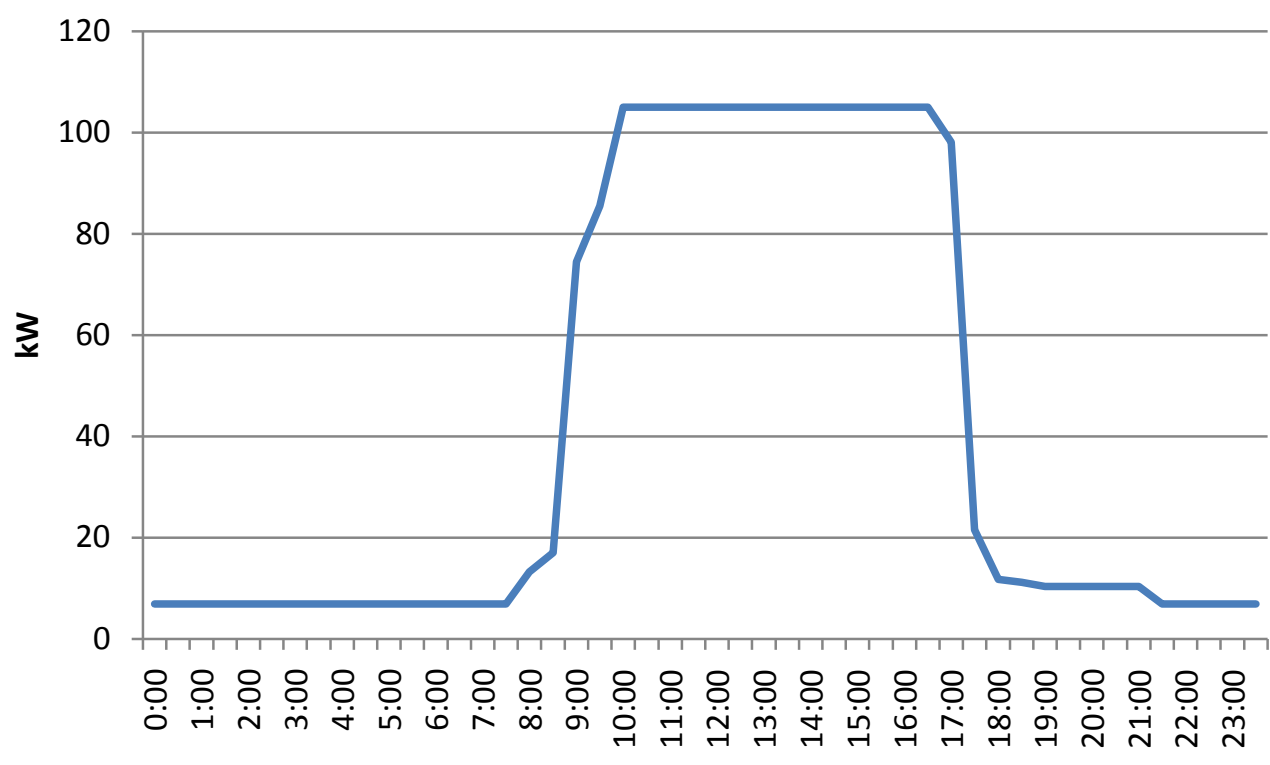

Figure 88: Combined Lighting Load Profile (Otaki Retail Strip)

Figure 88 shows the 33 stores, all areas, lighting load profile calculated for an average Friday. The expected maximum load is $105 \mathrm{~kW}$, which is flat from 10:00 am to 5:00 pm, with the overnight load $7 \mathrm{~kW}$ from 10:00 pm to 8:00 am. The shoulder loads are due to the different opening hours for the 33 stores and the tail that is evident from 18:00 through to 21:00 is a result of using Friday as one store has a late night, remaining open for an additional three hours. 


\subsection{LAMP EXCHANGE}

The first optimisation activity is to change to more efficient lamps - changing the incandescent, MR-16 or the double-ended linear halogen lamps for their energy efficient equivalent.

Lamp replacement is a regular requirement in order to maintain the desired lighting level. On the $14^{\text {th }}$ March 2011, Paul Pearce Electrical in Otaki was contacted concerning the replacement and maintenance of lamps. The senior electrician stated that before any lamp exchange took place, the store would be surveyed as to the type and number of lamps to be changed. The advice would be to wait for $10 \%$ failure of each lamp type and then completely replace that lamp type. This decision would be made by the owner, who has a choice of exchanging one lamp for a minimum charge of $\$ 45.00$ or changing all at $\$ 60.00$ an hour (plus GST). The electrician's practice was to leave a selection of lamps with the store so that they can change failed lamps themselves, although this was not advised with the halogen and metal halide lamps due to safety concerns.

Each lamp type and the benefits from replacement by their efficient equivalent will now be examined. Figure 89 through to Figure 96 provides a running total of the energy and power reductions that could be achieved by implementing each of the recommendations.

\subsubsection{CHANGE INCANDESCENT FOR COMPACT FLUORESCENT LAMPS}

Along the retail strip there were 131 lamps identified as being either GLS or PAR incandescent lamp - together they represent $12 \mathrm{~kW}$ or $11 \%$ of the overall lighting peak power and account for approximately $32,000 \mathrm{kWh}$ or $8 \%$ of the annual lighting electrical energy use.

Replacing an incandescent lamp directly by its CFL equivalent can potentially save up to $80 \%$ of the installed power and energy use. Figure 89 provides a comparison of incandescent lamps and their CFL watt equivalents. To maximise the savings, each lamp needs to be replaced by the direct equivalent e.g. if a 75 Watt incandescent is exchanged for a 23 Watt CFL (instead of a 13 Watt CFL), then the savings are only $30 \%$. 


\begin{tabular}{|ccc|}
\hline $\begin{array}{c}\text { Incandescent Lamp } \\
\text { Wattage }\end{array}$ & $\begin{array}{c}\text { Equivalent CFL } \\
\text { Wattage }\end{array}$ & $\begin{array}{c}\text { Percentage of Potential } \\
\text { Savings }\end{array}$ \\
\hline 40 W GLS & 8 & $80 \%$ \\
\hline 60 W GLS & 11 & $82 \%$ \\
\hline 75 W GLS & 13 & $82 \%$ \\
\hline 100 W GLS & 18 & $82 \%$ \\
\hline 120 W GLS & 23 & $81 \%$ \\
\hline 150 W GLS & 32 & $79 \%$ \\
\hline 80 W PAR-38 & 14 & $82 \%$ \\
\hline 120 W PAR-38 & 23 & $81 \%$ \\
\hline Figure 89: CFL and GLS wattages and potential savings ${ }^{\mathbf{1 5}}$.
\end{tabular}

Figure 90 shows the levels of electrical savings that maybe realised if the correct CFL are fitted as replacements for the incandescent lamps - this would reduce the existing 32,000 $\mathrm{kWh} / \mathrm{yr}$ by $80 \%$ to $6,400 \mathrm{kWh} / \mathrm{yr}$, giving a $7 \%$ energy saving on the overall annual lighting use. The peak power requirement would fall by $9.4 \mathrm{~kW}$ to $2.1 \mathrm{~kW}$ which represents just $2 \%$ of the total load.

\begin{tabular}{|cccc|}
\hline $\begin{array}{c}\text { Maximum Annual } \\
\text { Lighting Load }\end{array}$ & $\begin{array}{c}\text { Savings Due to } \\
\text { CFL }\end{array}$ & $\begin{array}{c}\text { Optimised load } \\
\text { due to CFL }\end{array}$ & $\begin{array}{c}\text { Percentage of Savings from } \\
\text { Annual Load }\end{array}$ \\
\hline $370,000 \mathrm{kWh} / \mathrm{yr}$ & $27,258 \mathrm{kWh} / \mathrm{yr}$ & $342,742 \mathrm{kWh} / \mathrm{yr}$ & $7 \%$ \\
\hline Daily Load kW & $\begin{array}{c}\text { Savings Due to } \\
\text { CFL }\end{array}$ & $\begin{array}{c}\text { Optimised load } \\
\text { due to CFL }\end{array}$ & $\begin{array}{c}\text { Percentage of Savings from } \\
\text { Daily Load }\end{array}$ \\
\hline $105 \mathrm{~kW}$ & $9 \mathrm{~kW}$ & $96 \mathrm{~kW}$ & $9 \%$ \\
\hline \multicolumn{4}{r}{ Figure 90: Possible Savings Due to CFL Installation } \\
\hline
\end{tabular}

During the audit, three businesses supplied actual invoices which each showed the rate charged by Energy Online during May 2010 was $\$ 0.2148$ (excluding GST) per unit $(\mathrm{kWh})$. This rate will be used to estimate the savings in this section. Changing the incandescent lamps to CFL would give potential savings of $\$ 5,855$ per year.

Lamps sourced from 'The Lightbulb Man' (The Lightbulb Man, 2010) and 'Fetchalamp' (Fetchalamp, 2010) are priced between $\$ 9.90$ and $\$ 20.50$ for the range of lamps required. A simple payback calculation is given in Figure 91.

\begin{tabular}{|ccc|}
\hline Price per CFL & $\begin{array}{c}\text { Estimated Savings @ } \\
\mathbf{\$ 0 . 2 1 4 8 / k W h}\end{array}$ & $\begin{array}{c}\text { Simple Payback in } \\
\text { Months }\end{array}$ \\
\hline$\$ 9.90^{\wedge}$ & $\$ 5855$ & 3 \\
\hline$\$ 12.25^{\#}$ & $\$ 5855$ & 3 \\
\hline$\$ 20.50^{\#}$ & $\$ 5855$ & 6 \\
\hline $\begin{array}{l}\hat{\imath} \text { (The Lightbulb Man, 2010) } \\
\text { (Fetchalamp, 2010) }\end{array}$ & \\
\hline \multicolumn{3}{|c|}{ Figure 91: Payback for CFL Replacement } \\
\hline
\end{tabular}

\footnotetext{
${ }^{15}$ OSRAM comparison chart (OSRAM, 2010, pp. 4 - 7 \& 12)
} 
The range provided by 'The Lightbulb Man' is $\$ 9.90$ for all lamp sizes and types, whereas the 'Fetchalamp' range cost alters depending on wattage and lamp type. The simple payback above is calculated by dividing the cost of purchase by the expected savings and rounding to the nearest month. Even with a doubling in the cost of lamps, exchanging the incandescent lamps to CFLs would have a payback of less than 6 months.

The life expectancy of the CFL lamp is also longer than the incandescent lamps. Typically an incandescent lamp is expected to last around 1000 hours (NZ Lighting, 2010) while the CFL can typically last for between 7,500 hours and 15,000 hours (OSRAM, 2010).

On average, each store is open for approximately 2,800 hours annually, so each incandescent lamp type would require replacement two to three times each year, while the equivalent CFL can be expected to be replaced only every two to five years. These cost savings have not been included in Figure 91.

\subsubsection{CHANGE MR-16 LAMP FOR ITS MORE EFFICIENT ALTERNATIVE}

Two higher efficiency MR-16 lamps are now available as direct replacements for the MR-16 dichroic reflector halogen.

The first is a variation on the existing technology, where changes in the lamp technology allow it to perform at higher temperatures producing more light for less input power. The OSRAM lighting Catalogue 2010 offers a $35 \mathrm{~W}$ replacement for the $50 \mathrm{~W}$ MR-16-a savings of $30 \%$ (OSRAM, 2010). This lamp will be referred to as the EE MR-16 (Energy Efficient).

The second type of technology uses the Light Emitting Diode (LED) lamp, which is advertised as consuming between 8 and 12 Watts to provide a similar lighting level to that provided by a 50W MR-16 lamp, resulting in energy savings up to $85 \%$. These will be referred to as LED MR-16 lamps.

There are 11 stores that have the 50 Watt MR-16 lamps installed, with a total of 200 lamps and 11,000 Watts used for either down lighting or as spotlights $-10 \%$ of the 105 $\mathrm{kW}$ overall lighting estimate (see Section 7.5). These consume approximately 29,500 $\mathrm{kWh}$ or $8 \%$ of the overall annual lighting energy use.

Replacing each $50 \mathrm{~W}$ MR-16 lamp with its $35 \mathrm{~W}$ energy efficient alternative lowers the installed load to 7,160 Watts - a saving of $4 \%$ of the total installed load and a $2 \%$ savings of the annual energy use, as shown in Figure 92. 


\begin{tabular}{|cccc|}
\hline $\begin{array}{c}\text { Optimised Maximum } \\
\text { Annual Lighting } \\
\text { Load }\end{array}$ & $\begin{array}{c}\text { Savings Due to } \\
\text { Energy Efficient MR- } \\
\mathbf{1 6}\end{array}$ & $\begin{array}{c}\text { Optimised load due to } \\
\text { Energy Efficient MR-16 }\end{array}$ & $\begin{array}{c}\text { Percentage of } \\
\text { Savings from } \\
\text { Annual Load }\end{array}$ \\
\hline $342,742 \mathrm{kWh} / \mathrm{yr}$ & $7,565 \mathrm{kWh} / \mathrm{yr}$ & $335,177 \mathrm{kWh} / \mathrm{yr}$ & $2 \%$ \\
\hline Daily Load kW & $\begin{array}{c}\text { Savings Due to } \\
\text { Energy Efficient MR- } \\
\mathbf{1 6}\end{array}$ & $\begin{array}{c}\text { Optimised load due to } \\
\text { Energy Efficient MR-16 }\end{array}$ & $\begin{array}{c}\text { Percentage of } \\
\text { Savings from } \\
\text { Daily Load }\end{array}$ \\
\hline $96 \mathrm{~kW}$ & $4 \mathrm{~kW}$ & $92 \mathrm{~kW}$ & $4 \%$ \\
\hline \multicolumn{4}{|c|}{ Figure 92: Possible Savings Due to Energy Efficient MR-16 Installation } \\
\hline
\end{tabular}

At $\$ 0.2148$ per $\mathrm{kWh} 7,565 \mathrm{kWh} / \mathrm{yr}$ gives an annual cost of $\$ 1,625$. The quality of lamp and expected life cycle can affect the unit price. The OSRAM IRC EE MR-16 has a life expectancy of 5,000 to 6,000 hours but is retailed at approximately $\$ 20$ per unit ${ }^{16}$ while the conventional MR-16 retails for around \$5 per unit (The Lightbulb Man, 2010) and has a life expectancy of 3,000 hours ${ }^{17}$.

\begin{tabular}{|ccc|}
\hline Price of Energy Efficient MR-16 & $\begin{array}{c}\text { Estimated Savings @ } \\
\mathbf{\$ 0 . 2 1 4 8} \text { per kWh }\end{array}$ & $\begin{array}{c}\text { Simple Payback in } \\
\text { Months }\end{array}$ \\
\hline$\$ 15$ & $\$ 1,625$ & 22 \\
\hline$\$ 20$ & $\$ 1,625$ & 30 \\
\hline Figure 93: Payback for OSRAM EE MR-16 Purchase (The Lightbulb Man, 2010) \\
\hline
\end{tabular}

At a unit cost of $\$ 20$ then the payback period will possibly exceed the expected life of the EE MR-16 lamp. At an average use of 2,800 hours a year, in 30 months the lamp would be used for approximately 7,000 hours which is greater than the 6,000 expected life. The EE MR-16 becomes viable when the lamp costs about $\$ 15$ giving a payback of approximately 22 months or 5,000 operating hours.

The newest technology for energy efficient lighting are LEDs - although using 8 to 12 Watt to provide a similar level of illuminance to a MR-16 provides the cost per unit range from $\$ 30$ to over $\$ 150$ (January 2011 prices from The Lightbulb man (The Lightbulb man, 2011))

The 12 Watt LED MR-16s provide 75\% savings compared to the 50 Watt MR-16 lamp. Figure 94 shows the potential levels of savings if the MR-16 lamps are replaced with the LED MR-16.

\footnotetext{
${ }^{16} 35 \mathrm{~W} 12 \mathrm{~V} 24^{\circ}$ IRC 5,000 hrs Mega Glass Covered identified on 10 March 2011, on the Lightbulb man Website (http://lightbulbman.co.nz/shop/P50021/35w-12v-24-irc-5-000-hrs-megaglass-covered) (The Lightbulb Man, 2011).

${ }_{17} 50 \mathrm{~W} 38^{\circ} 3,000 \mathrm{hrs}$ Open Aluminum Backed on the 10 March 2011 on the Lightbulb man Website (http://lightbulbman.co.nz/shop/P50042/50w-38-3-000-hrs-open-aluminum-backed) (The Lightbulb Man, 2011).
} 


\begin{tabular}{|cccc|}
\hline $\begin{array}{c}\text { Optimised Maximum } \\
\text { Annual Lighting } \\
\text { Load }\end{array}$ & $\begin{array}{c}\text { Savings Due to LED } \\
\text { MR-16 }\end{array}$ & $\begin{array}{c}\text { Optimised load due to } \\
\text { LED MR-16 }\end{array}$ & $\begin{array}{c}\text { Percentage of } \\
\text { Savings from } \\
\text { Annual Load }\end{array}$ \\
\hline $342,742 \mathrm{kWh} / \mathrm{yr}$ & $18,443 \mathrm{kWh} / \mathrm{yr}$ & $324,299 \mathrm{kWh} / \mathrm{yr}$ & $5 \%$ \\
\hline Daily Load kW & $\begin{array}{c}\text { Savings Due to LED } \\
\text { MR-16 }\end{array}$ & $\begin{array}{c}\text { Optimised load due to } \\
\text { LED MR-16 }\end{array}$ & $\begin{array}{c}\text { Percentage of } \\
\text { Savings from } \\
\text { Daily Load }\end{array}$ \\
\hline $96 \mathrm{~kW}$ & $9 \mathrm{~kW}$ & $87 \mathrm{~kW}$ & $9 \%$ \\
\hline \multicolumn{4}{r}{ Figure 94: Possible Savings Due to LED MR-16 Installation } \\
\hline
\end{tabular}

Figure 94 shows that the replacement of the MR-16 lamps by their LED MR-16 equivalent reduces the load by a further $9 \mathrm{~kW}$, giving annual energy savings of 18,443 $\mathrm{kWh}$ or $\$ 3,961$ for the year. Although the savings are more than double the EE MR-16 lamps, the calculation of the payback is not as simple.

If the lamp could be directly exchanged, then a 12 Watt LED MR-16 costing \$30 will have a simple payback of 18 months. However, in most cases they cannot be directly exchanged, even if they are the same design, due to the different voltage requirements. The $50 \mathrm{~W}$ MR-16's require a 12 Volt transformer, which is typically sized for 20 to 70 Watts (The Lightbulb Man, 2011). For it to operate correctly, without the risk of failure or damage, the load must be above 20 Watts and below 70 Watts which means it can supply only one 50 Watt lamp.

The LED MR-16s also require a 12 Volt transformer; but as the LED MR-16 is only 12 Watts, it is too small for most existing transformers (Lightbulb_Man, 2011). While multiple LED lamps may be connected to an existing MR-16 transformer; their combined wattage must be within the operating band 20 to 70 Watts (2 to 5 LED MR-16 lamps) of the transformer or a new LED transformer is required. This would suggest that new transformers are required to use LED MR-16 lamps, at a cost of about $\$ 60$ per unit (NZ Lighting, 2010), (The Lightbulb Man, 2010), increasing the payback to 54 months (excluding installation costs). LED MR-16 lamp packages that allow direct connection to the mains voltage cost about $\$ 40$ dollars per unit, depending on the fitting (The Lightbulb Man, 2010), giving a simple payback of around two years.

The LED MR-16 lamps have long life expectancy, with some manufacturers claiming up to 50,000 hours (OSRAM, 2010), (NZ Lighting, 2010) - up to 10 times the life of a MR16. This gives the LED MR-16 lamp lower replacement and maintenance costs. 


\subsubsection{REMAINING LAMPS}

The remaining lamps that could be replaced are the 100 and 500 Watt double ended linear halogen lamps that are used in five stores, giving a combined load of $6.5 \mathrm{~kW}$ consuming $17,121 \mathrm{kWh}$ per year.

Drop-in replacement bulbs that operate at a higher temperature and are more energy efficient are available. (OSRAM, 2010). The savings from these are given in Figure 95.

\begin{tabular}{|ccc|}
\hline Halogen Lamp & Energy Efficient Alternative & Savings \% \\
\hline $500 \mathrm{~W}$ & $400 \mathrm{~W}^{18}$ & $20 \%$ \\
\hline $100 \mathrm{~W}$ & $80 \mathrm{~W}^{19}$ & $20 \%$ \\
\hline Figure 95: Comparison of Energy Savings for Halogen Lamps. (OSRAM, 2010) \\
\hline
\end{tabular}

Figure 95 shows that savings of $20 \%$ may be realised by the use of the energy efficient bulb. The $6.5 \mathrm{~kW}$ load would reduced by $1.3 \mathrm{~kW}$, and energy use by $3,406 \mathrm{kWh} / \mathrm{year}$ as shown in Figure 96

\begin{tabular}{|cccc|}
\hline $\begin{array}{c}\text { Optimised } \\
\text { Maximum Annual } \\
\text { Lighting Load }\end{array}$ & $\begin{array}{c}\text { Savings Due to } \\
\text { Halogen Replacement }\end{array}$ & $\begin{array}{c}\text { Optimised load due to } \\
\text { Halogen Replacement }\end{array}$ & $\begin{array}{c}\text { Percentage of } \\
\text { Savings from } \\
\text { Annual Load }\end{array}$ \\
\hline $324,299 \mathrm{kWh} / \mathrm{yr}$ & $3,406 \mathrm{kWh} / \mathrm{yr}$ & $320,893 \mathrm{kWh} / \mathrm{yr}$ & $1 \%$ \\
\hline Daily Load kW & $\begin{array}{c}\text { Savings Due to } \\
\text { Halogen Replacement }\end{array}$ & $\begin{array}{c}\text { Optimised load due to } \\
\text { Halogen Replacement }\end{array}$ & $\begin{array}{c}\text { Percentage of } \\
\text { Savings from Daily } \\
\text { Load }\end{array}$ \\
\hline $87 \mathrm{~kW}$ & $1 \mathrm{~kW}$ & $85 \mathrm{~kW}$ & $1 \%$ \\
\hline Figure 96: Possible Savings Due to the Halogen Replacement Installation \\
\hline \multicolumn{2}{r}{}
\end{tabular}

Replacement of these lamps could occur as the existing lamps fail due to end of life, particularly as the 400 Watt IRC lamp cost about the same as the standard 500 Watt lamp at $\$ 5-\$ 10$ (The Lightbulb Man, 2010).

\subsubsection{OVERALL LAMP EXCHANGE SAVINGS}

The changes discussed in this section would result in 352 lamps being swapped for more energy efficient alternatives. The LED package replacement for MR-16 has been included as an energy saving recommendation, as it is expected that the existing fittings could take the package without too much modification. The metal halide to halogen

\footnotetext{
${ }^{18}$ The Philips 100plus double ended linear 500 Watt lamp has a lumen output of $9660 \mathrm{~lm}$ at 19 $1 \mathrm{~m} /$ watt (Philips, 2011). Replacing it with the 400 Watt IRC lamp from Osram reduces the lumen output to 9000 lumens but increases the output to $22.5 \mathrm{~lm} /$ watt (OSRAM, 2010, p. 2.15).

${ }^{19}$ The Philips PLUSLine Pro Compact 100W lamps produce $1550 \mathrm{~lm}$ at $15.5 \mathrm{~lm} / \mathrm{W}$ (Philips, 2011). Replacing with the 80 Watt OSRAM IRC reduces lumens to $1500 \mathrm{~lm}$ at $18.7 \mathrm{~lm} / \mathrm{W}$ (OSRAM, 2010, p. 2.15)
} 
exchange was not included as the luminaires would require complete replacement to provide the necessary control gear.

The total potential annual energy savings from these changes of would 49,107 $\mathrm{kWh}$ per year $(370,000 \mathrm{kWh} / \mathrm{yr}$ reduced to $320,893 \mathrm{kWh} / \mathrm{yr}$ ) reducing the peak load by $20 \mathrm{~kW}$ $(105 \mathrm{~kW}$ reduced to $85 \mathrm{~kW})$.

\subsection{DE-LAMPING}

De-lamping requires no initial capital outlay in order to make savings. De-lamping is only proposed in stores that use recessed troffer styled LFL's (see Appendix B for further information), as the audits found these often had three or four tubes installed. Depending on the activity, these lamps may be over illuminating the tasks (as discussed in Section 4.3) giving potential energy and power savings of up to $1 / 3$ - the removal of 1 out of 3 tubes. This recommendation addresses the store activity, the lux levels, the number and type of lamps.

Five stores have been identified as using multi-tube troffer luminaires, with 508 lamps giving a combined load of $23 \mathrm{~kW}$ and annual consumption of 67,893 kWh. Figure 97 sets out the savings from removing one lamp in each of the luminaires.

\begin{tabular}{|cccc|}
\hline $\begin{array}{c}\text { Optimised Maximum } \\
\text { Annual Lighting Load }\end{array}$ & $\begin{array}{c}\text { Savings Due to } \\
\text { De-lamping }\end{array}$ & $\begin{array}{c}\text { Optimised load due to } \\
\text { De-lamping }\end{array}$ & $\begin{array}{c}\text { Percentage of Savings } \\
\text { from Annual Load }\end{array}$ \\
\hline $320,893 \mathrm{kWh} / \mathrm{yr}$ & $20,300 \mathrm{kWh} / \mathrm{yr}$ & $300,593 \mathrm{kWh} / \mathrm{yr}$ & $5 \%$ \\
\hline Daily Load kW & $\begin{array}{c}\text { Savings Due to } \\
\text { De-lamping }\end{array}$ & $\begin{array}{c}\text { Optimised load due to } \\
\text { De-lamping }\end{array}$ & $\begin{array}{c}\text { Percentage of Savings } \\
\text { from Daily Load }\end{array}$ \\
\hline $85 \mathrm{~kW}$ & $7 \mathrm{~kW}$ & $78 \mathrm{~kW}$ & $8 \%$ \\
\hline \multicolumn{4}{r}{ Figure 97: Possible Savings Due to De-lamping } \\
\hline
\end{tabular}

As there is no expenditure (assuming the tubes are removed by store staff, or an electrician on another visit) on this recommendation, payback is immediate. Figure 97 shows savings of 20,300 kWh per year, reducing lighting energy use to $300,593 \mathrm{kWh}$ per year and the installed load to $78 \mathrm{~kW}$. The energy savings of $\$ 4,400$ per annum would start as soon as the lamps were removed.

The de-lamping has been recommended in these stores as they all average over 1,000 lux ambient lighting. The IESNA recommends for outlet and middle stores, the ambient light levels are between 300 - 1,000 lux (IESNA, 2000). De-lamping one tube from a multitube troffer should only reduce the lux levels by around a third, but once the recommendation has been carried out the lux levels need to be re-measured to ensure that all areas meet with the lighting levels recommended by the IESNA and AS/NZS 1680. Part 1: 2006, as discussed in Section 2.9. 


\subsection{TURN OVERNIGHT Lighting OFF}

Apart from the four stores that are not connected in any way to their neighbours, the rest are located under common verandas which have council provided, daylight controlled fluorescent lamps. During the hours of darkness, these lamps provide sufficient light onto the display window and into the store that internal lighting can be considered as waste.

Of the four identified stores that are not connected to their neighbours, only one uses overnight lighting. This store has not been included in the results shown in Figure 98.

Again this recommendation does not require any expenditure (beyond a small amount of normal management and staff time) to access the potential savings. In total, 33,960 $\mathrm{kWh} / \mathrm{yr}$ are used for overnight lighting at a cost of $\$ 7,300 / \mathrm{yr}$.

\begin{tabular}{|cccc|}
\hline $\begin{array}{c}\text { Optimised Maximum } \\
\text { Annual Lighting } \\
\text { Load }\end{array}$ & $\begin{array}{c}\text { Savings Due to } \\
\text { Switching off the } \\
\text { overnight lighting }\end{array}$ & $\begin{array}{c}\text { Optimised load due to } \\
\text { Switching off the } \\
\text { overnight lighting }\end{array}$ & $\begin{array}{c}\text { Percentage of } \\
\text { Savings from } \\
\text { Annual Load }\end{array}$ \\
\hline $300,593 \mathrm{kWh} / \mathrm{yr}$ & $33,960 \mathrm{kWh} / \mathrm{yr}$ & $266,633 \mathrm{kWh} / \mathrm{yr}$ & $9 \%$ \\
\hline Daily Load kW & $\begin{array}{c}\text { Savings Due to } \\
\text { Switching off the } \\
\text { overnight lighting }\end{array}$ & $\begin{array}{c}\text { Optimised load due } \\
\text { Switching off the } \\
\text { overnight lighting }\end{array}$ & $\begin{array}{c}\text { Percentage of } \\
\text { Savings from } \\
\text { Daily Load }\end{array}$ \\
\hline $78 \mathrm{~kW}$ & $0 \mathrm{~kW}$ & $0 \mathrm{~kW}$ & $0 \%$ \\
\hline \multicolumn{2}{|c|}{ Figure 98: Possible Savings Due to Switching off the overnight lighting } \\
\hline
\end{tabular}

As these lights are used during the day to illuminate the display window, removing the overnight lighting load from the annual maximum lighting load further reduces the overall consumption to $266,633 \mathrm{kWh} / \mathrm{yr}$, but the installed daily load is unchanged as these lamps are still used during the day.

\subsection{SwITCH OfF UNUSED LAMPS}

The last recommendation involves switching off lamps in infrequently occupied rooms and spaces such as the stock and utility areas. If all of the above recommendations are implemented the stock and utility spaces will use only energy efficient lighting, so the next step is to ensure lights are only being used as required. This may be as simple as a management instruction to staff to be aware of the lighting and to switch it off when it is not required e.g. when high levels of daylight are available. However, the audits and discussions (see Appendix F) identified that although some stores had trialled switching unused lights off they had found that even in unused spaces it was not suitable for their operations.

If the lamps that are used in the stock/utility areas were able to be permanently switched off the savings would be approximately $20,000 \mathrm{kWh} / \mathrm{yr}$ or $\$ 4,296 / \mathrm{yr}$. As these lights are located in areas of the store used by staff, the alternative is to install occupancy sensors. 
The rate of occupancy of these seldom used spaces was not monitored, but it is estimated they would be occupied for around $10 \%$ of the standard week. If these lights were able to be switched off for the remaining $90 \%$ of the week then there is a potential to save around $18,300 \mathrm{kWh}$ annually as shown in Figure 99 . The installed daily $\mathrm{kW}$ would not reduce as these lamps would still be installed and operated during the year.

\begin{tabular}{|cccc|}
\hline $\begin{array}{c}\text { Optimised Maximum } \\
\text { Annual Lighting Load }\end{array}$ & $\begin{array}{c}\text { Savings Due to } \\
\text { Switching }\end{array}$ & $\begin{array}{c}\text { Optimised load due to } \\
\text { Switching }\end{array}$ & $\begin{array}{c}\text { Percentage of Savings } \\
\text { from Annual Load }\end{array}$ \\
\hline $266,633 \mathrm{kWh} / \mathrm{yr}$ & $18,312 \mathrm{kWh} / \mathrm{yr}$ & $248,321 \mathrm{kWh} / \mathrm{yr}$ & $5 \%$ \\
\hline Daily Load kW & $\begin{array}{c}\text { Savings Due to } \\
\text { Switching }\end{array}$ & $\begin{array}{c}\text { Optimised load due to } \\
\text { Switching }\end{array}$ & $\begin{array}{c}\text { Percentage of Savings } \\
\text { from Daily Load }\end{array}$ \\
\hline $78 \mathrm{~kW}$ & $0 \mathrm{~kW}$ & $0 \mathrm{~kW}$ & $0 \%$ \\
\hline Figure 99: Possible Savings Due to Switching Unused Lamps 'OFF" \\
\hline
\end{tabular}

Following all of the above recommendations, the maximum annual lighting energy use for the Otaki retail strip would be reduced to $248,321 \mathrm{kWh}$ per year - $67 \%$ of the original energy use. The peak load would also be reduced, and would be $78 \mathrm{~kW}-74 \%$ of the original peak daily load.

\subsection{DAYLiGHT HARVESTING}

Natural light can be effectively harvested and brought inside the store in order to provide free illumination with no running costs.

'Daylight', for the purpose of this study, is all lighting derived from the sun, excluding the direct component which is identified separately as 'sunlight'. As discussed in Section 3.5 , direct sunlight is undesirable in retail stores as the resulting glare causes security and product appraisal issues, and it is a major factor in product degradation in fashion and food stores.

The most obvious means of introducing daylight into a store is through the main display window. These windows are all full height and are generally $80-90 \%$ of the wall area facing State Highway One - east or west facing depending on the side of the street. To assess how these openings impact on the overall lighting within a store, the two fashion examples from Appendix E and Appendix F will be examined using some basic 'rules of thumb'. 
The following calculations are used to calculate the depth that daylight may penetrate into a store. Figure 100 gives the limiting depth for daylight access based on the width of the room the height of the window and the reflectance of the surfaces in the space.

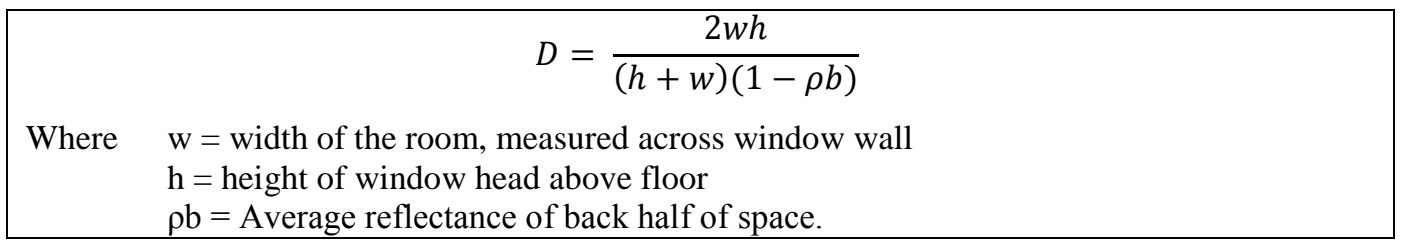

Figure 100: The Limiting Depth Rule (Otis \& Reinhart, 2009)

The calculation in Figure 100 does not consider any exterior obstructions such as overhangs or other buildings. For the average reflection of the back half of the space $(\rho b)$ the recommended average of 0.5 from the New Zealand Building Code Clause G8 on calculating the interior reflectance will be used (Department of Building and Housing, 2001). Applying this calculation to the two example buildings:

- The boutique store (Appendix E) with a 95\% glazed front wall, the window three metres wide by three metres high will allow daylight to penetrate the space up to six metres.

- The outlet store (Appendix F) with a fully glazed front wall at nine metres wide by three metres high, will allow daylight through to nine metres in depth.

These depths can be considered as best case, as the calculation gives the maximum depth that daylight may penetrate if the window is unobstructed.

The depth rule in Figure 101 considers the height of the work plane and the amount of visible sky that the window is exposed to.

$$
D=(h-\text { workplane height }) x \tan \theta
$$

Where $\mathrm{h}=$ height of window head above floor

Work plane height $=$ height of the displays

$\operatorname{Tan} \theta=$ vertical angle of visible sky

Figure 101: The No-Skyline Limiting Depth Rule (Otis \& Reinhart, 2009) 
Because both stores have window overhangs and buildings opposite, the calculation in Figure 101 calculates the limiting depth based on the window height, the work plane and the amount of 'sky' that is visible to the store.
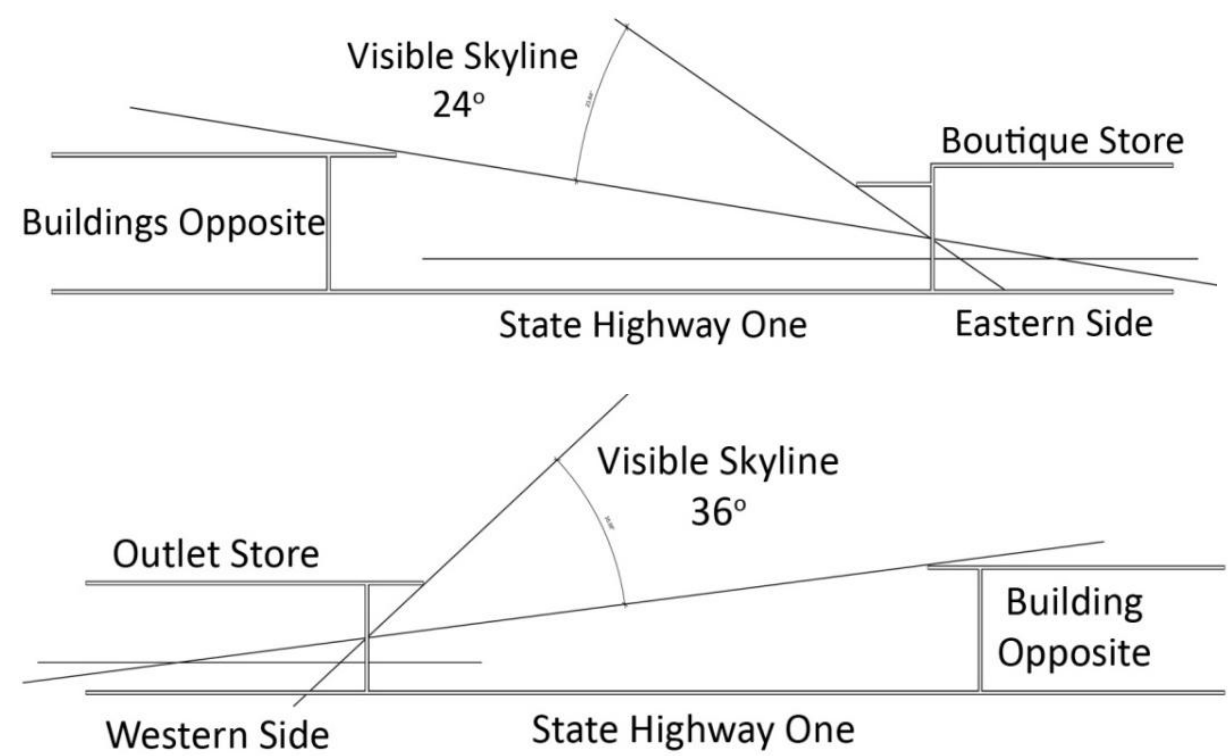

Figure 102: Visible Skyline in the Boutique Store and Outlet Store

Figure 102 shows the visible angle that each store has after allowing for overhangs and buildings opposite. Using the calculation in Figure 101, the boutique store has usable daylight penetration to $0.9 \mathrm{~m}$ and the outlet store to $1.5 \mathrm{~m}$. It should be noted that this calculation identifies the usable depth of daylight that can effectively offset the artificial lighting within the store. Usable daylighting has been defined as being between 2 and 5\% of the external daylight illuminance (Otis \& Reinhart, 2009).

In both stores, the calculated distance is only just beyond the window display area, and would be further limited by the stock placement in these areas. The boutique store also uses blinds to limit the late afternoon sunlight, effectively removing the possibility of any daylighting through that window.

These conflicting needs, and the limited depth in the store in which daylight is available, mean the display window is not a viable means to supply daylight into the store.

Another approach would be to insert windows or skylights into the roof. Although this allows daylight into the rear of the space, it will also admit sunlight which is undesirable for many of the stores. To prevent this, the skylights could be tinted, frosted to produce an opaque light or oriented to the south. The insertion of skylights would require the redesign of the roof, additional construction and possible modification of the lighting 
systems so is considered to be outside of the scope of the study and will not be further investigated.

A commercial product that allows light to be delivered through the roof without concern for the admission of direct sunlight is the solar tube. This device penetrates the roof, providing a diffuse light to the space and excluding sunlight and hence related issues such as UV (Ultra Violet) and summertime overheating. Figure 103 shows the spacing for each unit.

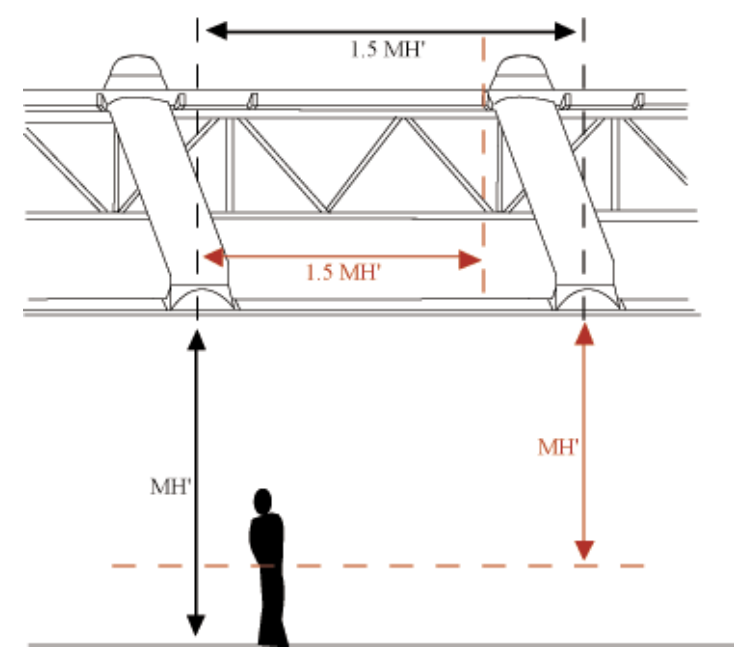

MH - Mounting Height of the diffuser above the working plane or floor (Solatube, 2010)

Spacing Criteria for Open Plan Areas with ceilings (Solatube, 2010)

From Wall: $\quad$ Spacing $\geq 0.5 \times \mathrm{MH}(1.0 \times \mathrm{MH}=$ Maximum $)$

Unit Spacing: $1.0 \mathrm{xMH}<$ Spacing < 1.3xMH(Maximum Spacing = 1.5xMH )

Figure 103: Spacing Criteria for the Solar Tube (Solatube, 2010)

Solar tubes only provide an effective offset of the ambient light levels as they produce a diffuse light and not a direct 'spot'. This diffuse light could offset the installed ambient lighting systems in all of the stores. The retail area ambient lighting load only has been calculated to be $50 \mathrm{~kW}$ of the installed load and consume $146,060 \mathrm{kWh}$ per year.

Without simulation it is difficult to accurately gauge the impact on ambient light levels and possible energy savings, as the amount of light transmitted into the space is dependent on the exterior light levels. An estimate can be made of the availability of sunlight. Figure 104 shows the sunshine hours for the last three years from Paraparaumu airport, located to the south of Otaki.

The three year average shows that the sunshine hours vary widely, with the summer monthly average in January of 232 hours and the winter monthly average in June of just 95 hours. By dividing the average hours by the number of days in each month, a daily 
average can be created. In January there are on average 7.5 hours per day of sunlight, but in June the average is 3.2 hours. Over the year, the average is 5.3 sunshine hours per day.

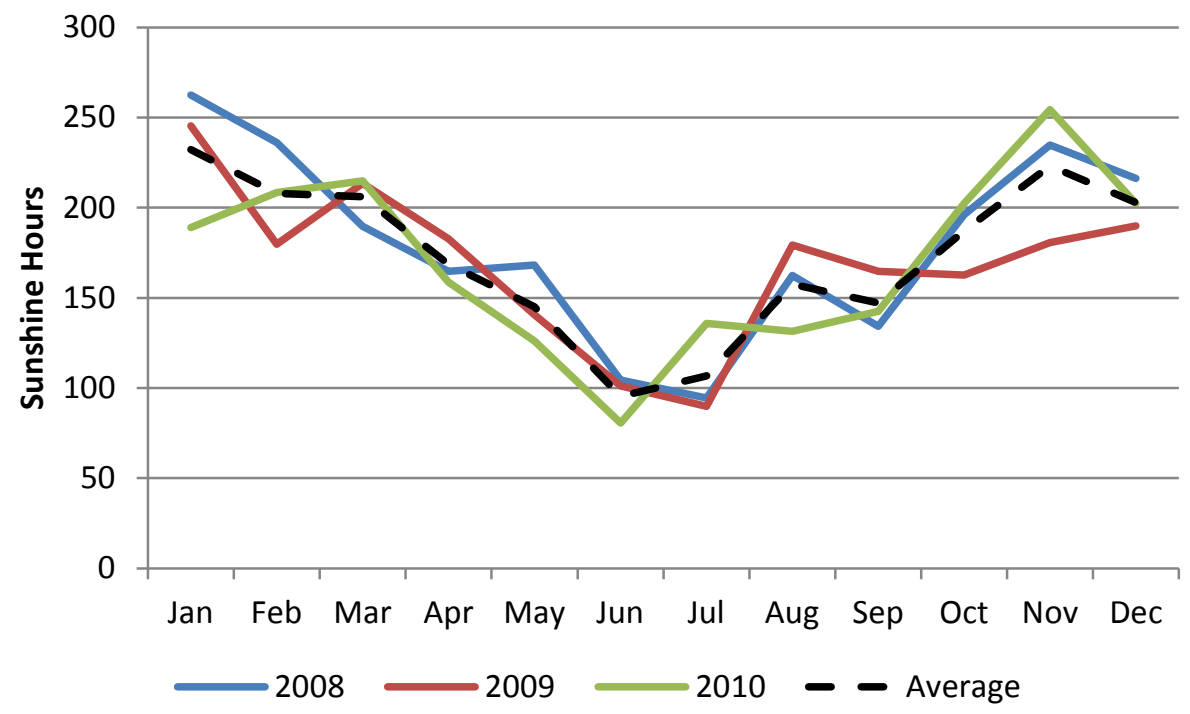

Figure 104: Sunshine hours for Paraparaumu Airport (NIWA, 2011)

Figure 105 shows savings from using daylight to offset the ambient lighting. The number of trading days has been developed from Section 6.2 and the Department of Labour (Department of Labour, 2011).

\begin{tabular}{|ccccr|}
\hline $\begin{array}{l}\text { Retail Ambient } \\
\text { Lighting Load }\end{array}$ & $\begin{array}{l}\text { Average } \\
\text { Sunshine Hours }\end{array}$ & $\begin{array}{l}\text { Potential Daily } \\
\text { Load Offset }\end{array}$ & $\begin{array}{l}\text { Nominal Number of } \\
\text { Trading Days/Year }\end{array}$ & Annual Savings \\
\hline $50 \mathrm{~kW}$ & 3 (June) & $150 \mathrm{kWh}$ & 361.5 & $54,225 \mathrm{kWh}$ \\
\hline $50 \mathrm{~kW}$ & 5 (Year) & $250 \mathrm{kWh}$ & 361.5 & $90,375 \mathrm{kWh}$ \\
\hline $50 \mathrm{~kW}$ & 7 (January) & $350 \mathrm{kWh}$ & 361.5 \\
\hline \multicolumn{5}{c}{ Figure 105: Load Offset due to Sunlight Hours. } \\
\hline
\end{tabular}

At an average of five hours a day, daylight will offset the ambient load by $90,375 \mathrm{kWh}$ per year, giving cost savings of $\$ 19,332$. Even with seasonal variations, the solar tubes should provide light even during periods of low daylight such as high cloud cover or the early evening. Automated controls of the ambient light system would provide a seamless integration between the artificial and natural light. As this would require significant additional work, the use of solar tubes was deemed to be beyond the scope of this study that is looking at offsetting the load without altering the original design intent.

\subsection{OVERALL}

If all the savings opportunities identified in this chapter are implemented then, 121,679 $\mathrm{kWh} / \mathrm{yr}$ can be saved, or $\$ 26,136 / \mathrm{yr}$ at $\$ 0.21$ per $\mathrm{kWh}$. This has the effect of reducing the 
estimated overall load from approximately $370,000 \mathrm{kWh} / \mathrm{yr}$ of electrical energy down to $248,321 \mathrm{kWh}$ per year. As some of the opportunities involve lamp replacement and removal, the load would be reduced from $105 \mathrm{~kW}$ to $77 \mathrm{~kW}$. The effect of this would be to improve the opportunities for the use of renewable electricity generation to meet the lighting needs of the Otaki shops. 


\section{LOAD OFFSETTING}

This chapter examines the opportunities and possibilities for the retail lighting energy load of $248,321 \mathrm{kWh}$ per year to be supplied from renewable sources. It will explore the range of possible systems based on currently available technologies and policies. It should be noted that this lighting load is based on the lower electricity use and power demand of the optimised lighting systems, rather than the currently installed systems.

The renewable resources that will be considered are: solar radiation; wind; and hydro. The necessary time-series climate data has been collected and made available by NIWA (NIWA, 2011). For the purposes of this research, either long-run average data or appropriate recent data have been used.

\subsection{SOlAR POWER - PhOTOVOLTAICS}

Photovoltaic cells (PV) use the radiation from the sun to create electricity (EECA, 2009), so are only able to produce electricity when the sun is visible - daylight hours. They do not store energy, so must either feed a load which provides its own storage, or be connected to some other suitable storage which could be the main electric grid or near-by batteries (Hoskins \& BRANZ, 2009).

The load profile for the retail strip has a period of maximum occupancy between 9:00am and 5:30pm (see Section 6.11) which suggests that PV should offer a good match for onsite electricity generation.

Research has shown that New Zealand has an excellent solar power potential (Liley, Bodeker, \& Tait, 2005). Over the last ten years the average solar global radiation at Paraparaumu Airport, the nearest solar radiation weather station to Otaki, has been 1,420 $\mathrm{kWh} / \mathrm{m}^{2} / \mathrm{yr}$ (NIWA, 2011).

Unsurprisingly, higher levels of solar radiation are available during the summer months, as shown in Figure 106. The $1,420 \mathrm{kWh} / \mathrm{m}^{2} / \mathrm{yr}$ average at Paraparaumu compares favourably to the $1,497 \mathrm{kWh} / \mathrm{m}^{2} / \mathrm{yr}$ in Gisborne, $1360 \mathrm{kWh} / \mathrm{m}^{2} / \mathrm{yr}$ in Christchurch and $1292 \mathrm{kWh} / \mathrm{m} 2 / \mathrm{yr}$ in Invercargill (EECA, 2001). 


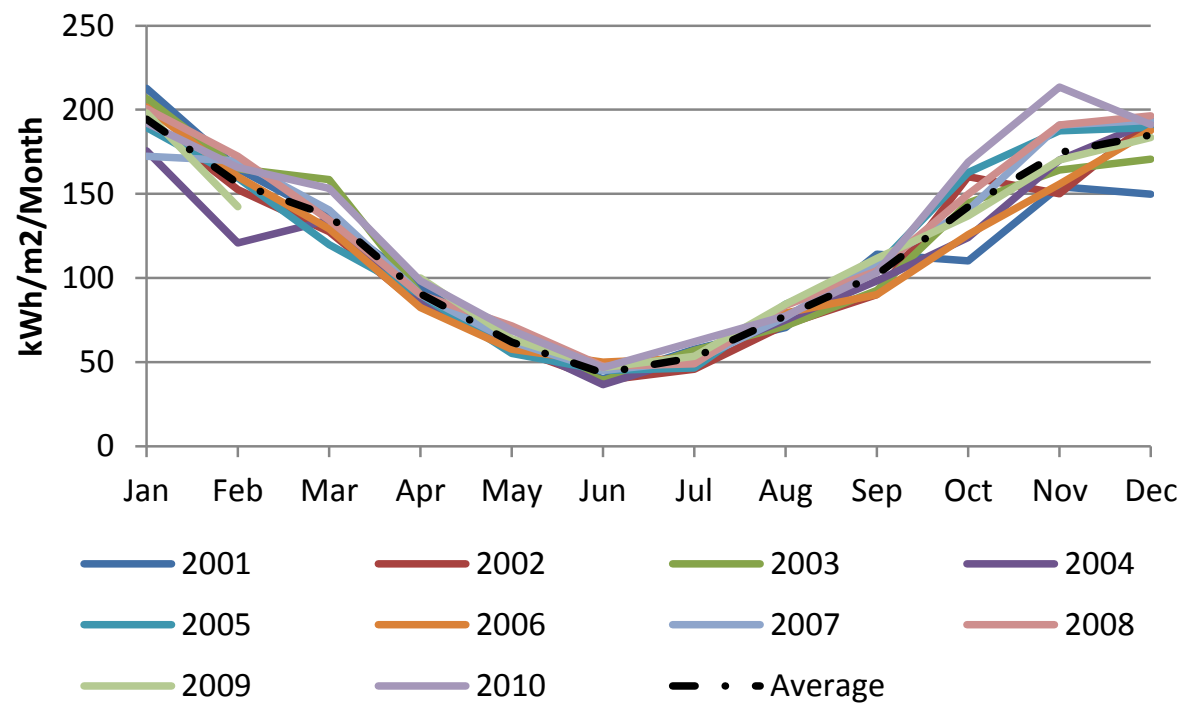

Figure 106: Paraparaumu Solar Radiation by Month (NIWA, 2011)

Figure 106 shows that while the available solar radiation varies over the year, the monthly radiation is fairly constant year to year. The seasonal variation is significant, with the lowest month in winter (June) with solar radiation just one third of the maximum recorded summer (January).

A simple calculator developed by the US National Renewable Energy Laboratory (NREL) has been used to estimate the generation from PV. The NREL PVWatt calculator uses weather files to estimate the available radiation and generation capabilities of a selected PV array for the selected location (NREL, 2010).

The closest city to Otaki with a PVWatt weather file is Wellington. NIWA have identified that solar radiation in the greater Wellington region is not expected to vary to any great degree (Liley, Bodeker, \& Tait, 2005), therefore the Wellington weather file has been used to represent Otaki.

It was decided in order to assess the importance of the location, the calculator would be used for three centres (Auckland, Wellington and Christchurch), as shown in Figure 107. 


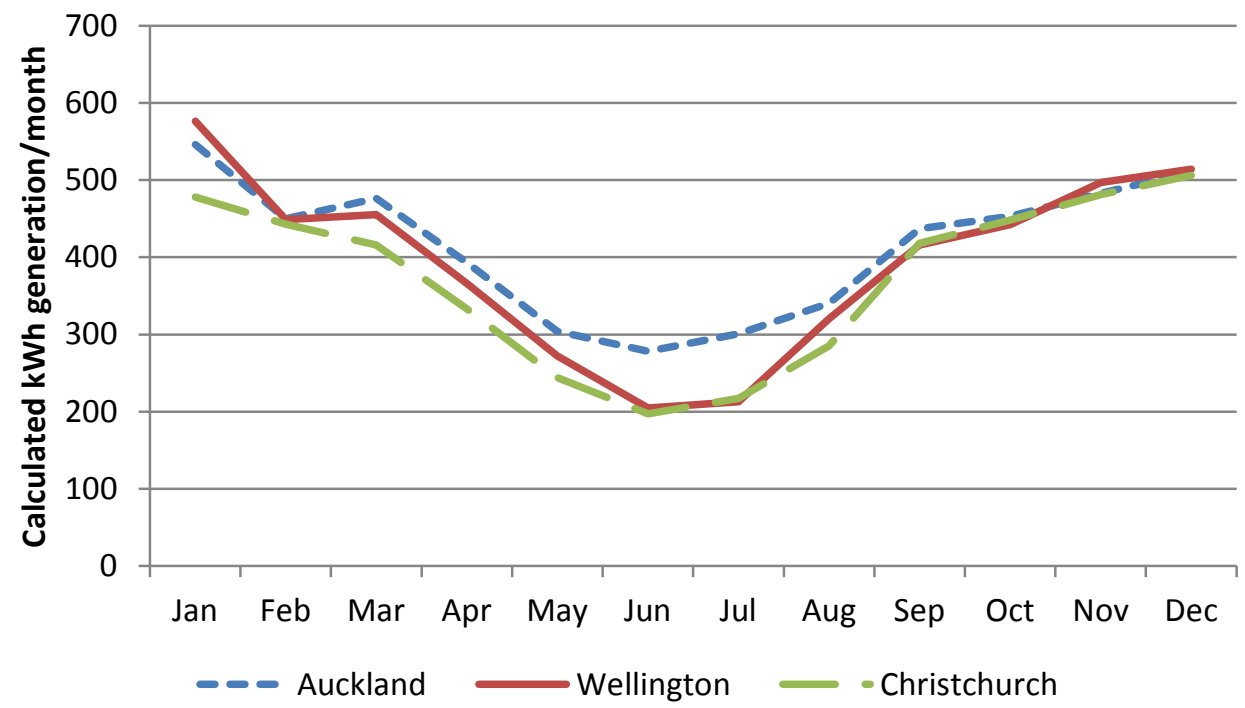

Figure 107: NREL Calculator Results for PV Generation (3 Main Centres)

Figure 107 shows the results using the NREL calculator default settings (4 kW PV array of $35 \mathrm{~m}^{2}$ area, tilted at the location's latitude for optimum generation potential). In Wellington this angle of latitude is approximately $41^{\circ}$. (Liley, Bodeker, \& Tait, 2005). Auckland is $36^{\circ}$ and Christchurch $43^{\circ}$. (Maps of the World, No Date) The monthly generation is similar for the three cities, except during the Auckland winter where the higher levels of solar radiation result in higher generation.

PVWatt, using the default values, calculates each $4 \mathrm{~kW}$ array will generate $4,724 \mathrm{kWh} / \mathrm{yr}$. The overall lighting load for the 33 stores is around $250,000 \mathrm{kWh} /$ year, requiring 53 $4 \mathrm{~kW}$ arrays which would cover $1,885 \mathrm{~m}^{2}$ of roof area.

As discussed in Section 6.1, the floor area for the 33 stores is 5,600 $\mathrm{m}^{2}$, which can also be assumed to be the roof area - thus the 53 PV arrays would cover about one third of the roof area.

Figure 108 shows the calculated lighting load (dotted line) and the PVWatt calculated monthly generation for $534 \mathrm{~kW}$ PV arrays. For 7 months (September to March) the PV generation is at least equal to the lighting energy use but for the remaining 5 months (April to August) the generation is insufficient, so additional electricity is required. 


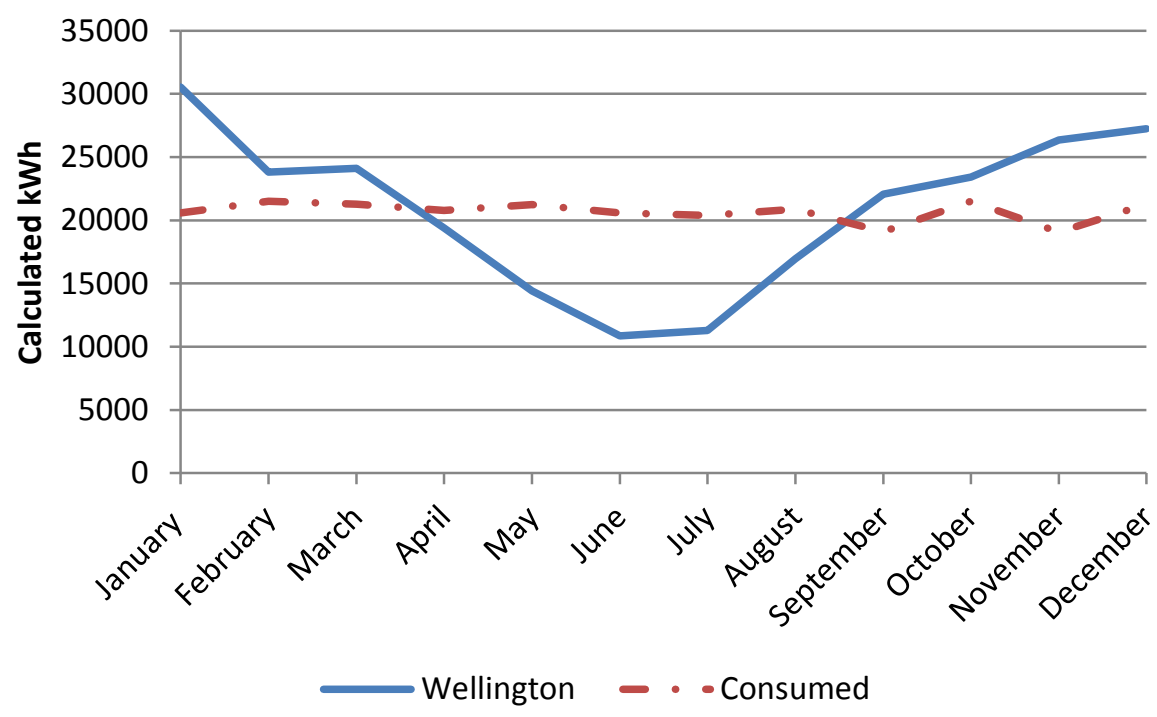

Figure 108: Monthly Comparison of the Calculated PV Generation and Consumption

One approach to meeting this winter deficit would be to use the extra summer generation, either additional PV, on site battery storage or by using the national grid. The use of additional PV is discussed in section 9.1.5.

The cost of battery storage would be high. For example, the Cellpower Website (www.cellpower.co.nz, $9^{\text {th }}$ March 2011) gave the price of a $2.4 \mathrm{~kW}$ off grid system with batteries as $\$ 57,500$ or $\$ 23.96$ per watt. This option has not been further explored.

To use the national electricity grid, the excess generation would be 'bought back' at an agreed price and then the deficit would be supplied during the low PV generation months. At the time of writing (March 2011), few energy suppliers were offering 'buy back' for onsite generation.

Energy Online ${ }^{20}$, suppliers to $48 \%$ of the audited stores, does not 'buy back' energy. Contact Energy ${ }^{21}$ and Genesis Energy ${ }^{22}$ have implemented a 'Distributed Grid' system, where residential customers can install generation technologies up to $10 \mathrm{~kW}$ and sell any surplus electrical generation. At present both companies deal with commercial generation on a case-by-case basis and have no general set of rules. Genesis Energy did indicate that small commercial generation under $10 \mathrm{~kW}$ would most likely be subject to the same

\footnotetext{
${ }^{20}$ Energy Online, 0800086400 (02 March 2011)

${ }^{21}$ Contact Customer Service, 0800809000 , (01 March 2011)

${ }^{22}$ Genesis Energy Contact Centre 0800600 900, (03 March 2011)
} 
'rules' as a residential customer. Therefore for the purposes of this study the residential buy-back schemes will be used.

The 2009 report Assessment of the future costs and performance of solar photovoltaic technologies in New Zealand (Watt, 2009) identified that energy retailers have no obligation to purchase electricity from the customer; there are no pricing principles to ensure fair pricing if they do; and to further limit choice their customers must deal exclusively with the energy retailer as they cannot access the wholesale electricity market. This situation is still the case in March 2011.

At present both Contact Energy and Genesis Energy will purchase any excess generation at the current wholesale rate, which is substantially lower than the retail rate paid by the Otaki businesses $^{22}$. Thus any surplus generation would be sold at a lower price than would be paid for electricity required to make up any deficit.

Figure 109 shows the monthly average spot or wholesale electricity prices for last (2010) year. While not strictly spot prices, which are determined half hourly, they provide an insight into the possible 'buy back' levels offered by the energy retailers for any surplus PV generated electricity.

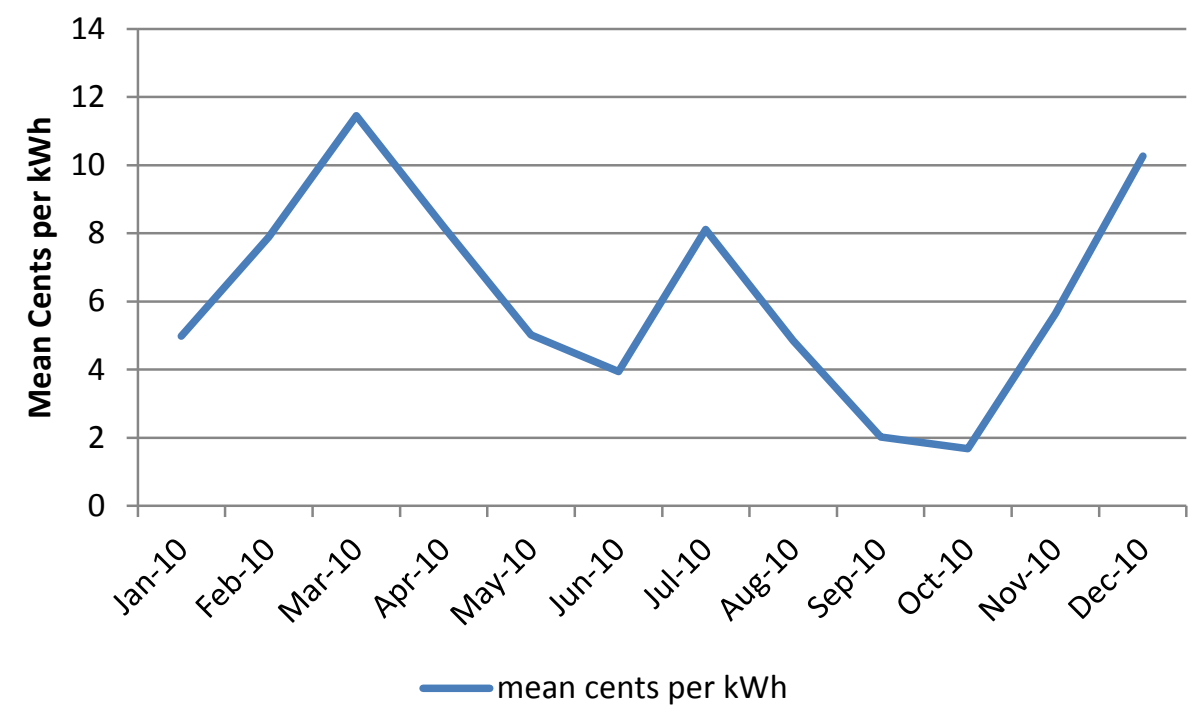

Figure 109: Wholesale Market Prices for 2010 (Electricity Authority, 2010)

The following three scenarios explore the use of the PV generation, based on $534 \mathrm{~kW}$ panels, to meet the optimised lighting load developed in Chapter 8. 


\subsubsection{SCENARIO 1: NET METERING}

Net Metering allows electricity to flow in both directions (into the site from the national grid and out from the site into the national grid) with payment made for the difference between generation and consumption. Figure 110 shows the calculated monthly PV generation, the calculated consumption and the difference (net) between the two. This totals at the end of the year to show a surplus from the PV generation.

\begin{tabular}{|lccc|}
\hline & Generated kWh & Consumed kWh & Difference kWh \\
\hline Jan & 30,528 & 20,581 & 9,947 \\
\hline Feb & 23,797 & 21,529 & 2,268 \\
\hline Mar & 24,115 & 21,270 & 2,845 \\
\hline Apr & 19,398 & 20,801 & $-1,403$ \\
\hline May & 14,416 & 21,262 & $-6,846$ \\
\hline Jun & 10,865 & 20,589 & $-9,724$ \\
\hline Jul & 11,289 & 20,407 & $-9,118$ \\
\hline Aug & 16,960 & 20,876 & $-3,916$ \\
\hline Sep & 22,048 & 19,126 & 2,922 \\
\hline Oct & 23,426 & 21,529 & 1,897 \\
\hline Nov & 26,341 & 19,081 & 7,260 \\
\hline Dec & 27,242 & 21,270 & 5,972 \\
\hline \multicolumn{4}{|}{} \\
\hline Totals & 250,425 & 248,321 & 2,104 \\
\hline Figure 110: Net Metering - Generated kWh Versus Consumed kWh \\
\hline
\end{tabular}

Figure 110 suggest that with net metering the $53,4 \mathrm{~kW}$ PV arrays will meet the lighting energy load over the year, providing a net surplus of 2,104 kWh.

Present electricity industry rules do not include allowance for 'Net Metering'. Genesis Energy anticipates that the process of net metering will not be used in the future due to grid load reconciliation and billing and cost issues (Genesis Energy, 2010). 


\subsubsection{SCENARIO 2: BUY AND SELL}

This scenario looks at a grid tied system that does not directly use the on-site generated electricity. This scenario has the site purchasing all of its electricity from the grid at the retail price and selling all of its generation into the grid at the wholesale price.

\begin{tabular}{|c|c|c|c|c|c|c|c|}
\hline Month & $\begin{array}{c}\text { kWh } \\
\text { Lighting } \\
\text { Consumption }\end{array}$ & $\begin{array}{r}\text { Retail } \\
\text { Price } \\
\text { Cents/ } \\
\mathbf{k W h}^{23}\end{array}$ & $\begin{array}{r}\text { Purchase } \\
\text { all } \\
\$\end{array}$ & $\begin{array}{r}\mathrm{kWh} \\
\underset{24}{\text { Generated }}\end{array}$ & $\begin{array}{r}\text { Wholesale } \\
\text { mean } \\
\text { cents/ } \\
\mathbf{k W h}^{25} \\
\end{array}$ & $\begin{array}{r}\text { sell all } \\
\$\end{array}$ & $\begin{array}{r}\text { difference } \\
\$\end{array}$ \\
\hline Jan-10 & 20,581 & 22 & 4,528 & 30,528 & 4.979 & 1,520 & 3,015 \\
\hline Feb-10 & 21,529 & 22 & 4,736 & 23,797 & 7.887 & 1,877 & 2,870 \\
\hline Mar-10 & 21,270 & 23 & 4,892 & 24,115 & 11.446 & 2,760 & 1,962 \\
\hline Apr-10 & 20,801 & 23 & 4,784 & 19,398 & 8.195 & 1,590 & 3,071 \\
\hline $\begin{array}{l}\text { May- } \\
10 \\
\end{array}$ & 21,262 & 23 & 4,890 & 14,416 & 5.023 & 724 & 4,042 \\
\hline Jun-10 & 20,589 & 23 & 4,736 & 10,865 & 3.946 & 429 & 4,184 \\
\hline Jul-10 & 20,407 & 23 & 4,694 & 11,289 & 8.106 & 915 & 3,697 \\
\hline Aug-10 & 20,876 & 23 & 4,801 & 16,960 & 4.849 & 822 & 3,898 \\
\hline Sep-10 & 19,126 & 23 & 4,399 & 22,048 & 2.027 & 447 & 3,871 \\
\hline Oct-10 & 21,529 & 24 & 5,167 & 23,426 & 1.68 & 394 & 4,648 \\
\hline Nov-10 & 19,081 & 24 & 4,579 & 26,341 & 5.646 & 1,487 & 2,972 \\
\hline Dec-10 & 21,270 & 24 & 5,105 & 27,242 & 10.269 & 2,797 & 2,183 \\
\hline Totals & & & $\$ 57,312$ & & & $\$ 15,762$ & $\$ 41,550$ \\
\hline
\end{tabular}

Figure 111 shows that purchase of the required $248,321 \mathrm{kWh}$ from the grid would cost $\$ 57,312 / \mathrm{yr}$, while the sale of the $250,425 \mathrm{kWh}$ generated on site would give income of $\$ 15,762$, resulting in a deficit of $\$ 41,550 / \mathrm{yr}$ even though the on-site generation was 2,104 $\mathrm{kWh}$ more than used. It should be noted this analysis does not include any tax on the sales income which would further increase the deficit.

\footnotetext{
${ }^{23}$ Retail price generated from 2010 retail market average for Energy Suppliers represented along the retail strip (Consumer.Power Switch, 2011)

${ }^{24}$ PV generation as calculated by NREL PVWatt calculator, scaled up to $53-4 \mathrm{~kW}$ arrays (NREL, 2010)

${ }^{25}$ Monthly average of Wholesale spot pricing (Electricity Authority, 2010)
} 


\subsubsection{SCENARIO 3: PURCHASE AS REQUIRED AND SELL AS REQUIRED.}

Scenario 3 is similar to Scenario 2, except that all of the on-site generated electricity is used on-site and the over generation is sold in order to pay for purchases during periods of under generation. The purchase and sale prices remain the same, as can be seen in Figure 112

\begin{tabular}{|c|c|c|c|c|c|c|c|c|}
\hline Month & $\begin{array}{c}\text { kWh } \\
\text { Consumed }\end{array}$ & $\begin{array}{c}\text { kWh } \\
\text { Generated }\end{array}$ & $\begin{array}{c}\text { Over } \\
\text { Generated }\end{array}$ & $\begin{array}{c}\text { Wholesale } \\
\text { c/kWh }\end{array}$ & $\begin{array}{c}\text { Sell } \\
\$\end{array}$ & $\begin{array}{c}\text { Under } \\
\text { Generated }\end{array}$ & $\begin{array}{l}\text { Retail } \\
\text { c/kWh }\end{array}$ & $\begin{array}{c}\text { Purchase } \\
\$\end{array}$ \\
\hline Jan-10 & 20,581 & 30,528 & 9,947 & 5 & 497 & - & - & - \\
\hline Feb-10 & 21,529 & 23,797 & 2,268 & 8 & 181 & - & - & - \\
\hline Mar-10 & 21,270 & 24,115 & 2,845 & 11 & 313 & - & - & - \\
\hline Apr-10 & 20,801 & 19,398 & - & - & - & 1,403 & 23 & 323 \\
\hline May-10 & 21,262 & 14,416 & - & - & - & 6,846 & 23 & 1,575 \\
\hline Jun-10 & 20,589 & 10,865 & - & - & - & 9,724 & 23 & 2,237 \\
\hline Jul-10 & 20,407 & 11,289 & - & - & - & 9,118 & 23 & 2,097 \\
\hline Aug-10 & 20,876 & 16,960 & - & - & - & 3,916 & 23 & 901 \\
\hline Sep-10 & 19,126 & 22,048 & 2,922 & 2 & 58 & - & - & - \\
\hline Oct-10 & 21,529 & 23,426 & 1,897 & 2 & 38 & - & - & - \\
\hline Nov-10 & 19,081 & 26,341 & 7,260 & 6 & 436 & - & - & - \\
\hline Dec-10 & 21,270 & 27,242 & 5,972 & 10 & 597 & - & - & - \\
\hline Totals NZ\$ & & & & & 2,121 & & & $\$ 7,132$ \\
\hline Total kWh & & & 33,111 & & & 31,007 & & \\
\hline
\end{tabular}

Even if all the on-site generated electricity was used it would still be necessary to purchase $\$ 5,011$ worth of electricity at $\$ 0.23(\$ 7,132-\$ 2,121)$ or generate a further $31,007 \mathrm{kWh}$ during the winter months. In this scenario, appropriate taxes would also need to be paid on the income stream from the generation.

Figure 112 suggests that at the current retail rate, assuming no tax on sales, the annual savings would be $\$ 57,312$ ('Purchase All' column in Figure 111). The benefit of Scenario 3 over Scenario 2 is that the taxable income is just $\$ 2,121$ as opposed to $\$ 15,762$. 


\subsubsection{DISCUSSION}

Scenario 1 shows that a PV system of 53 by $4 \mathrm{~kW}$ arrays can generate enough electricity over the year to meet the needs of the 33 stores. The net result of $\mathrm{kWh}$ generated to $\mathrm{kWh}$ consumed is a surplus of approximately $2,100 \mathrm{kWh}$, but there will be a summer surplus and a winter deficit.

Scenario 2 shows that selling all the generated electricity to the grid and purchasing all electricity requirements will cost $\$ 41,500$ a year to purchase the deficit energy, ignoring any tax issues.

Scenario 3 shows that if all the generated electricity is used in Otaki (i.e. create an Otaki mini-grid) and only the winter deficit is purchased from the national grid, this will cost the town $\$ 5,011$. The costs of creating this mini-grid have not been evaluated. 


\subsubsection{CAPITAL COSTS}

PV generation requires capital expenditure, not by the electricity generator but by the user - in this case the Otaki shops (or some other agency). EECA's EnergyWise website estimates that PV costs between $\$ 10$ and $\$ 13$ per installed Watt (EECA, 2009).

\begin{tabular}{|lccc|}
\hline Array Size kW & $\begin{array}{c}\text { Approximate Energy } \\
\mathbf{k W h}\end{array}$ & Cost & Cost / Watt \\
\hline $1.0 \mathrm{~kW}$ & $1400-1550 \mathrm{kWh} / \mathrm{yr}$ & $\$ 8,500.0$ & $\$ 8.50$ \\
\hline $1.5 \mathrm{~kW}$ & $2100-2300 \mathrm{kWh} / \mathrm{yr}$ & $\$ 11,500.0$ & $\$ 7.66$ \\
\hline $2.3 \mathrm{~kW}$ & $3200-3500 \mathrm{kWh} / \mathrm{yr}$ & $\$ 15,500.0$ & $\$ 6.74$ \\
\hline $4.5 \mathrm{~kW}$ & $6300-6900 \mathrm{kWh} / \mathrm{yr}$ & $\$ 28,500.0$ & $\$ 6.30$ \\
\hline \multicolumn{4}{c}{ Figure 113: Cost of PV Arrays in New Zealand (Cell Power, 2010) } \\
\hline
\end{tabular}

As the NREL PVWatt calculator uses a $4 \mathrm{~kW}$ array as the base unit, the prices will be calculated using the per Watt cost based on for the $4.5 \mathrm{~kW}$ array from Figure 113. At $\$ 6.30$ per watt, each $4.0 \mathrm{~kW}$ array will cost approximately $\$ 25,200$ each. This would mean that to service the retail strip the capital cost would be $\$ 1,335,600$ (\$25,200x 53).

\section{Scenario 1 Payback}

This Scenario considers net metering where each $\mathrm{kWh}$ generated is credited against each $\mathrm{kWh}$ consumed. Annually this method is expected to account for the consumption along the retail strip with a net surplus of generation of 2,100 $\mathrm{kWh}$. This method gives equal value to both the generated $\mathrm{kWh}$ and the consumed $\mathrm{kWh}$. Because the annual consumption can be met, this scenario represents energy savings of $\$ 57,312 / \mathrm{yr}$ (2010).

At the current price of electricity $(\$ 0.23 / \mathrm{kWh})$ the simple payback overall is about 23 years. If the cost of electricity increases by $50 \%(\$ 0.33 / \mathrm{kWh})$ then the estimated savings would be approximately $\$ 80,500$ which reduces the payback to 17 years.

\section{Scenario 2 Payback}

This Scenario sells all generation to the grid at wholesale prices and purchases all of its requirements from the grid at retail prices. An analysis of the 2010 year shows that retail strip would have required $248,321 \mathrm{kWh}$ at $\$ 57,312$ worth of electrical energy and that the generation of $250,425 \mathrm{kWh}$ could have been sold at $\$ 15,762$. This scenario still requires the purchase of $\$ 41,550 / \mathrm{yr}$ of electrical energy, resulting in savings of the generated amount at $\$ 15,762$.

At $\$ 15,762 / y r$ of savings, this Scenario can expect to pay back in 85 years. 


\section{Scenario 3 Payback}

This Scenario uses all of the generated electricity on site and sells any surplus to the grid at wholesale rates. During the winter months the deficient must be purchased from the grid at retail rates, which leads to an annual net deficit of $\$ 5,011 / \mathrm{yr}$.

This deficit means that the Scenario saves $\$ 52,301 / \mathrm{yr}$ on the current electrical costs. Because of this Scenario can expect to pay back in 26 years.

\subsubsection{DISCUSSION}

To gain maximum savings and to completely supply the retail strip's lighting energy the winter deficit needs to be met.

One option would be to increase the number of PV panels to fully meet the winter demand. Based on the figures in Figure 112, with 10,000 kWh needing to be generated in June, a further 50 arrays need to added to meet the short fall. At a cost $\$ 25,200$ per array, this would require an extra capital expenditure of $\$ 1,260,000$ in order to supply the additional energy that would cost $\$ 5,011$ if purchased from the grid - clearly uneconomic. This option has not been further investigated.

The analysis does suggest it is possible to meet the electricity needs of the Otaki shops outside the 5 month winter period, although the wholesale-based payment for the PV generated energy being sold to the national grid means it is not possible to create a positive cash flow scenario.

\section{Net Metering}

The United States has provided net metering in some form since 2008 when it passed into law that utility companies (Power Companies) had to provide for net metering to any connected customer (US GPO, 2005). How each utility company chooses to account for net metering depends on the State in which they are located and the company itself. The DSIRE website (www.dsireusa.org, $9^{\text {th }}$ March 2011) provides a database of Federal incentives on a State by State basis. An example is the Rocky Mountain Power Utility in Wyoming that provides one for one $\mathrm{kWh}$ credits for each $\mathrm{kWh}$ generated by a consumer (Department of Energy, 2011).

European countries such as France and Germany use a slightly different model where the $\mathrm{kWh}$ being generated is valued higher than the retail rate. This model is known as 'Feed in Tariff' and is believed to be one of the better methods of stimulating renewable growth (Institute for Building Efficiency, 2011). 
Both of these models shown here provide the equality for renewable generation that would create positive cash flow scenarios. As yet, New Zealand policy does not provide for either model, forcing any extra generation to be sold at wholesale rates.

\subsection{WIND}

Wind as a resource in New Zealand is abundant but unpredictable (EECA, 2011). The advantage that wind generation has over PV is that wind, if present, is able to generate overnight and throughout winter.

Wind generation uses turbines which are available in sizes from approximately 500 Watts (sized for battery charging) through to the large $3 \mathrm{MW}$ machines for onshore wind farms. Some offshore wind farms may have turbines as large as $10 \mathrm{MW}$, each of which would be capable of powering 2,000 to 3,000 residential homes (Doyle, 2010).

The turbines are rated in their capacity in Watts, which is the optimum output for a given wind speed (EECA, 2011). A wind turbine rated at $1 \mathrm{~kW}$ for wind speed of $10 \mathrm{~m} / \mathrm{s}$ will only generate $1 \mathrm{~kW}$ when the wind is blowing at $10 \mathrm{~m} / \mathrm{s}$. If the wind speed is lower, the turbine will still generate, but not to full capacity.

An industry rule of thumb has a wind turbine generating between $10 \%$ and $40 \%$ of its rated output per hour of operation (EECA, 2011). Using this rule of thumb the 250,000 $\mathrm{kWh} / \mathrm{year}$ identified as the Otaki retail strip lighting load would require a wind turbine rated at approximately $285 \mathrm{~kW}$ at $10 \%$ and $71 \mathrm{~kW}$ at $40 \%{ }^{26}$. However, the actual output will depend on average wind speeds, the location and surrounding terrain.

The Brooklyn wind turbine in Wellington is rated at $225 \mathrm{~kW}$. During the year its recorded output can be as high as $1 \mathrm{GWh}$ (New Zealand Wind Energy Association, 2010). This output is high due to the high number of wind hours at that site. It is unlikely that a wind turbine situated in Otaki will have such a high generation. In locations such as Otaki, the turbines are expected to be subject to turbulent and erratic winds due to buildings, trees and other obstacles (EECA, 2011).

The physical size of a single turbine, even at a $225 \mathrm{~kW}$ rating, also makes the urban locale unpractical. The Brooklyn Turbine has a tower height of 33.5 metres with a blade length of 13.5 metres (New Zealand Wind Energy Association, 2010). This would tower over the average four metre high Otaki shop.

\footnotetext{
${ }^{26} 250,000 \mathrm{kWh}=$ (Turbine Capacity) $x$ Hours of operation $x$ Efficiency Rating $(10 \%$ or $40 \%)$
} 
The other option is to place multiple smaller $1.3 \mathrm{~kW}$ turbines in the town, however due to their height (12 metres (Pacific Wind Energy, No Date)) they would more susceptible to turbulence. In order to provide a total of $225 \mathrm{~kW}$ there would have to be 173 of these small turbines (SolarOnline, 2011).

The turbine(s) could be relocated to the hills to the east of the township, although this would increase transmission line losses, meaning a large turbine may be required. The connection of the turbine generation to the retail strip would also need careful design.

As the wind turbine can generate at any time, including when there is no store load, some form of storage would be required. In the case of the smaller turbines, batteries can be used as bulk storage although with the large number of small turbines would make this a major logistical exercise. The larger turbine could be connected to the grid under an appropriate operating regime. The variation in operation due to the wind may lead to the lines network requesting the turbine output is controlled (Sinclair Knight Merz, 2006).

Without a suitably sophisticated control or management system, the national grid could not be used as the storage as described in PV Scenario 3. This would mean the turbine would be supplying the grid at wholesale prices whenever it was operational and the stores would be paying retail prices for their electricity.

This analysis suggests it is possible to supply the Otaki shop's electricity requirements through wind generation, although the issues of cost, turbine location and grid interaction would need further detailed investigation.

\subsection{HYDRO}

Hydro electricity generation relies on water to turn the turbine, rather than wind. Hydroelectricity is a well-used resource in New Zealand, providing approximately 57\% of the nation's electrical supply (Ministry of Economic Development, 2010, p. 103).

Small hydro is classed into three size bands, micro-hydro at $1 \mathrm{~kW}-10 \mathrm{~kW}$, mini at 10 $\mathrm{kW}-1000 \mathrm{~kW}$ and small at $1000 \mathrm{~kW}$ through to $10 \mathrm{MW}$ (EECA, 2009). The water source can be either run of river or from a storage dam or pond. As hydroelectricity is generated from the flow of water, provided the water flow was continuous or from a controllable storage, the demand from the retail strip could be matched as required.

The EECA small hydro fact sheet (EECA, 2009) identifies the following conditions required for small hydro - each heading is provided with information on Otaki: 
- Suitable Waterway: The 2006 renewable energy assessment of the Greater Wellington region by Sinclair Knight Merz (SKM) identified 4 MW rated scheme on the Otaki River located at Hautere (Sinclair Knight Merz, 2006).

- Water rights: this scheme would need the involvement of two councils (Kapiti Coast District Council and the Greater Wellington Regional Council), and would have to consider other users, such as the local Maori, recreational and irrigation users and that the river is also the town's water supply.

- Capital: the distance that the scheme is located from the demand will increase the overall capital costs. As this site is $5 \mathrm{~km}$ south west of the retail strip it is assumed that costs would be incurred to connect the two.

- Wiring requirements: Again like wind generation, the long history of hydroelectric generation means there are network or connection issues.

- Maintenance: all intakes must be kept clear and de-silted to prevent blockages. The site must also be flood protected that may impact on other users.

Assuming all of these conditions can be met, it would appear that local hydro generation is capable of meeting the electricity demand for the retail strip. It is likely to have the capacity to generate year round and can be matched to the demand as required. However, due to the location and other interested parties in the installation of such a scheme, further research would be required for this to be viable. This option has not been investigated any further.

\subsection{COMMUNITY BASED GENERATION}

Based on the above discussions, PV is suited to directly offset the retail lighting load due to its operational period and minimal transmission losses due to its roof top location. However, without over sizing the system for summer demands, PV fails to meet the winter demand. Wind generation and hydroelectricity both have the ability to provide adequate supply year round, provided all the required resources are available. Their use would require further investigation.

In order to meet the annual lighting load, the PV array discussed above would need to be provided either equally or in part by the 33 retailers along the retail strip. The calculations carried out in Section 9.1 suggest their needs could be met for 7 months of the year by $534 \mathrm{~kW}$ arrays spread across $1,885 \mathrm{~m}^{2}$ of the available roof space. Some electricity purchases from the national grid would be required during the remaining four months. 
If the above generation is distributed equally across all the shops, then each retailer along the strip would be responsible for approximately $6.4 \mathrm{~kW}$ load which would be met with approximately $55 \mathrm{~m}^{2}$ of PV array. This method would favour the larger users of energy, as the energy use is not evenly spread along the retail strip.

The other way is for each firm to install an array that is suited to the load consumed by the store. It has been calculated that the smallest user of the optimised load would also be the smallest store by floor area at $35 \mathrm{~m}^{2}$ which consumes $1,960 \mathrm{kWh}$ annually for lighting. The largest user of energy consumes $30,250 \mathrm{kWh}$ per year for lighting and has a roof area of $380 \mathrm{~m}^{2}$.

Based on the estimated generation for an array in Figure 113, the smallest user could install a $1.5 \mathrm{~kW}$ array that would use around $12 \mathrm{~m}^{2}$ of roof area. This array is estimated to generate between 2,100 and 2,300 kWh/yr (Cell Power, 2010), meeting this store's lighting load for a capital expenditure of $\$ 11,500$. At $\$ 0.23$ per $\mathrm{kWh}$ the current annual expenditure is $\$ 451$, giving a simple payback (no install or maintenance costs) of 25 years.

The larger store using $30,000 \mathrm{kWh}$ annually would require five $4.5 \mathrm{~kW}$ arrays each of which generates approximately $6500 \mathrm{kWh} /$ year, requiring $175 \mathrm{~m}^{2}$ of the roof area. Five $4.5 \mathrm{~kW} \mathrm{PV}$ arrays are expected to cost $\$ 142,500$ giving a payback for this store at $\$ 0.23 /$ $\mathrm{kWh}$ of 21 years.

As these two stores show both ends of the scale, and both need an excess of 20 years before the scheme becomes profitable, it can be assumed that the rest of the retail strip would be in a similar situation.

For the strip to meet with the goals of the Greater Otaki Project, the 33 stores would need to outlay capital of $\$ 1,335,600$ and still require grid supplied electricity during five winter months.

Another method would be to use the Otaki community, rather than just the retail stores, to generate the required electricity. If homes were wired for PV and directly connected to the retail strip, then when the homes are empty during the day, they would be directly supplying the retail load. If homes were all installed using $4 \mathrm{~kW}$ arrays, then 50 homes could be used to offset the annual load. 100 homes would meet the deficiency in the generation over winter, with each home contributing to the initial costs. This would allow the scheme to be spread over many instead of being met by a few. The excess electricity would be stored in each house to provide service during the evening and early morning. 
There is little financial incentive to fit PV at this scale - $\$ 2,500,000$ pays for more electricity than many will use during their time on the strip. The main outcome from this is to take Otaki off the grid rather than offsetting the load to use 'free' energy. As capital costs decrease the PV option will become more viable as a business opportunity rather than just as a community project.

There may also be a way to incorporate wind or hydro from the rural community to operate in a similar fashion, although to guarantee the supply, batteries would have to be used which would require further investigation. 


\section{CONCLUSIONS}

The aim of this study was to explore the use of renewable energy sources to offset the lighting use of the Otaki retail strip. The lighting use along the retail strip was firstly identified and then the energy use optimised without altering the design intent. The optimisation was necessary to reduce the capital requirements for any future renewable energy installation.

The percentage of lighting used depended on the store type and the process energy used within it. The selection of stores that were individually looked at showed that while lighting types remained similar for the various tasks, the process energy and plug loads varied the impact that the lighting selection could have on the overall consumption.

To identify the lighting load, energy audits from standard AS/NZS 3598:2000, Energy Audits were used to create a consistent set of results. These audits, reported in Chapter 5, identified the types and the numbers of lamps along the strip.

The results were analysed in Chapter 6 to identify the various ways that the stores used their lighting energy. It was initially expected that the various stores would use speciality lamps supporting illumination according their own branding and product lines. What was found was that the stores all used basic lighting, such as linear fluorescent lamps to illuminate the ambient spaces and lights such as incandescent and metal halide lamps in other spaces or for spotlights.

These findings allowed an estimation of the lighting load in the stores that had not participated in the study. This suggested that the lighting in the 33 stores along the retail strip consume 370,000 kWh per year. This includes all retail areas, stock / utility areas and all overnight lighting.

To preserve the existing design intentions that each store has, it was decided that the load optimisation would only target the 'low hanging fruit' of potential energy saving opportunities. Using these low capital cost savings opportunities this study was able to identify $33 \%$ of possible savings in the annual lighting load or $121,679 \mathrm{kWh}$ per year. 
The following optimisations that have been identified show the possible savings to the annual consumption and the installed load.

- Lamp exchange for their energy efficient alternative is calculated to reduce the annual load by $13 \%$ or $49,107 \mathrm{kWh} / \mathrm{yr}$. This would also reduce the installed lighting load by $19.7 \mathrm{~kW}$ or $18.7 \%$.

- De-lamping the selected stores would reduce the annual load by $5.4 \%$ or 20,300 $\mathrm{kWh} / \mathrm{yr}$ and result in a reduction to the installed load of $7 \mathrm{~kW}$ or $6.6 \%$.

- Turn off the overnight lighting is calculated to reduce the annual load by $9 \%$ or $33,960 \mathrm{kWh} / \mathrm{yr}$. As all of the lighting identified in this area is still required during the day, there would be no installed load savings.

- Switching off the underutilised lamps saves $5 \%$ or $18,312 \mathrm{kWh}$ of the annual lighting consumption. Again as these lamps may be required during the day, there would be no resulting savings to the lighting load.

The optimised load identified in Chapter 8 is $248,321 \mathrm{kWh} / \mathrm{yr}$ which would need to be provided using renewable resources.

Chapter 9 considered the use of PV, wind and hydro as the renewable energy sources to provide the power to offset the retail lighting load. Of the three PV was identified as the most accessible and therefore the most likely of the three to proceed.

The advantage of PV is that any of the retailers can have it installed and that its period of maximum generation occurs during the period of maximum demand from the retail strip.

A $212 \mathrm{~kW}, 1885 \mathrm{~m}^{2} \mathrm{PV}$ array is capable of generating enough electricity to offset the load for an entire year, but although there is a surplus in summer during winter the array under generated by approximately $10,000 \mathrm{kWh}$.

The best cost scenario for PV is Net Metering with a payback of 23 years. This Scenario has electricity supplied to the grid credited at the same value as electricity purchased from the grid. This allows a grid tied generator to use the grid as storage, balancing demand with generation over the course of a year. At present this scenario is opposed by industry due to grid load reconciliation and billing and cost issues. Net metering has been shown to work in both the United States and Europe where in some cases it is possible for the customer to on sell their generation at a higher rate than retail.

The lack of net metering means any Otaki generation must be used as it is generated and the difference purchased when demand exceeds the generation - a situation that will occur with PV in winter. The best alternative involves the use of locally generated 
electricity when it is available, and purchase only of the generation deficit. This option means that using a PV array sized for summer performance an additional \$5,000 (2010 prices) of electricity must be purchased from the grid per year to meet the demand.

The present situation is that excess generation is purchased at wholesale prices that fluctuate from 1.7 cents in October 2010 through to a high of 10 -11 cents in March 2010. This compares to the 23 cents per $\mathrm{kWh}$ price that electricity is supplied to the Otaki retail stores.

The lack of income from the PV and high initial capital costs make it prohibitive to the retailers to install in any quantity. If the lighting loads currently used in Otaki were continued, a $374 \mathrm{~kW}$ PV array would be required at a purchase cost of \$2,091,600, giving a simple payback of 26 years. After optimising the lighting system used in the Otaki shops, the array size could be reduced to $212 \mathrm{~kW}$ which at a cost of $\$ 1,335,600(\$ 25,200$ $x 53$ ) has a simple pay-back of the order of 23 years.

The recommendations made to optimising the lighting load in the Otaki retail shops are all cost effective now, and would be of benefit both to the store owners and operators, and the Greater Otaki Project as a practical demonstration of the benefits from exploring energy alternatives.

In terms of moving the Otaki retail shops off the grid, the best way forward is through the Greater Otaki Project and including the community as a source of generation. This allows the initial capital costs to be spread over many instead of just the 33 stores. The added benefit is that the community could sell direct to the stores at market rates if the connections allowed, however the installations should not be about income but rather be about making Otaki energy self-sufficient. 


\section{WORKS CITED}

AILite. (2010, June 29). LED Track Lighting Systems. Retrieved March 9, 2011, from AILite: http://www.xgailite.com/news/company/2010/0629/212.html

ANZSIC. (2006). Industrial Classifications 2006. Wellington: Australian Bureau of Statistics and Statistics New Zealand .

ASHRAE. (2008). Advanced Energy Design Guide for Small Retail Buildings. Atlanta: American Society of Heating, Refrigerating and Air-Conditioning Engineers Inc.

Cell Power. (2010, November 12). Grid Tie systems. Retrieved March 10, 2011, from

Cell power: http://www.cellpower.co.nz/index.php?pr=Grid_Tie_Sytems

CIBSE. (1982). CIBSE Building Energy Code part 4 - Measurement of Energy

Consumption and Comparison with Targets for Existing Buildings and Services 1982.

London: Chartered Institution of Building Service Engineers.

CIBSE. (1999). TM22 Technical Manual. London: CIBSE.

Consumer.Power Switch. (2011, March). Price Trends. Retrieved March 10, 2011, from Consumer.Power Switch:

http://www.consumer.org.nz/powerswitch/region/N09/N095/price_trends

Contact, C. S. (2010, November 18). 080080 9000. (Q. Heap, Interviewer)

Department of Building and Housing. (2001, July 01). New Zealand Building Code

Clause G8. Retrieved February 23, 2011, from Department of Building and Housing:

http://www.dbh.govt.nz/UserFiles/File/Publications/Building/Compliance-

documents/clause-g8.pdf

Department of Building and Housing. (2008). New Zealand Building Code Clause H1:

Energy Efficiency - Third Edition. H1/AS1 6.1.1 . Wellington.

Department of Energy. (2009, October). Buildings Energy Data Book. Retrieved

November 4, 2010, from US. Department of Energy:

http://buildingsdatabook.eren.doe.gov/TableView.aspx?table=5.6.9

Department of Energy. (2011). Federal Incentives. Retrieved March 10, 2011, from

DSIRE - Database of State Incentives for Renewables and Efficiency:

http://www.dsireusa.org/ 
Department of Labour. (2011, February 8). Shop Trading Hours. Retrieved February 10, 2011, from Department of Labour: http://www.ers.dol.govt.nz/holidays_act_2003/shoptrading-easter2011.html

Dictionary.com Unabridged. (n.d). downlight. Retrieved November 04, 2010, from Dictionary.com: http://dictionary.reference.com/browse/downlight

Doyle, A. (2010, March 29). Offshore wind turbines may be $10 \mathrm{MW}$ giants: Veritas. Retrieved March 9, 2011, from Reuters: http://www.reuters.com/article/2010/03/29/usenergy-wind-idUSTRE62S2ZP20100329

EECA. (2003, April 3). Emprove: A technical guide. Retrieved January 21, 2011, from Energy Efficiency and Conservation Authority: http://www.eeca.govt.nz/sites/all/files/technical-guide-improving-office-lighting.pdf EECA. (2007). Energy Audit Manual. Wellington: Energy Efficiency and Conservation Authority.

EECA. (2007). Energy Audit Manual. Wellington: Energy Efficiency and Conservation Authority.

EECA. (2009, March 1). Small Hydro. Retrieved March 9, 2011, from Energy Efficiency and Conservation Autority: http://www.eeca.govt.nz/sites/all/files/small-hydro-factsheet-05.pdf

EECA. (2011). Small wind turbines. Retrieved March 9, 2011, from EECA Energywise: http://www.energywise.govt.nz/how-to-be-energy-efficient/generating-renewableenergy-at-home/small-wind-turbines

EECA. (2011). Small Wind Turbines. Retrieved February 23, 2011, from EECA Energywise: http://www.energywise.govt.nz/how-to-be-energy-efficient/generatingrenewable-energy-at-home/small-wind-turbines

EECA. (2009). Solar electricity generation. Retrieved December 23, 2010, from EECA Energy Wise: http://www.energywise.govt.nz/how-to-be-energy-efficient/generatingrenewable-energy-at-home/solar-electricity-generation

EECA. (2001, May). Solar Energy Use and Potential in New Zealand. Retrieved March 9, 2011, from SolarMax: http://www.solarmax.co.nz/uploads/downloads/Solar\%20Energy\%20Potential\%20in\%20 NZ.pdf 
EIA. (No Date). Description of CBECS Building Types. Retrieved June 10, 2010, from U.S. Energy Information Administration:

http://www.eia.gov/emeu/cbecs/building_types.html

Electricity Authority. (2010, December 31). Wholesale Prices - Mean Price. Retrieved March 10, 2011, from Electricity Authority:

http://www.ea.govt.nz/industry/modelling/cds/centralised-dataset-web-

interface/wholesale-prices-mean-price

Fetchalamp. (2010). Compact Fluorescent Lamps. Retrieved December 23, 2010, from Fetch A Lamp: http://www.fetchalamp.co.nz/light-bulbs/compact-fluoro-mainsvoltage/osram?page $=4$

Fitch, R., \& Knobel, L. (1990). Retail Design. New York: Whitney Library of Design. Gael Ferguson. (2010). SP-10-807 Update on the Greater Otaki Project. Otaki: Otaki Community Board.

Ganslandt, R., \& Hofman, H. (1992). Handbook of Lighting Design. Germany: ERCO.

Genesis Energy. (2010). Generate Your Own Power with HomeGen. Retrieved March 8, 2011, from Genesis Energy: http://www.genesisenergy.co.nz/genesis/generation/homegen/generating-your-ownpower.cfm

Google. (2010). Google Earth. Retrieved April 10, 2010, from Google Earth.

Heap, Q. (2009). Testing non-invasive auditing methods for overnight lighting in the Wellington Central Business District (CBD). Victoria University of Wellington: Report completed in requirement for Bachelor of Building Science (Honours) .

Hoskins, G., \& BRANZ. (2009). Level sustainable building series, no. 11. Wellington: Printlink.

IEA. (2006). Lights Labours Lost, Policies for Energy-efficient Lighting. Paris Cedex 15, France.: International Energy Agency.

IESNA. (2000). IES lighting handbook. (M. S. Rea, Ed.) New York,, New York: Illuminating Engineering Society of North America. 
Institute for Building Efficiency. (2011). Around the Globe, Emerging Energy Policies Promote Renewables and Efficiency. Retrieved March 10, 2011, from Institute for Building Efficiency: http://www.institutebe.com/energy-policy/energy-policies.aspx Isaacs, N., Baird, G., Sterios, P., \& Rollo, J. (1993). BETARG2 Manual. Wellington: Centre for Building Performance Research.

Isaacs, N., Saville-Smith, K., Babylon, M., Bishop, R., Camilleri, M., Donn, M., et al. (2010). STUDY REPORT: SR 236 (2010) Building Energy End-Use Study (BEES) Year 3. Wellington: BRANZ.

Isaacs, N., Saville-Smith, K., Babylon, M., Bishop, R., Camilleri, M., Donn, M., et al. (2009). Study Report: SR224 (2009) Building Energy End-use Study (BEES) Years 1 \& 2 . Wellington: BRANZ.

Itron. (2006). California Commercial End-Use Survey. United States Electricity Commission.

Kapiti Coast District Council. (1999). District Plan Maps. Retrieved November 12, 2010, from Kapiti Coast District Council:

http://www.kapiticoast.govt.nz/Documents/Downloads/District\%20Plan\%20Maps/maps0 3_zones\%20and\%20feat_ver_01.pdf

Kapiti Coast District Council. (2009). District Plan. Kapiti Coast. Volume One: C3-1. Paraparaumu: Kapit Coast District Council.

Kapiti District Council. (2009). Kapiti Coast Choosing Futures, Community Plan Part 1. Kapiti Coast.

KEMA. (2007). Efficiency Potential Study - Vol 1. Wellington: Electricity Commission.

LDS Group. (2010). LED Lighting. Retrieved December 18, 2010, from LDS Group: http://www.lds-group.org/technologies/led-lighting/

Levin, J., Niemczycki, T., Walton, V., \& Woloschin, I. (2007, February 23). A study of Overnight Lighting in Non-Domestic Buildings. Retrieved January 20, 2009, from Worcester Polytechnic Institute: http://www.wpi.edu/Pubs/E-project/Available/E-project022307070651/unrestricted/Carbon_IQP_FINAL.pdf

Lightbulb_Man, T. (2011, February 24). LED transformer connections. (Q. Heap, Interviewer) 
Liley, B., Bodeker, G., \& Tait, A. (2005, December). Solar Energy. Retrieved December 23, 2010, from NIWA: http://www.niwa.co.nz/news-and-

publications/publications/all/wa/13-4/solar

Maps of the World. (No Date). New Zealand Latitude and Longitude. Retrieved March 10, 2011, from Maps of the World: http://www.mapsofworld.com/lat_long/newzealandlat-long.html

Ministry of Economic Development. (2010, July 02). Energy Data File. Retrieved August 11, 2010, from Ministry of Economic Development: http://www.med.govt.nz/templates/StandardSummary 15169.aspx

New Zealand Standards. (2007). NZS 4243:Part2:2007 Energy Efficiency - Large Buildings. Wellington: New Zealand Standards.

New Zealand Wind Energy Association. (2010). Brooklyn wind turbine . Retrieved March 9, 2011, from New Zealand Wind Energy Association:

http://www.windenergy.org.nz/nz-wind-farms/operating-wind-farms/brooklyn

NIWA. (2011, February). The National Climate Database. Retrieved February 22, 2011, from NIWA: http://cliflo.niwa.co.nz/pls/niwp/wgenf.genform1_proc

NIWA. (2011, February). The National Climate Database. Retrieved February 28, 2011, from NIWA: http://cliflo.niwa.co.nz/pls/niwp/wgenf.genform1

NREL. (2010, February 5). PVWatts. Retrieved February 12, 2011, from National Renewable Energy Laboratory: http://www.nrel.gov/rredc/pvwatts/version1.html NZ Lighting. (2010). Led Drivers. Retrieved December 23, 2010, from NZ Lighting: http://www.nzlightingltd.co.nz/shop/LED+Lights++Lighting/LED+Drivers/LED+350mA + Driver.html

NZ Lighting. (2010). Lighting Resources. Retrieved December 23, 2010, from NZ Lighting: ttp://www.nzlightingltd.co.nz/Lighting+Resources/Colour+Temperature+and+Rendering. html

OSRAM. (2010). General Lighting Applications. Retrieved October 20, 2010, from OSRAM :

http://www.osram.com/_global/pdf/Professional/General_Lighting/Applications/199W00 4GB_Shoplighting.pdf 
OSRAM. (2010). OSRAM Catalog. Retrieved October 28, 2010, from OSRAM:

http://catalog.myosram.com/zb2b/b2b/start.do?browsername=mozilla\%2F5.0\%2520\%25

28windows $\% 253 \mathrm{~B} \% 2520 \mathrm{u} \% 253 \mathrm{~B} \% 2520$ windows $\% 2520 \mathrm{nt} \% 25206.1 \% 253 \mathrm{~B} \% 2520 \mathrm{en}-$

$\mathrm{gb} \% 253 \mathrm{~B} \% 2520 \mathrm{rv} \% 253 \mathrm{~A} 1.9 .2 .6 \% 2529 \% 2520 \mathrm{gecko} \% 2 \mathrm{~F} 20100625 \% 2520$ firefox\%2F3. $6.6 \% 2520 \% 2528 \% 2520 . n e t \% 2520 \mathrm{clr} \% 25203.5 .3072$

Otis, T., \& Reinhart, C. (2009, March 16). Diffuse Daylighting Design. Retrieved February 26, 2011, from Harvard University, Graduate School of Design:

http://www.gsd.harvard.edu/research/gsdsquare/Publications/DiffuseDaylightingDesignS equenceTutorial.pdf

Otto Riewoldt. (2002). Brandscaping:worlds of experience in retail design. (O. Riewoldt, Ed.) London: Birkhauser.

Oxford University Press. (2010). Oxford Dictionary. Retrieved November 29, 2010, from Oxford Dictionaries:

http://www.oxforddictionaries.com/view/entry/m_en_gb0048510\#m_en_gb0048510

Pacific Wind Energy . (No Date). Pacific Wind Energy Turbines . Retrieved March 9, 2011, from Pacific Wind Energy: http://www.pacificwindenergy.co.nz/products

Philips. (2011). PLUSLine Pro Compact . Retrieved March 9, 2011, from Philips: http://www.ecat.lighting.philips.com/l/catalog/catalog.jsp? userLanguage=en\&userCountr $\mathrm{y}=$ nz\&catalogType=LP_PROF_ATG\&_dyncharset=UTF-

8\&categoryid=LP_CF_HDECOMP_EU_FA_NZ_LP_PROF_ATG\&productid=9239200 45780_EU_NZ_LP_PROF_ATG\&title=PLUSLine $\% 20$ Pro\%20Compact $\% 20100$

Philips. (2011). PLUSLine Pro Small. Retrieved March 10, 2011, from Philips:

http://www.ecat.lighting.philips.com/l/catalog/catalog.jsp?userLanguage=en\&userCountr $\mathrm{y}=\mathrm{nz} \&$ catalogType=LP_PROF_ATG\&_dyncharset=UTF-

8\&categoryid=LP_CF_HDESMALL_EU_FA_NZ_LP_PROF_ATG\&productid=924735 545579_EU_NZ_LP_PROF_ATG\&title=PLUSLine\%20Pro\%20Small\%20500W

Philips. (2010). Product Catalogue - Lighting. Retrieved September 20, 2010, from Philips: http://www.ecat.lighting.philips.com/l/en/nz/

Philips. (2010). Quality White Lighting with LEDS. Retrieved November 4, 2010, from Philips: http://www.philipslumileds.com/technology/quality-white-light

Philips. (2010). Retail. Retrieved November 10, 2010, from Philips: http://www.lighting.philips.com/main/application_areas/shop/index.wpd 
Sinclair Knight Merz. (2006, August 2006). Renewable Energy Assessment, GREATER WELLINGTON REGION. Retrieved March 9, 2011, from Energy Efficiency and Conservation Authority: http://www.eeca.govt.nz/sites/all/files/regional-renewableenergy-assessment-wellington-07.pdf

SolarOnline. (2011). Wind Turbines. Retrieved March 4, 2011, from Solar Online Australia: http://www.solaronline.com.au/wind-turbines

Solatube. (2010). Spacing Criteria. Retrieved December 23, 2010, from Solatube: http://solatube.co.nz/commercial/trs_solatube_spacing_criteria.php

Standards New Zealand. (2006). AS/NZS 1680.1:2006 Interior and Workplace Lighting General. Wellington: Standards New Zealand.

Standards New Zealand. (2000). AS/NZS 3598:2000 Energy Audits. Wellington: Standards New Zealand.

Standards New Zealand. (1982). NZS 4220:1982 Code of practice for energy conservation in non-residential buildings. Wellington: New Zealand Standards. Standards New Zealand. (2007). NZS 4243:Part2:2007 Energy Efficiency - Large Buildings. Wellington: Standards New Zealand.

The Lightbulb Man. (2010). Featured Products. Retrieved Jan 5, 2011, from The Lightbulb Man: http://lightbulbman.co.nz/?gclid=CLPZzNeloaYCFU2CpAod9USgng The Lightbulb Man. (2010). Fluorescent - 240V Compact Fluorescent (CFL) - Spiral. Retrieved December 23, 2010, from The Lightbulb Man: http://lightbulbman.co.nz/shop/C10110/spiral?sort=wattage $\& \mathrm{p}=2$

The Lightbulb Man. (2011). Halogen Lamps. Retrieved March 10, 2011, from The Lightbulb Man: http://lightbulbman.co.nz/shop/P50021/35w-12v-24-irc-5-000-hrs-megaglass-covered

The Lightbulb man. (2011). LED. Retrieved March 10, 2011, from The Lightbulb man: http://lightbulbman.co.nz/shop/C10073/led?

The Lightbulb Man. (2011). Transformers. Retrieved March 10, 2011, from The Lightbulb Man: http://lightbulbman.co.nz/shop/P200438/electronic-transformer-20w70w-halogen 
US GPO. (2005, August 8). Public Law 109-58 Energy Policy Act. Retrieved March 10, 2011, from United States Government Printing Office:

http://www.gpo.gov/fdsys/pkg/PLAW-109publ58/content-detail.html

US. EIA. (2010). Commercial Buildings Energy Consumption Survey. Retrieved January 22, 2011, from Energy Information Administration:

http://www.eia.doe.gov/emeu/cbecs/contents.html

Watt, M. (2009, April). Assessment of the Future Costs and Performance of Solar

Photovoltaic Technologies in New Zealand. Retrieved March 1, 2011, from Ministry of Economic Development:

http://www.med.govt.nz/upload/67238/PV\%20in\%20New\%20Zealand.pdf

Wills, J. (No Date). Generation Brands. Retrieved March 8, 2011, from Merchandising and Display Workbook: http://www.generation-brands.com/GB-Merchandising-AndDisplay-Workbook.pdf 


\section{Appendix A LAMP TYPES}

The following is a basic description of each lamp types identified in Section 2.5. It will detail the different types of light and identify some of the more common styles used in retail.

\section{Incandescent}

The General Lighting Service (GLS) lamp is one of the most common available lamp types, and comes in a variety of sizes and wattages. This type of bulb is best described as a point source of light that produces light in an omni directional manner - light leaves the source in all directions at the same intensity.

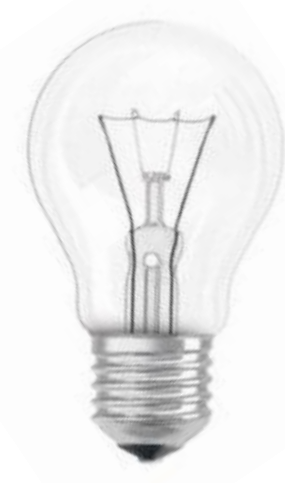

Figure 114: GLS incandescent lamp

An incandescent lamp is a light source that uses an electric current to heat a filament of wire to a 'white hot' state. It is this heating of the filament, usually tungsten, which produces the light.

Because much of the electrical current is required to heat the filament, the incandescent lamp is considered to be an inefficient method of converting electricity into light. The modern incandescent lamp only manages to turn around $9 \%$ of the input power into visible light (OSRAM, 2010)

These lamps are sized based on the rated watts - lamp rated at $60 \mathrm{Watts}$ will produce more light than a lamp rated at 40Watts.

A variation on the GLS lamp is the Parabolic Aluminised Reflector (PAR) styled lamp. This lamp is constructed with an internal reflector to direct the light. The PAR lamps are 
sized using the American National Standard Institute (ANSI) standard. The number following the PAR designation represents the diameter of the bulb in eighths of an inch. Therefore a PAR 38 is a parabolic reflector lamp 38/8 across or in metric terms the lamp diameter is $175 \mathrm{~mm}$.

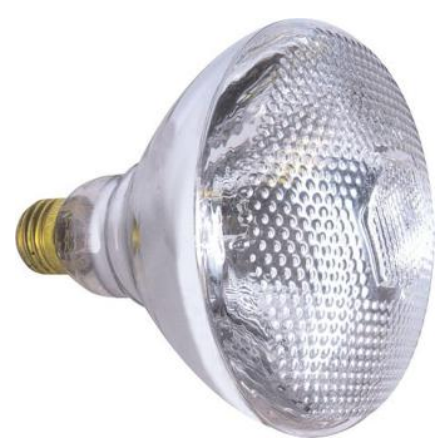

Figure 115: Example of a PAR Lamp (Source: OSRAM)

The PAR type of lamp appears to produce a more efficient light than the GLS styled incandescent, however this is due to the reflector directing more light in one direction (OSRAM, 2010).

\section{Halogens}

The halogen lamp is an improvement on the standard incandescent lamp, although the technology is still based on a heated filament. The difference is that these lamps use halides that allow the filament to be heated to a higher temperature and produce light more efficiently. This increase in efficiency allows the lamp packages to be smaller. Halogens are available in high and low voltage types.

The high voltage (240V) lamps allow direct replacement of the standard tungsten halogen lamps (an example is shown in Figure 116, which can provide energy savings of around 30\% (OSRAM, 2010).

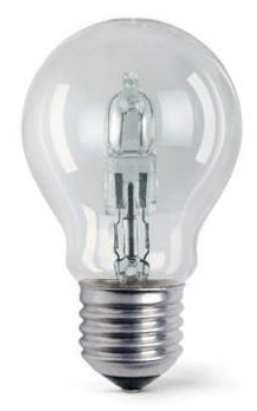

Figure 116: Halogen lamp in classic configuration (Source: OSRAM) 
The low voltage bulbs (typically $12 \mathrm{~V}$ ) require specialised control gear and fixtures.

Some of the styles that may be used in a retail setting are described here.

MR-16 and MR-11's are constructed in the same way with only difference being the size and lumen output. Figure 117 shows an image of a typical MR-16 which uses an internal, dichroic reflector to direct the light. The result is usually small pools of light, but lamps can have different beam widths to provide spotlighting on their own without the use of directional luminaires.

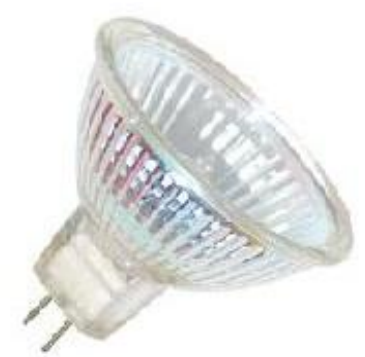

Figure 117: MR 16 Dichroic spot lamp (Source: OSRAM)

The halogen lamp (Figure 118) uses the same technology but without a reflector, therefore the light output is again omni directional.

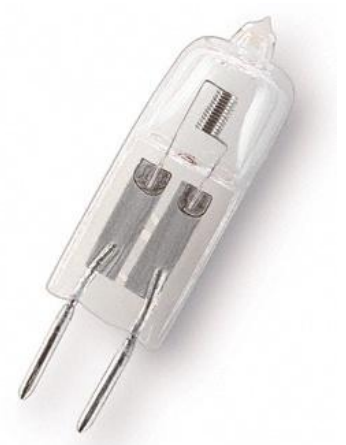

Figure 118: Halogen Lamp in Capsule Form (Source: OSRAM)

The last of the type covered here will be the halogen strip light. Figure 119 is an example of the linear halogen lamp that is used for area and wall flood lighting. This particular lamp package is provided in a double ended tube that requires specialised contactors to operate as well as dedicated luminaires that can handle the temperature and be able to direct the light. In this configuration the lamp is available in wattages ranging from just 60 Watts up to 2000 Watts (OSRAM, 2010). 


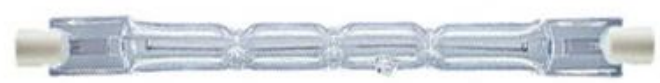

Figure 119: Linear halogen lamp (Source: Osram)

\section{Linear Fluorescent Lamp (LFL)}

The lineal fluorescent lamp (Figure 120) is tubular in construction and is a low pressure discharge lamp. Light is produced by an arc between two electrodes placed at either end of the gas filled tube. The tube itself is coated in a phosphorus material so that when the arc passes through the gas, UV light is emitted, that in turn excites the phosphors. It is these excited phosphors on the tube walls that emit visible light.

Figure 120: Image of a Fluorescent lamp $1200 \mathrm{~mm} 36 \mathrm{~W}$ (Source: Osram)

The light from the fluorescent is not easily directed like a spot light. This is because the lamp produces light down its entire length in an even manner.

In New Zealand the linear fluorescent tubes are measured in diameter by the millimetre. Their designation may also be by a ' $\mathrm{T}$ ' value. The ' $\mathrm{T}$ ' value for the linear fluorescent lamp was developed by the American National Standard Institute (ANSI). The T size relates to the diameter of a tube in eighths of an inch (IESNA, 2000). Common values are the T-12, the T- 8 and the T-5, where the T-12 represents $12 / 8$ or an inch and a half (38 $\mathrm{mm})$, the $\mathrm{T}-8$ is $8 / 8$ or one inch $(25 \mathrm{~mm})$ and the T-5 is $5 / 8$ or .625 of an inch $(16 \mathrm{~mm})$.

The lengths of the tubes are typically between $300 \mathrm{~mm}$ and $1500 \mathrm{~mm}$ (OSRAM, 2010). The T-8 was introduced as the energy efficient replacement for the T-12, generally saving around $10 \%$ on the energy consumption. 
The T-5 was introduced as the energy efficient alternative to the T-8 producing savings in the order of $30 \%$. However the T-5 lamps are shorter than the T-12 and T-8 lamps. This means that the T-5 cannot be used as a direct replacement for the larger diameter tubes.

\section{Compact Fluorescent Lamp}

The Compact Fluorescent Lamp (CFL) is the energy efficient alternative for the standard GLS lamp (Figure 121). Using the same fittings and luminaires, the CFL has its lamp sizes based on the overall wattages of the GLS.

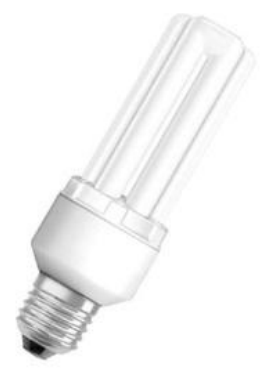

Figure 121: Image of CFL lamp (Source: Osram)

They are based in the same technology as the linear fluorescent lamp. The shape of the lamp does not alter the way the fluorescent lamp operates.

To maintain the light the CFL requires additional control gear to run. In many of the different forms of CFL, the control gear can be integrated in the base of the unit or be separate as part of the luminaire. Depending on the style and type of CFL this control gear may allow dimming, however this is considered to be a specialist operation.

\section{Metal Halide}

The metal halide lamp produces light by passing an electrical discharge through high pressure gas that has metal halides in it. These metals when electrically excited under pressure produce a good mix of primary colours, which combine to give an even white light (OSRAM, 2010).

Earlier lamps of this type suffer from 'colour shift'; this occurs as the lamp ages and shifts from its normal white output to a much greener/blue light (Figure 122). Newer technologies can counter this that allowing the lamp to produce a whiter light longer. 

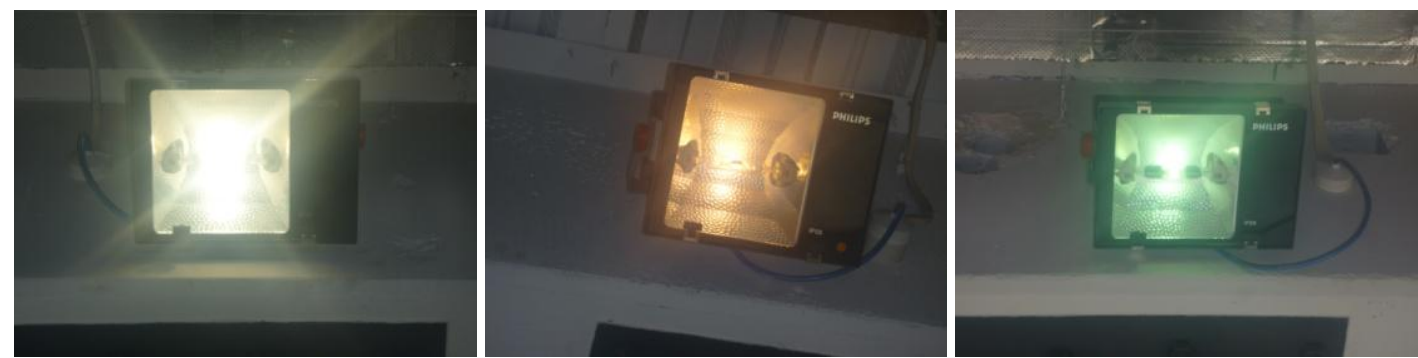

Figure 122: Colour Trends of the Metal Halide Lamp(Source: Authors Own)

Metal Halide lamps require a starter and ballast for normal operation. The starter is required to ignite the arc and the ballast to restrict the operating current. These lamps have a slow start cycle, which means they may need a run-up time before they reach full operating temperatures and light output. Once up to full operating temperatures, they will require a cool down period if switched off, before they can re-ignite.

This light source has become highly versatile and is now produced in a variety of sizes and fitting styles (Figure 123). They can be constructed in either the single ended or double ended tube and can be used in multiple scenarios. The lamp types include interior and exterior floodlights but they can also be repackaged to act as spotlights.
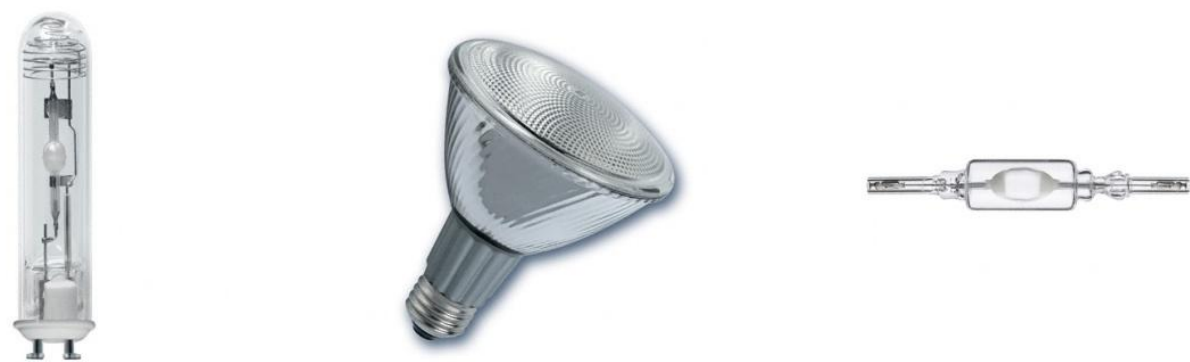

Figure 123: Examples of Metal Halide Lamps (Source: OSRAM) 


\section{Appendix B LUMINAIRE TYPES}

The luminaire is the light fitting that houses the lamp and its associated control gear, reflectors and diffusers. It can protect the lamp and direct the light to where it is needed. A luminaire can deliver the light either directly or indirectly to where it is required.

- A direct method is where the light source delivers light directly to the surface being lit.

- Indirect lighting is usually reflected first so that light is provided in a diffuse pattern.

- It is also possible for luminaire to deliver light in both of these ways. These luminaires can be classified as 'semi direct', 'general diffused', and 'semiindirect' (Standards New Zealand, 2006).

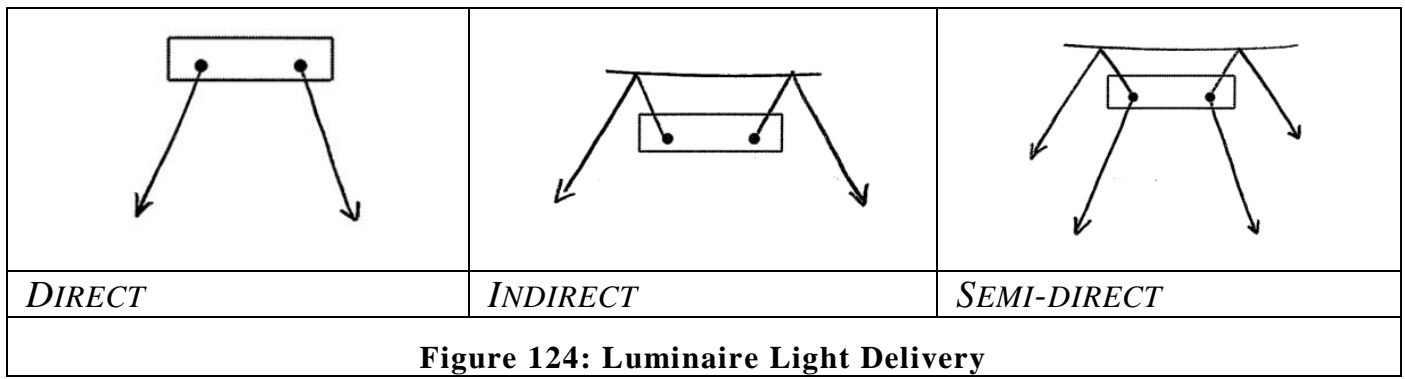

Luminaires are not constrained to fitting one category or classification and many fittings can be used in many situations, often combining the qualities of other luminaires.

The style of luminaire may be recessed or exposed. As a recessed luminaire it is cut into the mounting surface so that it has a flush finish. The same luminaire may also be mounted on the face of a surface so that it becomes an exposed luminaire.

\section{General Lighting Service and CFL Luminaires}

The types and numbers of luminaires to fit these lamps is vast and numerous. However the basic aims remain the same and that is to simply mount the lamp to a ceiling or wall plane to provide direct light. 


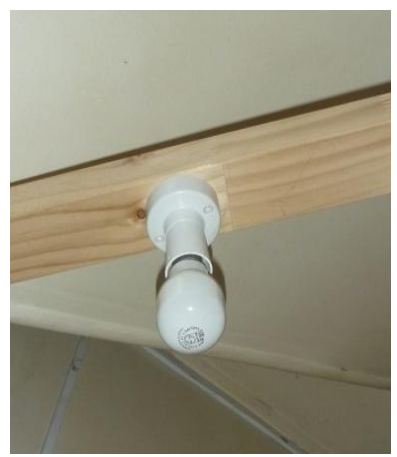

Figure 125: GSL lamp Fitting(Authors Own Photo)

To diffuse the lamp the light source will be covered by a translucent material that lets some degree of light through or it can be directed using reflective or white materials.

\section{Down Lights}

"A lamp, often a light bulb set in a metal cylinder, mounted on or recessed into the ceiling so that a beam of light is directed downward".

(Dictionary.com Unabridged, n.d)

The 'downlight' as such can contain any type of lamp style. The ones shown here are to illustrate how this is achieved and how they can be altered to fit any style.

Figure 126 shows two sample downlights.

- The CFL down light uses a lamp that does not contain its own control gear. This is provided in the luminaire up behind the ceiling. The reflector has reflective metal that directs the light down.

- The 100 Watt halogen lamp is capable of connecting direct to mains supply and therefore it does not require any control gear. The fitting itself houses and protects the lamp that has its own internal reflector to direct the light downward.

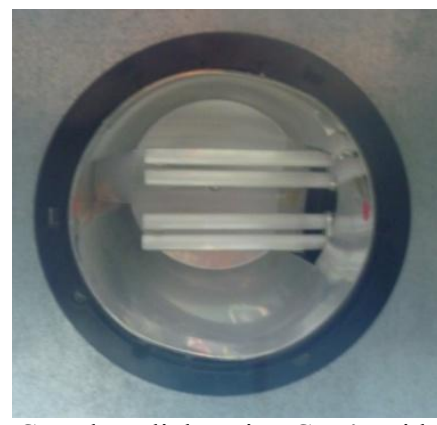

CFL downlight using CFL's with external control gear (Authors Photo)

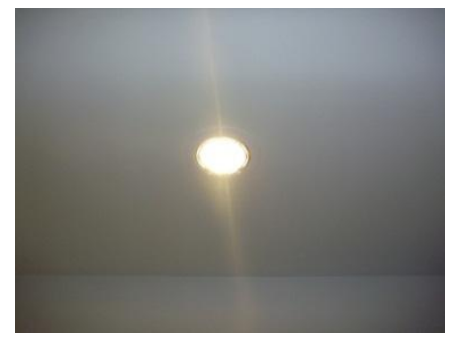

Halogen Down Light and Luminaire (Authors Own Photo)

Figure 126: Examples of Down lighting Luminaires (Authors Own Photos) 


\section{Spotlights}

"A strong, focused light thrown upon a particular spot, as on a small area of a stage or in a television studio, for making some object, person, or group

$$
\text { especially conspicuous ". }{ }^{27}
$$

Spotlight fittings have been developed for a large number of lamps and because of the potential design component to the light, there are many styles and types. The lamp and luminaire shown here is the combination typically installed along the retail strip and houses the MR-16 lamp.

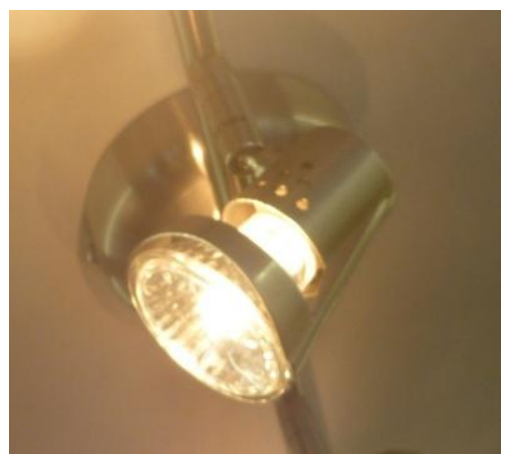

Figure 127: MR-16 Luminaire (Authors Own Photos)

\section{Flood Lighting}

Flood lighting or Wall Wash luminaires can come in a variety of types and sizes. The luminaire can cater for any number of lamps, such as the halogen (strip and bulb), the incandescent or CFL, and the metal halide (bulb and strip).

27 spotlight. (n.d.). Dictionary.com Unabridged. Retrieved November 04, 2010, from Dictionary.com website: http://dictionary.reference.com/browse/spotlight 


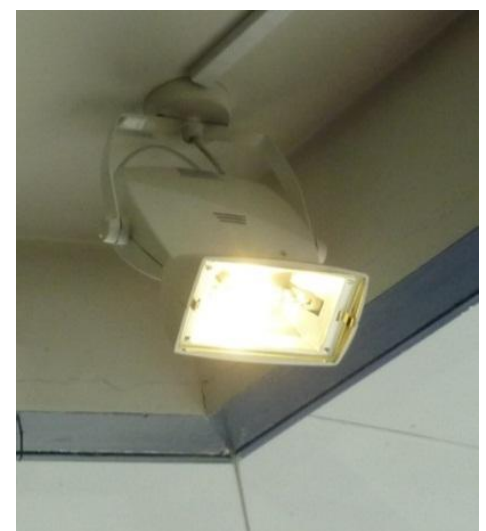

Figure 128: Flood light Luminaire (Authors Own Photos)

Depending on the light source the luminaire may or may not contain control gear. The reflector is normally positioned to allow a wash of light.

\section{Lineal Fluorescent Lamp Luminaires}

The LFL luminaire will contain all of the circuitry and ballasts required to operate the lamp. The luminaires are designed based on the lamp length and came in a variety of types.

\section{The Exposed LFL}

This style of luminaire for the LFL may be the most basic form of mounting this light source. The batten mount can be either the exposed bare lamp or covered by a diffuser. In both configurations it is generally affixed to the ceiling.

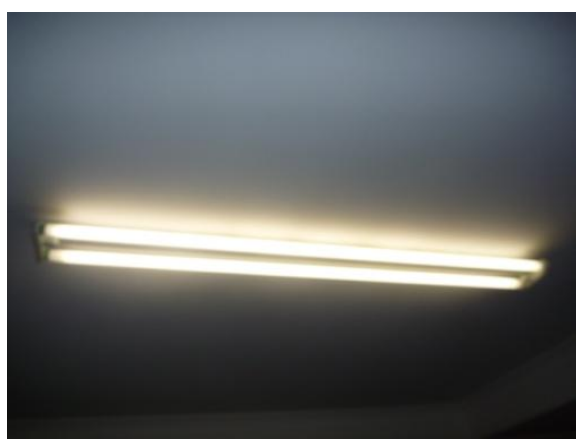

Exposed, Double style

Figure 129: Batten Style Fluorescent Luminaires (Authors Own Photos)

In Figure 129 a basic batten mount exposed LFL is shown, these can enhanced using rear reflectors that are positioned above the lamp and direct the light down ward.

\section{Diffused Luminaire}

This style is more suited to the office ceiling. It is usually recessed into the ceiling plane, disguising the depth and control gear that is required for the fluorescent tube, although it 
is also possible to hang these luminaires from the ceiling in a similar manner to high bay lighting. The troffer luminaire can be diffused opaque plastic or directed using a 'crate' styled grid.

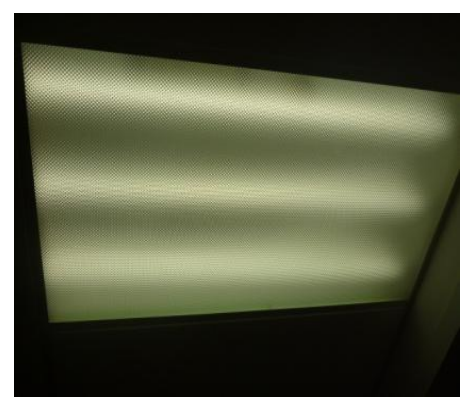

Figure 130: Diffused Linear Fluorescent Lamp (Authors Own Photos)

\section{High Bay Lighting}

High bay lighting usually uses the High Intensity Discharge (HID) lamps such as the metal halide to produce light over a large area. Like the name suggests these lamp are usually positioned in areas of height to allow the light to cover more area.

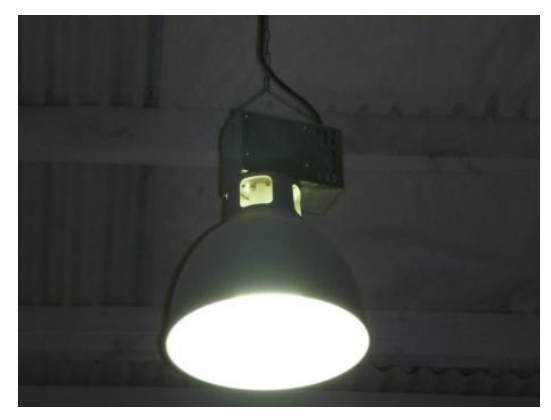

Figure 131: High Bay (Authors Own Photos)

These lamps may or may not directly contain the control gear for the lamp. In the cases where the control gear is not integral to the luminaire it is likely to be mounted in a box above the luminaire. 


\section{Appendix C COLOUR TEMPERATURES}

Figure 132shows the range of colour temperatures and the associated lamp types.

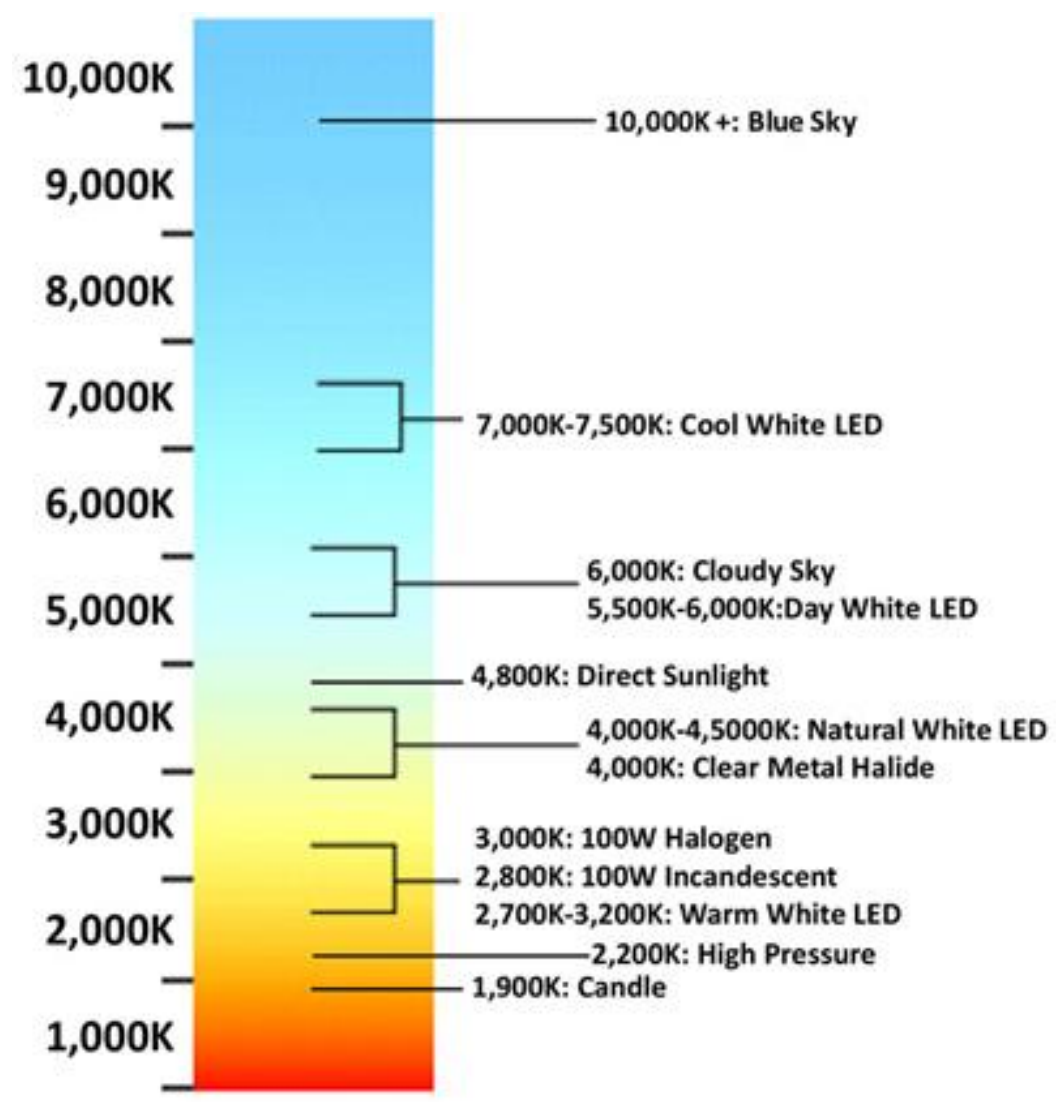

Figure 132: Colour temperature chart (LDS Group, 2010) 


\section{Appendix D THE INFORMATION PACK.}

\section{Letter of intent.}

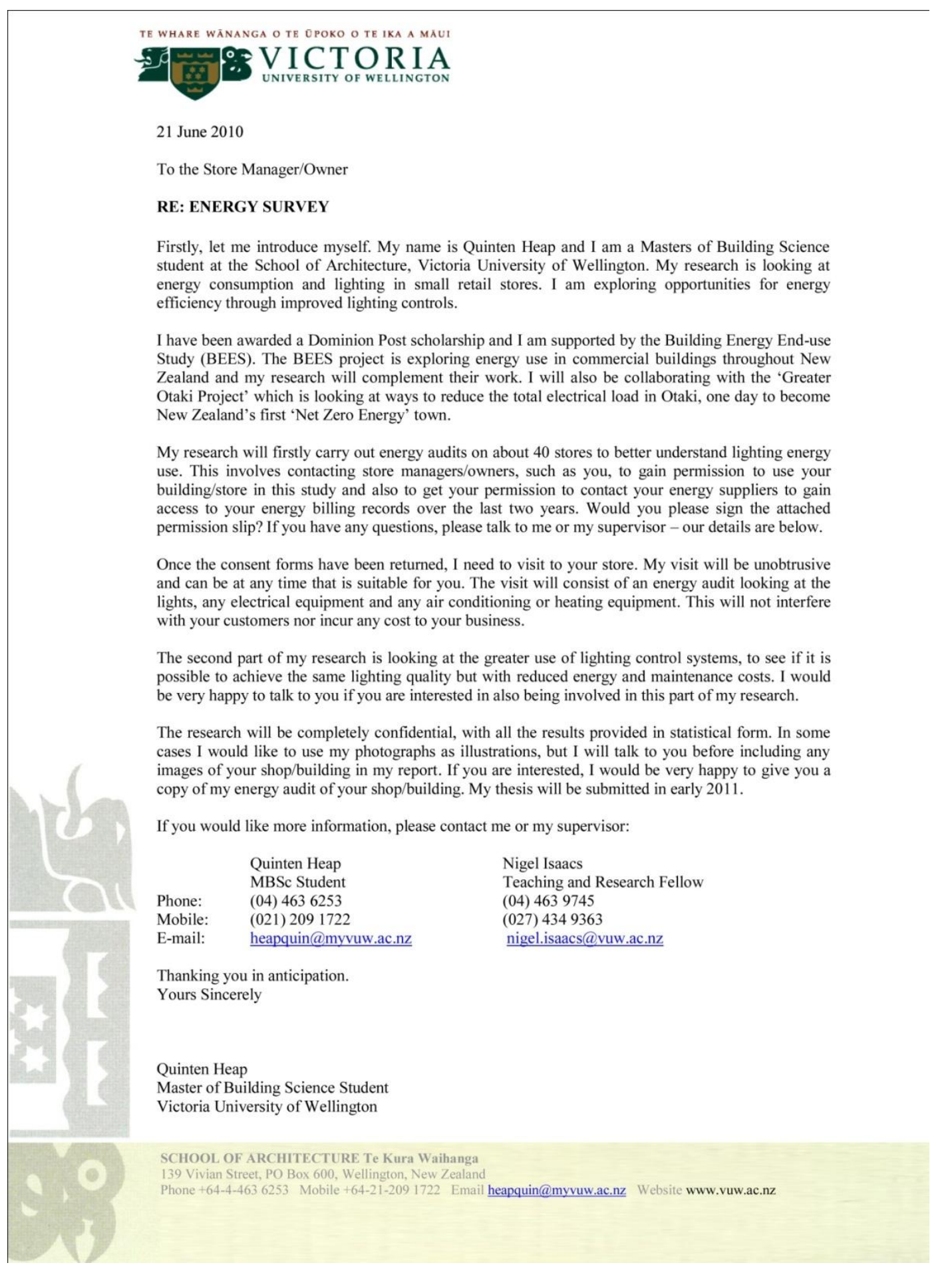




\section{Consent to use the store.}

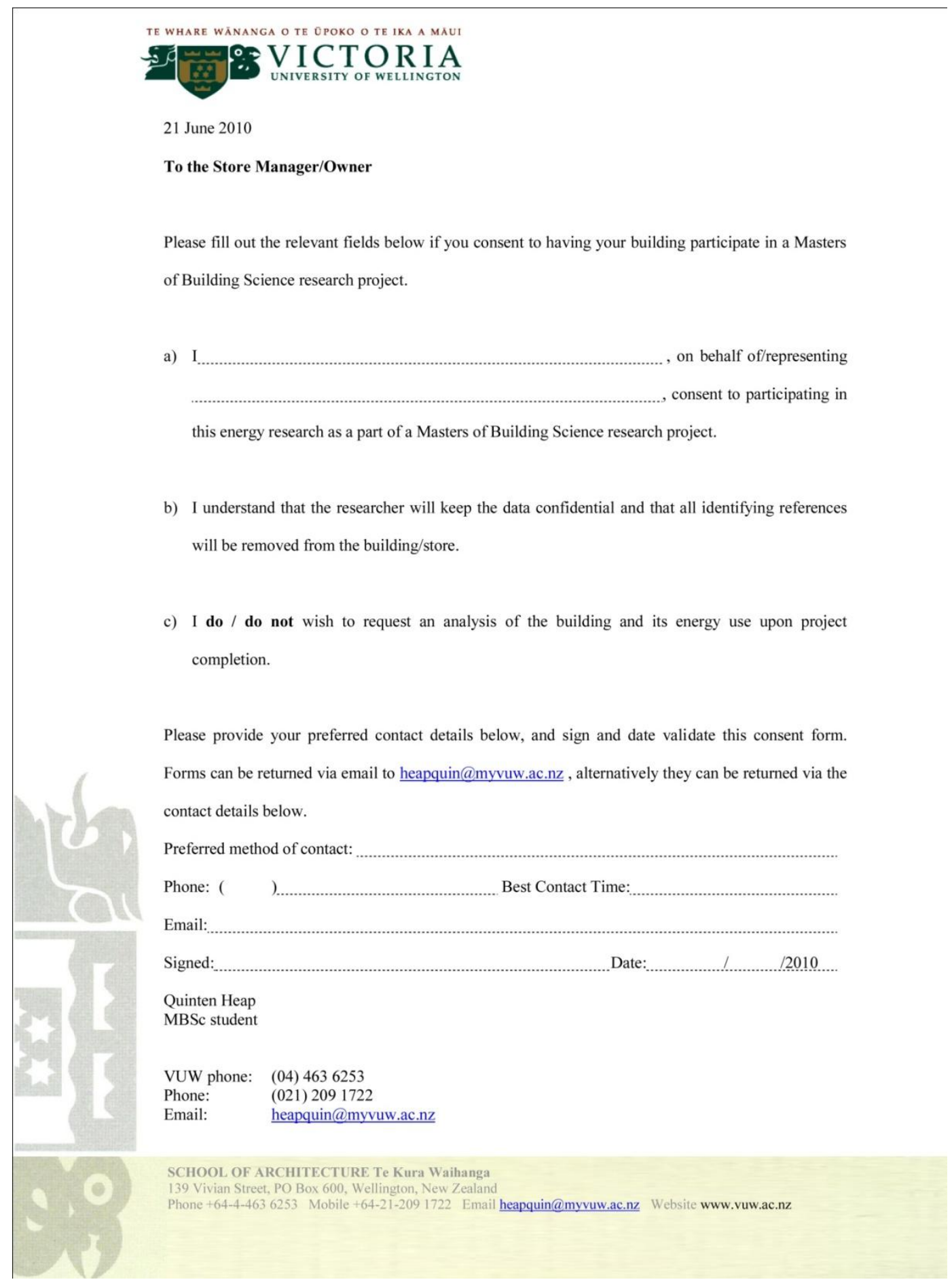




\title{
Consent to gain access to Billing records.
}

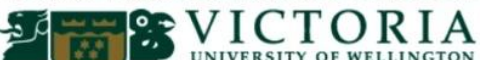

\section{Permission to Access Energy Information}

\begin{abstract}
I agree to allow Quinten Heap, Master of Building Science student, Building Energy End-use Study (BEES) staff and their subcontractors to access my energy billing records for the related energy use data for the purposes conducting an energy audit. I confirm that I have the authority to give such consent in respect of all the utility accounts specified below and I acknowledge that Quinten Heap, BEES staff and/or its subcontractors intend to provide a copy of this consent to each utility supplier listed below and that each of those suppliers will act in reliance on this consent form in disclosing my billing records and related energy data for the purposes of a
\end{abstract} Masters of Building Science research project.

Building/Store Name and/or Address

Name of account holder (s)

Name

Position or Title

Signature Date 12010

(Please post or email the completed form to the VUW address below)

\section{Account Details}

\section{Electricity Provider:}

Account Number:

ICP number:

The ICP can be found on your account near the electrical usage section. Generally it is a 15 digit number.

Please list all other power supply companies (for your current premises) that you have used in the past two years.

This consent is valid until the Masters of Building Science research is finished, or 23 February 2011, whichever is first. It will only be used to obtain the listed data from the named suppliers. Contact: (021) 2091722

SCHOOL OF ARCHITECTURE Te Kura Waihanga

Phone+64-4-4636253 Mobile+64-21-2091722 Email heapquin@myvuw.ac.nz Website www.vuw.ac.nz 


\section{Greater Otaki Project}

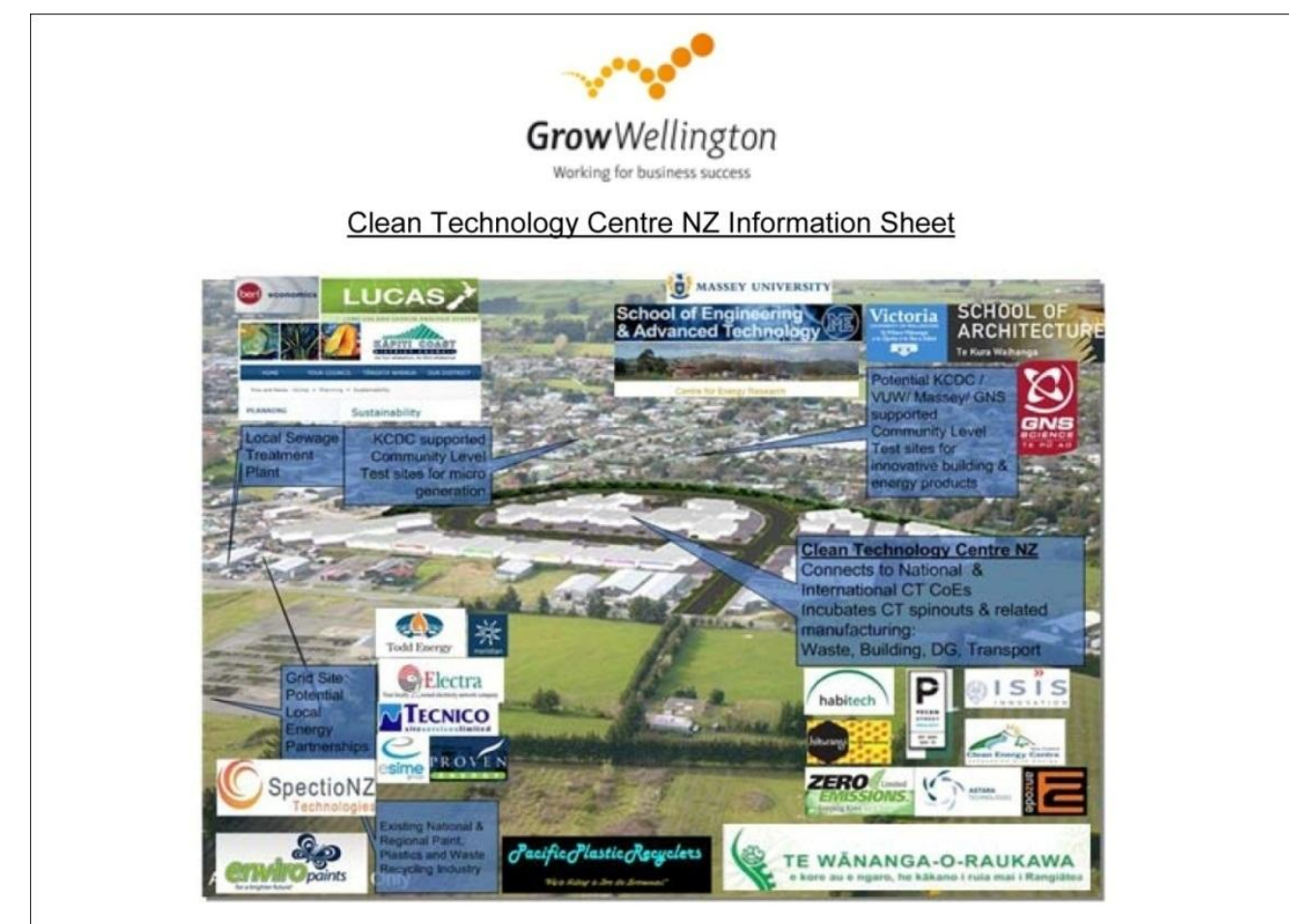

The Clean Technology Centre NZ is a Centre of Excellence from Grow Wellington which proposes a purpose-built clean technology incubator attracting regional, national and international clean technology innovators, investors and entrepreneurs, as the potential collaborations illustrate, above.

Its goal is to provide specialist physical incubation and clean technology support to create inspirational high growth export-oriented clean technology businesses. This goal aligns with the goal of the Otaki Community Board:

\section{That the Otaki community aspires to be the first New Zealand 'off-grid' town by becoming a net supplier to the national energy grid.}

As a core supporter in this concept, Victoria University School of Architecture are currently designing the physical fitout of the facility at Miro St, and also beginning to support the achievement of this goal by connecting related research projects to assess current energy demand, and provide tools to enable more efficient and cost effective energy use.

I am pleased to introduce Quinten Heap and this important first piece of community level research, which is the first step in enabling Otaki to be leading New Zealand in the drive for sustainable living. Please contact me if you require any further information.

Steven Finlay

General Manager (Acting), Centres of Excellence

Grow Wellington Ltd

DDI +64 43820072 Fax +64 43820098 Mob +64 212223873

www.growwellington.co.nz 
Greater Otaki Project (from Otaki Mail, 25 February 2010 )

\section{Report Back on the Greater Ōtaki Project}

About four years ago, the Ôtaki community 政 the Greater Otaki Vision.

From time to time there have been newsletters and report-backs in the newspapers about important to people in the Greater Otaki area.

The community vision ranges from a view on the physical development of the town, 'bilingual town' or a town where people are comfortable with a range of languages, to ments to local streams and main centres.

This report-back covers two major projects or update on the $\mathrm{M}$ the town and also gives

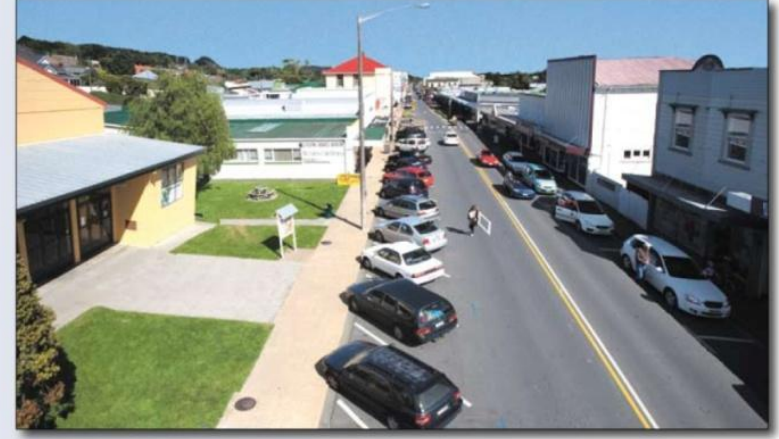

\section{Upgrade to Main Street}
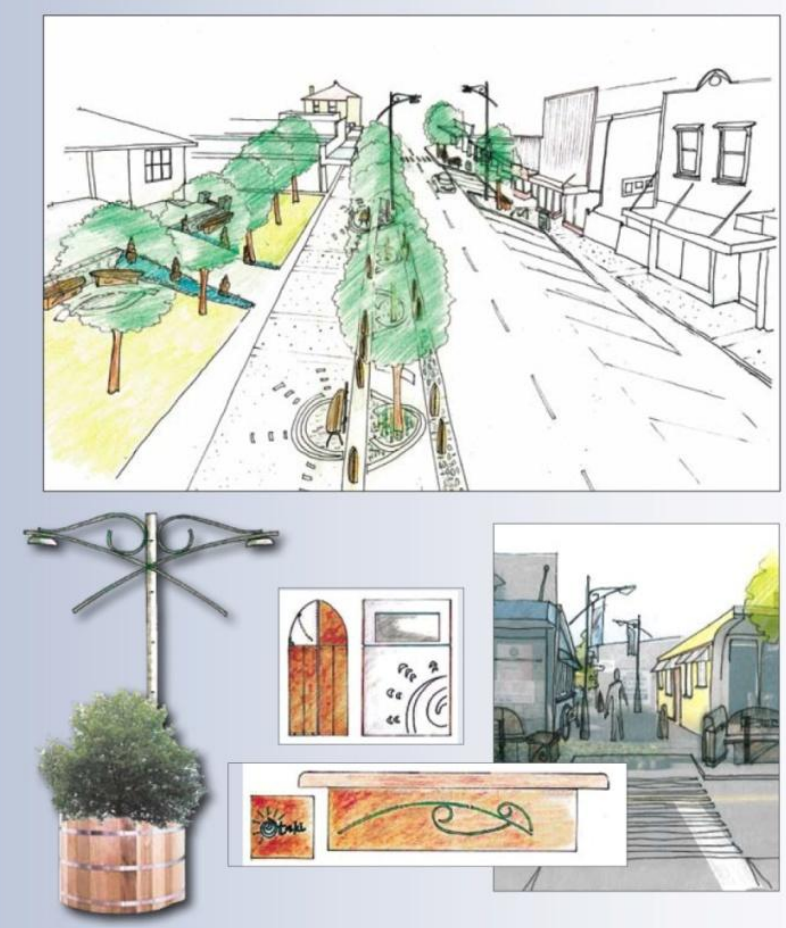

On 16 February, 2010 the Otaki Community Board gave its endorsement to final concepts Aotaki Street to Te Rauparaha Street.

Tenders have now been called to complete the detailed engineering designs and construction is planned to start in November. Final start retailers about the best time to undertake the work.

The latest round of community discussion resulted in a clear favourite option and the Community Board agreed that this was the one they wanted to see developed.

The design keeps angle parking, (a clear community wish), on the north side of the street. This allows the footpath and pavement to be widened on the south side to make best use of Sunny Otaki's sunshine.

There will be a drop-off area in front of the Town Hall and tree planting. Street furniture designed specifically for Main Street is also planned, based on the community design competition. It may seem a long time since the ideas were first discussed but keep in mind the improvements to the railway carpark which have been completed in between.

Given that Otaki had had this earlier project, other town centres were in line for upgrade projects ahead of Main Street. But the Counci decided last year to bring forward the Main Street improvements so the momentum of the Greater Claki project was kept going. So, not long to go before Main Street gets a major facelift.

KAPRT COAST

O I S T R I C T C O U N C I D
me huri whakamuri, ka titiro whakamua 


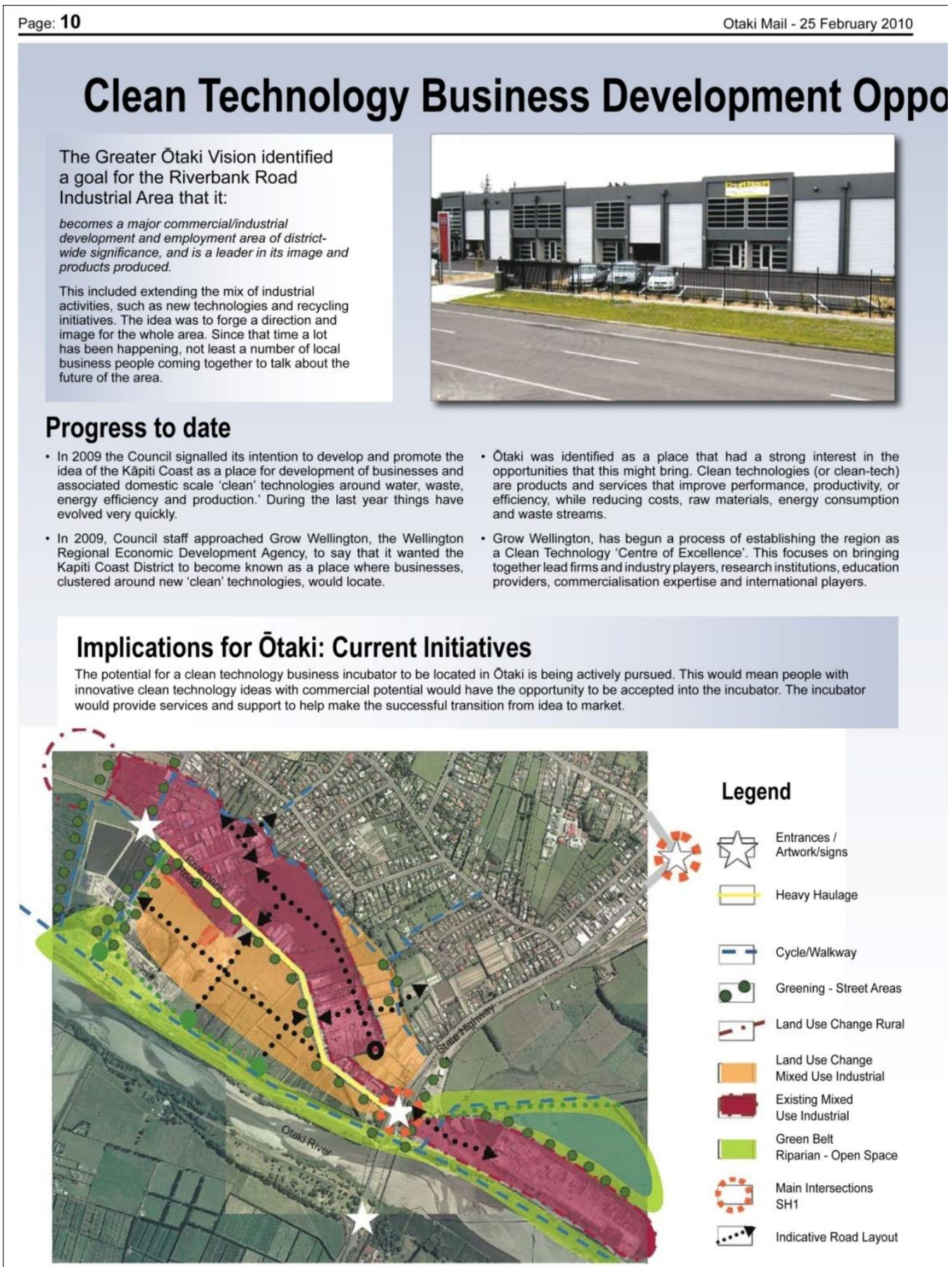




\section{rtunities for the Riverbank Road Industrial Area}

\section{New Business}

A new business (SpectioNZ) has successfully passed through this incubation phase assisted by Grow

Well is now. Spectionz pis in the next stage

can turn harmful waste products, such as plastics and bio-mass, into usable products such as fuel for power generation.

Kapiti Coast District Council has provided SpectioNZ with the ability to build and develop a small scale pilot model Plant using the dried sewage sludge.

They will also be testing wet sludge from the Ōtaki wastewater treatment plant. Should this prove successful the wastewater sludge at the Otaki treatment plant.

\section{Implications for Ōtaki:} Future Opportunities

At the same time, clean technology businesses will be encouraged to locate in the area, providing an increasing 'mass' which will attract other research interests and new business to th

Grow Wellington's Centre of Excellence concept also includes the plan that a physical Clean Technology Centre will be developed and located in Otaki.

As well as encouraging business clustering, the centre would be a place where universities could physically locate research students working with technology development.

\section{Clean Technology Centre New Zealand: Potential Live Collaborations}

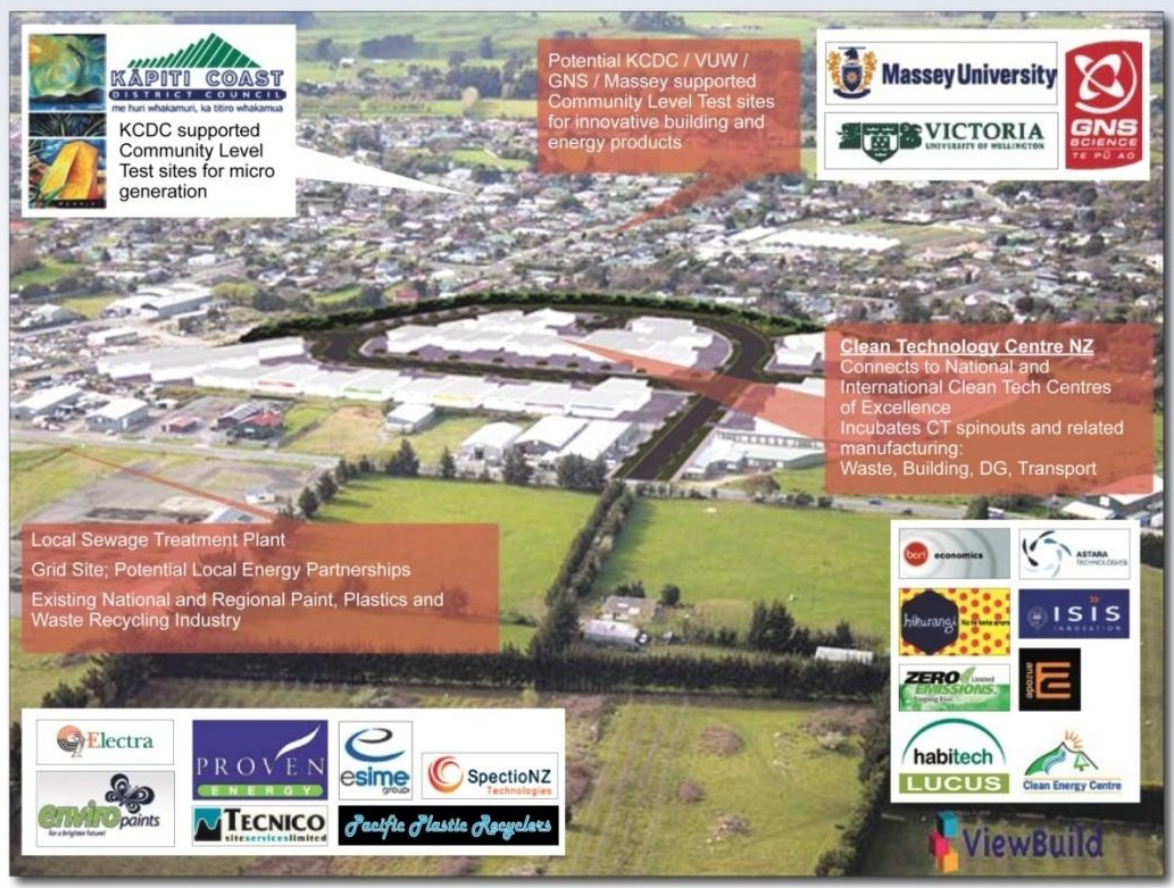

\section{Enthusiastic community and Council support}

One of the factors which would encourage this to happen is to have Otak seen as a town where researchers and businesses can physically trial new ideas, such as innovative building products or energy systems in existing buildings. If there is enthusiastic community and Council support for this
partnership approach it would be a significant building block. 


\section{Going Off Grid}

\section{A Vision of Ōtaki as a Town Which Supplies the National Energy Grid}

As the current Centre of Excellence concept has developed over the last few months, the possibility of Otaki declaring itself as a

This would be a major attraction for clean technology companies especially businesses developing new, community scale, energy technologies

Combining this with a community working in partnership with the Council to provide support for on-the-ground testing of microgeneration projects would be a significant contribution. It would help cement an Ôtaki Centre for Clean Technology and new business development.

For Otaki, the term 'off-grid' would be a short-hand term for the town becoming a net supplier of energy to the national grid. This supply could be achieved through the activities of businesses and households and could even have the town operating as an earne of income from energy.

Imagine every house with solar power and small windmills, or a small waste converter on their kitchen bench which converts waste to

There would be two areas of action:

- energy efficiency systems for housing, other buildings and systems - e.g. housing insulation and design, street lighting assist in moving Otaki to recuce the demand for energy an

- micro-generation systems. By this is meant development of household, neighbourhood or town small-scale generation systems. For example, small windmills, innovation in solar heating, to energy, wevelopment of local wood coppicing trees for supply of wood to boilers for major services. The Council is already converting some of its diesel powered boilers to wood supply.
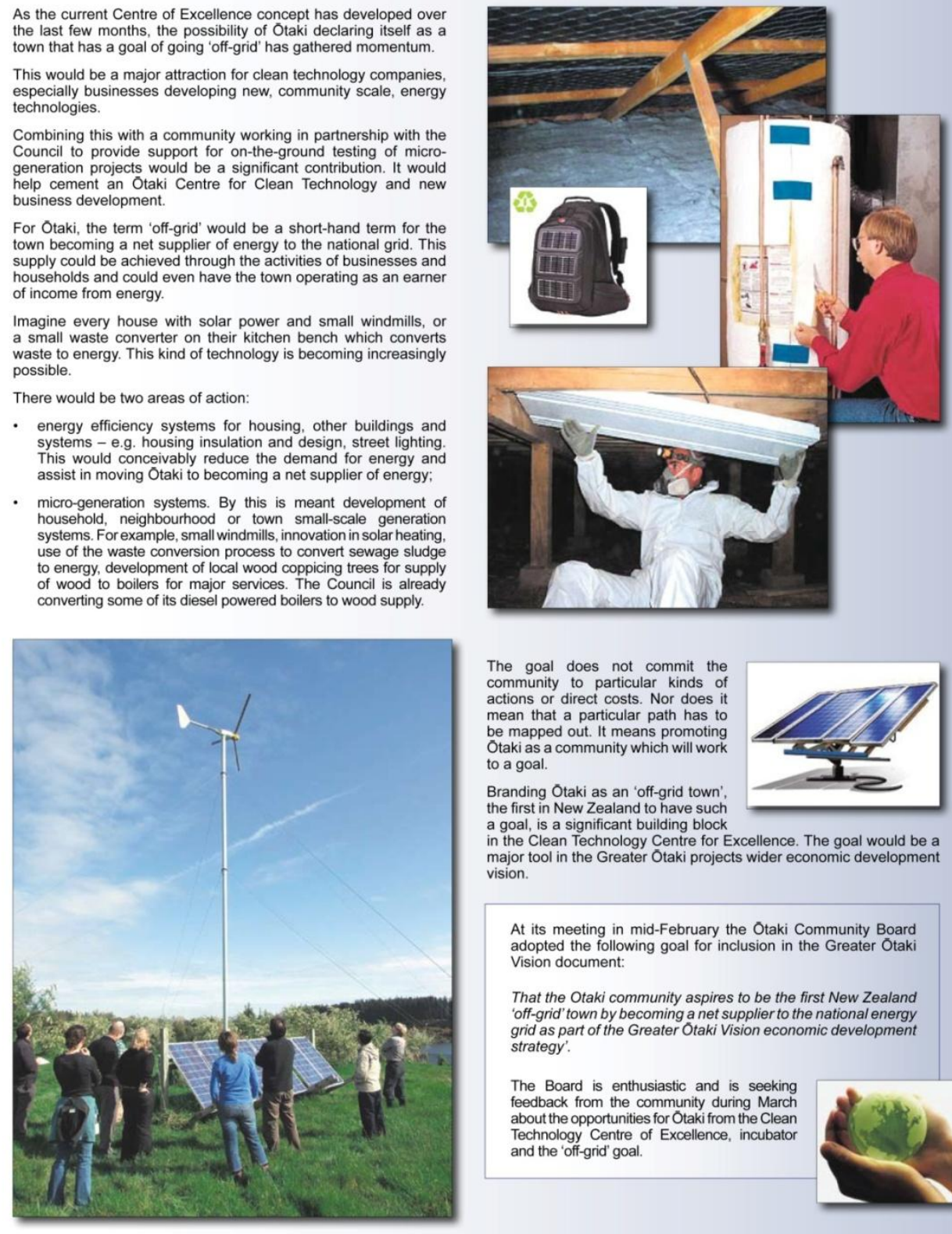

The goal does not commit the community to particular kinds of actions or direct costs. Nor does it mean that a particular path has to Otrkips a community which will work to a goal.

Branding Otaki as an 'off-grid town', the first in New Zealand to have such

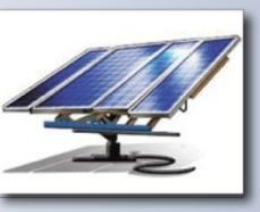
a goal, is a significant building block

in the Clean Technology Centre for Excellence. The goal would be a vision.

At its meeting in mid-February the Otaki Community Board

That the Otaki community aspires to be the first New Zealand 'off-grid' town by becoming a net supplier to the national energy strategy'.

The Board is enthusiastic and is seeking feedback from the community during March about the opportunities for Otaki from the Clean Technology Centre of Excellence, incubator and the 'off-grid' goal.

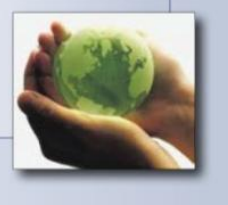




\section{Appendix E The Boutique FASHION STORE}

This and the following Appendices (Appendix E - Appendix I) use five store types to explore the results from the energy audits:

- Boutique Fashion Store;

- Outlet Fashion Store;

- Sports Store;

- Food Sales; and

- Other Store types

They explore how electricity is used in the different stores and then based on revenue meter data calculates lighting electricity consumption. The last part of each appendix uses these observations to estimate lighting electricity use by time of day and for the year for each of the selected Otaki retail stores.

\section{Floor Plans}

The plans reproduced here are not to scale and are used to provide reference for the store layouts and lighting locations.

\section{The Boutique Store}

The boutique store differentiates itself from the outlet stores through specialising in selected fashion lines that are not available at wholesale or discounted prices. Located on the eastern side of State Highway One, the example store faces the road with approximately three metres of display window, with the main entrance positioned halfway along. Figure 133 is a floor plan of the store, showing a rectangular shaped store with floor area split by a dividing wall between the main retail area to the front and a stock/utility room to the rear

The total floor area is approximately 40 square metres, split so the retail area is about $85 \%$ of the available space. 


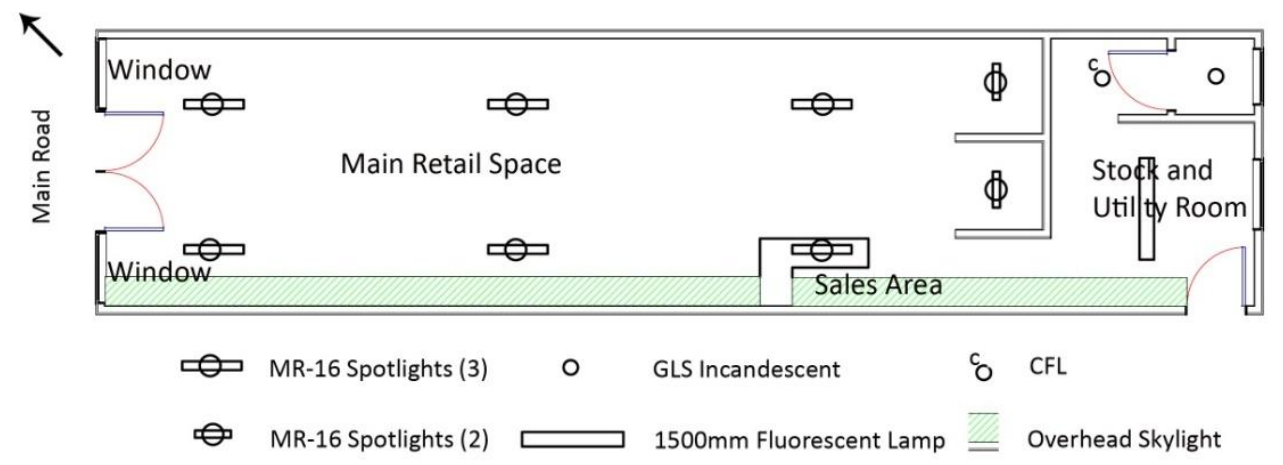

Figure 133: Floor and Lighting Plan of the Boutique Store

The concrete-block building has a wood and plaster board interior finished in a mixture of light colours, fabric and polished wood. The fit-out design was developed by the owner and has free standing displays near the walls as well as wall mounted merchandise. The centre of the store is clear, with the sales counter at the rear of the store on the right.

\section{Lighting Types}

The lighting design was developed by the owner in conjunction with the local electrician. The fittings are similar to other stores on the strip that contain the same lamp type. Figure 134 provides the count of the lamps within the space.

\begin{tabular}{|lclccc|}
\hline Lamp Type & $\begin{array}{c}\text { Lamp } \\
\text { Count } \\
\text { A }\end{array}$ & Fitting & $\begin{array}{c}\text { Lamp } \\
\text { Watts } \\
\text { B }\end{array}$ & $\begin{array}{c}\text { Control or } \\
\text { Ballast } \\
\text { C }\end{array}$ & $\begin{array}{c}\text { Total Watts } \\
=\text { A * (B+C) }\end{array}$ \\
\hline MR-16 & 22 & Specialist & 50 & 5 & 1210 \\
\hline $\begin{array}{l}1500 ~ m m \\
\text { Fluorescent }\end{array}$ & 2 & $\begin{array}{l}\text { Exposed } \\
\text { Batten }\end{array}$ & 58 & 14 & 144 \\
\hline CFL & 1 & GLS Mount & 20 & 4 & 24 \\
\hline Incandescent & 1 & GLS Mount & 100 & 0 & 100 \\
\hline Total & 26 & & & \\
\hline \multicolumn{5}{r}{ Figure 134: Total Lamp Count within the Stores } \\
\hline
\end{tabular}

As shown in the floor plan, Figure 133 above, in the main retail space the ambient light is provided by the MR-16 spot lights which are also used to highlight some of the free standing displays. The lamps are mounted in a three lamp luminaire that allows the 'beam' of light to be directed as required. The change rooms use the same style of luminaire, but each fitting has only two lamps. The stock / utility room is lit by a twin fluorescent lamp, while the toilet uses a CFL and the wash room an incandescent lamp.

The installed lighting load is given by area in Figure 135. 


\begin{tabular}{|lcc|}
\hline & Retail Area & Storage/Staff Area \\
\hline Installed Watts & 1210 & 268 \\
\hline Percent of Load & $82 \%$ & $18 \%$ \\
\hline Floor Area & $34 \mathrm{~m}^{2}$ & $6 \mathrm{~m}^{2}$ \\
\hline Percent of Floor Area & $85 \%$ & $15 \%$ \\
\hline LPD & $36 \mathrm{~W} / \mathrm{m}^{2}$ & $45 \mathrm{~W} / \mathrm{m}^{2}$ \\
\hline \multicolumn{2}{|}{ Figure 135: Light Power Densities for Floor Area by Use } \\
\hline
\end{tabular}

The calculated light power density for the store is $37 \mathrm{~W} / \mathrm{m}^{2}$, which is high compared to the $20 \mathrm{~W} / \mathrm{m}^{2}$ recommended by ASHRAE for clothing stores. (Section 2.9)

\section{Lighting Circuits}

The store has been lit using six lighting circuits, split evenly across the two areas. Each of the three luminaires in the rear storage/staff area is individually switched. The front retail area also uses three circuits: one for the change rooms, one for the front two luminaires and one for the lights in the main retail area.

\section{Trading Hours}

The store owner stated that the advertised hours were basically followed, with only odd deviations due to customer numbers or the season. The shop aimed to be open for approximately 7.5 hours a day, 7 days a week. Although if the weekend proved successful then it was possible on the following Monday that the shop could remain closed or open later.

Staff did not enter the store any earlier than opening time, as stock-take and clean-up occurred during the open hours. At night, the lights were turned off, the alarm set and the staff departed, so the advertised opening hours fairly represented the operating day.

\section{Lighting}

It was reported that only the two front luminaires remained on overnight and only during the winter months, as in the summer there were no lamps left on inside the store.

The average weekly consumption for the winter and summer lighting load is shown in Figure 136 and Figure 137. 
Winter:

\begin{tabular}{|lccccc|}
\hline Lamp & $\begin{array}{c}\text { Total } \\
\text { Watts }\end{array}$ & $\begin{array}{c}\text { Average Daily } \\
\text { 'On' Time }\end{array}$ & $\begin{array}{c}\text { Watt hour } \\
\text { /day }\end{array}$ & $\begin{array}{c}\text { Average } \\
\text { Weekly Hours }\end{array}$ & $\begin{array}{c}\text { Watt hour } \\
\text { /Week }\end{array}$ \\
\hline MR-16 Main & 660 & 7.5 & 4,950 & 49 & 32,340 \\
\hline $\begin{array}{l}\text { MR-16 } \\
\text { Front }\end{array}$ & 330 & 24 & 7,920 & 168 & 55,440 \\
\hline $\begin{array}{l}\text { MR-16 } \\
\text { Change }\end{array}$ & 220 & 7.5 & 1,650 & 49 & 10,780 \\
\hline Fluorescent & 144 & 7.5 & 1,080 & 49 & 7,056 \\
\hline $\begin{array}{l}\text { CFL and } \\
\text { GLS }\end{array}$ & 124 & 1 & 124 & 7 & 868 \\
\hline Total & & & & $\mathbf{1 0 6 , 4 8 4}$ \\
\hline \multicolumn{7}{l}{ Figure 136: Lighting Load Consumption - Winter. } \\
\hline
\end{tabular}

\section{Summer:}

\begin{tabular}{|c|c|c|c|c|c|}
\hline Lamp & $\begin{array}{l}\text { Total } \\
\text { Watts }\end{array}$ & $\begin{array}{c}\text { Average Daily } \\
\text { 'On' Time }\end{array}$ & $\begin{array}{c}\text { Watt } \\
\text { Hour/day }\end{array}$ & $\begin{array}{c}\text { Average } \\
\text { Weekly Hours }\end{array}$ & $\begin{array}{c}\text { Watt } \\
\text { Hour/Week }\end{array}$ \\
\hline MR-16 Main & 660 & 7.5 & 4,950 & 49 & 32,340 \\
\hline MR-16 Front & 330 & 7.5 & 2,475 & 49 & 16,170 \\
\hline MR-16 & 220 & 7.5 & 1,650 & 49 & \\
\hline Change & & & & & 10,780 \\
\hline Fluorescent & 144 & 0 & 0 & 0 & \\
\hline $\begin{array}{l}\text { CFL and } \\
\text { GLS }\end{array}$ & 124 & 0 & 0 & 0 & \\
\hline Total & & & 9,075 & & 59,290 \\
\hline
\end{tabular}

The decision to run the front two luminaires (MR-16 Front, Figure 136 and Figure 137) over winter means an increase of 6649 Watthours per day. Weekly this translates to an increase of 47,194 Watthours/week $(59.2 \mathrm{kWh} /$ week in summer increases to 106.5 $\mathrm{kWh} /$ week in winter), due to an additional 119 hours operating hours per week. This extra run time means as well increased operating costs, the need for bulb replacement and maintenance will also be increased.

\section{Plug Loads}

The plug loads for the recorded appliances are shown in Figure 138. Typical Wattages were developed using the EECA Audit Manual 2007 (EECA, 2007) and through personal observations on-site, as discussed in Section 6.3. These have been listed in Figure 138. 


\begin{tabular}{|c|c|c|c|c|c|c|c|}
\hline & & \multicolumn{6}{|c|}{ Average Hourly Load (Watts) } \\
\hline Equipment type & $\begin{array}{c}\text { Coun } \\
t\end{array}$ & $\begin{array}{l}\text { Per } \\
\text { Day }\end{array}$ & $\begin{array}{c}\text { Per } \\
\text { Night }\end{array}$ & $\begin{array}{c}\text { Day } \\
\text { (7.5hrs) }\end{array}$ & $\begin{array}{c}\text { Night } \\
\text { (16.5hrs) }\end{array}$ & $24 \mathrm{hr}$ & $\begin{array}{c}\text { Per } \\
\text { Week }\end{array}$ \\
\hline EPoS Till & 1 & 65 & 5 & 487 & 82 & 570 & 3,990 \\
\hline Fridge & 1 & 20 & 20 & 150 & 330 & 480 & 3,360 \\
\hline Printer & 1 & 5 & 5 & 37 & 5 & 42 & 297 \\
\hline Electric Jug & 1 & 40 & 0 & 300 & 0 & 300 & 2,100 \\
\hline Stereo/Phone/EFTPoS & 1 & 12 & 8 & 90 & 132 & 222 & 1,554 \\
\hline Total & & 142 & 38 & $\mathbf{1 , 0 6 5}$ & 549 & 1,614 & 11,301 \\
\hline
\end{tabular}

The plug load consumption, based on an average trading day and the expected overnight on hours, is given in Figure 138 as $11.3 \mathrm{kWh} /$ week.

The overall load varies with the season - in winter about $118 \mathrm{kWh} /$ week while in summer it drops to about $65 \mathrm{kWh} /$ week. This is a result of the store switching off the fridge and electric jug during summer.

\section{Lux Levels}

The light levels in this store had to be measured in the late afternoon on Wednesday the $9^{\text {th }}$ of June 2010 as this was the only time that the manager was available. At this time of the day, the sun's low angle meant sunlight penetrated into the store through the display windows. Lux levels varied from 29,000 lux in the sunlight at the window down to 380 lux at the back of the store, while underneath the MR-16 spotlights measurements were up to 500 lux.

\section{Daylight}

The premise has access to daylight through the display windows, overhead skylights and through windows in the storage/staff area.

- There are only four stores on the Otaki strip with access to daylight through overhead skylights. In this store, the skylights are shown in Figure 133 as hatched lines on the southern wall. Despite the skylight illuminating the sales counter and half of the merchandise, daylight is not used to reduce the lighting load.

- In contrast, the rear storage/staff room makes full use of the eastern facing vertical windows. The owner's policy is to leave these lights off at all times unless required for a specific task, a policy that also covers the toilet and wash area.

- The main display windows appear to be the best opportunity for the store to utilise daylight as a free light source. The displays in the windows are free 
standing and do not compromise the view from the street in to the exterior. As the building faces west and the buildings opposite are all single storey, the low angle winter sun can penetrate deep into the store. This is undesirable for two reasons: firstly as the UV in the sunlight fades merchandise; and secondly that low angle sun masks customers entering the store from the shop assistants which will affect both the store safety and security.

To counteract the sunlight through the display windows, the store owner uses two black, drop screens to shield the rest of the store. Even so, the screens leave the display windows exposed, and according to the owner, once merchandise has been displayed in the window it is unlikely to be sold due to sun damage. The black screens also have the effect of making the store appear closed from the outside, which then leads to the doors remaining open during the trading hours ('open door' policy) with its own set of safety and security issues.

\section{Billing}

The meter electricity billing data covered the period from April 2008 through to May 2010, but as noted in Section 6.11 for the purposes of comparison the year from 1 June 2009 to 31 May 2010 has been used, as shown in Figure 139.

\begin{tabular}{|lll|}
\hline Store Type & Type & Total Consumed \\
\hline Fashion & Electrical Energy & $4,541 \mathrm{kWh} / \mathrm{yr}$ \\
\hline & Average Weekly Consumption & $87 \mathrm{kWh} / \mathrm{week}$ \\
\hline \multicolumn{3}{|c|}{ Figure 139: Amount Consumed for Year (June 2009 - May 2010) } \\
\hline
\end{tabular}

Figure 139 gives the total annual electricity consumption as $4,541 \mathrm{kWh}$, with an average weekly use of $87 \mathrm{kWh}$.

The EUI has been calculated as $108 \mathrm{kWh} / \mathrm{yr} \cdot \mathrm{m}^{2}$ and is rated in the fair range of Figure 75 suggesting that some energy savings potential exists.

\section{Monthly Consumption}

The store bi-monthly electricity consumption is shown below in Figure 140. As discussed in Section 6.11, bimonthly comparisons can provide valid consumption over a year when every second month bill is an estimate.

The temperature in red represents the mean average temperature for each month during the billed period (NIWA, 2011). The temperature has been graphed to show the seasonal variation, to allow any changes in energy use to be compared to the changes in temperature. 


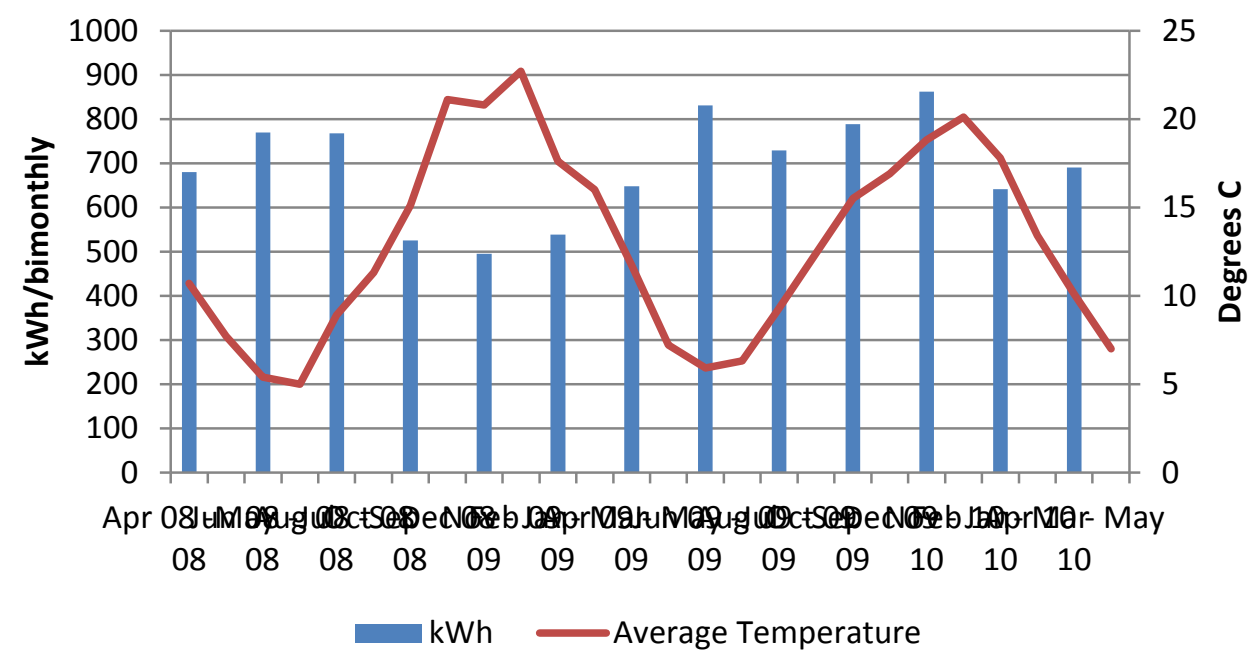

Figure 140: Billing Records for Store (Bi-monthly April 2008 - May 2010)

During the energy audit there was no sign of electric space heating, but Figure 140 suggests that there is seasonal variation.

The choice of lights in the retail area represents the largest consumers of energy in the space. They are calculated to consume $93 \%$ of all the electrical energy consumed on site and are directly responsible for the site consuming on average $377 \mathrm{kWh}$ per month.

Figure 141 shows the range of lighting that can be altered by the occupant against the billed amount for the bi-monthly period. The lower end of vertical black line represents the identified plug loads and the lighting used in the retail area, including the sales area, changing rooms and window displays but not any overnight lighting. The top of the vertical black line is the high use that would occur if all of the lighting and plug loads in the store were in use throughout the day. The green triangle shows the billed energy use.

As the green triangle (billed amount) is situated within the lighting range (black line), Figure 141 suggests that the seasonal variation could be accounted for by the selection of lighting and hours of use, without the need for any electrical heating or equipment changes. 


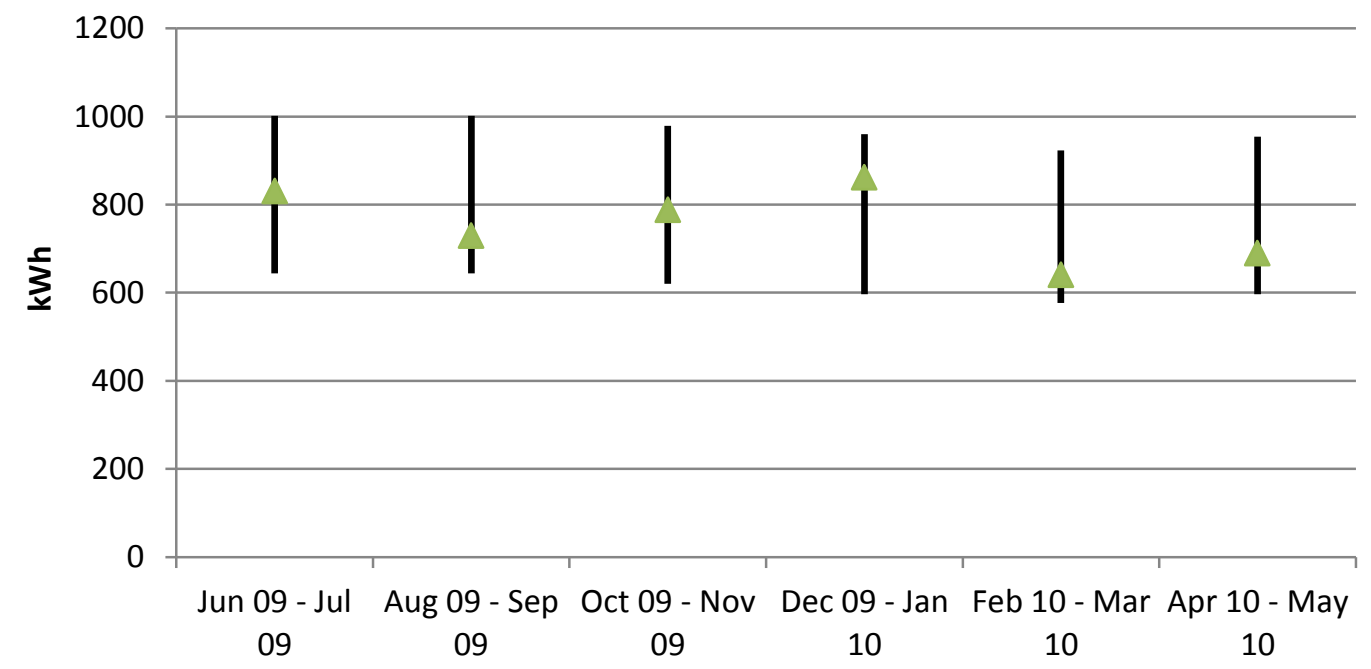

Bi-Monthly Billed Amount

Range of Selectable Lighting

Figure 141: Range of Calculated Loads and Billing Total.

\section{Load Profile}

Figure 142 is a simplified load profile developed by applying the advertised trading hours to the calculated plug and lighting loads.

Based on the distribution shown in Figure 140, the highest consumption for a winter occurs during the June - July 09 period. To calculate an average winters month for the year the bi-monthly period is divided by two $(830 \mathrm{kWh} / 2)$ to give $415 \mathrm{kWh}$, while for an average summer month (December 09 - January 10) it is $431 \mathrm{kWh}$.

The average daily consumption figure was then created by dividing the bi-monthly total by the number of days in that period (e.g. $830 \mathrm{kWh} / 61$ days). To then create a weekly or monthly consumption figure, the daily rate is multiplied by the appropriate number of days. An average winter's week consumption is $95 \mathrm{kWh}$ and an average summer's week is $97 \mathrm{kWh}$.

Figure 142 provides simplified hourly load profiles for winter and summer. The magnitude is the power required by the store in $\mathrm{kW}$, while the area beneath the graph is the daily consumption in $\mathrm{kWh}$ which when multiplied by seven will represent an average week's energy use. Lighting energy use is shown in blue and other appliances in red. 

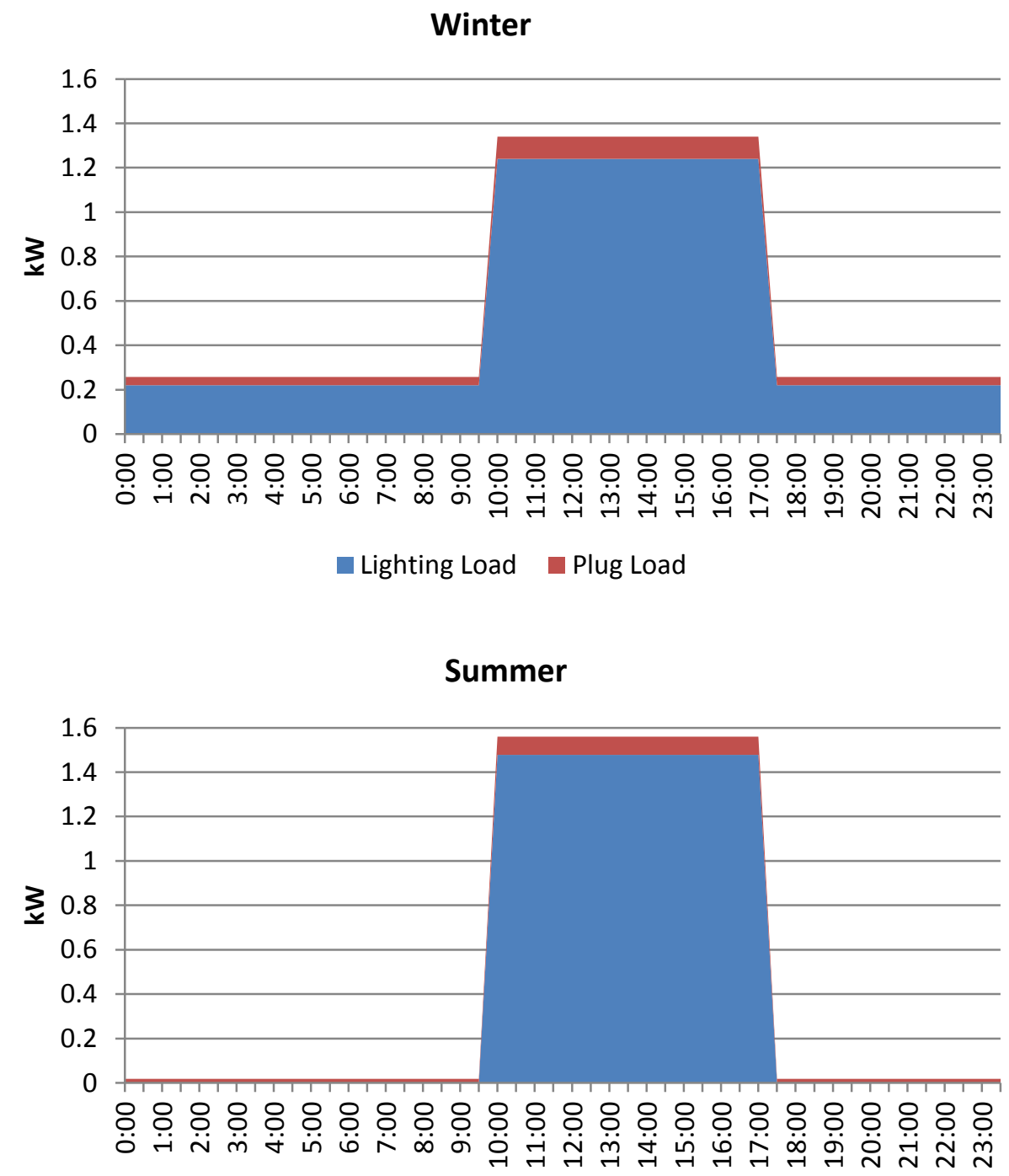

- Lighting Load Plug Load

Figure 142: Simplified Load Profiles for Summer And Winter

An average week's energy use based on the area under the graph is $95 \mathrm{kWh}$ for winter and $97 \mathrm{kWh}$ for summer which is within the $15 \%$ required for an energy balance by the EECA audit manual (EECA, 2007, p. 15).

In this store, Figure 142 shows that lighting is the significant load in both summer and winter, largely due to the lack of heating. As store management indicated that the display window lights were switched off at night in summer, the load balance assumed a higher load during the day which could be selected by the occupants. This is shown in summer graph above and in Figure 141 


\section{Energy Saving Opportunities}

The operation of this store would appear to have some opportunities for improved energy efficiency. The most obvious would be to turn off the front two overhead lights. On each of the three afterhours visits to Otaki (Section 5.2), it was noted that the drop down screens remained pulled which masked the lights, suggesting the expected security benefits were not achieved.

The potential saving opportunities of switching these front two overhead lights 'off' are approximately $38 \mathrm{kWh}$ per week, or 1,982 kWh per year.

There are six 50Watt MR-16 lamps housed in these two overhead luminaires (three in each) and each lamp requires 5 watts of control gear. Each lamp consumes 55 Watts of electrical energy: 55Watts $x$ 6lamps $=330$ Watts installed.

For the average trading week of $\mathbf{5 2 . 5}$ hours, night-time use requires the lamps to operate for an extra 115.5 hours: $115.5 \mathrm{hrs} x 330 \mathrm{Watts}=38 \mathrm{kWh} /$ average week. Annually this would equate to an average consumption of $38 \mathrm{kWh} /$ week $\times 52$ Weeks $=1,982 \mathrm{kWh}$. This calculation is been based on the average advertised trading week and a standard year of 52 weeks. It does not account for public holidays or no-trade days such as ANZAC day or Christmas.

The remaining MR-16 lamps could also be exchanged for their Energy Efficient alternatives. The light output from the 50 Watt MR-16 can be produced using an energy efficient Infra Red Coated (IRC) lamp at just 35 Watts (OSRAM, 2010). The remaining lamps in the store account for 660 Watts consuming 4,950 Watthours/day. Over a year these lamps may consume $1789 \mathrm{kWh} / \mathrm{yr}$. Energy savings by fitting the energy efficient lamps would equate to $30 \%$ on the installed and consumed load. Therefore savings of 537 $\mathrm{kWh} / \mathrm{yr}$ may be realised.

The fridge is an appliance of interest - if it is required only for six months of the year, then it is unlikely to be extensively used during the rest of the year. If the fridge was removed, there is the potential for a further $50 \mathrm{kWh}$ to be saved. 


\section{Appendix F The OUtLET FASHION STORE}

The outlet store promotes 'cheaper' items that are generally advertised as permanently on sale. Along the Otaki retail strip, the only outlet stores are part of the Fashion category. These stores usually promote a single brand or product range such as swimwear or woollen clothing.

The selected store is located on the western side of State Highway One with about nine metres of window display. Figure 143 shows that the store is rectangular in shape, with a floor area of approximately 180 square metres. This space is divided into a main retail area and a storage/staff area to the rear, with the retail area is around $80 \%\left(144 \mathrm{~m}^{2}\right)$ of the total available floor area.

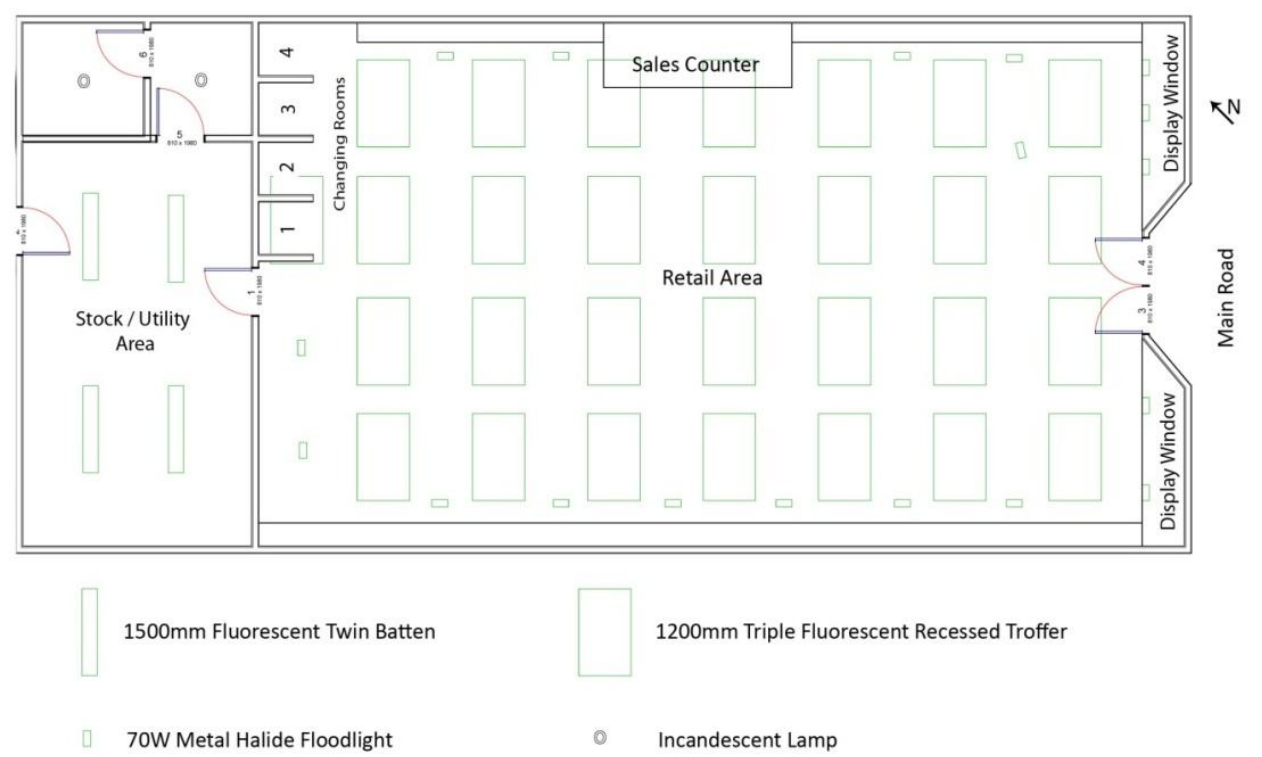

Figure 143: Floor Plan and Lighting Layout of Selected Outlet Store

The concrete block building has a plaster board and timber lining. The interior and exterior colours and merchandising displays are brand orientated, as determined by the business's head office.

\section{Lighting Types}

Two lighting systems light the store. Recessed fluorescent lamps are used for ambient lighting while perimeter lighting uses ceiling mounted, metal halide, and flood lights. Figure 144 gives the on-site lamp count. The 115 lamps have a maximum load of $6.2 \mathrm{~kW}$. 


\begin{tabular}{|lccccc|}
\hline Lamp Type & $\begin{array}{c}\text { Lamp } \\
\text { Count } \\
\boldsymbol{A}\end{array}$ & Fitting & $\begin{array}{c}\text { Lamp } \\
\text { Watts } \\
\boldsymbol{B}\end{array}$ & $\begin{array}{c}\text { Control or } \\
\text { Ballast } \\
\boldsymbol{C}\end{array}$ & $\begin{array}{c}\text { Total Watts } \\
\boldsymbol{=} \boldsymbol{A} *(\boldsymbol{B}+\boldsymbol{C})\end{array}$ \\
\hline $\begin{array}{l}1200 \mathrm{~mm} \\
\text { Fluorescent }\end{array}$ & 87 & $\begin{array}{c}\text { Recessed } \\
\text { Troffer }\end{array}$ & 36 & 9 & 3,915 \\
\hline $\begin{array}{l}1500 \mathrm{~mm} \\
\text { Fluorescent }\end{array}$ & 8 & $\begin{array}{c}\text { Exposed } \\
\text { Batten }\end{array}$ & 58 & 14 & 576 \\
\hline Metal Halide & 18 & Wall Flood & 70 & 14 & 1,512 \\
\hline Incandescent & 2 & GLS Holder & 100 & 0 & 200 \\
\hline Total & $\mathbf{1 1 5}$ & & $\mathbf{6 , 2 0 3}$ \\
\hline \multicolumn{7}{r}{} \\
\hline
\end{tabular}

The Figure 143 floor plan also shows the store lighting layout. The $1200 \mathrm{~mm}$ fluorescent lamps are positioned in grid pattern to provide an even light throughout the retail area.

The metal halide lamps are used primarily to illuminate the walls and wall-mounted merchandise. These lamps have been positioned symmetrically around the store to produce an even and consistent lighting effect on the walls. Five of the eighteen metal halide lamps light the display window, with three of these remaining on permanently.

The changing rooms, located in the retail area, are lit by the overhead, ambient fluorescents. The storage and staff area is lit using four, twin batten $1500 \mathrm{~mm}$ fluorescents, giving a total of eight lamps. The toilet and wash area are lit by two incandescent lamps. Figure 145 gives the lighting electric load for the two spaces.

\begin{tabular}{|lcc|}
\hline & Retail Area & Storage/Staff Area \\
\hline Installed Watts & 5,427 & 776 \\
\hline Percent of Load & $87 \%$ & $13 \%$ \\
\hline Floor Area & $144 \mathrm{~m}^{2}$ & $36 \mathrm{~m}^{2}$ \\
\hline Percent of Floor Area & $80 \%$ & $20 \%$ \\
\hline LPD & $37 \mathrm{~W} / \mathrm{m}^{2}$ & $21 \mathrm{~W} / \mathrm{m}^{2}$ \\
\hline \multicolumn{2}{|c|}{ Figure 145: Light Power Densities for Floor Area by Use } \\
\hline
\end{tabular}

For the store as a whole, the average LPD is $21 \mathrm{~W} / \mathrm{m}^{2}$. This is similar to the ASHRAE recommended levels for a clothing store at $20 \mathrm{~W} / \mathrm{m}^{2}$ (see Section 2.9).

\section{Lighting Circuits}

The store has seven separate lighting circuits installed. The retail area ambient fluorescent lamps are switched separately, as are the display window metal halide lamps. The toilet, washroom and storage/staff area each have their own switch located conveniently by their door. 


\section{Trading Hours}

The 'normal' trading hours for this store also follow the advertised hours, being open for 8.5 hours during the week and on Saturdays and for 7.5 hours on Sundays and Public holidays. These hours can be extended, or reduced, at the discretion of the store's manager.

The lighting systems are turned on at start of each day, with the cleaning and re-stocking being carried out continually throughout the day, depending on customer numbers. Three of the display window lights are left on at all times as a form of advertising, while the remaining lights are switched off at the close of each trading day. The store maintains the same trading hours throughout the year. Figure 146 provide the calculation of the average lighting energy consumption for the store. The advertised 'on' time is different to the advertised trading hours due to the change in hours between a weekday and the Sunday. This is a simple calculation that averages the overall 'on time' across all seven days.

\begin{tabular}{|lccccc|}
\hline Lamp & $\begin{array}{c}\text { Installed } \\
\text { Lighting } \\
\text { Watts }\end{array}$ & $\begin{array}{c}\text { Average Daily } \\
\text { 'On' Time }\end{array}$ & $\begin{array}{c}\text { Watt } \\
\text { hours } \\
\text { /day }\end{array}$ & $\begin{array}{c}\text { Average } \\
\text { Weekly } \\
\text { Hours }\end{array}$ & $\begin{array}{c}\text { Watt hours } \\
\text { /Week }\end{array}$ \\
\hline $\begin{array}{l}1200 \mathrm{~mm} \\
\text { Fluorescent }\end{array}$ & 3,915 & 8.35 & 32,690 & 58.5 & $229,027.5$ \\
\hline $\begin{array}{l}\text { Metal Halide } \\
\text { Wall Flood }\end{array}$ & 1,260 & 8.35 & 10,521 & 58.5 & 73,710 \\
\hline $\begin{array}{l}\text { Metal Halide } \\
\text { Display } \\
\text { Window }\end{array}$ & 252 & 24 & 6,048 & 168 & 42,336 \\
\hline $\begin{array}{l}\text { 1500 mm } \\
\text { Fluorescent } \\
\text { Staff/Storage }\end{array}$ & 576 & 8.35 & 4,810 & 58.5 & 33,696 \\
\hline GLS & 200 & 8.35 & 1,670 & 58.5 & 11,700 \\
\hline Total & \multicolumn{5}{c}{55,739} \\
\hline \multicolumn{5}{l}{ Figure 146: Lighting Load Consumption - All Year } \\
\hline
\end{tabular}

While the $1200 \mathrm{~mm}$ fluorescent lamps are the main lighting style, Figure 146 shows the continuous operation of the three display window lamps means they consume $36 \%$ of the energy used by the 18 metal halide lamps. This extra operating time not only increases the cost of operation but will also reduce the time to replacement. The display window lamps are on for 109 hours longer per week than the same type of lamp used in the store. Metal halide lamps have an average life of 12,000 hours $^{28}$. The window lamps are on for

\footnotetext{
${ }^{28}$ The average lifespan for the 70Watt metal halide lamp the "HCl-T 70/830 WDL PB" by OSRAM is 12,000 Hours (OSRAM, 2010)
} 
8760 hours per year, requiring replacement on average every 16 months, while the other lamps are on for 3014 hours (trading hours) requiring replacement every 47 months.

\section{Plug Loads}

Figure 147 shows the calculated average plug load is approximately $22 \mathrm{kWh}$ per week, which when combined with the lighting load, is approximately $412 \mathrm{kWh} /$ week.

\begin{tabular}{|lccccccc|}
\hline Equipment type & Count & Day & Night & $\begin{array}{c}\text { Day Hourly Load (Watts) } \\
\text { (8.35hrs) }\end{array}$ & $\begin{array}{c}\text { Night } \\
(\mathbf{1 5 . 6 5 h r s})\end{array}$ & $\mathbf{2 4 h r}$ & $\begin{array}{c}\text { Per } \\
\text { Week }\end{array}$ \\
\hline EPoS Till & 2 & 130 & 10 & 1,086 & 157 & 1,242 & 8,697 \\
\hline Fridge & 1 & 20 & 20 & 167 & 313 & 480 & 3,360 \\
\hline Printer & 1 & 5 & 5 & 42 & 5 & 47 & 327 \\
\hline Electric Jug & 1 & 40 & 0 & 334 & 0 & 334 & 2,338 \\
\hline Stereo/Phone/EFTPoS & 1 & 12 & 8 & 100 & 188 & 288 & 2,016 \\
\hline Microwave & 1 & 12 & 1 & 100 & 78 & 178 & 1,248 \\
\hline Watercooler & 1 & 25 & 25 & 209 & 391 & 600 & 4,200 \\
\hline Total & \multicolumn{7}{c}{ Figure 147: Plug loads for Average Daily and Weekly Consumption } \\
\hline \multicolumn{7}{r}{} \\
\hline
\end{tabular}

Figure 147 does not include the main store area space heating load (from December 2008 a $9 \mathrm{~kW}$ heating capacity heat pump), the small personal fan heater used in the storage and staff areas, and the under sink hot water cylinder as their pattern of use and energy consumption will vary. During the interview, the store manager reported the store did not have a policy covering the use of the heat pump or personal heaters.

\section{Lux Levels}

The lux readings were taken at around $10 \mathrm{am}$ on Tuesday the $25^{\text {th }} \mathrm{June} 2010$. As the store is positioned on the western side of the State highway, by opening time the high angle of the sun means that direct sunlight cannot penetrate into the interior. The store appears bright on inspection, with the products and colours easily distinguishable. In discussion with the store manager, they remarked that although the store appears bright, if the metal halide lamps were switched off, the store would feel dark and 'cave like'. The only windows in the store are the main display windows facing the street. The stock and utility area to the rear of the store does not have any windows which may be explained as being a security based decision.

The lux levels were within the $1500-1600$ lux band across the retail floor. Measurements were taken on the horizontal plane, as much the merchandise is displayed on tables located in the centre of the store. One of metal halide lamps located behind the display window is positioned so that it illuminates back into the retail space, directly 
above the horizontal display tables. Measurements taken on the display table under this light source exceeded 3000 lux.

As noted above, the changing rooms are under the main retail space lighting grid, with a single three lamp luminaire over the four changing rooms, as illustrated in Figure 148. Directly beneath this light source, 1500 lux was measured but the luminaire position does not give consistently even light over all the changing rooms, giving only 1200 lux in the number four changing room closest to the wall.

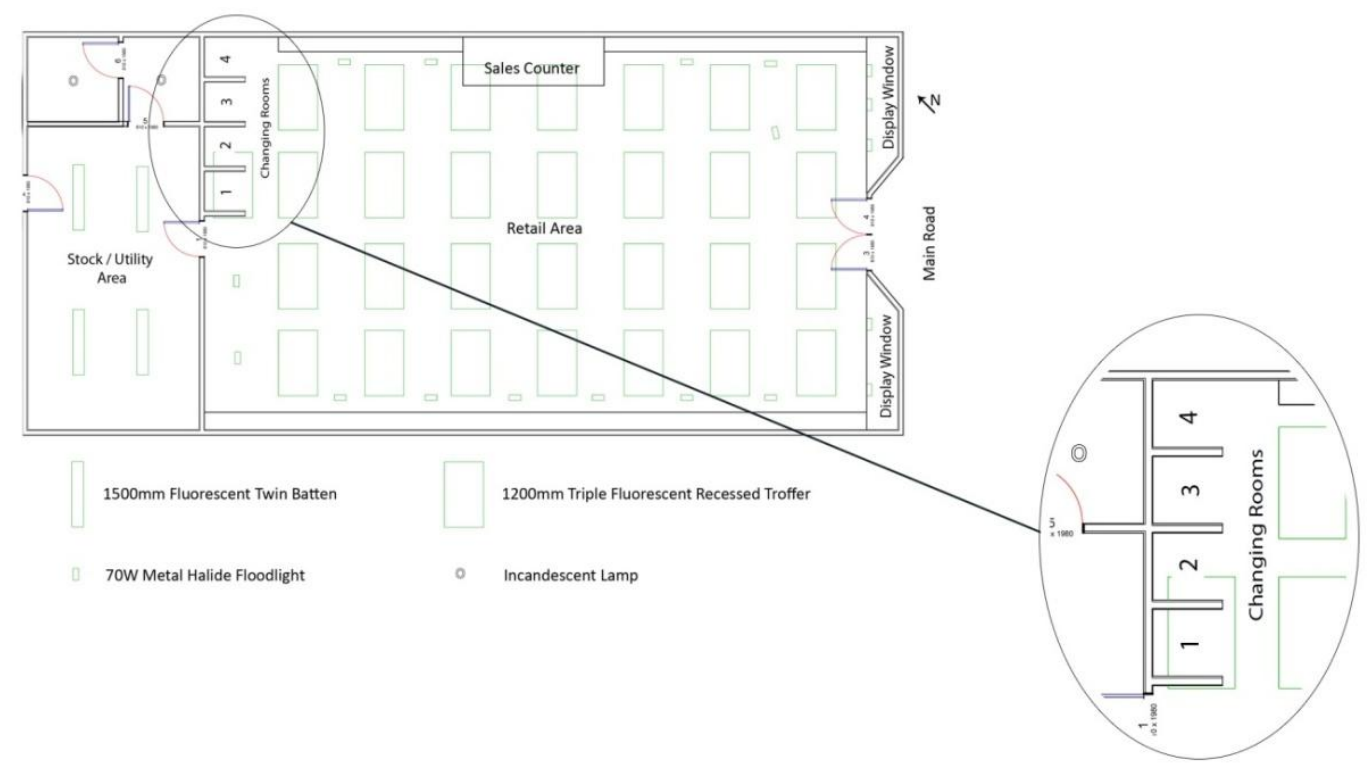

Figure 148: Luminaire Position over Changing Rooms

The stock/utility room at the rear of the store was lit with four batten style, twin $1500 \mathrm{~mm}$ fluorescent style luminaires, giving 600 lux, which while not as bright as the main retail space, was more than adequate for the uses of this area. The AS/NZS 1680.1:2006 Interior and Workplace Lighting Part 1 has store rooms between 160 and 320 lux (Standards New Zealand, 2006, p. 19).

\section{Daylight}

As noted above, the only windows into the retail area are the main display windows at the front of the store. The store uses a security grill to define the window display space, separating it from the main retail area. In the display window, the presentation is based around simple torso mannequins displaying men's and women's clothing. This style of window display allows clear views from the exterior into the store. However, the display 
window is also lit with the five metal halide flood lights reducing the benefit and the impact of daylight within the space.

\section{Billing}

The billing data received for this store covers the period from January 2007 through to June 2010. Figure 149 gives the electrical consumption for the stores over the year June 2009 - May 2010.

\begin{tabular}{|lll|}
\hline Store Type & Type & Total Consumed \\
\hline Fashion & Electrical Energy & $31,752 \mathrm{kWh} / \mathrm{yr}$ \\
\hline & Average Weekly Consumption & $611 \mathrm{kWh} / \mathrm{week}$ \\
\hline \multicolumn{3}{|c|}{ Figure 149: Electricity Consumption for Year (June 2009 - May 2010) } \\
\hline
\end{tabular}

Over the year, this store consumed $31,752 \mathrm{kWh}$ at an average weekly rate of $611 \mathrm{kWh}$, giving a calculated AEUI of $176 \mathrm{kWh} / \mathrm{m}^{2} / \mathrm{yr}$. When comparing this EUI to benchmarks (Figure 75) the site can be considered as a fair user of energy, but at the higher half of the rating some form of energy savings potential may exist

The billing data for the two and a half years from January 2007 through to June 2010 is displayed below in Figure 150. The temperature in red represents the mean average temperature for each month during the billed period (NIWA, 2011). The temperature has been graphed to show the seasonal variation, to allow any changes in energy use to be compared to the changes in temperature.

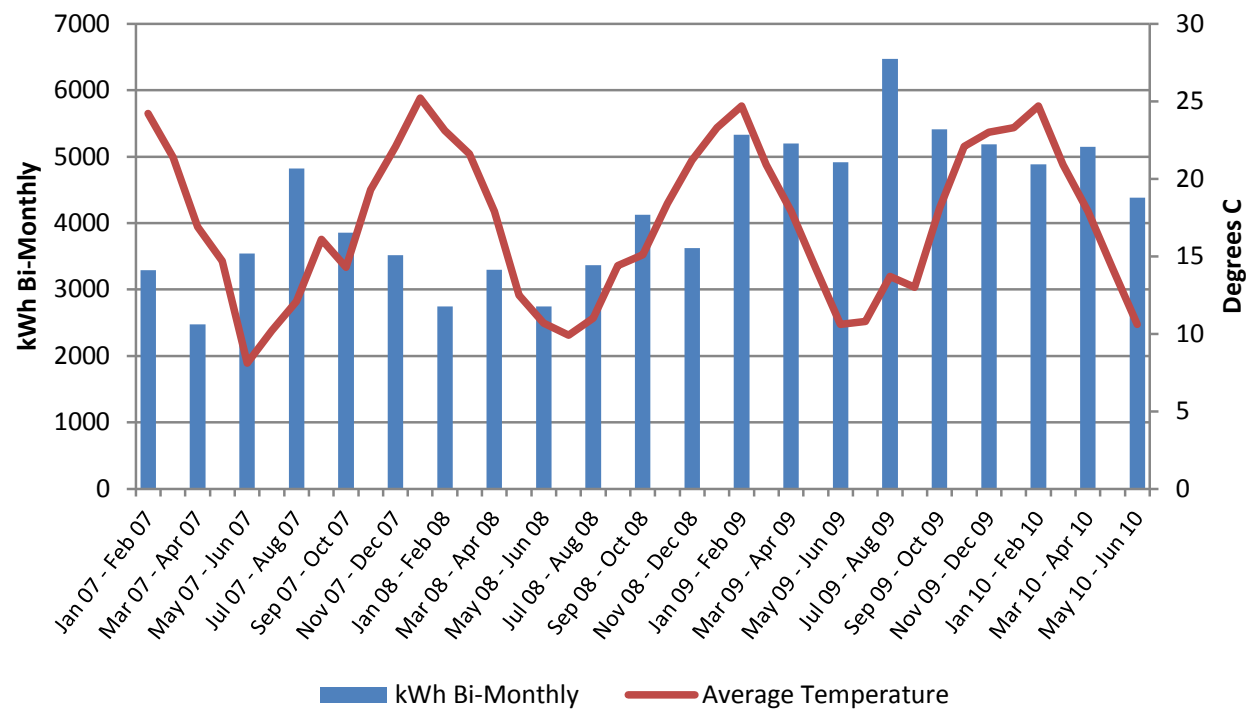

Figure 150: Billed Energy Consumption (Jan 07 - Jun 10) 
The bi-monthly billing records show a variation in electrical energy use prior to January 2009 that appears to be seasonal. It shows that is energy increasing during the winter periods. Prior to December 2008 it is not known how the store was heated, although the variation in Figure 150 suggests it was electrical. After December 2008, the store acquired the next door shop, effectively doubling the retail floor area.

As the observed lighting system is symmetrically laid out across the entire shop, it is expected that when the floor area next door was taken over; the lighting grid was expanded to account for the extra space. This caused more lamps to be installed, therefore increasing the lighting load.

The increased electricity use after November - December 2008 is considered to be a result of the increased lighting and equipment loads. The store also maintains a higher level of electrical use even in the summer months after November - December 2008, suggesting that the heat pump is being used for cooling as well as heating.

Figure 151 is a comparison between the range of lighting electrical consumption and the billed amount (see the section on the Boutique Store for a discussion of the symbols). The minimum lighting load is only the lights required for sales excluding overnight lighting and observed plug loads, while the maximum load is all the plug loads, all building lights plus the observed overnight lighting. In fact, the store maintained $100 \%$ lighting on when it was audited and seen to be still maintaining these levels during later observations.

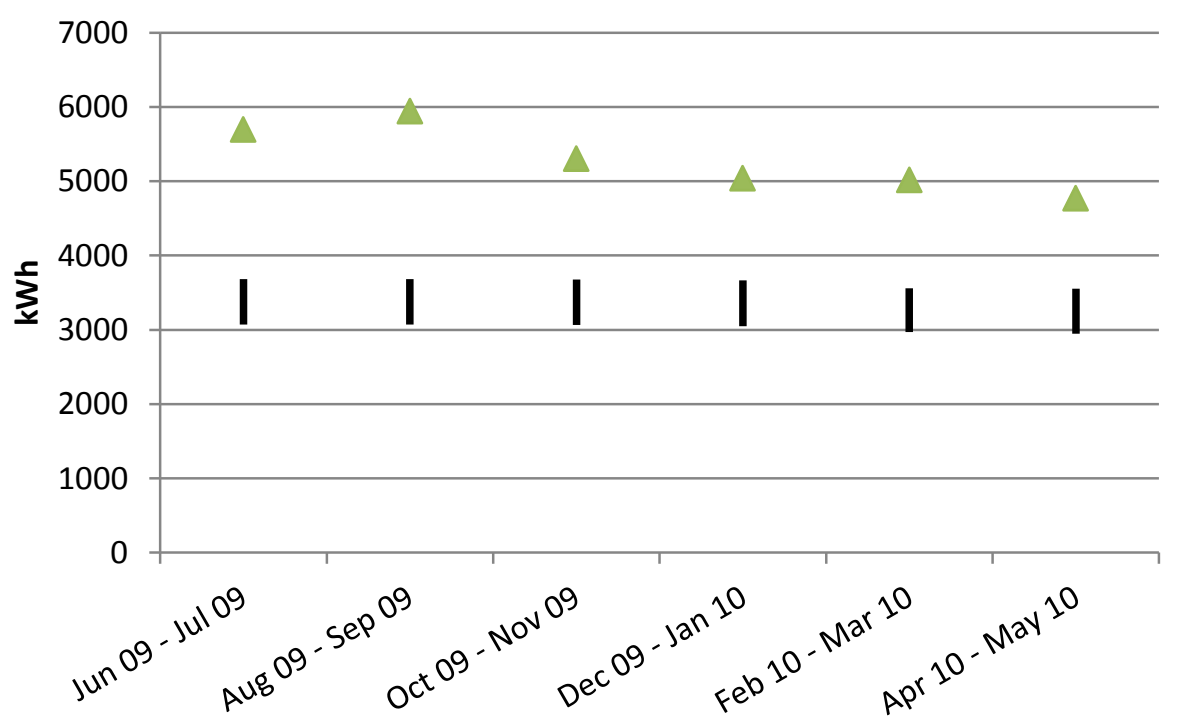

Bi-Monthly Billed Amount

Range of Selectable Lighting

Figure 151: Lighting Electrical Energy Consumption and Billed Amount 
Comparing the calculated electrical loads with the billed records shows that on average the calculated lighting and plug loads account for approximately $68 \%$ of the billed consumption levels. This would indicate that the plug loads, the domestic hot water cylinder and heating/cooling loads account for $30 \%$ of the billed total.

\section{Load Profile}

The load profile for this store was developed based on an average week from the bimonthly period of July and August 2009, and an average summer month from the January - February 2010 period. An average week in July/August has been calculated as consuming $730 \mathrm{kWh}$ while the average for January/February is $632 \mathrm{kWh}$.
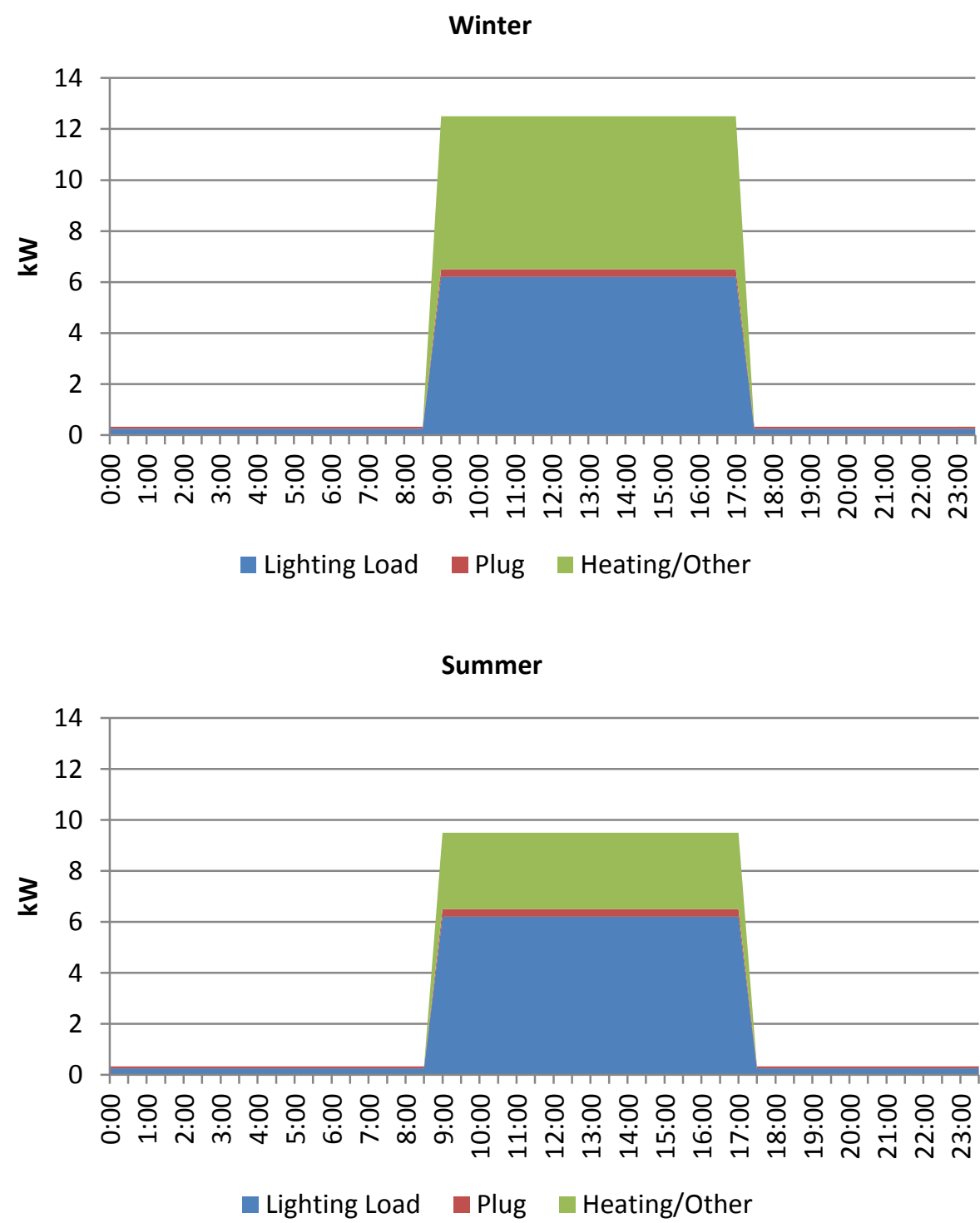

Figure 152: Simplified Load Profiles for Summer And Winter 
The load profiles in Figure 152 show that stores winter plug loads are more than double the summer amount. This could be expected as the store has $2 \mathrm{~kW}$ personal fan heaters and the heat pump in the retail space. The store has an open door policy, leaving the street doors open during normal trading hours. This increases the winter heating load, but the energy impact has not been calculated. Based on observations and interviews with staff members, it has been assumed the summer and winter lighting load are the same.

The area under the graph in Figure 152 gives the weekly loads of $779 \mathrm{kWh}$ in winter and $601 \mathrm{kWh}$ in summer. Both of these figures are within the recommended $15 \%$ of the average consumption levels of $730 \mathrm{kWh}$ and $632 \mathrm{kWh}$ respectively.

\section{Energy Saving Opportunities}

There is a number of possible energy saving opportunities in this store.

\section{De-lamp Linear Fluorescent Lighting}

Lighting levels over 1000 lux are recommended by AS/NZS 1680.1:2006 Interior and workplace lighting Part 1: General principles and recommendations, as being suited to high level tasks and intricate work. Reducing the ambient levels to 600 lux as recommended for most inspection tasks and colour matching would lower the energy consumption levels by approximately one third.

One possible method would be to de-lamp the retail area - removing the central tube in each of the overhead recessed luminaires. At present there are $871200 \mathrm{~mm}$ fluorescent lamps installed giving a load of $3.9 \mathrm{~kW}$ (29 Luminaires $x 3$ lamps $=87$ lamps total, 87 lamps X 45 Watts/lamp = 3,915Watts).

By removing the central tube this installed load is cut to 2.6kW (29 Luminaires X 2 lamps $=58$ Lamps Total, therefore 58 lamps X 45 Watts/lamp $=2610 \mathrm{Watts}$ ). Across an average trading year of approximately 3000 hours, the store could expect to save up to 3,933 kWh.

The other effect that de-lamping has is the reduction in maintenance costs, as there would be fewer lamps to replace and maintain.

\section{Switch Off Overnight Display Window Lighting}

Based on $168 \mathrm{hrs}$ per week (24hrs $x 7$ days) and trading hours of $58.5 \mathrm{hrs}$ a week then compared to the lights in the rest of the store, the 3 display window lights each operate for an extra 109.5hrs longer (168hrs - 58.5hrs), or 5,694hours per year (109.5hrs $x$ 
52 Weeks). The three lamps represent a load of 252 watts which over the year use 1,435 kWh $(5,694 h r s \times 252 W)$.

Switching the display lights off with the store lights will not only reduce energy use, but will also save on replacement costs. The metal halide lamps in the store can be expected to need replacement once every 24 months $(6,000 \mathrm{hr}$ life (The Lightbulb Man, 2010)), but the lamp left on in the display window will need replacement approximately once every 50 weeks.

Supporting this recommendation is that during an afterhours visit to Otaki, it was observed that the front of this store is adequately lit by the veranda fluorescent tubes.

\section{Switch Off the Stock / Utility Area Lights When Not in Use}

The storage/staff room remains largely unoccupied during the day except for re-stocking and tea breaks. To make an accurate estimate of potential savings, the actual occupancy time would need to be monitored for several weeks, as the time that the space is used depends on the store activities and on the occupant.

If it is assumed that over the course of the day that the room was used for three hours in total, then on an average day it is unoccupied and lit for approximately 5.5 extra hours, or 38.5 hours a week ( 7 days $x$ 5.5hrs $=38.5 \mathrm{hrs}$ ) more than is required. The space is lit by eight $1500 \mathrm{~m}$ fluorescent tubes with an installed load of 576Watts, giving a weekly annual potential saving of $22.2 \mathrm{kWh}$ or $1,153 \mathrm{kWh}$ per year.

The store manager was asked if there was any staff policy concerning light management. They reported they had tried implementing a policy of switching the store room lights off, but the light switches were positioned by the rear entrance door and not beside the door used by staff to enter from the store. This meant that the lights were left on regardless of the policy.

It is recommended that an occupant detector be installed in the staff and storage area. This would only activate the lights when the space was occupied, and by using an acoustic sensor rather than an infra red sensor would eliminate the switching off if someone remained in the room and was not moving.

It is also recommended that the single 100Watt GLS lamps in the toilet and wash rooms are replaced by appropriate CFL bulbs. These lamps were observed to remain on during the day. Although an occupant sensor would be beneficial, immediate savings of $70-80 \%$ would be realised simply by changing these incandescent for their CFL counterparts. If 
these incandescent lamps remain lit during an average trading year, they have been calculated to consume $608 \mathrm{kWh} /$ year while replacement by the equivalent CFL could realise savings of $80 \%(487 \mathrm{kWh})$.

\section{Switch Off Poorly Positioned Lamp}

The final recommendation is for the metal halide lamp that illuminates back into the store should be positioned downwards to remove the glare or switched off entirely. This lamp is positioned at an angle that creates glare to any of the customers in the store while the light benefit is limited as shines into a space which is already lit to 1500 lux. Switching off would result in an average annual saving of $255 \mathrm{kWh} /$ year.

If all of these recommendations were followed $8,235 \mathrm{kWh} /$ year could be saved, although this would vary with the actual store trading hours and the occupant actions. 


\section{Appendix G The Sports StORE}

During the audit period, there was only one retail store that dealt in specialist outdoor equipment, although there are stores selling outdoor fashion.

This chain store, located on the western side of State Highway One, uses national rules that detail the colour scheme, the general store layout, lighting styles and product lines to make the brand recognisable throughout New Zealand.

Entrance is through the portico/entrance lobby located centrally on the wall facing the State Highway. The store is rectangular in shape and at $340 \mathrm{~m}^{2}$ it is one of only five audited Otaki stores of over $300 \mathrm{~m}^{2}$.

In Figure 153 the store layout is given. The retail area includes the entire front and central rear sections. The staff areas are split across the rear of the store with the manager's office on one side and the toilets/kitchenette on the other. The area split is $87 \%$ for retail and $13 \%$ for staff and storage areas.

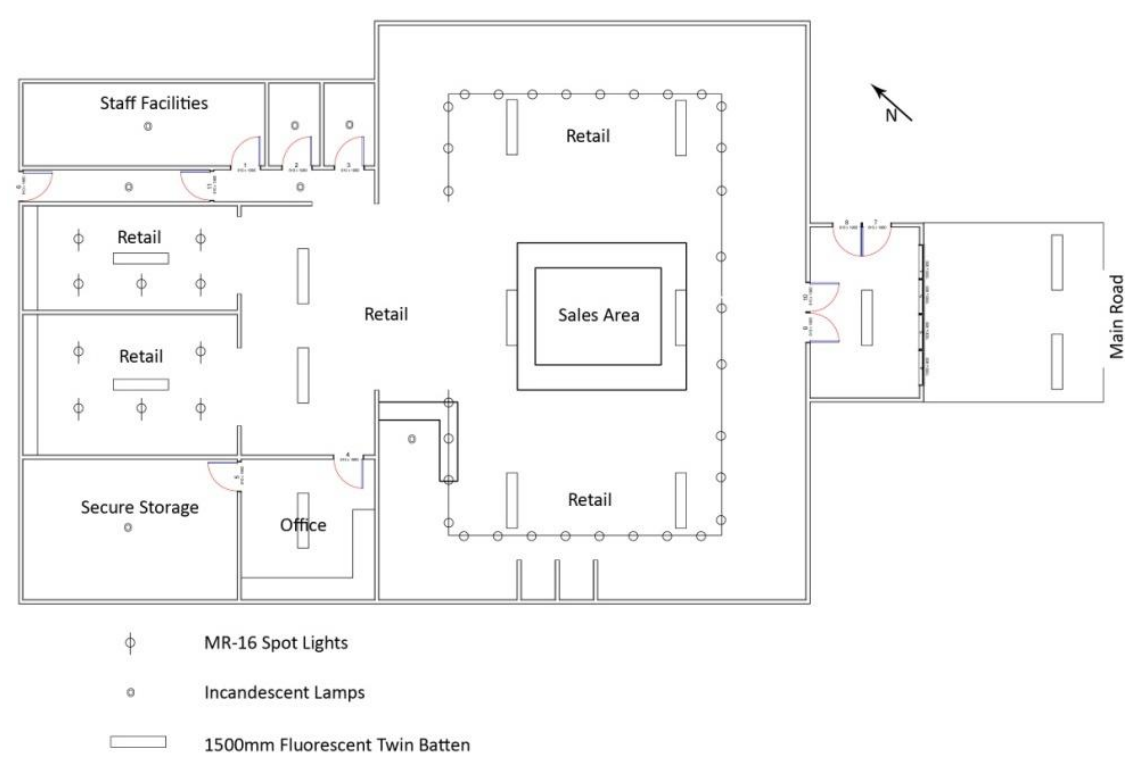

Figure 153: Sport Store Floor Plan showing Lighting Layout

The building construction is fairly simple, with the exterior a steel portal framed shed, clad in profile steel sheeting. The interior is wood, plaster board and plywood that is designed to enhance the head office developed branding. 
In the centre of the main retail space is a square sales area, set up as the central hub location for the store's two sales workers. A third administrative worker is employed part-time in the office space.

During the audit, the manager was asked about how they operated their lighting systems. They said that as all of the lighting controls for the retail space are located in the rear access way they were all are turned on during the day. The other rooms such as the office and the stock and utility spaces were only turned on as they are required. The last staff member out at night is responsible for checking which lights have been left on and for turning the lights all off.

At night the store is lit by a single twin $1500 \mathrm{~mm}$ batten fluorescent over the entrance and two more twin-batten fluorescents under the portico, unlike the remainder of the retail strip these lights are controlled by the store itself and not the council. Signage and area lighting is provided externally through four low-pressure sodium flood lights of about 200Watts each.

\section{Lighting Types}

The store uses two lighting systems that blend to create the ambient lighting levels as well as spotlighting certain product lines. The main ambient light sources are the 1500 $\mathrm{mm}$ fluorescent tubes with additional lighting being provided by the MR-16 spotlights. Figure 154 details the on-site lamp count, showing that the 91 lamps give a total installed load of $6.6 \mathrm{~kW}$.

\begin{tabular}{|lllccc|}
\hline Lamp Type & $\begin{array}{l}\text { Lamp } \\
\text { Count } \\
\boldsymbol{A}\end{array}$ & Fitting & $\begin{array}{c}\text { Lamp } \\
\text { Watts } \\
\boldsymbol{B}\end{array}$ & $\begin{array}{c}\text { Control or } \\
\text { Ballast } \\
\boldsymbol{C}\end{array}$ & $\begin{array}{c}\text { Total Watts } \\
\boldsymbol{=} \boldsymbol{A} *(\boldsymbol{B}+\boldsymbol{C})\end{array}$ \\
\hline $\begin{array}{l}1500 \mathrm{~mm} \\
\text { Fluorescent }\end{array}$ & 36 & Exposed Batten & 58 & 14 & 2,592 \\
\hline MR-16 & 44 & Exposed Spotlight & 50 & 5 & 2,420 \\
\hline Incandescent & 7 & GLS Lamp Holder & 100 & 0 & 700 \\
\hline Sodium & 4 & Flood Light & 200 & 20 & 880 \\
\hline Total & 91 & & & 6,592 \\
\hline \multicolumn{5}{c}{ Figure 154: Total Lamp Count within the Store } \\
\hline
\end{tabular}

The floor plan in Figure 153 shows the lighting layout within the store. The $1500 \mathrm{~mm}$ fluorescents are positioned throughout the store in an even pattern and are used to provide an ambient low level light in the front portion of the retail area.

The MR-16 lamps are on a track system that allows them to be individually positioned and changed as required. The MR-16s are used as spotlights to highlight specific products and displays but also add light to the overall ambience within the store. 
In the retail areas to the rear of the store, $1500 \mathrm{~mm}$ fluorescent lamps are used to provide higher levels of ambient light, while the MR-16's are used as recessed down lights to increase the level of light on the horizontal plane to allow the products to be inspected on tables appropriately positioned below the down lights.

\begin{tabular}{|lcc|}
\hline & Retail Area & Storage/Staff Area \\
\hline Installed Watts & $4,292 \mathrm{~W}$ & 1,420 \\
\hline Percent of Load & $75 \%$ & $25 \%$ \\
\hline Floor Area & $295 \mathrm{~m}^{2}$ & $45 \mathrm{~m}^{2}$ \\
\hline Percent of Floor Area & $87 \%$ & $13 \%$ \\
\hline LPD & $15 \mathrm{~W} / \mathrm{m}^{2}$ & $32 \mathrm{~W} / \mathrm{m}^{2}$ \\
\hline \multicolumn{3}{|c|}{ Figure 155: Light Power Densities for Floor Area by Use } \\
\hline
\end{tabular}

Overall the store has a LPD of $19.3 \mathrm{k} \mathrm{W} / \mathrm{m}^{2}$, which is higher than the $18 \mathrm{~W} / \mathrm{m}^{2} \mathrm{LPDL}$ given in Figure 11, Section 2.9.

As its overall floor area exceeds $300 \mathrm{~m}^{2}$, if the store was to be built now it would be subject to New Zealand Standard NZS4243 Part 2: 2007 Lighting Energy Efficiency Large Buildings.

NZS4243: Part 2:2007 only deals with the LPDL for ambient lighting systems, which is $16 \mathrm{~W} / \mathrm{m}^{2}$ for a building use of this type. There are three ambient lighting systems in the building that would be subject to the standard. The ambient lighting scheme throughout the store is the $1500 \mathrm{~mm}$ fluorescent lamps that have an installed lighting load of 3,292 Watts.

The MR-16 lamps used in the retail spaces to the rear can be considered as ambient lighting, although the MR-16 lamps used in the main retail space are exempt as they are considered as specific lighting used for spotlighting product. The included MR-16 lamps have a lighting load of 660 Watts. The final lamps to be included are the incandescent lamps that have been used to illuminate the stock / utility areas at 700 Watts.

The ambient lighting systems have an installed load of 4,652 Watts, which represents a LPDL of $13.6 \mathrm{~W} / \mathrm{m}^{2}$ which would be acceptable to NZS4243: Part 2:2007.

\section{Lighting Circuits}

The store has the greatest number of lighting circuits observed in the Otaki retail stores, with 21 individual lighting switches. The main retail space to the front of the store has four circuits to control the MR-16 lamps, the fluorescents and a single incandescent lamp over a work station. The remaining spaces in the store are each switched independently. 
In non-retail areas the switches are located by the entrance door in the room of operation while in the main retail area is controlled by a bank of light switches located in the access corridor to the rear of the store (and out of the direct vision of customers entering the store).

The outside lights are controlled by two manual switches, with one controlling the sodium lamps and the other the fluorescent tubes, and are also fitted with exterior light sensors. When the manual switches are on, the sensors operate the lamps when the external light levels fall below a preselected level and turn the lights off in the morning when the ambient light levels rise.

\section{Trading Hours}

The manager confirmed that the advertised hours for the store could be considered as the 'normal' trading times for the store. During the week the store is open from 8:00am to 5:30pm, Monday to Thursday, with Friday late night shopping when the store is open until 9:00pm. On the weekends the store is only open between 9:00am and 1:00pm on Saturdays. The store can alter its hours based on the season and specialist events as required.

Figure 156 gives average consumption based on the advertised hours. The operation of the Sodium lamps and the Entrance Fluorescent lamps depend on exterior light levels. As these levels vary across the year, they are assumed to operate 10 hours per night, every night. The storage area lighting has been left as zero as it is not used in the normal operation of the store as it is lit using overhead skylights.

\begin{tabular}{|lccccc|}
\hline Lamp & $\begin{array}{l}\text { Total } \\
\text { Watts }\end{array}$ & $\begin{array}{l}\text { Average } \\
\text { Daily 'On' } \\
\text { Time }\end{array}$ & $\begin{array}{l}\text { Watt } \\
\text { Hour /day }\end{array}$ & $\begin{array}{l}\text { Average } \\
\text { Weekly } \\
\text { Hours }\end{array}$ & $\begin{array}{l}\text { Watt } \\
\text { Hour } \\
\text { /Week }\end{array}$ \\
\hline $\begin{array}{l}\text { 1500 mm Fluorescent } \\
\text { Retail }\end{array}$ & 1,584 & 9.2 & 14,573 & 55 & 87,120 \\
\hline $\begin{array}{l}1500 \mathrm{~mm} \text { Fluorescent } \\
\text { Entrance }\end{array}$ & 432 & 10 & 4,320 & 70 & 30,240 \\
\hline $\begin{array}{l}1500 \mathrm{~mm} \text { Fluorescent } \\
\text { Storage }\end{array}$ & 576 & 0 & 0 & 0 & 0 \\
\hline MR-16 & 2,420 & 9.2 & 22,264 & 55 & 133,100 \\
\hline GLS Lamps & 700 & 9 & 6,300 & 55 & 38,500 \\
\hline Sodium & 880 & 10 & 8,800 & 70 & 61,600 \\
\hline Total & \multicolumn{5}{c}{56,257} \\
\hline & Figure 156: Lighting Load Consumption \\
\hline
\end{tabular}

Although all of the retail spaces in the store use the fluorescent lamps as the primary illumination, the significant lamp in terms of electrical energy consumption is the MR-16 spot light. 


\section{Plug Loads}

Figure 157 calculates the plug loads for the store. Daytime loads are calculated at $0.6 \mathrm{~kW}$ and $0.3 \mathrm{~kW}$ overnight, resulting in an annual load of $108 \mathrm{kWh}$.

\begin{tabular}{|c|c|c|c|c|c|c|c|}
\hline & & & & Average & ourly Lo & Watts) & \\
\hline $\begin{array}{l}\text { Equipment } \\
\text { type }\end{array}$ & Count & $\begin{array}{l}\text { Per } \\
\text { Day }\end{array}$ & $\begin{array}{c}\text { Per } \\
\text { Night }\end{array}$ & $\begin{array}{c}\text { Day } \\
\text { 8.0hrs }\end{array}$ & $\begin{array}{l}\text { Night } \\
\text { 16.0hrs }\end{array}$ & $24 h r$ & Per Week \\
\hline $\begin{array}{l}\text { EPoS Till + } \\
\text { LCD }\end{array}$ & 2 & 65 & 5 & 1,066 & 158 & 1,224 & 8,568 \\
\hline EFTPoS & 1 & 7 & 7 & 57 & 111 & 168 & 1,176 \\
\hline Printer small & 1 & 5 & 5 & 41 & 79 & 120 & 840 \\
\hline Phone & 1 & 0.3 & 0.3 & 2.5 & 4.7 & 7 & 50.4 \\
\hline TV & 2 & 105 & 5 & 1,722 & 158 & 1,880 & 13,160 \\
\hline DVD Player & 1 & 10 & 0 & 82 & 0 & 82 & 574 \\
\hline Stereo & 1 & 5 & 0 & 41 & 0 & 41 & 287 \\
\hline Desktop & & & & & & & \\
\hline Computer & 1 & 40 & 5 & 328 & 79 & 407 & 2,849 \\
\hline LCD monitor & 2 & 20 & 5 & 328 & 158 & 486 & 3,402 \\
\hline Desktop printer & 1 & 5 & 5 & 41 & 79 & 120 & 840 \\
\hline Fax Machine & 1 & 5 & 5 & 41 & 79 & 120 & 840 \\
\hline Microwave & 1 & 10 & 5 & 82 & 79 & 161 & 1,127 \\
\hline Jug & 1 & 40 & 0 & 328 & 0 & 328 & 2,296 \\
\hline Fridge/Freezer & 1 & 120 & 120 & 984 & 1,896 & 2,880 & 20,160 \\
\hline Chest Freezer & 2 & 156 & 156 & 2,558 & 4,930 & 7,488 & 52,416 \\
\hline Water Pump & 1 & 5 & 0 & 41 & 0 & 41 & 287 \\
\hline Total & & 598 & 323 & 7,743 & 7,809 & 15,553 & 108,872 \\
\hline
\end{tabular}

The calculated plug load in this store is higher than found in the fashion stores. Analysis of Figure 157 suggests this is because the sports store uses freezers as part of its merchandising and product storage. During the visits to the store, in the winter months between May and August, it was observed that there was no space heating in use as the occupants increased their layers of clothing rather than use electric heating.

\section{Lux Levels}

The average lux values in the main store area range between 80 and 300 lux with an average value being around 160 lux. The store appears quite dark on entry; with the MR-16 lamps providing small pools of light that highlight the displayed products.

The main lighting features are the $30 \mathrm{MR}-16$ track mounted spot lights. These physically small lights provide product spotlighting and perimeter lighting for the front retail area.

To the rear of the store, the two speciality product rooms are lit typically to around 400 lux using $1500 \mathrm{~mm}$ twin batten fluorescent tubes. In each of the speciality product rooms MR-16 spot lights are positioned in a grid like pattern to increase the light available in 
the centre of the room. This allows the product to be appraised easily either by being held up in the air or placed upon a display table directly beneath the lamp.

The office and retail space directly outside the office space are both lit to around 400 lux, also by $1500 \mathrm{~mm}$ fluorescent twin batten tubes. The staff areas and toilets are all been lit using incandescent lamps.

The manager commented that the greatest difficulty with this lighting design was that many customers did not adjust quickly to the lower light levels when entering from the outside.

\section{Daylight}

The retail space itself is designed to have very little connection with the exterior. The only glazing in the store is the entrance lobby located underneath the central portico. This glazing is often covered with advertising materials and is purposefully obscured for security reasons.

The storage area is located above the retail area at the back of the store. This space is lit using overhead skylights that provide sufficient light throughout the day so that the lighting in this space is not normally used, even in the winter months.

\section{Billing}

Billing data for this premise was provided by the energy supplier for the period of February 2008 through to June 2010. Figure 158 gives the electrical consumption for the store over the year June 2009 - May 2010.

\begin{tabular}{|c|c|c|}
\hline Store Type & Type & Total Consumed \\
\hline Sporting Goods & Electrical Energy & $22,501 \mathrm{kWh} / \mathrm{yr}$ \\
\hline & Average Weekly Consumption & $433 \mathrm{kWh} /$ week \\
\hline \multicolumn{3}{|c|}{ Figure 158: Amount Consumed for Year (June 2009 - May 2010) } \\
\hline
\end{tabular}

The annual consumption was $22,501 \mathrm{kWh}$ at an average weekly rate of $433 \mathrm{kWh}$, giving a calculated AEUI of $66 \mathrm{kWh} / \mathrm{yr} . \mathrm{m}^{2}$. Figure 75 compares this EUI to benchmarks, which shows that the site is in the good category, although there are improvements which could be made to further lower the energy use.

The billing data for the site is displayed below in Figure 159 for the period from February 2008 to May 2010. The temperature in red represents the mean average temperature for each month during the billed period (NIWA, 2011). The temperature has been graphed to 
show the seasonal variation, to allow any changes in energy use to be compared to the changes in temperature.

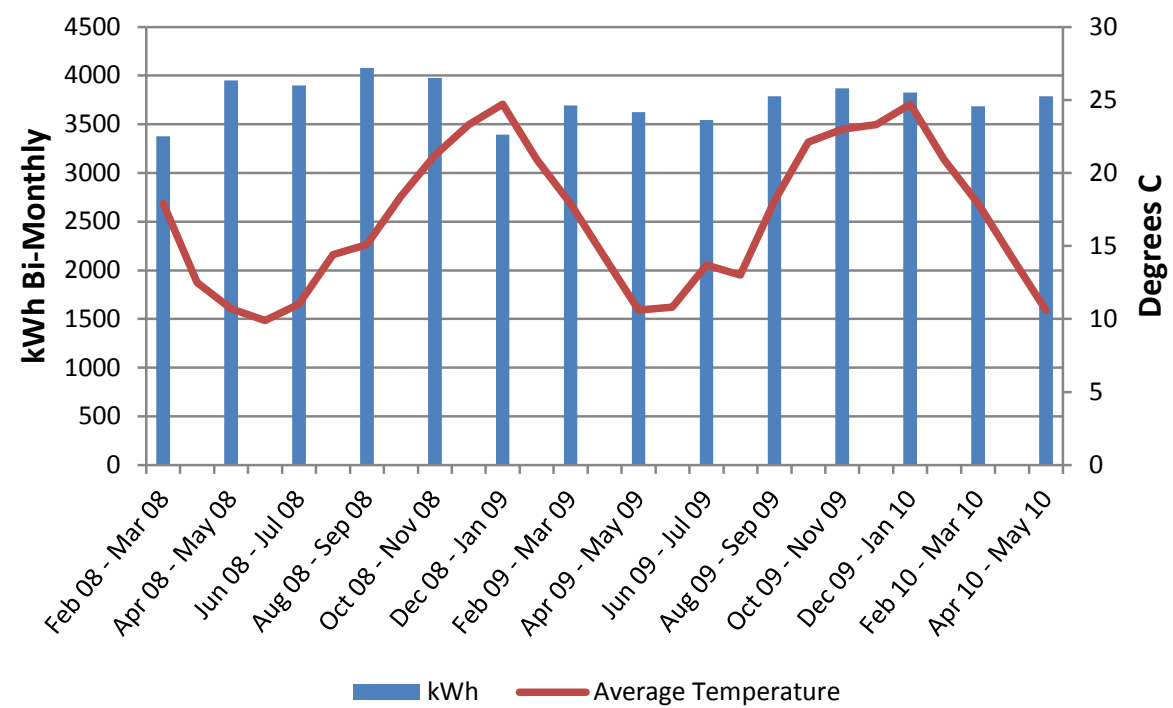

Figure 159: Billing Data on Monthly Consumption (Feb 2008 - Jun 2010)

Figure 159 shows that the stores energy use is reasonably constant over this time period, but with some variation. The variation appears to be seasonal, however with no electric heating it is most likely a result of different seasonal use patterns and the exterior light sensors.

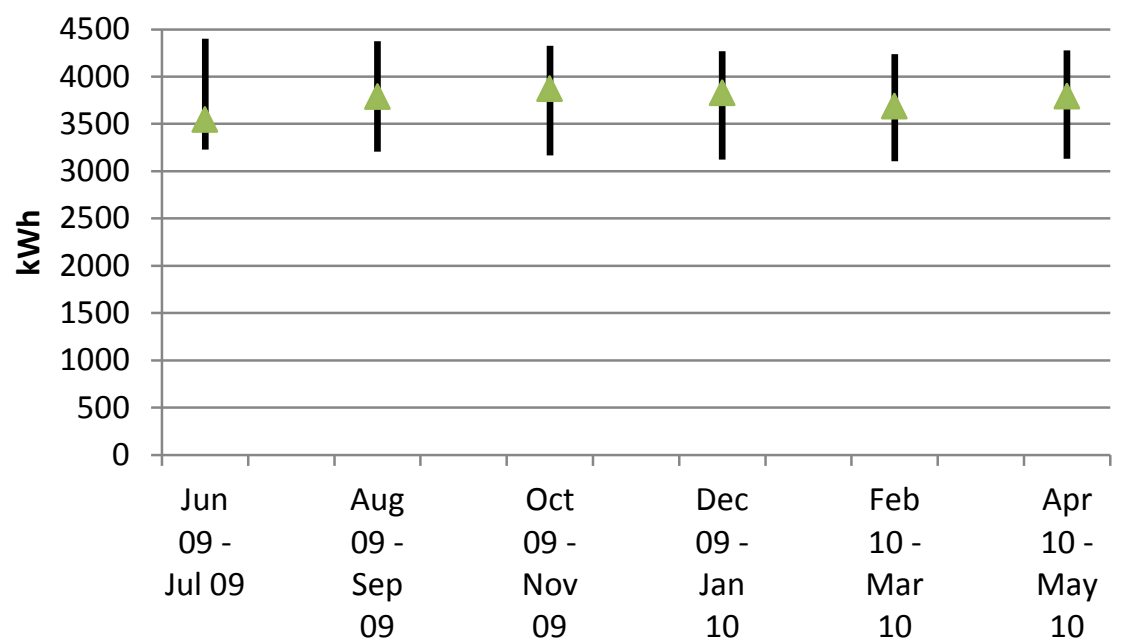

Figure 160: Lighting Electrical Energy Consumption and Billed Amount 
Figure 160 displays the range of store lighting energy use to help explain the variation identified in Figure 159. The lower end of the energy use is only the plug loads and the lighting used to illuminate the retail area, while the upper end of the range consists of the observed plug loads and all of the lighting 'on' during normal trading and observed overnight lighting. Figure 160 suggests that the variation in the billed amount can be accounted for without any heating load being present.

\section{Load Profile}

The load profile for this store, shown in Figure 161, was developed based on an average week from June and July 2009, and an average summer month of January - February 2010. An average week in July has been calculated as consuming $396 \mathrm{kWh}$ and the average for January is $432 \mathrm{kWh}$.
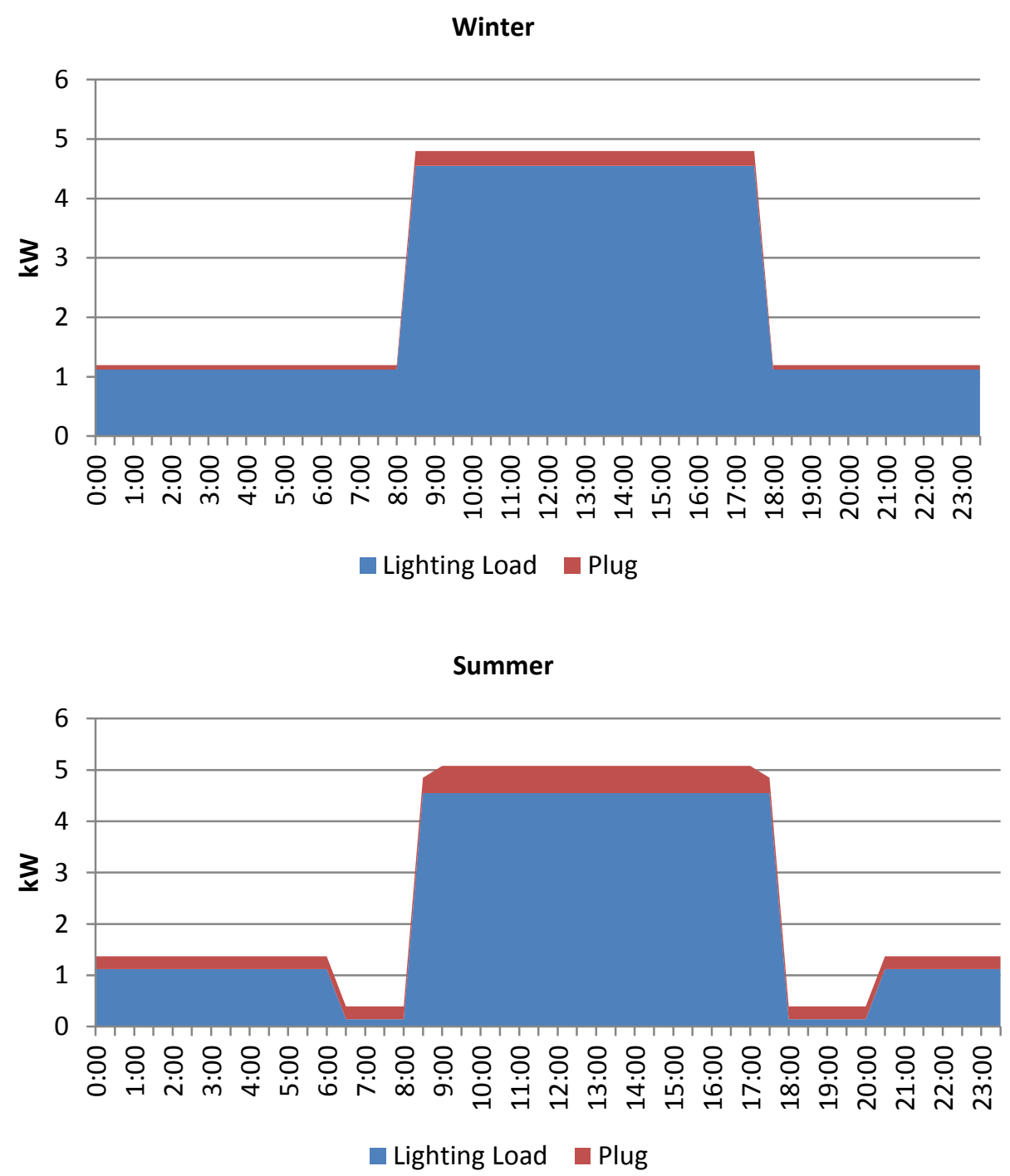

Figure 161: Simplified Load Profiles for Summer And Winter 
The area beneath the winter graph in Figure 161 represents $63 \mathrm{kWh}$ per day or $440 \mathrm{kWh}$ per week. If the lighting levels are maintain at the observed levels, it is expected that the plug load must be reduced in some manner over the winter. This can be achieved if the two freezers in the staff area are switched off during the winter months, which would appear possible as the demand for frozen bait would be reduced.

The summer load profile represents $63 \mathrm{kWh}$ per day or $444 \mathrm{kWh}$ per week.

As the final calculation is within $15 \%$ of the summer and winter average billed totals, the load balance could represent both seasons. The summer energy use differs slightly due to the light level sensor control of the overnight lighting. This can be observed in Figure 161 as the 'notches' around 7:00 am and 6:00 pm. It has been assumed that in summer these periods will occur as the sun will still be providing enough light to override the sensors. These periods can only be estimated, as variables such as cloud cover, maintenance and occupant control will alter the overall energy use.

\section{Energy Saving Opportunities}

The store uses seven incandescent 100 Watt bulbs to light the staff and toilet areas. The manager does not have policy involving the switching of these lights and believed that they were switched on at the start of each day and that they would remain on until closing. During the site visits it was observed that these lights were being switched off, but at what frequency and when could not be determined.

If these lamps were exchanged for the equivalent CFL then savings of up to $80 \%$ could be realised, so this action is recommended. Seven 100 Watt incandescent lamps over the course of an average day ( $9 \mathrm{hrs}$ ) can be expected to consume $6.3 \mathrm{kWh}$ of electrical energy per day. If the equivalent CFL's were installed $(18 \mathrm{~W})$ this usage would drop to $1.2 \mathrm{kWh}$ per day.

With current technologies the MR-16 used as spot lights can now be replaced with Energy Saver versions that operate at 35 Watts, (30\% savings) or LED lamps. The 35Watt versions cost similar to the 50 Watt (The Lightbulb Man, 2010) however the LED lamp may cost up to 10 times the face value of the 35 Watt bulb. At present a LED MR16 lamps is expected to have a life of between 30,000 and 50,000 hours. This represents an increase in the life over the standard MR-16 by a factor of between 6 and 10 depending on the version, although the actual light output may not be the same (Department of Energy, 2009). 
If the 44 installed MR-16 lamps were all changed to the Energy Saver version at 35 Watts, the $30 \%$ expected savings would decrease the installed lighting load by 726 Watts, taking the installed load to 1,694 Watts, potentially giving savings of 2,080 kWh per year. 


\section{Appendix H FOOD SALES}

The selected food retail store is the only one of its type surveyed on the strip. The store only sells food which has been prepared and packaged off-site.

The store is located on the eastern side of State Highway One, with approximately four meters of display window facing the highway. The $50 \mathrm{~m}^{2}$ store is rectangular in shape and stretches back away from the road, as shown in Figure 162. The door is positioned to one side of the display window and the store interior is designed so customers are restricted to that side of the store. The retail area comprises of $82 \%$ of the available floor area $\left(41 \mathrm{~m}^{2}\right)$.

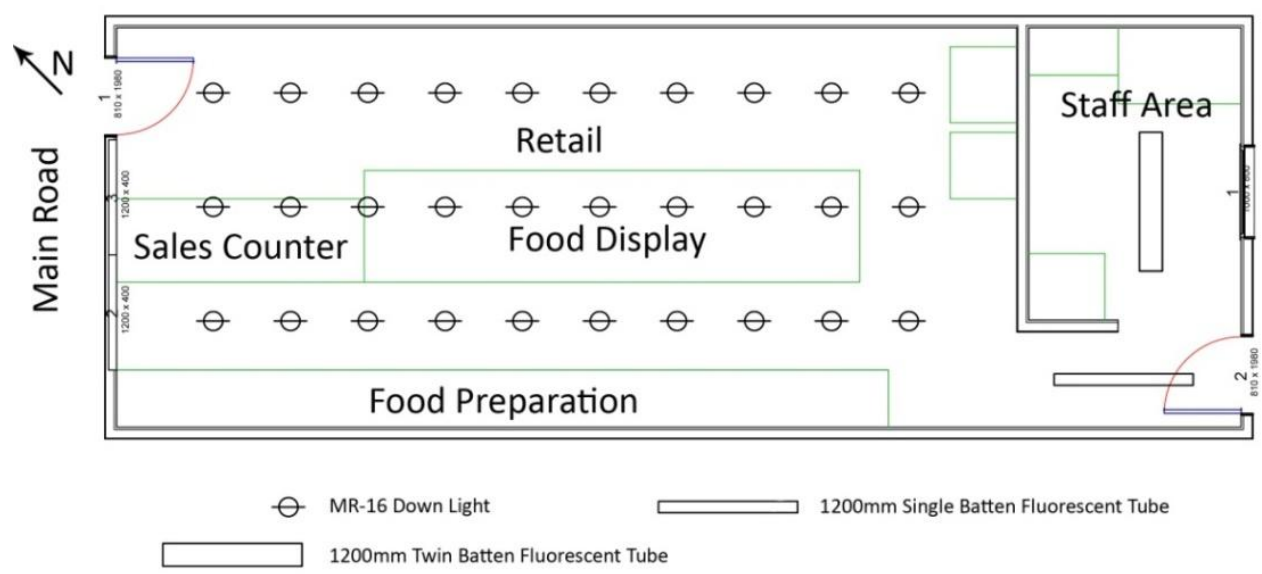

Figure 162: Floor Plan and Lighting Layout of Food Store

The store's construction is plasterboard and timber interior over a concrete block work building. It is one of seven stores in the building and is similar in size to two of others. The colour scheme was decided by head office and is similar to another one of their stores in Wellington. It has dark colours on the walls and is lit in the retail area exclusively with MR-16's.

\section{Lighting Types}

Figure 163 is the onsite lamp count of the store. The majority of the lighting is in the retail space with $88 \%$ of the installed load. The store has a total of $1.9 \mathrm{~kW}$ installed lighting, largely due to the MR-16 lamps being used as down lights. 


\begin{tabular}{|lclccc|}
\hline Lamp Type & $\begin{array}{l}\text { Lamp } \\
\text { Count } \\
\boldsymbol{A}\end{array}$ & Fitting & $\begin{array}{l}\text { Lamp } \\
\text { Watts } \\
\boldsymbol{B}\end{array}$ & $\begin{array}{l}\text { Control } \\
\text { Ballast } \\
\boldsymbol{C}\end{array}$ & $\begin{array}{l}\text { Total Watts } \\
\boldsymbol{=} \boldsymbol{A} * \boldsymbol{B}+\boldsymbol{C})\end{array}$ \\
\hline $\begin{array}{l}1200 \mathrm{~mm} \\
\text { Fluorescent }\end{array}$ & 3 & Exposed Batten & 36 & 9 & 135 \\
\hline MR-16 & 30 & Exposed Spotlight & 50 & 5 & 1,650 \\
\hline $\begin{array}{l}\text { Incandescent } \\
\text { PAR }\end{array}$ & 1 & GLS Lamp Holder & 80 & 0 & 80 \\
\hline Total & 34 & & \\
\hline \multicolumn{7}{c}{ Figure 163: Total Lamp Count within the Store } \\
\hline
\end{tabular}

The store is evenly lit by these physically small lamps due to their high density -1 lamp per $1.3 \mathrm{~m}^{2}$. The only other lamps are the three $1200 \mathrm{~mm}$ fluorescent tubes at the rear of the store in the staff area. Figure 164 provides the calculation of the LPD, which when the overnight PAR 38 lamp at the rear of the store in included, overall is $37 \mathrm{~W} / \mathrm{m}^{2}$.

\begin{tabular}{|lcc|}
\hline & Retail Area & Storage/Staff Area \\
\hline Installed Watts & 1,650 & 135 \\
\hline Percent of Load & $92 \%$ & $8 \%$ \\
\hline Floor Area & $41 \mathrm{~m}^{2}$ & $9 \mathrm{~m}^{2}$ \\
\hline Percent of Floor Area & $82 \%$ & $18 \%$ \\
\hline LPD & $40 \mathrm{~W} / \mathrm{m}^{2}$ & $15 \mathrm{~W} / \mathrm{m}^{2}$ \\
\hline \multicolumn{2}{|c|}{ Figure 164: Light Power Densities for Floor Area by Use } \\
\hline
\end{tabular}

\section{Lighting Circuits}

The store has been lit using seven internal circuits and one external circuit. The MR-16 lamps in the retail area are controlled using five circuits each switching six lamps. The remaining two internal circuits control the fluorescent lamps in the staff areas. The external PAR 38 lamp is only used for deliveries during periods of low light.

\section{Trading Hours}

The store maintains the advertised hours for much of the year. Only one staff member is on site at any one time with up to four people being employed to work at different times. The store is open seven days a week from 9:30 am to 5:00 pm. It is opened up 15 minutes before the public opening, to allow restocking and merchandise rotation (removal of old stock where required) and closes 15 minutes after the end of the day for stock removal, cleaning and shut down. This gives 8 hours open per day or 56 hours per week.

At night, the only security light left on is the twin $1200 \mathrm{~mm}$ fluorescent lamp positioned in the rear access.

Figure 165 uses the opening hours to calculate the average electrical energy consumption based on the installed lighting load. 


\begin{tabular}{|c|c|c|c|c|c|}
\hline Lamp & $\begin{array}{l}\text { Total } \\
\text { Watts }\end{array}$ & $\begin{array}{l}\text { Average } \\
\text { Daily } \\
\text { 'On' } \\
\text { Time }\end{array}$ & Watt hours/day & $\begin{array}{c}\text { Average Weekly } \\
\text { Hours }\end{array}$ & $\begin{array}{c}\text { Watt } \\
\text { hours } \\
\text { /Week }\end{array}$ \\
\hline $\begin{array}{l}1200 \mathrm{~mm} \\
\text { Fluorescent } \\
\text { Staff/Storage }\end{array}$ & 45 & 8 & 360 & 56 & 2,520 \\
\hline $\begin{array}{l}1200 \mathrm{~mm} \\
\text { Fluorescent } \\
\text { Access }\end{array}$ & 90 & 24 & 2,160 & 168 & 15,120 \\
\hline MR-16 & 1650 & 8 & 13,200 & 56 & 92,400 \\
\hline PAR Lamp & 80 & 0 & 0 & 0 & 0 \\
\hline Total & & & 15,720 & & 110,040 \\
\hline
\end{tabular}

The significant lighting type in the store is the MR-16 lamp at $84 \%$ of the calculated weekly lighting load.

\section{Plug Loads}

Figure 166 is provides the count and load of the store electrical equipment. The 12 pieces of equipment total $0.3 \mathrm{~kW}$ during the day and $0.06 \mathrm{~kW}$ overnight. The store is calculated to consume $3.9 \mathrm{kWh}$ per day and 1,420 kWh over the year.

\begin{tabular}{|c|c|c|c|c|c|c|c|}
\hline \multirow[b]{2}{*}{ Equipment type } & \multicolumn{7}{|c|}{ Average Hourly Load (Watts) } \\
\hline & Count & $\begin{array}{l}\text { Per } \\
\text { Day }\end{array}$ & $\begin{array}{c}\text { Per } \\
\text { Night }\end{array}$ & $\begin{array}{c}\text { Day } \\
(7.5 \mathrm{hrs})\end{array}$ & $\begin{array}{c}\text { Night } \\
\text { (16.5hrs) }\end{array}$ & $24 h r$ & $\begin{array}{l}\text { Per } \\
\text { Week }\end{array}$ \\
\hline Electronic Cash & & & & & & & \\
\hline Register & 1 & 11 & 11 & 88 & 176 & 264 & 1,848 \\
\hline EFTPoS & 1 & 7 & 7 & 56 & 112 & 168 & 1,176 \\
\hline Phone & 1 & 3 & 3 & 23 & 50 & 73 & 511 \\
\hline Radio & 1 & 3 & 0 & 24 & 0 & 24 & 168 \\
\hline Desktop Computer & 1 & 40 & 5 & 320 & 80 & 400 & 2,800 \\
\hline CRT monitor & 1 & 65 & 5 & 520 & 80 & 600 & 4,200 \\
\hline Fax Machine & 1 & 5 & 5 & 40 & 80 & 120 & 840 \\
\hline Microwave & 1 & 10 & 5 & 80 & 80 & 160 & 1,120 \\
\hline Jug & 1 & 40 & 0 & 320 & 0 & 320 & 2,240 \\
\hline Coffee Machine & 1 & 100 & 0 & 800 & 0 & 800 & 5,600 \\
\hline Fridge small & 2 & 20 & 20 & 320 & 640 & 960 & 6,720 \\
\hline Total & 12 & 301 & 58 & 2,591 & 1,298 & 3,889 & 27,223 \\
\hline
\end{tabular}

Not included in the above plug loads are the large refrigerated display cabinets that are dependent on daily temperatures and product load for their levels of consumption.

\section{Lux Levels}

The ambient light levels vary between 370 and 2330 lux dependant on the location of the reading. The light level measurements were all taken at the one metre height in a grid like 
pattern across the store, as all products are displayed at this height. The measurement directly beneath the lamp gave a maximum of 2330 lux while the minimum readings ( 370 lux) were in the spaces near the walls and corners away from the lamps.

\section{Daylight}

Although the store's display window is three meters wide, no merchandise is on display. Although some food retailers do use the front window as a display case, for this store the sunlight that penetrates the store in the late afternoon precludes the window being used in this manner. The window's primary use is static display advertising with the company logo and the daily specials.

The rear of the store has access to daylight through a small window in the staff room. This daylight enhances the quality and amount of light in the space, but is not used to alter the run times of the lamps in the room.

\section{Billing}

The energy supplier was able to provide consumption records for the billed period between June 2008 and June 2010. The AEUI has been calculated so that its energy consumption can be compared to other retail stores and is given in Figure 75.

\begin{tabular}{|lll|}
\hline Store Type & Type & Total Consumed \\
\hline Sporting Goods & Electrical Energy & $25,463 \mathrm{kWh} / \mathrm{yr}$ \\
\hline & Average Weekly Consumption & $490 \mathrm{kWh} / \mathrm{week}$ \\
\hline \multirow{2}{*}{ Figure 167: Amount Consumed for Year (June 2009 - May 2010) } \\
\hline
\end{tabular}

Figure 167 shows that for the year this store consumed 25,463 kWh at an average weekly rate of $490 \mathrm{kWh}$, giving a calculated EUI of $509 \mathrm{kWh} / \mathrm{yr} . \mathrm{m}^{2}$. Figure 75 gives the AEUI benchmarks and comparisons', suggesting the site is in the poor grouping. Most of the energy is being consumed by the large display cabinets in the store, but there are still some lighting opportunities that will decrease the overall lighting load.

The billing data provided for the site is displayed below in Figure 168 . 


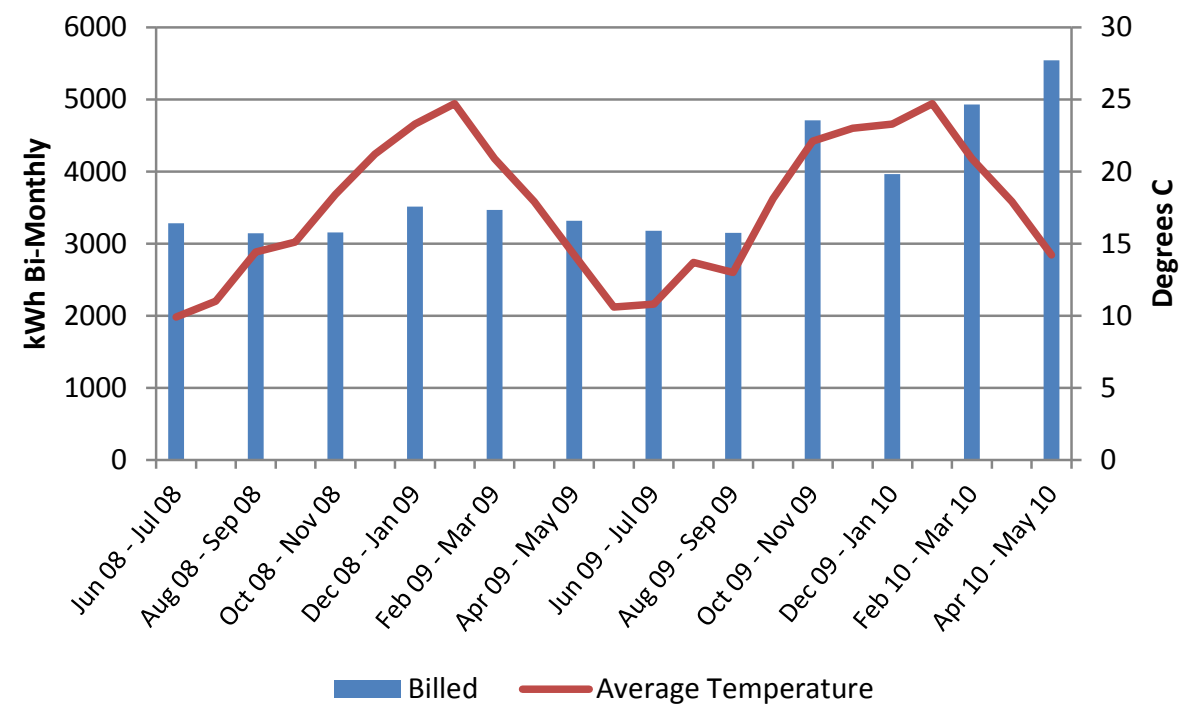

Figure 168: Bi-Monthly Consumption for the Period June 08 - June 2010

The store, because of its product base, does not use any form of heating within the store. All products in the store are located in an open topped refrigerated display that runs continuously and is only covered at night.

Before the energy increases at the end of 2009 , the previous year shows that the energy consumption levels were stable with minimal variation. The spikes in consumption rates remain unexplained by management, but may be related to some food preparation that began on-site over near the end of 2009. This preparation involves a commercial skillet and the installation of a coffee machine that can operate daily for long periods or not at all depending on customer requirements. 


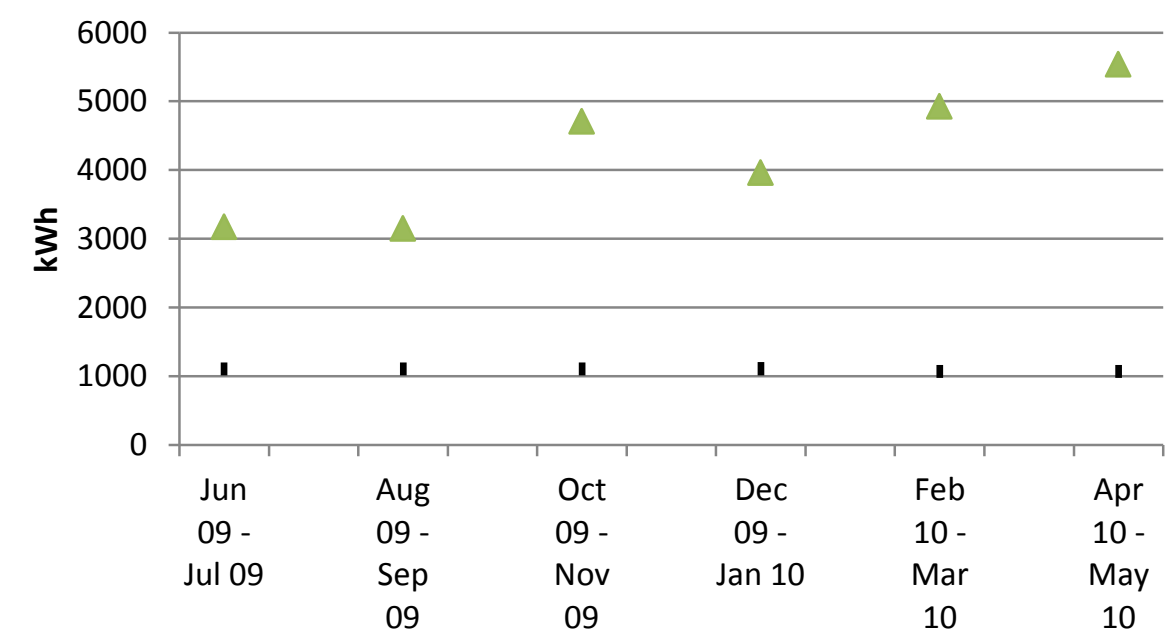

Bi-Monthly Billed Amount

Range of Selectable Lighting

Figure 169: Comparison of Billed Amount and Calculated Consumption

Figure 169 shows how little impact the calculated lighting energy use has on the bimonthly consumption. The variation and increase in energy consumption would appear to be related to the plug loads and equipment in operation within the store.

Unlike the previous stores, this stores energy consumption is not largely driven by the lighting load. The installed lighting energy use is only $20 \%$ of the billed amount.

\section{Load Profile}

Figure 170 shows a calculated load profile for the space based on an average winter's month and an average summer's month. The following average figures have been developed for winter (June - July 09) at $364 \mathrm{kWh}$ and for summer (December 09 -January 10) at $447 \mathrm{kWh}$. 

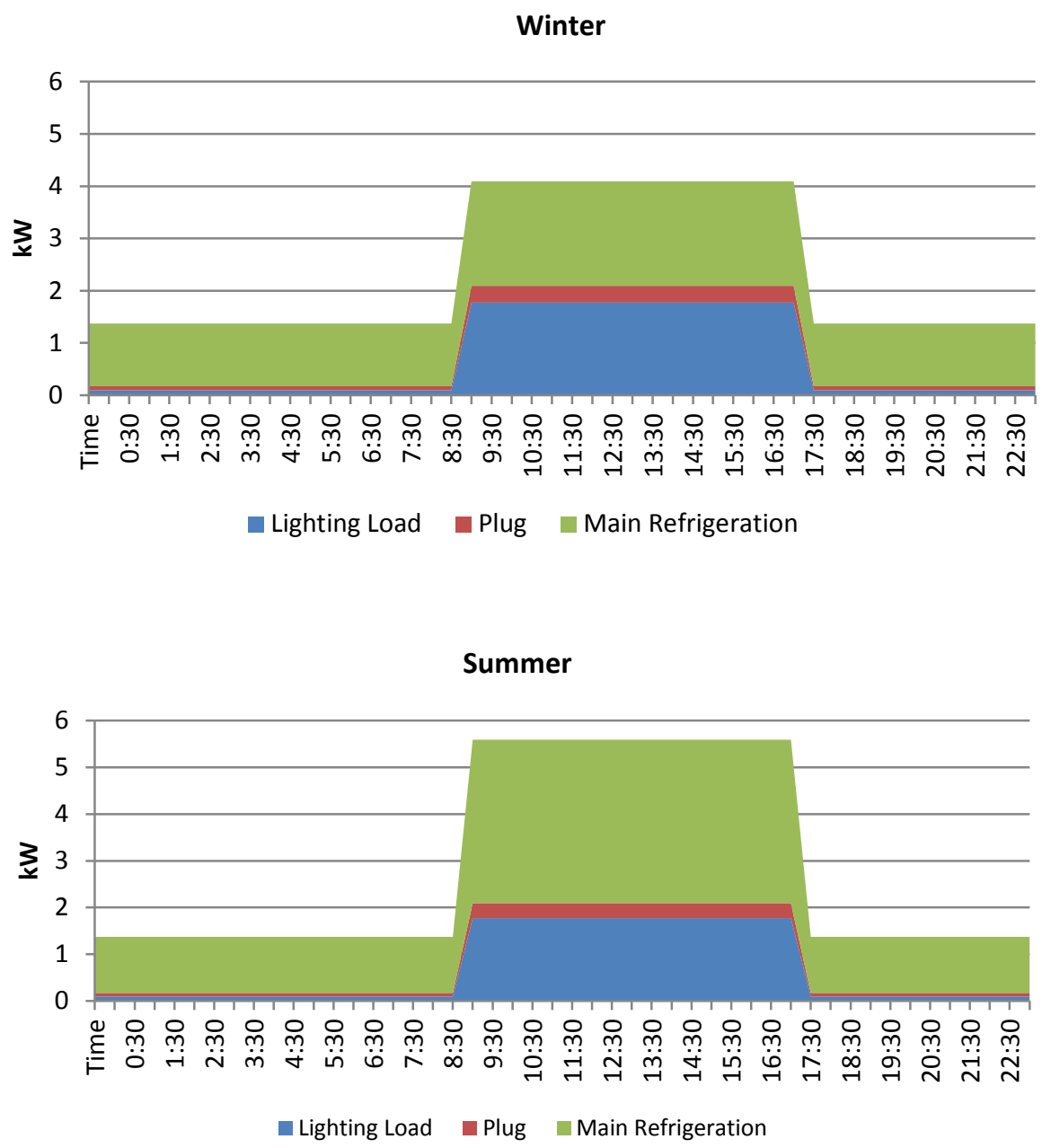

Figure 170: Simple Load Profile showing an Average Winter and Summer Month.

The load profile shows that the increases in summer are most likely a result of increased plug loads. Further monitoring would be required to determine if these increases in electricity use are a result of the increased customer services (e.g. more customers purchasing more food) or the refrigeration units have a longer duty time in summer.

The winter calculated load is $392 \mathrm{kWh}$ at $56 \mathrm{kWh}$ per day, while the summer load is 481 $\mathrm{kWh}$ at $69 \mathrm{kWh}$ per day. Both of these are within the $15 \%$ recommended by the energy audit manual for load balances.

\section{Energy Saving Opportunities}

Due to the amount of energy consumed by the process energy within the store, it is this which would provide the greater savings opportunities. 


\section{Retail Area}

The lighting load accounts for only $25 \%$ of the billed consumption annually, however if the MR-16 lamps were replaced with the energy saver options, then $30 \%$ savings of the lighting load may be realised. The 30 MR-16 lamps use 1,650 Watts in lighting load. If they were replaced with the equivalent energy saver at 35 Watts then the lighting load could be expected to decrease to 1,050 Watts installed. This would see an annual decrease in the calculated lighting consumption of $1,852 \mathrm{kWh} /$ Average Year.

\section{Display Cabinets}

Although not strictly part of the lighting load, the two upright display cabinets contain two $1200 \mathrm{~mm}$ fluorescent tubes in them. Both of these can be expected to operate permanently at 8760 hours/year. Removing these lamps would save $90 \mathrm{~W}$ per hour from the plug load, representing $788 \mathrm{kWh}$ per year.

Another option is to place these lamps on a timer circuit so that they only operate during the day, for advertising purposes. A timer circuit would reduce the lights operation to just 2710 hours per year (trading hours) saving $544 \mathrm{kWh} / \mathrm{yr}$. This method would also save on the overnight cooling plug load as the lights would not be providing any heating. 


\section{Appendix I GIFTWARE}

The selected gift store is one of two located on the Otaki shopping strip. It mainly sells small home ware and gift items. Located on the eastern side of State Highway One, it has a four and a half meter display window fronting a 12 metre deep rectangular store, as shown in Figure 171.

Like the businesses on either side, it has a $10 \mathrm{~m}^{2}$ small utility room at the rear. The retail area occupies the remaining $45 \mathrm{~m}^{2}$ or $82 \%$ of the available floor area, with the sales being centrally located to the rear of the store.

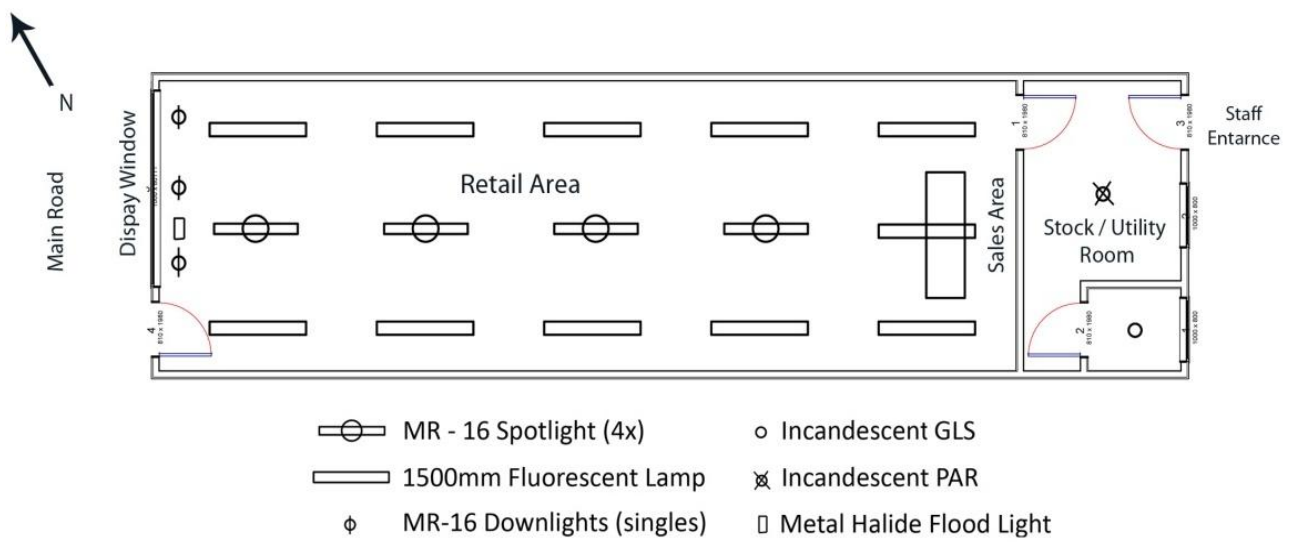

Figure 171: Floor Plan and Lighting Layout of the Giftware Store.

The store has an internal finish of plasterboard and timber framed walls, within a concrete block building. The colours are light with dark carpeted floor. The design and layout was developed by the owner and the store operator with the local electrician.

\section{Lighting Types}

Figure 172 gives the on-site count of the installed lamps. 


\begin{tabular}{|c|c|c|c|c|c|c|}
\hline Lamp Type & Lamp Type & $\begin{array}{c}\text { Lamp } \\
\text { Count } \\
\quad A \\
\end{array}$ & Fitting & $\begin{array}{c}\text { Lamp } \\
\text { Watts } \\
B \\
\end{array}$ & $\begin{array}{c}\text { Control or } \\
\text { Ballast } \\
C\end{array}$ & $\begin{array}{c}\text { Total } \\
\text { Watts }=A \\
*(B+C)\end{array}$ \\
\hline $\begin{array}{l}1500 \mathrm{~mm} \\
\text { Fluorescent }\end{array}$ & $\begin{array}{c}1500 \mathrm{~mm} \\
\text { Fluorescent }\end{array}$ & 13 & $\begin{array}{l}\text { Exposed } \\
\text { Batten }\end{array}$ & 58 & 14 & 936 \\
\hline MR-16 & MR-16 & 19 & $\begin{array}{l}\text { Exposed } \\
\text { Spotlight }\end{array}$ & 50 & 5 & 1,045 \\
\hline Incandescent PAR & $\begin{array}{l}\text { Incandescent } \\
\text { PAR }\end{array}$ & 1 & $\begin{array}{l}\text { GLS Lamp } \\
\text { Holder }\end{array}$ & 80 & 0 & 80 \\
\hline Incandescent GLS & $\begin{array}{c}\text { Incandescent } \\
\text { GLS }\end{array}$ & 1 & $\begin{array}{l}\text { GLS Lamp } \\
\text { Holder }\end{array}$ & 100 & 0 & 100 \\
\hline Metal Halide & $\begin{array}{c}\text { Metal } \\
\text { Halide }\end{array}$ & 1 & Wall Flood & 70 & 14 & 84 \\
\hline Total & Total & 34 & & & & 2,245 \\
\hline
\end{tabular}

Figure 171 and Figure 172 show the layout and count of the installed lamps. The lamps are symmetrically laid out along the store's long axis, with the single fluorescents being used on the outer perimeter and the MR-16's providing the contrast down the centre. The three rear fluorescent lamps are located above the sales desks to provide suitable the levels of illumination for the sales process.

The LPD is given below in Figure 173 as $46 \mathrm{~W} / \mathrm{m}^{2}$ for the retail area and $18 \mathrm{~W} / \mathrm{m}^{2}$ for the utility room.

\begin{tabular}{|lcc|}
\hline & Retail Area & Utility Room \\
\hline Installed Watts & 2,061 & 180 \\
\hline Percent of Load & $92 \%$ & $8 \%$ \\
\hline Floor Area & 45 & 10 \\
\hline Percent of Floor Area & $82 \%$ & $18 \%$ \\
\hline LPDL & $46 \mathrm{~W} / \mathrm{m}^{2}$ & $18 \mathrm{~W} / \mathrm{m}^{2}$ \\
\hline & Figure 173: Light Power Densities for Floor Area by Use \\
\hline
\end{tabular}

The calculated Light Power Density has been calculated as $41 \mathrm{~W} / \mathrm{m}^{2}$ for the entire store.

\section{Lighting Circuits}

The premise is lit with seven individual circuits. Each style of lamp is located on its own switch and can be operated independently from the other circuits in the store. This allows the display window MR-16's to be switched independently from the lamps in the general retail area.

\section{Trading Hours}

The giftware store has advertised hours of between 9:00 am and 5:00 pm for the six days Monday through Saturday and 10:00 am to 4:00 pm on Sundays and public holidays. The 
manager believed that the hours advertised offered a fair representation of normal opening hours, but acknowledged that they could change depending on customers, special events or staff time-off. Restocking and cleaning took place during the day during 'quiet' periods involving few or no customers. Figure 174 gives the average daily and weekly lighting loads, totalling $134.6 \mathrm{kWh} /$ week or $7,158 \mathrm{kWh} /$ year. The incandescent lamp is used infrequently and has not been included in the calculation.

\begin{tabular}{|lccccc|}
\hline Lamp & $\begin{array}{l}\text { Total } \\
\text { Watts }\end{array}$ & $\begin{array}{l}\text { Average Daily } \\
\text { 'On' Time }\end{array}$ & $\begin{array}{l}\text { Watt } \\
\text { hour/day }\end{array}$ & $\begin{array}{l}\text { Average } \\
\text { Weekly } \\
\text { Hours }\end{array}$ & $\begin{array}{l}\text { Watt } \\
\text { hour/Week }\end{array}$ \\
\hline $\begin{array}{l}1500 \mathrm{~mm} \\
\text { Fluorescent }\end{array}$ & 936 & 8 & 7,488 & 54 & 50,544 \\
\hline $\begin{array}{l}\text { Metal } \\
\text { Halide }\end{array}$ & 84 & 8 & 672 & 54 & 4,536 \\
\hline $\begin{array}{l}\text { MR-16 } \\
\text { Retail }\end{array}$ & 880 & 8 & 7,040 & 54 & 47,520 \\
\hline $\begin{array}{l}\text { MR-16 } \\
\text { Window }\end{array}$ & 165 & 24 & 3,960 & 168 & 27,720 \\
\hline PAR Lamp & 80 & 8 & 640 & 54 & 4,320 \\
\hline GLS Lamp & 100 & 0 & 0 & 0 & 0 \\
\hline Total & & & 19,800 & & 134,640 \\
\hline & & Figure 174: Lighting Load Consumption & \\
\hline
\end{tabular}

The ambient lighting system uses $1500 \mathrm{~mm}$ fluorescent lamps, augmented by the central MR-16 lamps being used as spotlights. Although the fluorescent lamps provide the ambient illumination, Figure 174 shows that the MR-16's use a similar amount of electricity each day.

\section{Plug Loads}

While the on-site audits were being carried out, a count of the installed equipment was made. The installed plug loads are noted below in Figure 175.

\begin{tabular}{|lccccccc|}
\hline & & \multicolumn{7}{c|}{ Average Hourly Load (Watts) } \\
\hline $\begin{array}{l}\text { Equipment } \\
\text { type }\end{array}$ & Count & $\begin{array}{c}\text { Per } \\
\text { Day }\end{array}$ & $\begin{array}{c}\text { Per } \\
\text { Night }\end{array}$ & $\begin{array}{c}\text { Day } \\
(\mathbf{7 . 5 h r s})\end{array}$ & $\begin{array}{c}\text { Night } \\
(\mathbf{1 6 . 5 h r s})\end{array}$ & $\mathbf{2 4 h r}$ & Weekly \\
\hline $\begin{array}{l}\text { Electronic } \\
\text { Cash Register }\end{array}$ & 1 & 11 & 11 & 79.2 & 184.8 & 264 & 1,848 \\
\hline EFtPoS & 1 & 7 & 7 & 50.4 & 117.6 & 168 & 1,176 \\
\hline Phone & 1 & 0.3 & 0.3 & 2.2 & 5 & 7.2 & 50.4 \\
\hline Radio & 1 & 3 & 0 & 21.6 & 0 & 21.6 & 151.2 \\
\hline Fax Machine & 1 & 5 & 5 & 36 & 84 & 120 & 840 \\
\hline Jug & 1 & 40 & 0 & 288 & 0 & 288 & 2,016 \\
\hline Total & 66.3 & 23.3 & 477 & 391 & 869 & 6,082 \\
\hline \multicolumn{7}{|c|}{ Figure 175: Plug loads for Average Daily and Weekly Consumption } \\
\hline
\end{tabular}


The calculated plug loads for the store is just $6 \mathrm{kWh}$ per week. When combined with the calculated $\mathrm{kWh}$ for the lighting load, the store consumes about $140 \mathrm{kWh}$ per week.

\section{Lux Levels}

The lux readings were taken on May the $21^{\text {st }}$ at 11:00 am. Because of the western orientation, only daylight (and no direct sunlight) was coming through the display window. At the display window the lux readings were 3500 lux while spot readings taken at the horizontal plane along the store read between 410 lux to 750 lux.

To the unaided eye, the store appeared bright with contrasting shadows around the light from the MR-16 spotlights. The metal halide flood light gave some glare as it has been positioned pointing back in to the store over the central display aisle.

\section{Daylight}

As for the other western facing stores, direct sunlight penetrates the space in the late afternoon. Unlike the fashion stores and food stores, the light has little damaging effect on the product but this is still undesirable due to the low angle and subsequent glare.

\section{Billing}

The energy consumption data provided by the energy supplier only covered the period from November 2008 (soon after the store opened) through to August 2010. Figure 176 shows the amount of electrical consumption for the premises over the year June 2009 May 2010. For the year this premises consumed 7,062 kWh at an average weekly rate of $136 \mathrm{kWh}$.

\begin{tabular}{|lll|}
\hline Store Type & Type & Total Consumed \\
\hline Giftware & Electrical Energy & $7,062 \mathrm{kWh} / \mathrm{yr}$ \\
\hline & Average Weekly Consumption & $136 \mathrm{kWh} / \mathrm{week}$ \\
\hline & Figure 176: Amount Consumed for Year & (June 2009 - May 2010) \\
\hline
\end{tabular}

The premise has a calculated EUI figure of $128 \mathrm{kWh} / \mathrm{yr} . \mathrm{m}^{2}$. Figure 75 compares the EUI to the benchmarks which shows that the site can be considered as a fair user of energy, but that some form of energy savings potential may exist.

The consumption data from the billed records is available below in Figure 177. 


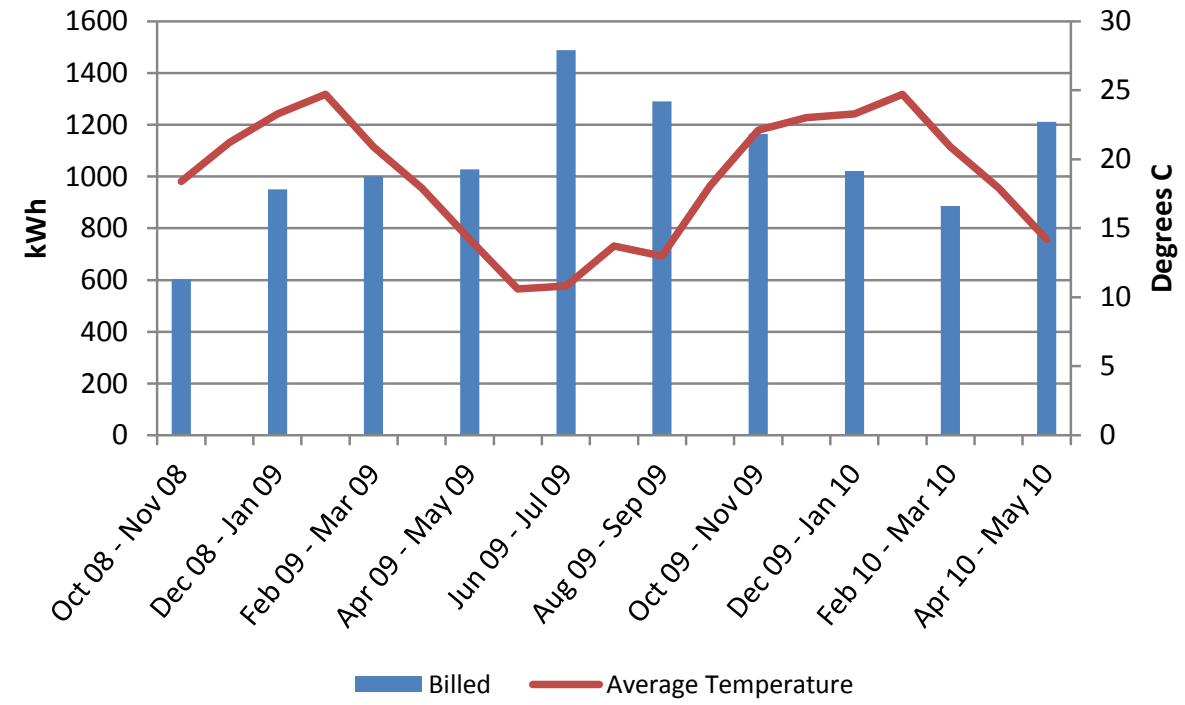

Figure 177: Billed Consumption Data (November 2008 - August 2010)

With a maximum calculated lighting and plug load of $140 \mathrm{kWh}$ per week, Figure 177 shows a seasonal variation above the base load. This would be expected to indicate some form of electric heating in the store, even although there was none visible during the audit.

Figure 178 compares the calculated lighting loads and the billed records. The minimum lighting load is based on the plug loads and retail lighting only while the maximum has all lights 'on' during normal trading and the observed levels of overnight lighting.

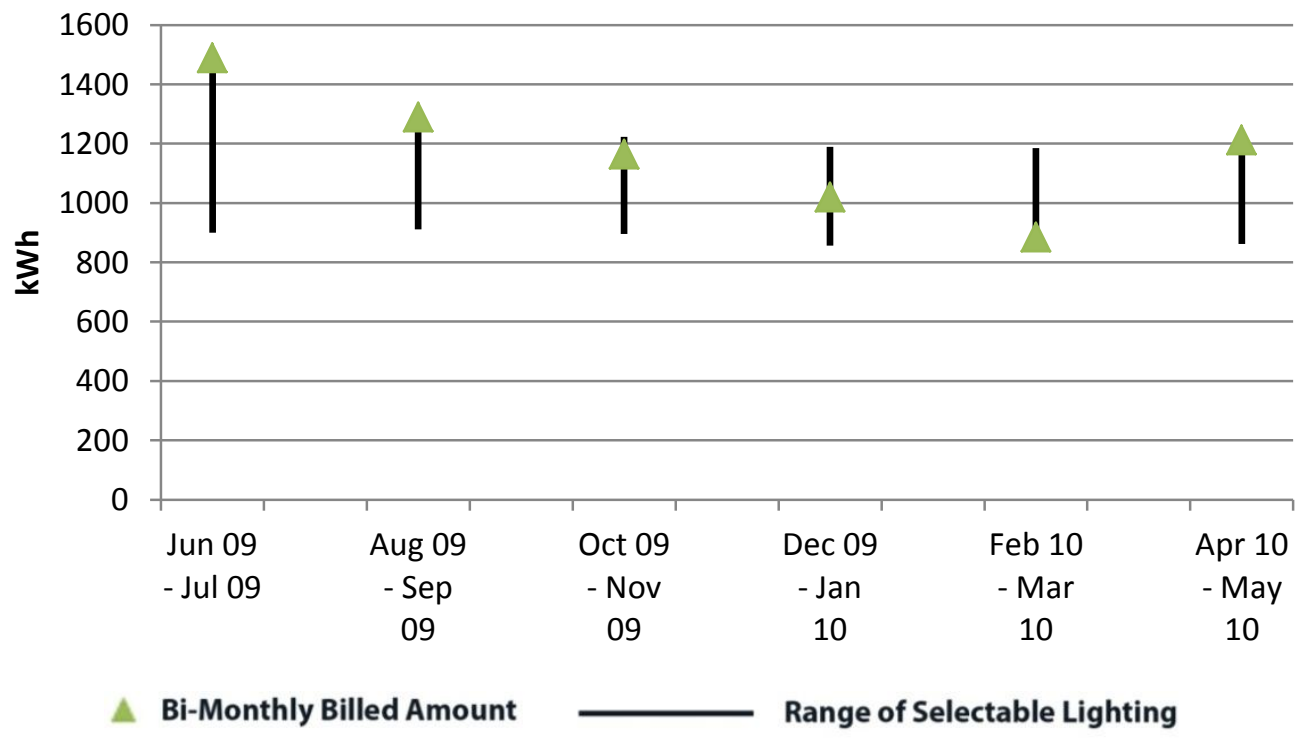

Figure 178: Comparison of Billed Amount and Calculated Consumption 
Figure 178 shows the store's total energy consumption varies with the season and is outside of the maximum lighting range for April through September, supporting the assumption that some form of heating is being used. During the summer months, December 2009 through March 2010, the store consumed at the lower levels of the calculated lighting loads, which is most likely due to all of the lighting being turned off at night.

The comparison between the billed and calculated amounts suggests the store must alter the lighting load in summer through either turning off the MR-16 spot lights at night and/or not operating some of the other lights.

\section{Load Profile}

The load profile (Figure 179) for this store was developed based on an average week from June and July 2009, and an average week from the summer months of January February 2010. During an average week in the June - July period the store consumes 171 $\mathrm{kWh}$ and for an average January - February week it is $115 \mathrm{kWh}$. 

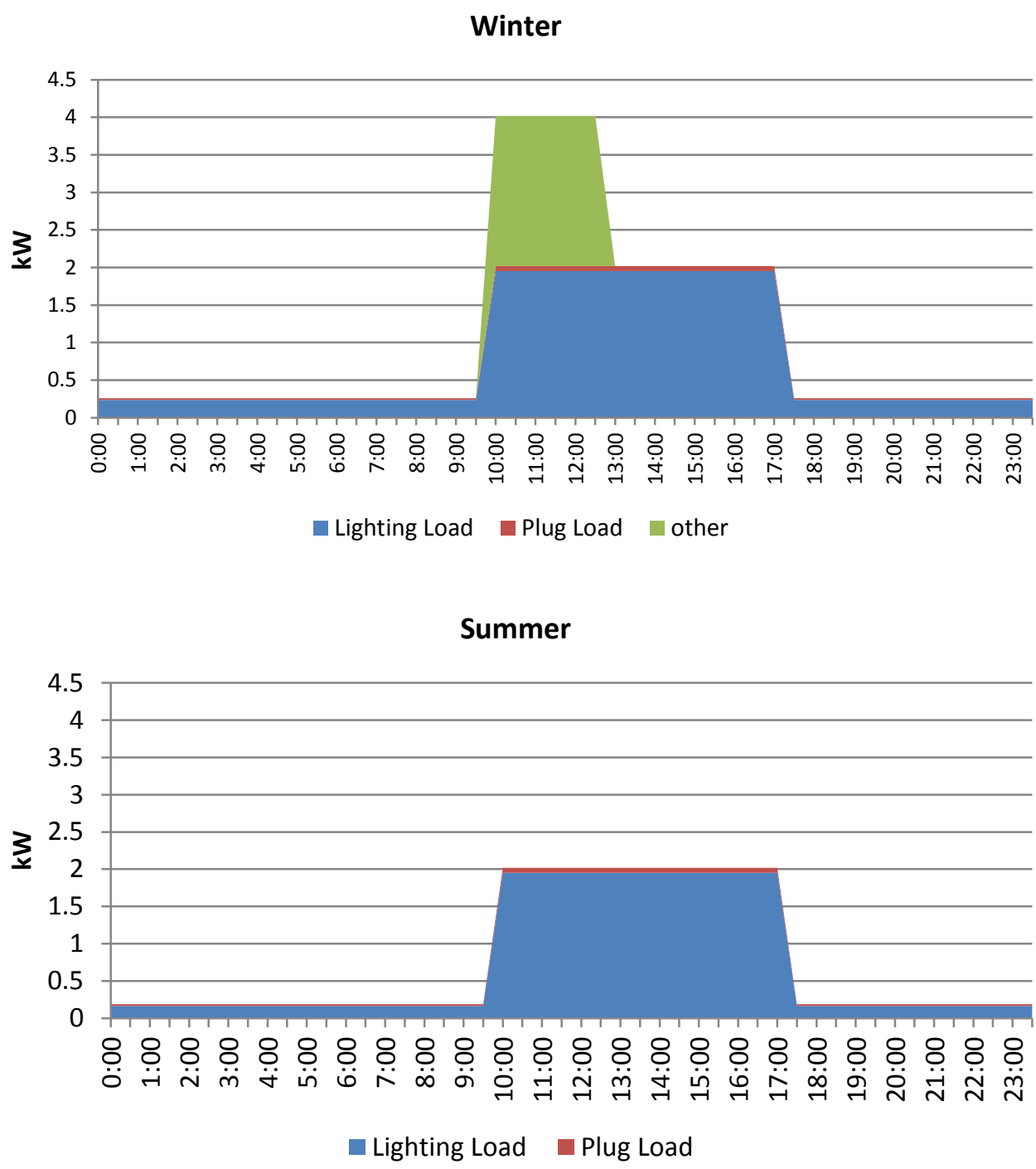

Figure 179: Simplified Load Profiles for Summer And Winter

The calculated area of the winter graph above is calculated to be the equivalent of 25 $\mathrm{kWh}$ per day or $178 \mathrm{kWh}$ per week. As the plug load that causes the billed data to exceed the maximum calculated load is unknown, the profile was developed assuming morning only use of a $2 \mathrm{~kW}$ heater.

The summer graph in Figure 179 shows the overnight lighting being turned off and the 'non-use' of the unknown load from winter. The summer graph has been calculated to have an area that is equivalent to $128 \mathrm{kWh}$ per week or $18 \mathrm{kWh}$ per day. Both of these have been calculated to be within the $15 \%$ as specified by the energy audit manual.

\section{Energy Saving Opportunities}

The recommendations for the store are based on exchanging lamps for their more efficient energy saver equivalents, and altering the direction and use of one of the lamps. 
In the store there are $16 \mathrm{MR}-16$ lamps that have been used to illuminate the retail area and a further three MR-16 lamps that have been used to illuminate the display window. The following energy saving opportunities will be discussed in relation to the area that they are installed.

\section{Display Window}

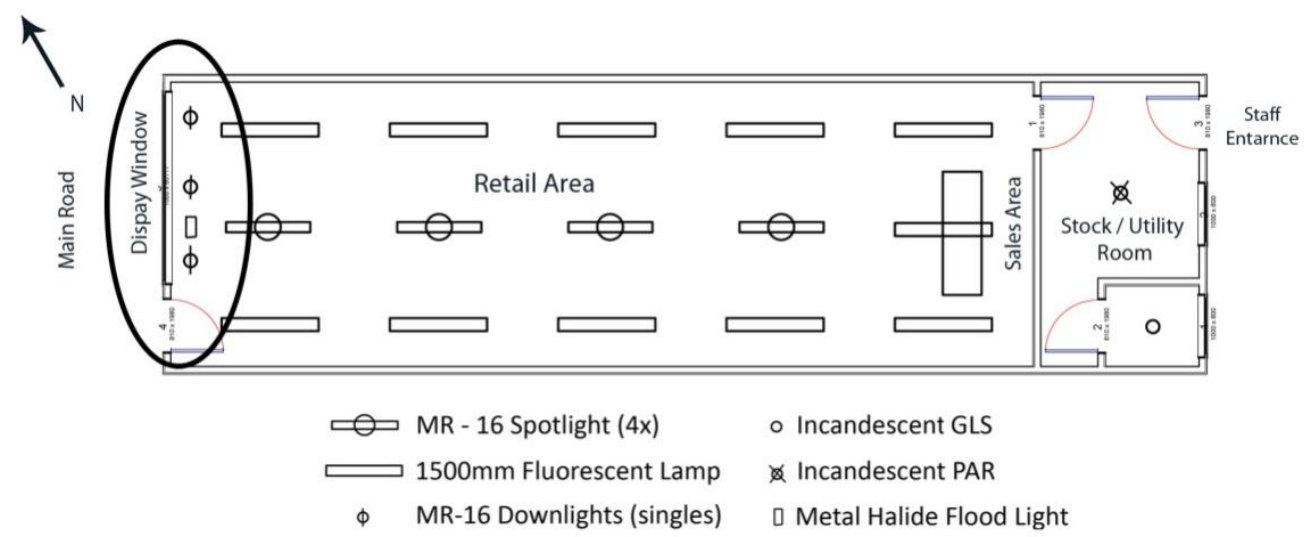

Figure 180: Area of Display Window

Figure 180 shows that there are actually four lamps of interest in the display window area. Three are the identified MR-16 lamps and the forth is a metal halide flood light that is focused not in the display window but back into the retail area. The metal halide in its current position is a source of glare because of the angle that it has been positioned.

The first recommendation then is to use the sole metal halide flood light as the light source for the display window. This would involve turning it around so that it was focused down on the display window area.

It is capable of delivering more light for fewer watts than the three MR-16s currently in the window. As the 84 Watt metal halide is already in use in the store, by repositioning it, all of the installed 165 Watts of the three MR-16's could be saved. Using the metal halide in this way also removes it as a source of glare within the store.

At present the MR-16 lamps run permanently in the display window. If the metal halide was used instead and placed on a timer this would see the weekly average operation drop from 168 hours down to 68 hours in total with two hours of run time after closing. Based on the advertised hours the lamp can expect to run for 5868 hours longer annually than the rest of the lights in the store. By removing the three MR-16 lamps, potentially 460 $\mathrm{kWh} / \mathrm{yr}$ could be saved 


\section{Retail Area}

In the retail area itself there are another 16 MR-16 lamps that have been used as spotlights down the centre of the store.

If these retail area MR-16s were exchanged for their energy saver equivalent at 35 Watts then $30 \%$ savings on the installed 880 Watts could be made. This $30 \%$ saving on the 880 Watts equals an installed load of 616 Watts or an annual savings of $736 \mathrm{kWh} / \mathrm{yr}$.

\section{Stock and Utility Area}

The last recommendation is to exchange the PAR $38-80$ Watt bulb for its 23 Watt CFL equivalent, which would save $71 \%$ of the energy consumed by this lamp. If it is assumed to operate for $10 \%$ of the year being in the stock room then it would save $16 \mathrm{kWh}$ per year. 


\section{Appendix J LOAD PROFILE Assumptions}

These are the assumptions made for the load profiles reported in the previous Appendix.

Lighting Loads and plug loads were identified in text in the relevant Appendix. These loads were identified as part of the audits.

\section{Boutique Store}

\section{Summer}

1. All lighting has been left on during trading hours (1478 Watts $x$ 7.5hours)

2. All identified plug loads minus the fridge and jug ( 82 Watts daily and 18 Watts night)

These settings will generate the load profile to $84 \mathrm{kWh}$ per week compared to the calculated average of $97 \mathrm{kWh}$. (84 / $97=86.5 \%$ - within $15 \%$ limit $)$

(This level of output can also be matched if the hover night lighting is left 'on' one night per week/month or for four nights in total).

\section{Winter}

1. There is on average 220 Watts of overnight lighting ( $66 \%$ of full load overnight all of the time)

2. This level of overnight lighting allows $100 \%$ retail area lighting during the day and the stock/utility rooms being used just $10 \%$ of the time.

3. All plug loads observed on $100 \%$ including fridge and jug.

This equals $14.3 \mathrm{kWh}$ per day or $100 \mathrm{kWh}$ per week.

With $100 \mathrm{kWh}$ calculated it compares to the weekly estimate of $95 \mathrm{kWh}$ within $\pm 5 \%$

\section{Outlet Store}

\section{Summer}

1. All lighting left on $100 \%$ during trading hours

2. $3 \times$ metal halides at 84 Watts each ( 252 Watts) on permanently 
3. All observed plug loads operating

With these assumptions the calculated load is still below the average estimate

1. Include $3 \mathrm{~kW}$ of 'cooling' by the heatpump can only then meet with estimated energy use.

The average consumption estimated in summer is $632 \mathrm{~kW} /$ week, these settings allow $601 \mathrm{kWh}$ per week that is within the $\pm 15 \%$.

\section{Winter}

1. All lighting left on $100 \%$ during trading hours

2. $3 \times$ metal halides at 84 Watts each (252 Watts) on permanently

3. All observed plug loads operating

With these assumptions the calculated load is still below the average estimate

1. Include $6 \mathrm{~kW}$ of 'heating;' to load using heat pump.

The average estimate in winter is $730 \mathrm{kWh}$, with the above settings the load can be met by $779 \mathrm{kWh}$ this is within the $\pm 15 \%$. 


\section{Sports Store}

\section{Summer}

1. Have maintained the observed lighting levels at $100 \%$ for retail area. Only the stock/utility, access way and storage area have not been lit.

2. Plug loads have been assumed to represent all internal plug loads that were observed.

3. Day lighting sensors have been assumed to operate between 6:30am and 8:00am in the morning and between 6:00pm and 8:00pm at night.

The summer load has been calculated to represent $444 \mathrm{kWh}$ per week that compares to the estimated average consumption of $396 \mathrm{kWh} /$ week.

\section{Winter}

1. Have maintained the observed lighting levels at $100 \%$ for retail area. Only the stock/utility, access way and storage area have not been lit.

2. Plug loads have been assumed to represent all internal plug loads that were observed. Minus the fridge freezers, that has been assumed to be switched off due to low use over this period.

3. Day lighting sensors have been assumed not to operate due to light levels and that they are either left on to auto - off are they are manually switched.

The winter load has been calculated as being $440 \mathrm{kWh} /$ week in winter that compares to the estimate of $396 \mathrm{kWh} /$ week.

\section{Food Sales}

All

1. All lighting and plug loads have been assumed as being $100 \%$.

Have not resolved main process equipment in space, but assuming light loads remain the same the energy is expected to be;

Summer: $\quad 3500$ Watts per day assumed due to due to higher ambient temperatures 1200 Watts per night, assumed to be covered and empty at night.

Winter: $\quad 2000$ Watts per day.

1200 Watts per night. 


\section{Summer}

Store is calculated to consume $447 \mathrm{kWh} /$ week in summer compared against the estimated consumption of $478 \mathrm{kWh} /$ week.

\section{Winter}

The store has been calculated at $364 \mathrm{kWh} /$ week that compares to the estimated 364 $\mathrm{kWh} /$ week.

\section{Giftware}

\section{Summer}

1. All lighting left on $100 \%$ during trading hours

2. Plug load seen to be $100 \%$

Summer load can be met. Estimated at $115 \mathrm{kWh} /$ week and the calculated is $109 \mathrm{kWh} /$

\section{Winter}

1. All lighting left on $100 \%$ during trading hours

2. Plug load seen to be $100 \%$

3. 3 x MR-16 lamps at 55 Watts each (165 Watts) on permanently

Shortfall when comparing to the estimated load

1. Can make shortfall using simulated 2000 Watt heater for 3-4 hours per day.

Or if all of the lighting is left on for 6 nights in a month and this would only occur in winter-mostly likely to be a source of heat.

Using heater and above assumption the estimated load of $171 \mathrm{kWh} /$ week can be compared to the calculated load of $178 \mathrm{kWh} /$ week. 